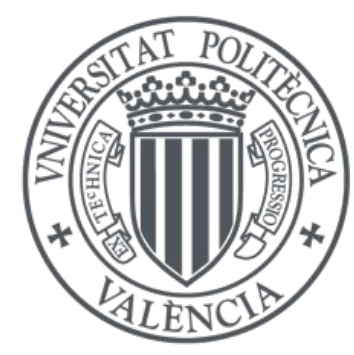

Universitat PolitècNicA de VALÈnCIA

TESIS DOCTORAL

\title{
Estudio de la conectividad funcional en cerebros de animales de experimentación a partir del análisis de imágenes de resonancia magnética mediante técnicas de clasificación no supervisada
}

\author{
Autor: Javier MOYA PAYÀ \\ Directores: \\ Dr. David Moratal PÉrez \\ Centro de Biomateriales e Ingeniería Tisular \\ Universitat Politècnica de València \\ Dr. Santiago CAnAls Gamoneda \\ Instituto de Neurociencias \\ Consejo Superior de Investigaciones Científicas - Universidad Miguel Hernández
}




\section{Agradecimientos Agraïments Acknowledgements}

Quisiera manifestar mi agradecimiento a mis directores de Tesis, los doctores David Moratal Pérez y Santiago Canals Gamoneda, tanto por su impecable labor de dirección como por haber sabido inculcarme los principios fundamentales de la doctrina científica. Quisiera también agradecer el trabajo de todos los técnicos y compañeros del Instituto de Neurociencias de Alicante (Consejo Superior de Investigaciones Científicas - Universidad Miguel Hernández de Elche)—especialmente a Efrén, así como a Ruth Prieto (Departamento de Neurocirugía, Hospital Clinico San Carlos, Madrid) y José María Pascual (Departamento de Neurocirugía, Hospital Universitario de La Princesa, Madrid), quienes nos han facilitado el acceso a los datos para el análisis de la corteza prefrontal.

El presente trabajo ha sido posible gracias al apoyo del Programa de Formación de Personal Investigador (FPI) de la Universidad Politécnica de Valencia-UPV (Convocatoria 2008/2009) así como del Ministerio de Ciencia e Innovación (ayudas del Plan Nacional I+D+I BFU2009-09938 y CSD2007-00023). Finalmente quisiera agradecer al Instituto Tecnológico de Informática (ITI/UPV) su respaldo económico, administrativo y técnico, en especial a su Director Científico Juan Carlos Pérez (quién además de involucrarse personalmente en la gestión económica de mi investigación, supo asesorarme de forma concisa sobre muchos aspectos de la inteligencia artificial, el reconocimiento de formas y el paradigma de la clasificación), a Sonia y Vanesa y a todos los técnicos de sistemas. También me gustaría dar las gracias a todas aquellas personas que se ofrecieron para resolver mis dudas sin esperar nada a cambio, como: Juanjo Lull, Alfons-Juan Císcar, Jorge Igual, Francisco Casacuberta y Luis Leiva, entre otros.

El més carinyós record va per als meus pares, el meu germà, Amélie, i a alguns dels meus amics (com Andrés, María, Chantal, Alberto o Nacho)—en general, a tots aquells que m'han ajudat a arribar al cim d'aquesta muntanya.

I would also like to thank Adam J. Schwarz (Translational Imaging, Exploratory and Program Medicine, Lilly Research Laboratories, Eli Lilly and Company, Indianapolis, USA) for providing us his digital multislice 2D rat brain atlas, and Ede Rancz (Division of Neurophysiology, NIMR, London, United Kingdom; Neuroscience, Physiology and Pharmacology, UCL, London, United Kingdom) who has leaded us in the analysis of the vestibular system. 


\section{Resumen}

El principal objetivo de esta Tesis Doctoral es el estudio de la conectividad funcional del cerebro in vivo combinando imagen por resonancia magnética funcional con microestimulación eléctrica cerebral en animales de experimentación.

Esta Tesis Doctoral se enmarca en un equipo multidisciplinar fruto de la estrecha colaboración que mantienen el Centro de Biomateriales e Ingeniería Tisular de la Universitat Politècnica de València y el Instituto de Neurociencias de Alicante del Consejo Superior de Investigaciones Científicas-Universidad Miguel Hernández.

El estudio de la conectividad funcional es de gran interés en la neurobiología básica actual y una pieza fundamental en la investigación preclínica de enfermedades psiquiátricas. No en vano, se trata del mecanismo sobre el que se fundamentan dos de los principios básicos de la neurobiología: la especialización y la integración funcional. El sistema nervioso implementa un procesamiento altamente distribuido de la información, con módulos especializados en aspectos específicos del procesamiento que se combinan entre sí de manera integral. Por ejemplo, la experiencia multisensorial de un episodio cotidiano se experimenta como una percepción única (o integrada). En este contexto, la conectividad eficiente entre módulos funcionales, o conectividad funcional, es un requisito indispensable. Para ser eficiente, dicha conectividad debe adaptarse a las necesidades del sistema en un entorno -el medio en que se desenvuelve el organismo- que está en continuo cambio. Por tanto, la configuración funcional del network es una característica dinámica determinada por mecanismos de plasticidad sináptica, adaptación y modulación, que define el flujo de información en el sistema. La gran similitud entre algunos modelos cerebrales (como el de los monos o ratas) y el cerebro humano, hace que la experimentación con animales permita extrapolar con relativa sencillez muchas de las conclusiones que sobre ellos se deriven.

Los métodos de análisis para el estudio de la conectividad funcional que aquí se presentan se han aplicado al caso específico de imágenes de resonancia magnética funcional de cerebros de rata que se estimulan eléctricamente. Para detectar las redes cerebrales que se conectan funcionalmente se han utilizado técnicas que asumen la correlación entre señales hemodinámicas cerebrales como indicadores de la conectividad, ya sea a partir del análisis estándar de la correlación cruzada o a partir de medidas multivariadas para la detección de patrones de varianza/covarianza.

Los seis primeros capítulos de la memoria introducen las bases teóricas y de conocimiento que permiten el diseño y desarrollo de todos aquellos métodos que se presentan como herramientas para nuestro estudio de la conectividad funcional. En esta primera parte de la Tesis Doctoral se exponen los siguientes conceptos clave:

1. Que la neurociencia moderna se postula en base a la doctrina de la neurona-una teoría que describe al cerebro humano como un sistema formado por billones de elementos discretos especializados en realizar operaciones muy concretas (llamados neuronas), que se conectan (a través de unas pequeñas conexiones electroquímicas llamadas sinapsis) con otros elementos o neuronas similares formando redes de mundo pequeño que responden de forma concreta frente a familias de estímulos determinados.

2. Que una de las formas más eficientes, en la actualidad, de estudiar la conectividad funcional es a través de las imágenes de resonancia magnética funcional (o IRMf) y el modelo lineal general, el cual permite la construcción de mapas estadísticos paramétricos que localizan las regiones cerebrales involucradas en una tarea cognitiva o percepción sensorial determinada. Los mapas estadísticos paramétricos se construyen en 
base al principio de Fick y a la señal dependiente del nivel de oxigenación sanguínea o BOLD (por sus siglas en inglés: blood-oxygen-level-dependent), la cual predice con un alto grado de confidencia la actividad neuronal subyacente [1].

3. Que para poder construir mapas estadísticos paramétricos que revelen de forma efectiva la actividad global neuronal son necesarias una serie de operaciones previas al análisis paramétrico, como son: el preprocesado de las imágenes funcionales, la modelización de las correlaciones serie o la normalización global—que previene el enmascaramiento de las respuestas funcionales segregadas.

4. Que la conectividad funcional es un concepto estadístico a través del cual se pretende cuantificar la información mutua entre las series temporales de eventos neurofisiológicos, y que uno de los mejores indicadores (o marcadores) de la conectividad funcional es la correlación entre señales BOLD-IRMf de uno o más vóxels que (por norma general) están separados anatómicamente. En este sentido, la asunción conectividad/correlación habilita multitud de técnicas de medida que van desde las más sencillas (como los análisis clásicos de correlación cruzada) hasta otras mucho más sofisticadas. Entre éstas últimas resultan muy populares las técnicas multivariadas basadas en la descomposición en componentes o coordenadas principales como por ejemplo la descomposición en valores singulares (o SVD, por sus siglas en inglés: single value decomposition) y la clasificación no supervisada o clustering.

Una vez expuestos los principios y mecanismos metodológicos básicos para el estudio de la conectividad funcional, en el Capítulo 7 se presentan los procedimientos experimentales que permiten adquirir las imágenes por resonancia magnética del cerebro de ratas de experimentación. En los distintos experimentos se combina la adquisición de imágenes funcionales con la implantación de uno (o dos) electrodos de microestimulación eléctrica cerebral mediante los cuales se consigue provocar una activación neuronal controlada [2]. Todas las ratas se someten a un estricto protocolo quirúrgico que permite colocar con gran precisión los electrodos de estimulación en unas coordenadas predeterminadas y bien conocidas (hecho fundamental en el diseño de nuestros métodos de análisis, dado que permite la obtención y discusión de gran parte de los resultados que presentamos).

Un complemento muy importante (indispensable en la mayoría de nuestros análisis) corresponde a un atlas anatómico multifuncional diseñado específicamente para el espacio anatómico de referencia de nuestros datos. La forma en que diseñamos dicho atlas cerebral de rata se presenta en un capítulo específico en la parte de métodos (vid. Capítulo 8-Síntesis de atlas tridimensionales para el estudio de la conectividad en cerebros de rata) dado que la metodología de diseño que presentamos se ideó para poder ser aplicada de forma genérica para la síntesis de atlas para espacios de referencia distintos al que asumimos como propio.

Por lo demás, el estudio de la conectividad lo afrontamos mediante dos vías de desarrollo bien diferenciadas, que se fundamentan en dos paradigmas de análisis ortogonales pero complementarios (pues ambos asumen la correlación como el marcador de la conexión neuronal):

- El primer grupo de métodos mide la conectividad funcional según la forma tradicional, es decir: en base a análisis de la correlación cruzada entre series temporales representativas de vóxels aislados o grupos de ellos. El uso de nuestro atlas cerebral multifuncional junto con un proceso iterativo que calcula la correlación cruzada entre todas las señales BOLD-IRMf medias de todas las regiones/etiquetas activas de cierto mapa estadístico paramétrico permite el cálculo de unas matrices cuadradas que revelan in vivo y dinámicamente el peso de las conexiones que identifican a cierto estado funcional. Dado que la estimulación eléctrica de un mismo núcleo cerebral debe mostrar un mismo patrón de modulación sináptica (incluso asumiendo el posible error experimental y la varianza en la respuesta funcional de cada sujeto), las matrices que calculamos (a las que llamamos huellas de conectividad) permiten el desarrollo de técnicas de clasificación de sujetos en base a estados funcionales concretos, y por tanto, las agrupaciones de sujetos revelan patrones de activación neuronal (o de conectividad funcional subyacente) reconocibles (y por tanto característicos) entre los sujetos de la población analizada (vid. Capítulo 9-Huellas de conectividad y análisis de grupos).

- La segunda vía de desarrollo de nuestro estudio de la conectividad funcional en el cerebro de rata tiene que ver con la visión multivariada de los datos de IRMf a través de su descomposición en valores singulares. En 
concreto, el análisis multidimensional de los datos lo realizamos combinando SVD y un proceso de clustering. En primer lugar, realizamos una proyección SVD de las series de tiempo BOLD-IRMf conocida como espacio funcional - un sistema métrico en el que la distancia entre cualesquiera dos vóxels se relaciona con el grado de conectividad que existe entre ellos. En segundo lugar y en virtud de la abstracción conectivi$\mathrm{dad} /$ distancia, sometemos al espacio funcional a un proceso de clasificación no supervisada, procedimiento por el cual somos capaces de identificar, como miembros de un mismo cluster, a aquellos vóxels que están conectados funcionalmente entre sí y, por lo tanto, con una respuesta funcional media representativa del sistema. Dado que dos vóxels próximos en el espacio funcional pueden estar segregados anatómicamente, utilizamos las agrupaciones del espacio funcional para construir mapas multiparamétricos de la conectividad funcional que permiten expresar la respuesta funcional de los efectos neuronales globales como suma de varios modos hemodinámicos (vid. Capítulo 10-Sistemas funcionales).

Finalmente, cabe mencionar que todas las metodologías de análisis de la conectividad funcional diseñadas en esta Tesis Doctoral han sido transcritas en decenas de funciones que, junto al atlas multifuncional del cerebro de rata que hemos diseñado específicamente para nuestros datos, nos permiten (a modo de resultados):

1. Crear un software de elaboración propia para el análisis de imágenes de resonancia magnética funcional de cerebros de rata que se estimulan eléctricamente. Dicho software (al que llamamos SPMrat) utiliza algunas funciones del paquete MATLAB conocido como SPM (SPM8, www.fil.ion.ucl.ac.uk/spm/software/spm8/) y permite de forma muy sencilla (a través de diálogos de pregunta/respuesta, funciones de fácil invocación e interfaces gráficas) un análisis integral y automático de las imágenes funcionales para el estudio de la conectividad funcional a partir del preprocesamiento de imágenes, el análisis de grupos de sujetos a partir de la clasificación de las huellas de conectividad o la extracción de sistemas funcionales a partir del análisis mean shift del sistema métrico de la conectividad funcional.

2. Sintetizar unas estructuras matriciales en representación de la actividad neuronal que revelan dinámicamente el sustrato anatómico asociable a un conjunto específico de conexiones establecidas (junto con sus pesos funcionales), identificando de forma única a cada sujeto aislado a partir de la actividad IRMf inducida.

3. Diseñar un clasificador de patrones de conectividad funcional (es decir, de las representaciones matriciales del apartado anterior o huellas de conectividad) que (a su vez) permite la identificación de los distintos estados funcionales que puedan generarse entre varios sujetos a los que se aplica uno o más paradigmas de estimulación eléctrica.

4. Implementar un procedimiento de clasificación no supervisada mediante el algoritmo mean shift que es capaz de extraer los modos de aquella distribución estadística que representa la conexión de los supra-vóxels representados en cierto espacio funcional y por tanto, la definición de clusters o sistemas funcionales identificables tanto espacialmente (a partir de unas máscaras binarias de membresía) como temporalmente (a partir de las señales medias BOLD-IRMf).

5. Elaborar unos mapas multiparamétricos que permiten expresar la respuesta funcional integrada en una suma de respuestas funcionales parciales, fundamentalmente a partir de la caracterización dispersiva de las funciones de respuesta hemodinámica según la propia descomposición mean shift del paso anterior.

En base a dichos resultados, podemos derivar las siguientes conclusiones biomédicas:

- Que las huellas de conectividad permiten predecir la posición de los electrodos de estimulación y los parámetros de estimulación empleados para generar las respuestas funcionales. Esto sugiere que trasladar estas técnicas al mundo clínico, y en concreto a las prácticas de la estimulación cerebral profunda, puede resultar muy beneficioso. Por ejemplo, puede confirmar la correcta implantación del electrodo y en caso contrario, modificar su posicionamiento para optimizar el resultado clínico_-vid. capítulos 12, 13 y/o 15. 
- Que el algoritmo mean shift permite la descomposición de la respuesta funcional integrada en varias respuestas parciales que identifican a grupos de vóxels que están funcionalmente conectados entre sí, por lo que podemos:

- Obtener conclusiones relativas a la causalidad o retardo sistemático [3] de las respuestas funcionales (según el principio del reposo inicial de los sistemas lineales invariantes en el tiempo).

- Estudiar la conectividad efectiva a partir del uso de dos o más electrodos de estimulación cuyas respuestas evocadas se interfieren asimétricamente.

- Crear unos mapas analíticos que nos permiten aislar anatómicamente sistemas macroscópicos conectados funcionalmente para, por ejemplo, diferenciar respuestas directas e indirectas (o monosinápticas vs. polisinápticas) o el estudio del problema asociado a las respuestas BOLD negativas—vid. Capítulo 14. 


\section{Resum}

El principal objectiu d'questa Tesi Doctoral és l'estudi de la conectividad funcional del cervell in vivo combinant imatge per ressonància magnètica funcional amb microestimulació elèctrica cerebral en animals d'experimentació.

Aquesta Tesi Doctoral s'emmarca en un equip multidisciplinar fruit de l'estreta col-laboració que mantenen el Centre de Biomaterials i Enginyeria Tisular de la Universitat Politècnica de València i l'Institut de Neurociències d'Alacant del Consell Superior d'Investigacions Científiques-Universitat Miguel Hernández.

L'estudi de la connectivitat funcional és de gran interés en la neurobiologia bàsica actual i una peça fonamental en la recerca preclínica d'enfermetats psiquiàtriques. No en va, es tracta del mecanisme sobre el que es fonamenten dos dels principis bàsics de la neurobiología: l'especialització i l'integració funcional. El sistema nerviós implementa un processament altament distribuït de la informació, amb mòduls especialitzats en aspectes específics del processament que es combinen entre sí de forma integral. Per exemple, l'experiència multisensorial d'un episodi quotidià s'experimenta com una percepció única (o integrada). En aquest context, la connectivitat eficient entre mòduls funcionals, o connectivitat funcional, és un requisit indispensable. Per a ésser eficient, dita connectivitat deu adaptar-se a les necessitats del sistema en un entorn -el mitjà en què es desenvolupa l'organisme- que està en continu canvi. Per tant, la configuració funcional del network és una característica dinàmica determinada pels mecanismes de plasticitat sinàptica, adaptació i modulació, que defineix el fluxe d'informació al sistema. La gran semblança entre alguns models cerebrals (com el dels micos o rates) i el cervell humà, fa que l'experimentació amb animals permeta extrapolar amb relativa senzillesa moltes de les conclusions que sobre ells es deriven.

Els mètodes d'anàlisis per a l'estudi de la connectivitat funcional que aquí es presenten s'han aplicat al cas específic per a imatges de ressonància magnètica funcional de cervells de rata que s'estimulen elèctricament. Per detectar les xarxes cerebrals que es connecten funcionalment s'han utilitzat tècniques que assumeixen la correlació entre senyals hemodinàmiques cerebrals com a indicadors de la connectivitat, ja siga a partir de l'anàlisi estàndard de la correlació creuada o a partir de mesures multivariades per a la detecció de patrons de variància/covariància.

Els sis primers capítols de la memòria introdueixen les bases teòriques i de coneixement que permeten el disseny i desenvolupament de tots aquells mètodes que es presenten com a eines per al nostre estudi de la connectivitat funcional. En aquesta primera part de la Tesi Doctoral s'exposen els següents conceptes clau:

1. Que la neurociència moderna es postula sobre la base de la doctrina de la neurona-una teoria que descriu al cervell humà com un sistema format per bilions d'elements discrets especialitzats en realitzar operacions molt concretes (anomenats neurones), que es connecten (a través d'unes petites connexions electroquímiques anomenades sinapsis) amb altres elements o neurones similars formant xarxes de món menut que responen de forma concreta front a families d'estímuls determinats.

2. Que una de les formes més eficients, en l'actualitat, d'estudiar la connectivitat funcional és a través de les imatges de ressonància magnètica funcional (o IRMf) i el model lineal general, el qual permet la construcció de mapes estadístics paramètrics que localitzen les regions cerebrals involucrades en una tasca cognitiva o percepció sensorial determinada. Els mapes estadístics paramètrics es construeixen sobre la base del principi de Fick i al senyal depenent del nivell d'oxigenació sanguínia o BOLD (per les seues sigles en anglès: 
blood-oxygen-level-dependent), la qual prediu amb un alt grau de confidència l'activitat neuronal subjacent [1].

3. Que per a poder construir mapes estadístics paramètrics que revelen de forma efectiva l'activitat global neuronal són necessàries una sèrie d'operacions prèvies a l'anàlisi paramètrica, com són: el pre-processat de les imatges funcionals, la modelització de les correlacions serie o la normalització global—que preveu l'emmascarament de les respostes funcionals segregades.

4. Que la connectivitat funcional és un concepte estadístic a través del qual es pretén quantificar la informació mútua entre les sèries temporals d'esdeveniments neurofisiològics, i que un dels millors indicadors (o marcadors) de la connectivitat funcional és la correlació entre senyals BOLD-IRMf d'un o més vòxels que (per norma general) estan separats anatòmicament. En aquest sentit, l'assumpció connectivitat/correlació habilita multitud de tècniques de mesura que van des de les més senzilles (com les anàlisis clàssiques de correlació creuada) fins a unes altres molt més sofisticades. Entre aquestes últimes resulten molt populars les tècniques multivariades basades en la descomposició en components o coordenades principals com per exemple la descomposició en valors singulars (o SVD, per les seues sigles en anglès: single value decomposition) i la classificació no supervisada o clustering.

Una vegada exposats els principis i mecanismes metodològics bàsics per a l'estudi de la connectivitat funcional, en el Capítol 7 es presenten els procediments experimentals que permeten adquirir les imatges per ressonància magnètica del cervell de rates d'experimentació. En els diferents experiments es combina l'adquisició d'imatges funcionals amb la implantació d'un (o dos) elèctrodes de microestimulació elèctrica cerebral mitjançant els quals s'aconsegueix provocar una activació neuronal controlada [2]. Totes les rates se sotmeten a un estricte protocol quirúrgic que permet col-locar amb gran precisió els elèctrodes d'estimulació en unes coordenades predeterminades i ben conegudes (fet fonamental en el disseny dels nostres mètodes d'anàlisis, donat que permet l'obtenció i discussió de gran part dels resultats que presentem).

Un complement molt important (indispensable en la majoria de les nostres anàlisis) correspon a un atles anatòmic multifuncional dissenyat específicament per a l'espai anatòmic de referència de les nostres dades. La forma en què dissenyem aquest atles cerebral de rata es presenta en un capítol específic en la part de mètodes (vid. Capítol 8-Síntesis de atlas tridimensionales para el estudio de la conectividad en cerebros de rata) atès que la metodologia de disseny que presentem es va idear per a poder ser aplicada de forma genèrica per a la síntesi d'atles per a espais de referència diferents al que assumim com a propi.

En quant a la resta, l'estudi de la connectivitat ho afrontem mitjançant dues vies de desenvolupament ben diferenciades, que es fonamenten en dos paradigmes d'anàlisis ortogonals però complementaris (donat què tots dos assumeixen la correlació com el marcador de la connexió neuronal):

- El primer grup de mètodes mesura la connectivitat funcional segons la forma tradicional, és a dir: sobre la base d'anàlisi de la correlació creuada entre sèries temporals representatives de vòxels aillats o grups d'ells. L'ús del nostre atles cerebral multifuncional juntament amb un procés iteratiu que calcula la correlació creuada entre tots els senyals BOLD-IRMf mitjanes de totes les regions/etiquetes actives de cert mapa estadístic paramètric permet el càlcul d'unes matrius quadrades que revelen in vivo i dinàmicament el pes de les connexions que identifiquen a cert estat funcional. Atès que la estimulació elèctrica d'un mateix nucli cerebral deu mostrar un mateix patró de modulació sinàptica (inclús assumint el possible error experimental i la variança en la resposta funcional de cada subjecte), les matrius que calculem (a les quals cridem empremptes de connectivitat) permeten el desenvolupament de tècniques de classificació de subjectes sobre la base d'estats funcionals concrets, i per tant, les agrupacions de subjectes revelen patrons d'activació neuronal (o de connectivitat funcional subjacent) reconeixedors (i per tant característics) entre els subjectes de la població analitzada (vid. Capítol 9-Huellas de conectividad y análisis de grupos).

- La segona via de desenvolupament del nostre estudi de la connectivitat funcional en el cervell de rata té a veure amb la visió multivariada de les dades de IRMf a través de la seua descomposició en valors singulars. 
En concret, l'anàlisi multidimensional de les dades el realitzem combinant SVD i un procés de clustering. En primer lloc, realitzem una projecció SVD de les sèries de temps BOLD-IRMf coneguda com a espai funcional-un sistema mètric en el qual la distància entre qualssevol dues vòxels es relaciona amb el grau de connectivitat que existeix entre ells. En segon lloc i en virtut de l'abstracció connectivitat/distància, sotmetem a l'espai funcional a un procés de classificació no supervisada, procediment pel qual som capaços d'identificar, com a membres d'un mateix cluster, a aquells vòxels que estan connectats funcionalment entre si i, per tant, amb una resposta funcional mitjana representativa del sistema. Atès que dos vòxels pròxims en l'espai funcional poden estar segregats anatòmicament, utilitzem les agrupacions de l'espai funcional per a construir mapes multiparamètrics de la connectivitat funcional que permeten expressar la resposta funcional dels efectes neuronals globals com una suma de diversos modes hemodinàmics (vid. Capítol 10_Sistemas funcionales).

Finalment, cal esmentar que totes les metodologies d'anàlisis de la connectivitat funcional dissenyades en aquesta Tesi Doctoral han sigut transcrites en desenes de funcions que, juntament amb l'atles multifuncional del cervell de rata que hem dissenyat específicament per a les nostres dades, ens permeten (a manera de resultats):

1. La creació d'un software d'elaboració pròpia per a l'anàlisi d'imatges de ressonància magnètica funcional de cervells de rata que s'estimulen elèctricament. Aquest software (al que cridem SPMrat) utilitza algunes funcions del paquet MATLAB conegut com SPM (SPM8, www.fil.ion.ucl.ac.uk/spm/software/spm8/) i permet de forma molt senzilla (a través de diàlegs de pregunta/resposta, funcions de fàcil invocació i interfícies gràfiques) una anàlisi integral i automàtic de les imatges funcionals per a l'estudi de la connectivitat funcional a partir del pre-processat d'imatges, l'anàlisi de grups de subjectes a partir de la classificació de les empremptes de connectivitat o l'extracció de sistemes funcionals a partir de l'anàlisi mean shift del sistema mètric de la connectivitat funcional.

2. Sintetitzar unes estructures matricials en representació de l'activitat neuronal que revelen dinàmicament el substrat anatòmic associable a un conjunt específic de connexions establides (juntament amb els seus pesos funcionals), identificant de forma única a cada subjecte aïllat a partir de l'activitat IRMf induïda.

3. Dissenyar un classificador de patrons de connectivitat funcional (és a dir, de les representacions matricials de l'apartat anterior o empremptes de connectivitat) que (al seu torn) permet la identificació dels diferents estats funcionals que puguen generar-se entre diversos subjectes als quals s'aplica un o més paradigmes d'estimulació elèctrica.

4. Implementar un procediment de classificació no supervisada mitjançant l'algorisme mean shift que és capaç d'extraure els modes d'aquella distribució estadística que representa la connexió dels supra-vòxels representats en cert espai funcional i per tant, la definició de clusters o sistemes funcionals identificables tant espacialment (a partir d'unes màscares binàries de pertinença) com temporalment (a partir dels senyals mitjans BOLD-IRMf).

5. Elaborar uns mapes multiparamètrics que permeten expresar la resposta funcional integrada en una suma de respostes funcionals parcials, fonamentalment a partir de la caracterització dispersiva de les funcions de resposta hemodinàmica segons la pròpia descomposició mean shift del pas anterior.

Sobre la base d'aquests resultats, podem derivar les següents conclusions biomèdiques:

- Que les empremptes de connectivitat permeten predir la posició dels elèctrodes d'estimulació i els paràmetres d'estimulació emprats per a generar les respostes funcionals. Açò suggereix que traslladar aquestes tècniques al món clínic, i en concret a les pràctiques de l'estimulació cerebral profunda, pot resultar molt beneficiós. Per exemple, pot confirmar la correcta implantació de l'elèctrode i en cas contrari, modificar el seu posicionament per a optimitzar el resultat clínic—vid. capítols 12, 13 i/o 15. 
- Que l'algorisme mean shift permet la descomposició de la resposta funcional integrada en diverses respostes parcials que identifiquen a grups de vòxels que estan connectats funcionalment entre sí, per la qual cosa podem:

- Obtenir conclusions relatives a la causalitat o retard sistemàtic [3] de les respostes funcionals (segons el principi del repòs inicial dels sistemes lineals invariants en el temps).

- Estudiar la connectivitat efectiva a partir de l'ús de dos o més elèctrodes d'estimulació les respostes evocades de la qual s'interfereixen asimètricament.

- Crear uns mapes analítics que ens permeten aïllar anatòmicament sistemes macroscòpics connectats funcionalment per a, per exemple, identificar respostes directes i indirectes (o monosináptiques vs. polisináptiques) o l'estudi del problema associat a les respostes BOLD negatives—vid. Capítol 14. 


\section{Abstract}

The main objective of this Ph.D. Thesis is the study of functional brain connectivity in vivo combining functional magnetic resonance imaging with electrical brain microstimulation in experimental animals.

This Ph.D. Thesis is part of a multidisciplinary team result of close collaboration between the Center for Biomaterials and Tissue Engineering of Universitat Politècnica de València and the Neuroscience Institute of Alicante of the National Research Council in Spain-Universidad Miguel Hernández.

The study of functional connectivity is of great interest in current basic neurobiology and a fundamental part of pre-clinical research of psychiatric illness. Indeed, it is the mechanism on which are based two of the basic principles of neurobiology: functional specialization and integration. The nervous system implements a highly distributed processing of information, with specialized modules on specific aspects of processing that are combined together in an integral form. For example, the multisensorial experience of a daily episode is experienced as a single (or integrated) perception. In this context, the efficient connectivity between functional modules, or functional connectivity, is an indispensable requirement. In order to be efficient, this connectivity must adapt to the needs of the system in an enviroment -the medium in which the body develops- which is in continuous change. Therefore, the functional configuration is a dynamic characteristic determined by synaptic plasticity mechanisms, adaptation and modulation, defining the flow of information in the system. The great similarity between some brain models (such as monkeys or rats) and the human brain, makes conclusions drawn from animal experiments relatively easy to extrapolate.

The analysis methods for studying functional connectivity presented here have been applied to the specific case of functional magnetic resonance imaging of rat brains that are stimulated electrically. In order to detect brain networks that are functionally connected, cerebral hemodynamical signal correlation techniques have been used as indicators of connectivity, either from the standard analysis of the cross-correlation or from multivariate measures for detecting patterns of variance/covariance.

The first six chapters of the doctoral dissertation introduce the theoretical and knowledge foundations that enable the design and development of all those methods that are presented as tools for our study of functional connectivity. In this first part of the Doctoral Thesis the following key concepts are shown:

1. That modern neuroscience is postulated on the basis of neuron doctrine-a theory that describes the human brain as a system composed of billions of discrete elements specialized in very precise operations (called neurons), that are connected (via a small electrochemical connections called synapses) with other elements or similar neurons forming small-world networks that respond specifically against certain stimuli families.

2. That one of the most efficient ways to study the functional connectivity, nowadays, is through functional magnetic resonance imaging (or fMRI) and the general linear model, which allows the construction of statistical parametric maps that locate the brain regions involved in a cognitive task or specific sensory perception. The statistical parametric maps were constructed based on the Fick principle and the blood-oxygen-leveldependent signal or BOLD, which predicts with a high degree of confidence the underlying neural activity [1].

3. That constructing statistical parametric maps to reveal the global neuronal activity in an effective way involves a set of operations prior to parametric analysis, such as: pre-processing of functional images, modeling 
of serial correlations or global standardization-which prevents the masking of the segregated functional responses.

4. That functional connectivity is a statistical concept whereby it is intended to quantify the mutual information between the time series of neurophysiological events, and that one of the best indicators (or markers) of the functional connectivity is the correlation between BOLD-fMRI signals of one or more voxels that (normally) are separated anatomically. In this sense, the assumption connectivity/correlation enables multiple measurement techniques ranging from the simplest (such as classical analysis of cross-correlation) to much more sophisticated. Among the latter are very popular those multivariate techniques which are based on the principal components or coordinates decomposition such as singular value decomposition (or SVD) and unsupervised classification or clustering.

Once exposed the principles and basic methodological tools for the study of functional connectivity, Chapter 7 presents the experimental procedures allowing to acquire the magnetic resonance imaging of experimental rat brains. In the various experiments functional imaging is combined with the implantation of one (or two) microstimulation electrodes that enable the elicitation of controlled neuronal activations [2]. All rats were subjected to a strict surgical protocol that allows an accurate placement of stimulation electrodes in a predetermined and well-known coordinates (which is a fundamental fact in the design of our analysis methods, allowing to reach and discuss many of the results that we present).

A very important complement (indispensable in most of our analysis) corresponds to an anatomical atlas designed specifically for the anatomical reference space of our data. The way we design the rat brain atlas is presented in a separate chapter in the methods (vid. Chapter 8-Síntesis de atlas tridimensionales para el estudio de la conectividad en cerebros de rata) as the design methodology presented here was conceived to be applied generically to the synthesis of atlases for different reference spaces instead of that we assume as own.

For the rest, we deal with the study of connectivity from two well differentiated development perspectives, which are based on two orthogonal but complementary paradigms of analysis (as they both assume the correlation as a marker of neuronal connectivity):

- The first group of methods measure the functional connectivity in the traditional way, e.g.: based on analysis of the cross-correlation between time series representing isolated voxels or groups of them. The use of our multifunctional brain atlas together with an iterative process that calculates the cross-correlation between all averaged fMRI-BOLD signals for all active regions/tags of a parametric statistical map allows the calculation of some square matrices that reveal in vivo and dynamically the weight of the connections that identify a functional state. Since electrical stimulation of a same brain nucleus should show the same pattern of synaptic modulation (accepting the possible experimental error and the variance in the functional response of each subject), the matrices we calculate (which we call connectivity fingerprints) support the development of subject classification techniques based on their specific functional states, and therefore, the groups of subjects reveal patterns of neural activation (or underlying functional connectivity) recognizable (and therefore characteristic) among subjects of the analyzed population (vid. Chapter 9-Huellas de conectividad y análisis de grupos).

- The second development track in our study of functional connectivity in the rat brain has to do with a multivariate vision of fMRI data through its singular value decomposition. In particular, we perform the multidimensional data analysis combining SVD and a clustering process. First, we perform a SVD projection of BOLD-fMRI time series known as functional space-a metric system in which the distance between any two voxels is related to the degree of connectivity between them. Secondly, by virtue of the abstraction connectivity/distance, we submit the functional space to a process of unsupervised classification, procedure by which we can identify, as members of the same cluster, those voxels which are functionally connected to one another, therefore, with an averaged functional response which is representative of the system. Since two voxels that are close in the functional space could be anatomically segregated, we use functional space clusters to construct multiparametric functional connectivity maps allowing to express the functional response of the global neuronal effects as a sum of several hemodynamic modes (vid. Capítulo 10_-Sistemas funcionales). 
Finally, it should be mentioned that all analysis methodologies designed functional connectivity in this Doctoral Thesis have been transcribed in dozens of functions that, along with the multifunctional atlas of the rat brain we designed specifically for our data, allows us to (as results):

1. Create a software of own elaboration for the analysis of functional magnetic resonance imaging in rat brains that are stimulated electrically. Such software (which we call SPMrat) use some features of the MATLAB package known as (SPM8, www.fil.ion.ucl.ac.uk/spm/software/spm8/) and allows a very simple (through dialogues of question/answer, friendly invoking functions and graphical interfaces) a comprehensive and automatic analysis of functional images for studying functional connectivity from image preprocessing, the analysis of groups of subjects by means of the connectivity fingerprints classification or the extraction of functional systems from the mean shift analysis over the functional connectivity metric system.

2. Synthesize some matrix structures representing the neural activity that dynamically reveal the anatomical substrate associable to a specific set of established connections (together with their functional weights), uniquely identifying each individual subject from the induced fMRI activity.

3. Design a functional connectivity pattern classifier (e.g., the matrix representations of the previous section or connectivity fingerprints) that (in turn) allows the identification of the different functional states that may result among several subjects to whom one or more electrical stimulation paradigms are applied.

4. Implement an unsupervised classification procedure using the mean shift algorithm which is able to extract the modes of that statistical distribution that represents the connection of the above-voxels represented in certain functional space and thus, the definition of identifiable clusters or functional systems both spatially (from binary membership masks) and temporally (from the mean BOLD-fMRI signals).

5. Develop some multiparametric maps allowing to express the integrated functional response into a sum of partial functional responses, mainly from dispersive characterization of hemodynamic response functions according to the mean shift decomposition from the previous step.

Based on these results, we can derive the following biomedical conclusions:

- Connectivity fingerprints allows to predict the position of stimulation electrodes and the stimulation parameters used to generate functional responses. This suggests that transfering these techniques to the clinical world, and specifically to the practice of deep brain stimulation, can be very beneficial. For example, it can confirm the correct placement of the electrode and otherwise modify its positioning to optimize the clinical outcome-vid. chapters 12, 13 and/or 15.

- Mean shift algorithm allows the decomposition of the integrated functional response in various partial responses that identify groups of voxels that are functionally connected to each other, so we can:

- Draw conclusions regarding functional responses causality or systematic delay [3] (according to the principle of the initial rest of linear time-invariant systems).

- Study effective connectivity from the use of two or more electrodes whose evoked stimulation responses are interfered asymmetrically.

- Create some analytical maps that allow us to isolate anatomically those functionally connected macroscopic systems to allow, for example, to differentiate direct and indirect responses (or monosynaptic vs. polysynaptic) or the study of the problem associated with negative BOLD responses_-vid. Chapter 14 


\section{Índice general}

$\begin{array}{ll}\text { Agradecimientos } & \text { III }\end{array}$

Resumen

Resum $\quad$ IX

$\begin{array}{lcl}\text { Abstract } & \text { XIII }\end{array}$

$\begin{array}{lc}\text { Motivación y objetivos } & \text { XXI }\end{array}$

$\begin{array}{lll}\text { I Introducción } & 1\end{array}$

1. El increíble accidente de Phineas P Gage $\quad 3$

2. Especialización, integración y conectividad $\quad 7$

2.1. Especialización funcional . . . . . . . . . . . . . . . . . . . . . 7

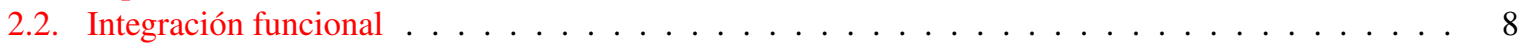

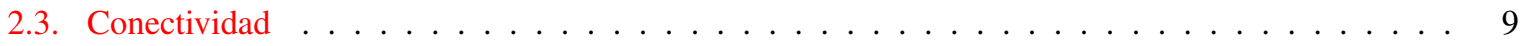

2.3.1. Conectividad anatómica . . . . . . . . . . . . . . . . . 9

2.3.2. Conectividad funcional . . . . . . . . . . . . . . . . . . . . . 10

2.3.3. Conectividad efectiva . . . . . . . . . . . . . . . . . . . . 10

2.4. Análisis conjunto de la conectividad anatómica y funcional . . . . . . . . . . . . . . . 11

3. Modelado de la actividad neuronal $\quad \mathbf{1 5}$

3.1. Imágenes funcionales por $\mathrm{RM} \ldots \ldots \ldots \ldots \ldots \ldots \ldots$

La señal BOLD-IRMf . . . . . . . . . . . . . . . . . . 16

Bases neuronales de la señal BOLD . . . . . . . . . . . . . . . . . . . . . . . . . . . . . . .

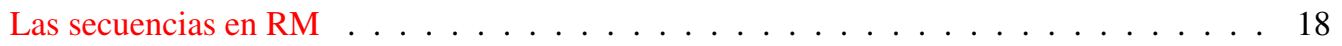

3.2. Modelos estadísticos . . . . . . . . . . . . . . . . . . . . . . 19

3.2.1. Introducción a los mapas estadísticos paramétricos . . . . . . . . . . . . . . . . 19

El modelo lineal generalizado . . . . . . . . . . . . . . . . . . . 20

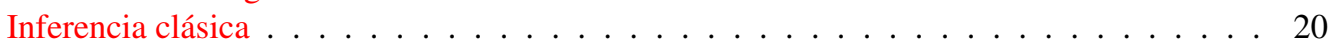

Modelos dinámicos . . . . . . . . . . . . . . . . . . 21

4. Preprocesado de las imágenes por RM para estudios funcionales 25

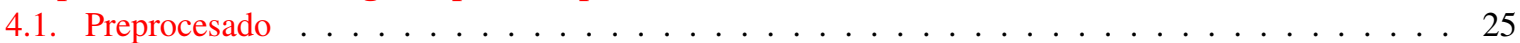

4.1.1. Realineado ........................... 26

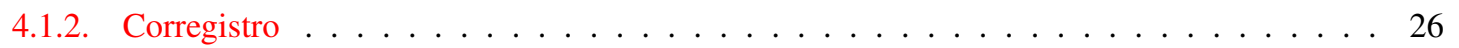


4.1.3. Normalización . . . . . . . . . . . . . . . . . . . . . . 26

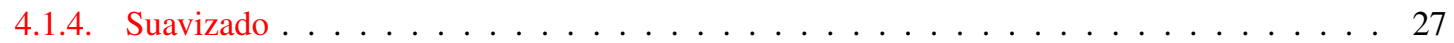

5. Mapas estadísticos paramétricos $\quad 2$

5.1. Diseño experimental . . . . . . . . . . . . . . . . . . . . . . . . . . . 29

5.1.1. Optimización del paradigma temporal . . . . . . . . . . . . . . . . 31

5.1.2. Correlaciones y filtrado . . . . . . . . . . . . . . . . . . . . . . . 31

5.2. Estimación de parámetros . . . . . . . . . . . . . . . . . . . . . . 32

5.3. Análisis estadístico para la caracterización de efectos neuronales globales . . . . . . . . . . 33

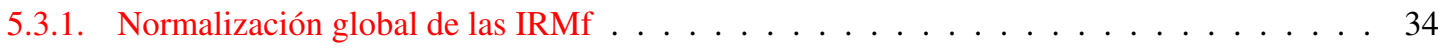

5.3.2. Teoría de campos aleatorios . . . . . . . . . . . . . . . . . . . . . . . . . . . . . . . . . . . . . . . . 34

5.3.3. Inferencia de las funciones base temporales . . . . . . . . . . . . . . . . . 36

Análisis clásico de primer nivel y segundo nivel . . . . . . . . . . . . . . . 37

6. Medidas de conectividad funcional mediante imágenes por RM 3

6.1. Medidas de conectividad funcional . . . . . . . . . . . . . . . . . . . . 39

6.1.1. Correlación . . . . . . . . . . . . . . . . . . . . . 40

6.1.2. Coherencia .......................... . . . 41

6.2. Medidas multivariadas . . . . . . . . . . . . . . . . . . . . . . . . 42

6.2.1. Descomposición en valores singulares . . . . . . . . . . . . . . . . . 43

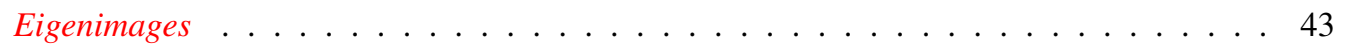

6.2.2. Clasificación no supervisada . . . . . . . . . . . . . . . . . . 45

$\begin{array}{ll}\text { II } & \text { Materiales } \\ \end{array}$

7. Adquisición de imágenes y herramientas de análisis 49

7.1. Animales de experimentación . . . . . . . . . . . . . . . . . . . . . . . . 49

7.1.1. Análisis de la corteza prefrontal . . . . . . . . . . . . . . . . . . . 50 50

7.1.2. Análisis del núcleo accumbens . . . . . . . . . . . . . . . . . . . . . . . . . . . . . . . . . . . . . . . . . . . 50

7.1.3. Análisis del sistema vestibular . . . . . . . . . . . . . . . . . . . 50

7.1.4. Estimulación con dos electrodos . . . . . . . . . . . . . . . . . . . 51

7.2. Parámetros IRMf . . . . . . . . . . . . . . . . . . . . . . . 51

7.3. Análisis IRMfe . . . . . . . . . . . . . . . . . . . . . . . . 52

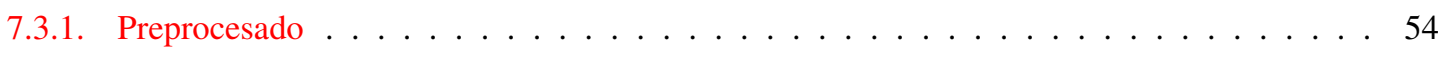

7.3.2. Inferencia estadística clásica de primer nivel . . . . . . . . . . . . . . . 54

$\begin{array}{lr}\text { III Métodos } & \mathbf{5 7}\end{array}$

8. Síntesis de atlas tridimensionales para el estudio de la conectividad en cerebros de rata 59

8.1. Análisis regional del cerebro de rata . . . . . . . . . . . . . . . . . . 59

8.1.1. Registro del atlas y las imágenes experimentales . . . . . . . . . . . . . . . . . . 60

8.1.2. El atlas-Schwarz . . . . . . . . . . . . . . . . . . . . . . 6 . . . . . . . . . . . 60

8.2. Síntesis de atlas de propósito general . . . . . . . . . . . . . . . . . . . . 61

8.3. Demostraciones prácticas . . . . . . . . . . . . . . . . . . . . . 62 
9. Huellas de conectividad y análisis de grupos $\quad 63$

9.1. Huellas de conectividad . . . . . . . . . . . . . . . . . . . . . 63

9.2. Análisis de grupos . . . . . . . . . . . . . . . . . . . . . . . . . . . . . . . . 64

9.2.1. Clasificador de la actividad funcional . . . . . . . . . . . . . . . . 65

9.2.2. Respuesta media de los grupos: análisis clásico de segundo nivel . . . . . . . . . . . . . 67

10. Sistemas funcionales $\quad 69$

10.1. Actividad correlada . . . . . . . . . . . . . . . . . . . . . . 69

10.1.1. Espacio funcional . . . . . . . . . . . . . . . . . . . 70

10.2. Análisis de la conectividad con mean shift . . . . . . . . . . . . . . . . . . 71

10.2.1. Algoritmo mean shift . . . . . . . . . . . . . . . . . . . . . . 72

10.2.2. Mapas analíticos del espacio funcional . . . . . . . . . . . . . . . 74

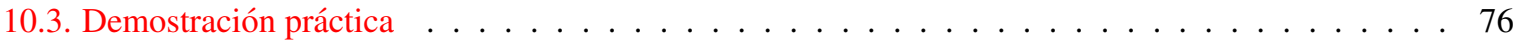

$\begin{array}{lll}\text { IV } & \text { Resultados y discusión } & \mathbf{8 1}\end{array}$

11. Análisis de la conectividad funcional en cerebros de rata: SPMrat $\mathbf{8 3}$

11.1. SPMrat ............................... . . 85

11.1.1. Análisis clásico de primer nivel . . . . . . . . . . . . . . . . . . . . . . . . . . . . . . 85

11.1.2. Atlas anatómico SPMrat . . . . . . . . . . . . . . . . . . . 86

11.2. Análisis de la conectividad funcional con SPMrat . . . . . . . . . . . . . . . . . . . 86

11.2.1. Análisis clásico de segundo nivel . . . . . . . . . . . . . . . . . . . 87

12. Análisis de la corteza prefrontal $\quad 89$

12.1. La corteza prefrontal . . . . . . . . . . . . . . . . . . . . . . . . . 89

12.1.1. Regiones que forman la corteza prefrontal . . . . . . . . . . . . . . . . . 89

12.2. Descripción del experimento . . . . . . . . . . . . . . . . . . . . . . . 89

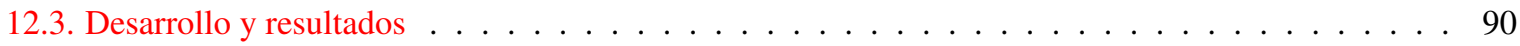

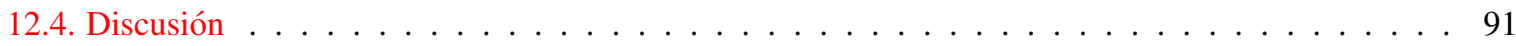

13. Análisis del núcleo accumbens $\quad 97$

13.1. El accumbens . . . . . . . . . . . . . . . . . . . . . . . . . 97

13.1.1. Aferencias y eferencias . . . . . . . . . . . . . . . . . . . . . . . . . . . . . . . . . .

Canales de entrada al accumbens . . . . . . . . . . . . . . . . . . . . . . . . . . . . . . . . . . . . 97

Canales de salida del accumbens . . . . . . . . . . . . . . . . . . . . . . . . . . . . . . . . . . . . . . . . .

13.2. Descripción del experimento . . . . . . . . . . . . . . . . . . . . . . . . . . . 98

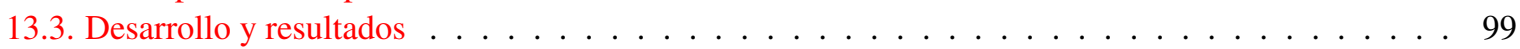

13.4. Discusión . . . . . . . . . . . . . . . . . . . . . 100

14. Análisis del sistema vestibular $\quad \mathbf{1 0 5}$

14.1. El sistema vestibular . . . . . . . . . . . . . . . . . . . . . . 105

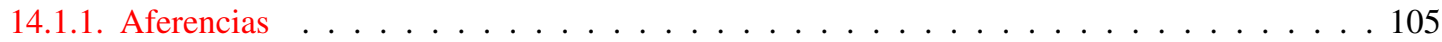

14.2. Descripción del experimento . . . . . . . . . . . . . . . . . . . . 105

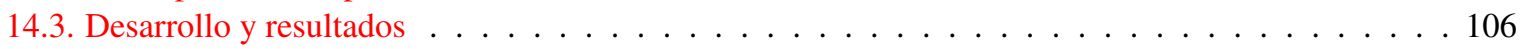

14.3.1. Mapas estadísticos paramétricos y huellas de conectividad . . . . . . . . . . . . . 106

14.3.2. Registro electrofisiológico . . . . . . . . . . . . . . . . . . . . 108

Sistemas funcionales y dianas para el registro . . . . . . . . . . . . . 108

14.4. Discusión . . . . . . . . . . . . . . . . . . . . . . . 110 
15. Principios funcionales de la ECP

15.1. Estimulación cerebral profunda ． . . . . . . . . . . . . . . . . . . . . 113

15.2. Descripción del experimento . . . . . . . . . . . . . . . . . . . . . . . 114

15.3. Desarrollo y resultados . . . . . . . . . . . . . . . . . . . . . . . . . . 114

15.4. Discusión . . . . . . . . . . . . . . . . . . . . . 116

$\begin{array}{lr}\text { V Conclusiones } & 121\end{array}$

$\begin{array}{lr}\text { VI Publicaciones derivadas } & 125\end{array}$

$\begin{array}{lr}\text { VII Líneas futuras } & 129\end{array}$

VIII Bibliografía $r$\begin{tabular}{l}
133 \\
\hline
\end{tabular} 


\section{Motivación y objetivos}

¿Cómo codifica, almacena y recupera nuestro cerebro la información que procesa? El aprendizaje modifica las conexiones neuronales o sinapsis, y con ello determina la estructura funcional del cerebro. De esta forma, las redes neuronales relevantes en un determinado contexto son reclutadas y garantizan la adaptación comportamental. No obstante y a pesar de su importancia, conocemos muy poco sobre las reglas que rigen la transformación sináptica de las redes neuronales - en un mecanismo que Jerzy Konorski redefine como plasticidad neuronal [4, p. 23: The modifiability of specific connections contributes to the adaptability of behavior]. La forma habitual de estudiar la plasticidad neuronal es a partir de medidas de información mutua entre señales de flujo sanguíneo de distintas regiones (o áreas) del cerebro. De este modo, se dice que dos regiones están conectadas funcionalmente si la información mutua entre ellas está por encima de cierto umbral. En este sentido, resultan de especial interés aquellas estructuras de datos que permiten analizar de forma conjunta todas las conexiones funcionales que, a lo largo del tiempo, puedan establecerse sobre un sustrato anatómico dado. En general, se trata de grafos y/o matrices capaces de representar las correlaciones cruzadas entre todas las regiones cerebrales de interés [5]. La construcción de este tipo de estructuras y (sobre todo) su análisis, representan un hito importante en esta Tesis Doctoraldado su previsible potencial para la caracterización de estados funcionales in vivo [6]. Dichas estructuras podrían utilizarse, por ejemplo, para investigar enfermedades neurológicas (comparando matrices de control con matrices de conexión en modelos animales de enfermedades humanas-como la esquizofrenia) o los principios funcionales de la estimulación cerebral profunda. Además, como se indicaba al principio, recientemente se ha demostrado que [7]: la plasticidad sináptica que determina el peso de una conexión es una parte fundamental de la conectividad funcional y que los circuitos neuronales que soportan el aprendizaje son funcionalmente reorganizados como consecuencia de la potenciación sináptica en el hipocampo [8]—una región cerebral de máxima relevancia en la gestión y almacenamiento de las memorias.

Por todo ello, el objetivo del presente trabajo de investigación es el desarrollo de metodologías de análisis que permitan el estudio de la conectividad funcional. En concreto, el estudio de la conectividad se llevará a cabo a partir de imágenes de resonancia magnética funcional con estimulación eléctrica (o IRMfe ${ }^{1}$ ) en cerebros de ratas de experimentación [2]. Las distintas metodologías desarrolladas se integrarán en un software implementado en MATLAB, que deberá ser sencillo de manejar y facilitará en la medida de lo posible el análisis automatizado de datos. Como mínimo, el software deberá incorporar e implementar todos aquellos elementos y programas que permitan ejecutar y/o sintetizar:

- Una metodología de preprocesado de las imágenes de resonancia magnética para estudios funcionales que permita el posterior análisis de la conectividad funcional tanto en sujetos aislados como en grupos de sujetos. Para ello, se podrán definir familias de imágenes anatómicas de referencia que definan una plantilla para la normalización espacial de las imágenes-por ejemplo, según la cantidad de cortes horizontales o coronales que se adquieran en las sesiones de IRMfe.

- Una metodología de análisis que obtenga mapas estadísticos paramétricos sobre los efectos neuronales globales que permitan localizar las regiones segregadas que, en cualquier lugar del cerebro, estén respondiendo

\footnotetext{
${ }^{1}$ En inglés, el término IRMf (o imagen por resonancia magnética funcional) corresponde al término fMRI (functional magnetic resonance imaging). Cuando las imágenes se adquieren mientras se estimula eléctricamente núcleos cerebrales específicos, el término IRMfe es equivalente a esfMRI (electric stimulation $f M R I)$.
} 
funcionalmente a cierto estímulo.

- Atlas multifuncionales digitales tridimensionales que permitan el análisis regional de la conectividad cerebral-por ejemplo, extrayendo la señal BOLD-IRMf [9, pp. 451-6: FMRI signal] media de una región etiquetada. Los atlas 3D podrán asociarse/sintetizarse para cualquier plantilla anatómica que se asuma como espacio de referencia y en cualquier caso permitirán la elaboración de mapas cartográficos cerebrales.

- Unas estructuras de datos (generalmente grafos y/o matrices) que permitan establecer los estados funcionales de un sujeto en base a un análisis de las correlaciones cruzadas de las señales medias BOLD-IRMf entre todas las regiones activas que se aíslen convenientemente mediante el atlas multifuncional.

- Un clasificador de los patrones de conectividad funcional extraídos en el paso anterior, que permita realizar las agrupaciones de sujetos más verosímiles en base a los estados funcionales que se encuentren.

- Un procedimiento que permita identificar en unos mapas multiparamétricos los distintos patrones de actividad correlada que integran la respuesta funcional global (presumiblemente bajo una proyección multivariada de las series de tiempo BOLD-IRMf), de forma que sobre ellos se puedan realizar distintas medidas que permitan caracterizar mejor el comportamiento funcional bajo estimulación eléctrica, por ejemplo, midiendo la dispersión temporal o las variaciones de intensidad BOLD entre las distintas respuestas segregadas.

Finalmente, aunque el software se diseñe específicamente para el análisis de IRMfe en cerebros de rata, abordaremos el estudio de algunos principios funcionales de la microestimulación cerebral para su extrapolación al caso de la estimulación cerebral profunda (o ECP) empleada en humanos—dado que a pesar de su gran potencial clínico no se conocen las bases neurofisiológicas de esta técnica. Una aproximación experimental como la usada en esta Tesis en conjunción con las herramientas desarrolladas nos ofrecen la posibilidad de investigar los principios funcionales de la ECP así como la identificación de nuevas dianas donde la estimulación eléctrica puede ser de valor terapéutico. 


\section{Parte I}

\section{Introducción}





\section{Capítulo 1}

\section{El increíble accidente de Phineas P Gage}

En septiembre de 1848, en Cavendish, Vermont, una pequeña ciudad de los Estados Unidos, ocurrió un hecho que iba a cambiar para siempre los preceptos de la relación entre el cerebro y el comportamiento humano. Phineas P Gage, un capataz de ferrocarril de 25 años, estaba preparando una explosión para dinamitar una roca que obstruía el trazado de un carril de tren. Ayudándose de una gran barra de hierro (de un metro de longitud, seis mm de diámetro y seis $\mathrm{kg}$ de peso), Gage estaba colocando pólvora en uno de los agujeros que justo acababa de cavar, cuando inesperadamente algo prendió el explosivo. La mala fortuna hizo que la gran barra de hierro con la que Gage prensaba la pólvora saliese disparada directamente hacia su mejilla izquierda, atravesándole por completo el cráneo. La fuerza con la que la barra salió disparada fue tal que Gage voló varios metros. Pese a las graves lesiones que pareció haber sufrido (en Harlow [10] se cita textualmente que la barra de hierro quedó untada de cerebro), Gage permaneció consciente en todo momento y sólo unos minutos después del accidente se puso a relatar el incidente en su diario de trabajo. Un poco antes, Gage había reconocido al Dr. Harlow, quien había acudido a socorrerlo y observaba atónito lo insólito de la situación.

La herida continuaba sangrando dos días después del accidente. Las cosas empeoraron cuando una grave infección afectó a Gage, debilitándolo hasta el punto de dejarlo inconsciente más de un mes. Aunque parecía que la situación no tenía remedio (incluso su ataúd fue encargado a la funeraria del pueblo), el Dr. Harlow siguió haciéndose cargo de Gage y milagrosamente, a la quinta semana de contraerla, la infección empezó a remitir. Phineas había perdido la visión del ojo izquierdo y sufría parálisis facial, pero aparentemente no padecía daño neurológico alguno.

Si la historia acabase aquí, esto sería un pequeño relato en reseña de la gran fuerza física de Gage y del acierto y la fe del Dr. Harlow en la recuperación del herido. Pero lo que hace de éste un evento histórico son los cambios que el Dr. Harlow pudo observar en la personalidad de Gage.

Inmediatamente después de haberse recuperado físicamente, el Dr. Harlow describía a Gage como sigue: "Recuerda eventos pasados y recientes sin problema, incluso los que acontecieron justo antes y después del accidente. No obstante se muestra menos hábil intelectualmente y raramente caprichoso, actuando como un niño indomable. Lo encuentro especialmente obstinado y parece dejarse llevar por sus deseos sin remordimiento alguno”. El Dr. Harlow recuerda también que los superiores de Gage (quienes lo calificaban como el capataz más eficiente y trabajador con el que nunca habían contado) no pudieron readmitirlo en su antiguo puesto de trabajo dado su brusco cambio de personalidad: "Tiene cambios bruscos de humor, es irreverente, blasfema constantemente de forma muy burda (algo que antes del accidente nunca habría hecho), manifiesta muy poco respeto por sus compañeros, no atiende a razones si algo va contra sus deseos; es voluble y su capacidad de concentración en sus tareas se ha perdido completamente (...). Su capacidad intelectual parece la de un niño, pero defiende sus pasiones como un hombre fuerte”. Su personalidad había cambiado de forma extrema, tanto que sus amigos y conocidos decían que Gage nunca volvió a ser Gage [11].

Sin empleo, Gage empezó a viajar por toda Nueva Inglaterra con su barra de hierro, llegando a trabajar en el circo, donde se mostraba a sí mismo frente al público como una curiosidad que admirar. Más tarde trabajó en 


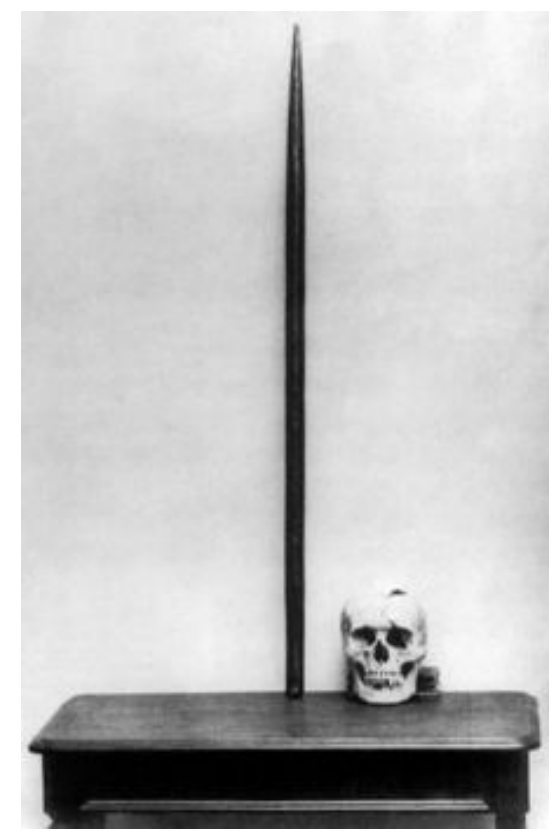

Figura 1.1: El cráneo de Gage y la gran barra de hierro que lo cambió para siempre.

varios establos y finalmente retornó al hogar familiar en San Francisco. Allí empezó a padecer episodios epilépticos y en mayo de 1861, doce años después del accidente, murió en status epilepticus. El Dr. Harlow escribió en sus informes del caso que si bien es cierto que a través de los años Gage consiguió cierta recuperación a nivel mental, sus facultades intelectuales fueron decididamente a peor, aunque sin perderse totalmente; nada parecido a la demencia, pese a que cada vez sus razonamientos eran más pobres, perfectos en la forma, pero no en el fondo.

Frente a la frenología ${ }^{1}$ y la afasia de Broca $^{2}$, las teorías del Dr. Harlow no parecían sostenerse. No fue hasta 1878 que David Ferrier en su contribución a las Goulstonian Lectures [12] dijo que: "Existen ciertas regiones en la corteza cerebral a las que se les puede asignar ciertas funciones (...). Los fenómenos que puedan aparecer tras lesiones en las distintas zonas corticales variarán de acuerdo a la propia localización del daño cerebral así como del carácter del sujeto que padece la lesión”. En esas mismas lecturas, Ferrier concluía (respecto a sus experimentos con monos): "La extracción parcial o total de los lóbulos antero-frontales no conlleva una efecto fisiológico estrictamente definido o caracterizable. No obstante, a pesar de esta aparente ausencia de síntomas fisiológicos, pude percibir claramente una alteración en el carácter del animal así como en su comportamiento, si bien es difícil establecer de manera precisa la naturaleza del cambio (...). Aunque no perdieron inteligencia, su capacidad de atención y observación sí se veía comprometida”. Ferrier nombraba también el incidente de Gage en sus lecturas. Tras hacer un estudio de la trayectoria que la barra de hierro siguió hasta alcanzar a Gage, llegó a la conclusión de que la barra debió dañar la región prefrontal y que entonces la ausencia de parálisis en el caso de Gage está en harmonía con los resultados de las exploraciones fisiológicas en monos. Visto de otro modo, el caso del accidente de Gage permitió que el Dr. Harlow observase en él los mismos síntomas que Ferrier pudo observar en sus posteriores experimentos con animales: que las lesiones de los lóbulos frontales de la corteza

\footnotetext{
${ }^{1}$ La frenología (en griego fren significa mente y logos conocimiento) es una antigua teoría que afirmaba la posible determinación del carácter y los rasgos de la personalidad, así como las tendencias criminales, basándose en la forma del cráneo, cabeza y facciones.

${ }^{2}$ Afasia de Broca: pérdida de la capacidad verbal, caracterizada por un habla confusa y fragmentada, con poca estructura gramatical. Se produce cuando se daña el área de Broca, una región del cerebro de los homínidos que en el ser humano se relaciona con la capacidad del habla. Su nombre se atribuye a su descubridor, Paul P. Broca.
} 
prefrontal del cerebro pueden causar cambios profundos en la personalidad, sin necesariamente detectarse otros déficits neurológicos evidentes.

Si el Dr. Harlow siguiese vivo a día de hoy sería testigo de una cantidad de investigaciones en la corteza frontal que nunca hubiese podido imaginar. Sabría que la función principal de la corteza prefrontal es la organización temporal de la conducta y la subordinación de la memoria a corto plazo [13]. Podría comprobar que el cambio de la personalidad que vio en Gage es consistente con lesiones en la parte ventral de la corteza orbitofrontal de su lóbulo frontal, de las que se sabe que afectan el afecto y la emoción. Quizá se sorprendería que en publicaciones recientes (como la de Fuster [13]) se refieran a sus avances en el caso de Gage como evidencias de gran valor científico e injustamente ignoradas durante años. También, casi con toda seguridad, se sentiría tranquilo al comprobar que ciento cincuenta años después de sus observaciones, se está un paso adelante en la comprensión de la relación entre la mente y el cerebro, hasta casi poder justificar sin ambigüedad por qué después de su accidente Phineas $\mathrm{P}$ Gage nunca volvió a ser Gage.

Extraído del artículo de O'Discroll y J.P. Leach titulado No longer Gage: an iron bar through the head. Early observations of personality change after injury to the prefrontal cortex. BMJ British Medical Journal, 317(7174):1673-1674, 1998. 


\section{Capítulo 2}

\section{Especialización, integración y conectividad}

\section{Introducción}

A principios del siglo XX, Ramón y Cajal [14] demostró que el sistema nervioso (cerebro, espina dorsal y ganglios periféricos) estaba formado por neuronas, un tipo de células altamente especializadas en la recepción de estímulos y conducción del impulso nervioso (por tanto, excitables eléctricamente por potenciales de acción) y logra describirlas por primera vez en forma aislada, según la función que desempeñan en el sistema nervioso. Cajal planteó que las neuronas actuaban como entidades discretas o individuales, intercomunicándose a través de contactos funcionales llamados sinapsis (estructuras que permiten la comunicación por contacto entre las terminaciones de las células nerviosas). Esta idea (reconocida como la doctrina de la neurona, uno de los elementos centrales de la neurociencia moderna) chocaba frontalmente con la de otros científicos de su época (encabezados por C. Golgi), quienes concebían el sistema nervioso como un amplia red de fibras nerviosas conectadas entre sí formando un continuo (en analogía a los vasos sanguíneos)—negando la hipótesis de las neuronas como entidades discretas interconectadas [4, pp. 22-25: Nerve cells are the main signaling units of the nervous system].

Con el devenir de los años se ha podido demostrar que existen grandes homologías o semejanzas estructurales y funcionales entre el sistema nervioso central del ser humano y el de otros mamíferos [16]. El funcionamiento del cerebro de los mamíferos se describe en base a dos principios neurofisiológicos fundamentales: la especialización y la integración funcional [17, pp. 471-6: Functional specialization and integration]. No en vano, la especialización e integración funcional no pueden entenderse sin la conectividad neuronal o cerebral. ¿Cómo conseguimos, por ejemplo, una percepción integral del mundo que nos rodea si cada uno de las modalidades sensoriales que la componen se procesa en áreas cerebrales especializadas y segregadas en el cerebro? Como ya se ha dicho, las neuronas se conectan unas a otras a través de sus sinapsis para formar sistemas cerebrales o redes neuronales especializadas. Muchos expertos afirman que el cerebro es un sistema biológico cuyo funcionamiento queda definido intrínsecamente por la gran cantidad de interconexiones de sus neuronas: cada una de las más de cien billones de neuronas que forman el cerebro humano, por ejemplo, tienen una media de siete-mil conexiones sinápticas hacia otras neuronas, es decir: 0,15 cuatrillones de sinapsis (o un trillón de sinapsis por centímetro cúbico de corteza cerebral) [18].

\subsection{Especialización funcional}

La especialización funcional es el primero de los principios que rigen el comportamiento humano del cerebro (o viceversa). Desde las primeras teorías anatómicas de F.J. Gall y tras el incidente de Gage en 1848, el localiza- 


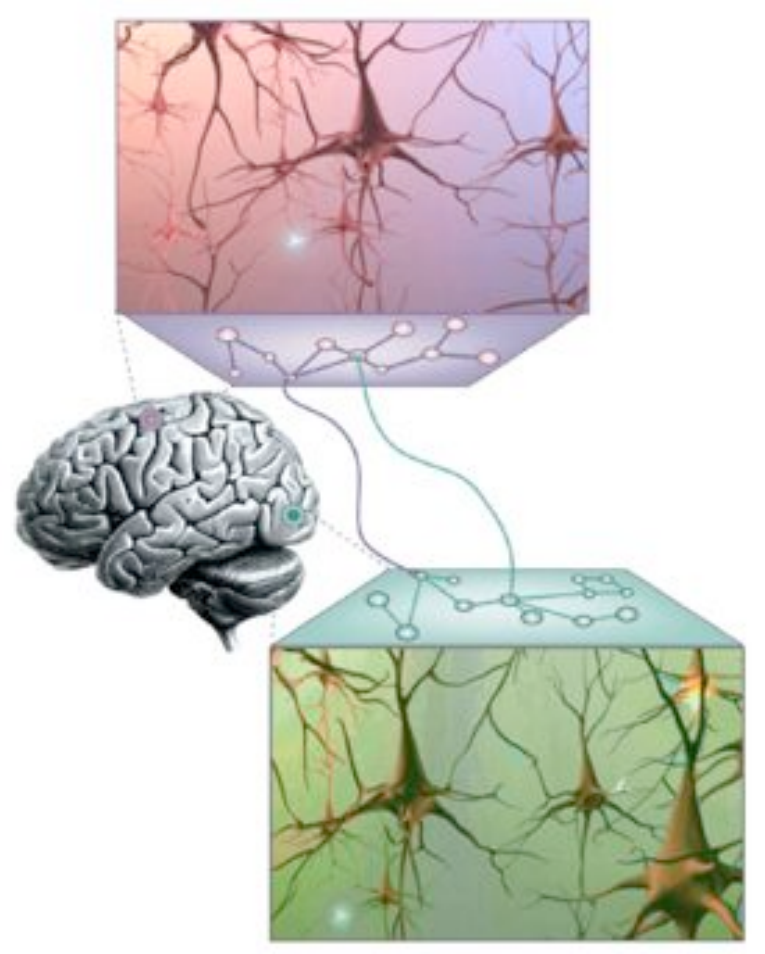

Figura 2.1: Especialización, integración y conectividad. Dos regiones especializadas y segregadas anatómicamente responden de forma sincronizada a un mismo estímulo. Las respuestas funcionales parciales pueden integrarse en una respuesta única por la conectividad cerebral subyacente [15].

tionism (o identificación de una región concreta del cerebro con una función específica) se convirtió en un tema de estudio de causa mayor entre la comunidad neurocientífica [19, 20]. Actualmente, el término de localización funcional ha quedado obsoleto como herramienta de estudio de la organización de la corteza cerebral [21] y se ha sustituido por el término especialización funcional: no es una función la que queda localizada en una región de la corteza cerebral, sino que es un área de la corteza cerebral la que se va especializando (evolutivamente, con el transcurso del tiempo y a través del aprendizaje) en ciertos aspectos del procesamiento perceptual o motor. Como ya se ha comentado, la especialización funcional no está reñida con la segregación anatómica, sino todo lo contrario: el concepto de segregación corrobora el principio de la especialización ya que requiere que las neuronas con unas mismas características funcionales estén agrupadas en la corteza cerebral. El hecho que varias áreas o regiones especializadas funcionalmente deban responder de forma conjunta a un mismo estímulo pone en la punta del iceberg del entendimiento del comportamiento humano (o del cerebro en general) a la integración y la conectividad funcional.

\subsection{Integración funcional}

Según el principio de especialización funcional, la infraestructura que soporta una respuesta funcional concreta puede involucrar (y es así por norma general) a una o más regiones especializadas distribuidas por todo el cerebro. El mecanismo que media entre las respuestas funcionales segregadas para generar una respuesta funcional única es la integración funcional que (como su propio nombre indica) suma o integra las respuestas funcionales parciales de las regiones segregadas en una sola. 
El hecho de que las respuestas funcionales involucren a agrupaciones (o clusters) de sistemas segregados de neuronas evidencia que la conectividad entre dichos grupos especializados es el mecanismo anatómico en el que se basan la especialización e integración funcional.

\subsection{Conectividad}

Según los apartados anteriores, el concepto clave que permite la complementariedad de la especialización y la integración funcional es la conectividad cerebral. Si la electrofisiología y la neuroimagen del cerebro han establecido firmemente la especialización funcional como base de la organización del cerebro y el comportamiento humano, el estudio de la integración funcional de las regiones especializadas es a día de hoy un problema de largo recorrido [22]. Dado que la integración funcional se refiere a las interacciones entre grupos segregados de neuronas especializadas y a la relación de dichas interacciones con el estímulo que las origina, es habitual el uso como instrumento de análisis de la integración funcional la dependencia estadística entre marcadores de la actividad neuronal de las regiones cerebrales remotas. Fundamentalmente existen dos medidas estadísticas para la caracterización de la integración funcional: la conectividad funcional y la conectividad efectiva. La conectividad funcional mide la información mutua entre los eventos neurofisiológicos remotos, usualmente a través de la correlación [23] o la coherencia [24] entre los patrones temporales que los caracterizan. Por su parte, la conectividad efectiva mide la causalidad en la interacción que una región o sistema cerebral ejerce sobre otra, generalmente a través de modelos causales [25] o la prueba estadística de Granger-que determinan si un patrón temporal de una región es predecible a partir de un patrón temporal remoto. Aunque en los últimos años ha habido un creciente interés en medir el flujo de información para identificar las interacciones causales en neuroimágenes [26, 27], su utilidad en la determinación de la direccionalidad de las conexiones en imágenes de resonancia magnética no está completamente establecida; por contra los estudios basados en estadísticos más sencillos como la correlación se muestran altamente eficientes [28].

Además de la conectividad funcional (o análisis de las dependencias estadísticas entre marcadores de conectividad) y de la conectividad efectiva (o análisis de las interacciones causales), la definición genérica de conectividad cerebral también contempla la conectividad anatómica como parte fundamental en la organización cerebral $[29,30]$.

\subsubsection{Conectividad anatómica}

La conectividad anatómica se refiere al estudio de las conexiones neuronales a nivel físico, describiendo parámetros característicos de las conexiones que puedan caracterizar a dicha red, como por ejemplo las zonas que interconecta (quién conecta con quién), el número de conexiones sinápticas (cuántos cables conectan las distintas regiones segregadas) o el tipo de red (excitador, inhibidor o modulador). El buen conocimiento del sustrato anatómico es fundamental para el posterior estudio funcional o dinámico del cerebro, ya que en última instancia es quien delimita las formas en las que pueden reconfigurarse las redes neuronales (en base a las distintas relaciones funcionales de contacto entre las terminaciones de las células nerviosas). En este sentido, los patrones físicos de conexiones anatómicas son relativamente estables a escalas cortas de tiempo, pero en escalas de tiempo mayores (horas, días) dichos patrones físicos de conexiones pueden estar sujetos a importantes cambios morfológicos [31]. Actualmente la única técnica de estudio que establece firmemente la conectividad anatómica es la tractografía invasiva, pese al alto potencial de técnicas como la de imagen ponderada por difusión o DTI (por sus siglas en inglés: diffusion tensor imaging) [32]. Pese a que las redes anatómicas (físicas o estructurales) de la corteza cerebral humana no han podido ser analizadas por completo, los resultados de los que se dispone hasta la fecha demuestran que la corteza cerebral está compuesta por patrones de grupos densos de neuronas interconectadas de forma global y recíproca en áreas corticales específicas [33]. 


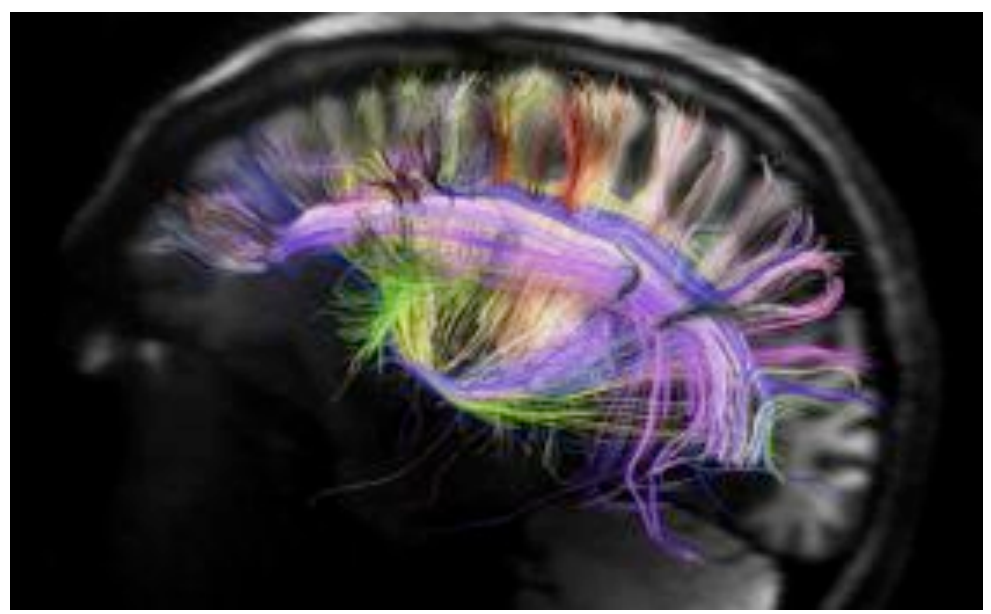

Figura 2.2: Análisis de la conectividad estructural mediante DTI por resonancia magnética. Las vías de fibra cerebral forman rejillas tridimensionales rectilíneas que se cruzan perpendicularmente entre sí de forma ordenada. Esta arquitectura es consistente con la idea de la especialización-segregación y conectividad funcional y encaja de forma natural en las teorías de la evolución humana del aprendizaje y la selección natural a través de la plasticidad cerebral o adaptación de la estructura a una función específica [33].

\subsubsection{Conectividad funcional}

Como ya se ha mencionado, el concepto de conectividad funcional que manejaremos en esta Tesis es esencialmente un concepto matemático que permite el estudio de la dependencia estadística entre dos o más neuronas (o grupos de ellas) segregadas por el cerebro, en representación de la actividad neuronal tras ciertos eventos neurofisiológicos. De esta forma, el grado de dependencia estadística entre las variables neurofisiológicas se asocia con el grado de conectividad funcional (que a su vez depende del peso sináptico de la conexión). Los datos sobre los que se mide la dependencia estadística son esencialmente de índole temporal. En el caso particular de este trabajo de investigación, el medio de estudio de la arquitectura funcional del cerebro son las imágenes de resonancia magnética funcional y por tanto, las series de tiempo de señal dependiente del nivel de oxigenación sanguínea o BOLD [34]. Los estudios de conectividad funcional (como se ha dicho, generalmente en base a patrones de correlación o coherencia entre las distintas regiones corticales) han demostrado que las redes neuronales funcionales se organizan como redes de mundo pequeño ${ }^{1}$ posiblemente debido a la organización estructural subyacente de conexiones anatómicas [35]. En este sentido la conectividad funcional permite el análisis de la modulación de los pesos sinápticos a la función sobre un mismo sustrato de conexiones físicas que se conectan y se desconectan para satisfacer correctamente el flujo de información que permita la integración de la respuesta.

\subsubsection{Conectividad efectiva}

Según lo visto hasta el momento, la conectividad funcional es un fenómeno observable que puede ser cuantificado con medidas sobre la información mutua $I(X ; Y)$ entre las series temporales de los eventos neurofisiológicos $X$ e $Y$-típicamente mediante la correlación o la coherencia. También definidas en el marco de la teoría de la información, las medidas de conectividad efectiva tratan de cuantificar la direccionalidad de las respuestas funcionales, determinando en este caso la influencia que una red neuronal ejerce sobre otra $(H(X \mid Y))$ y viceversa

\footnotetext{
${ }^{1}$ En matemáticas y física, una red de mundo pequeño es un grafo que representa la conectividad entre una serie de nodos donde se cumplen dos condiciones: que la mayoría de ellos no son vecinos entre sí y que cualquiera de los nodos puede comunicarse con cualquier otro nodo de la red a través de un número relativamente pequeño de saltos.
} 
$(H(Y \mid X))$. Una representación intuitiva de la relación entre información mutua o conectividad funcional y la conectividad efectiva es la que aporta la Figura 2.3.

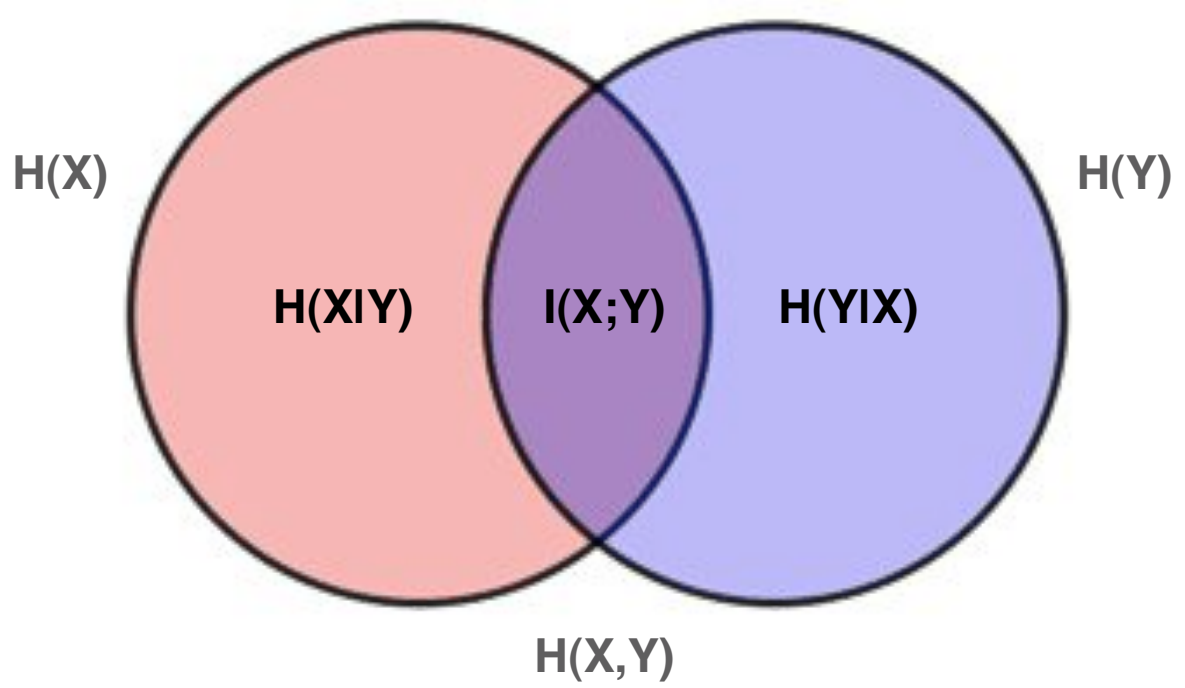

Figura 2.3: Diagrama clásico de la teoría de la información que relaciona la información mutua $I(X ; Y)$ con las entropías de $X$ e $Y$ y sus probabilidades condicionadas: $I(X ; Y)=H(X)-H(X \mid Y)=H(Y)-H(Y \mid X)$. Intuitivamente, las medidas de conectividad efectiva caracterizan la direccionalidad o flujo de la información dado que $H(X \mid Y) \neq H(Y \mid X)$.

Como se citaba con anterioridad, los efectos causales se pueden analizar de dos formas diferentes: bien infiriendo sobre un modelo sobre el que se especifican perturbaciones sistemáticas del sistema, o bien a través de análisis de series temporales-puesto que las causas deben preceder a los efectos temporales BOLD-IRMf [36]. En definitiva, el estudio de la conectividad efectiva consiste en intentar deducir los pares de parámetros (o valores) que permitan explicar o inferir las dependencias $H(X \mid Y) \neq H(Y \mid X)$ observadas sobre la propia conectividad funcional o información mutua, que sí es simétrica: $I(X ; Y)=I(Y ; X)$.

A resumidas cuentas, las medidas de conectividad anatómica (tractografía de fibras), conectividad funcional (correlaciones) y conectividad efectiva (flujo de información) engloban una serie de técnicas y métodos para la cuantificación de la conectividad que deben permitir el estudio y caracterización de la funcionalidad del cerebro. Formalmente, los patrones de conectividad (a cualquiera de los tres niveles) se representan en grafos y/o matrices de conectividad. Según podemos leer en [30], la conectividad anatómica se representa a partir de grafos distribuidos, donde las líneas que unen las distintas regiones cerebrales están ponderadas_por ejemplo, en representación de la densidad de fibras (Figura 2.2). Por otra parte, la conectividad funcional forma matrices simétricas de rango completo (donde cada uno de los elementos indican la dependencia estadística o proximidad entre dos regiones cerebrales), mientras que la conectividad efectiva genera matrices de rango completo pero no necesariamente simétricas. No obstante, pese a su previsible potencial para la caracterización de estados funcionales in vivo y hasta la fecha, los grafos y matrices de conectividad se han utilizado únicamente como estructuras de resumen en casos clínicos, pero no como instrumentos de análisis de la conectividad [6].

\subsection{Análisis conjunto de la conectividad anatómica y funcional}

Como se ha comentado con anterioridad, la construcción y análisis de grafos y/o matrices de conectividad representan un punto fundamental en esta Tesis Doctoral. En el marco experimental planteado (que viene determinado por el análisis de imágenes funcionales de cerebros de rata que se estimulan eléctricamente, Figura 3.1), existe 
una relación muy estrecha entre la conectividad anatómica y funcional. Esto se debe a la relación inherente causa/efecto que se establece entre los núcleos cerebrales que se estimulan eléctricamente y los núcleos segregados que responden al estímulo, que están conectados mono- o poli-sinápticamente al núcleo estimulado y de los cuales registramos su respuesta funcional. Dado que la intensidad de la respuesta funcional depende del peso sináptico de la conexión [7] y que en las imágenes de RM registramos las señales de todo el cerebro, podemos decir que la respuesta al estímulo en nuestros experimentos tiene connotaciones anatómicas y funcionales a la vez.

En este sentido, la construcción de matrices de conectividad funcional en un entorno experimental de imágenes por RMfe (a las que nos referiremos como huellas de conectividad, Capítulo 9) permite el análisis conjunto de la conectividad anatómica y funcional y, sujetas a dispositivos de análisis propios de la minería de datos (como la clasificación no supervisada) nos permitirán poner en contexto el patrón de modulación sináptica subyacente como respuesta funcional a cierta estimulación eléctrica, dependiendo por tanto de la ubicación estereotáctica del electrodo de microestimulación, así como de los parámetros de las corrientes eléctricas (como si de un experimento de estimulación cerebral profunda se tratase).

Existen otras formas (quizás, menos conocidas) de analizar la conectividad funcional. Por ejemplo, en [37] se presenta un análisis multivariado por el cual las series temporales de los vóxels se proyectan en un espacio vectorial (llamado espacio funcional), donde la distancia euclidiana entre sus puntos, muestras o vóxels implica el grado de conectividad entre ellos. En lo que concierne a esta investigación, los espacios funcionales asociados a las respuestas funcionales de cerebros de rata que se estimulan eléctricamente (y que por tanto, como ocurría con las huellas de conectividad, llevan asociados información tanto anatómica como funcional) se someten a un algoritmo de clustering que permite identificar grupos de vóxels cuyas respuestas BOLD-IRMfe están conectadas funcionalmente, es decir: pertenecen a un mismo patrón (o modo hemodinámico) de varianza/covarianza dentro de la respuesta global neuronal (Capítulo 10). En este contexto, resulta de especial interés el experimento de la demostración práctica incluido al final del capítulo que aborda el análisis de los espacios funcionales, en el que se utilizan dos electrodos de estimulación eléctrica. Como se ha comentado en el apartado anterior, la conectividad efectiva corresponde a la noción intuitiva de acoplamiento o influencia dirigida causal entre dos sistemas o núcleos neuronales. Cuando su estudio se realiza a partir de modelos causales, el análisis de conectividad efectiva recae fundamentalmente en un buen diseño estratégico del experimento IRMfe (en el que cada modelo causal debe corresponder a una hipótesis alternativa sobre cómo los datos observados fueron causados) y un análisis fuera de línea de las series temporales. En nuestros experimentos con dos electrodos, estas hipótesis pertenecen a los modelos causales inducidos por la estimulación con corrientes eléctricas desfasadas—que generan respuestas cerebrales que se interfieren pero que son identificables por nuestro método de análisis, sugiriendo un posible procedimiento experimental para estudiar la conectividad efectiva o la influencia asimétrica que un electrodo de estimulación puede ejercer respecto al resto de núcleos neuronales estimulados y del resto con éste. Finalmente, el análisis de los espacios funcionales en experimentos de un solo electrodo de estimulación permite la identificación de la respuesta funcional integrada como la suma de varias respuestas funcionales parciales que se retrasan sistemáticamente.

\section{Resumen}

En el presente capítulo se han expuesto los dos principios neurofisiológicos que rigen el funcionamiento del cerebro del hombre y de otros mamíferos: la especialización y la integración funcional [38]. La especialización funcional se refiere a la capacidad intrínseca de las neuronas de especializarse en el desarrollo de tareas concretas y por tanto, a organizarse en grupos especializados de ellas que se distribuyen por las distintas regiones corticales. Por su parte, la integración funcional es el mecanismo que da lugar a la activación coordinada de las poblaciones neuronales segregadas, permitiendo así la aparición coherente de la cognición y los estados de comportamiento. El nexo de unión entre la especialización o segregación y el principio de integración es la conectividad cerebral y sin ella la doctrina de la neurona no podría sostenerse. Desde el punto de vista contrario, la actividad neuronal está limitada por la conectividad cerebral ya que el manejo de la información generada por las distintas regiones especializadas es altamente diversificada y de difícil integración, y requiere por lo tanto de la creación de patrones 
de conectividad (o modulación sináptica) de alta complejidad. Desde los tres niveles de estudio, la conectividad funcional es clave para el estudio de la función cerebral [28]. Sea como fuere, en neurociencas, el análisis de la conectividad cerebral (anatómica, funcional o efectiva) se puede afrontar a partir de modelos experimentales sobre imágenes de resonancia magnética que se analizan estadísticamente en base a la información mutua y/o la transferencia de entropía entre las series temporales BOLD-IRMf. Formalmente, la conectividad se representa en unas estructuras de datos (generalmente grafos o matrices) que representan los patrones de conectividad asociados a estados funcionales. No obstante, hasta hace poco, dichas estructuras se han utilizado únicamente como elementos de visualización para casos de estudio, y no como elementos de análisis de la conectividad—siendo esta última la línea a seguir en la presente Tesis Doctoral [39]. 


\section{Capítulo 3}

\section{Modelado de la actividad neuronal}

\section{Introducción}

En neurociencias, la mayoría de estudios sobre la conectividad cerebral se realizan en base a un compendio de modelos conceptuales, anatómicos y estadísticos que modelan las respuestas funcionales observadas en imágenes de RMf del cerebro adquiridas mientras el sujeto bajo análisis está realizando cierta tarea [40]. En ese marco experimental, la herramienta básica en el análisis de neuroimágenes es el modelo lineal generalizado. En su versión más elemental, el modelo lineal generalizado se utiliza para localizar las áreas cerebrales que están respondiendo de forma estadísticamente significativa a la estimulación evocada por la tarea, a través de lo que se conoce como mapas estadísticos paramétricos. Con la incorporación de ciertas restricciones biológicas, el modelo lineal generalizado puede modificarse para que los test de hipótesis sobre los efectos regionales específicos puedan ser utilizados como instrumentos para cuantificar la conectividad entre los distintos sistemas cerebrales representados en los propios mapas estadísticos paramétricos. Como se dijo en el capítulo anterior, el análisis de la conectividad cerebral que incumbe al presente trabajo de investigación se fundamenta en el análisis temporal de las señales BOLD extraídas del análisis de las imágenes cerebrales de RM funcional. En concreto, el área de conocimiento y la búsqueda de resultados vienen definidos por las pautas experimentales establecidas en el trabajo de Canals et al. [2], donde se presenta una novedosa metodología para el análisis de la conectividad basada en la estimulación eléctrica de cerebros de rata. Dicha técnica es conocida como IRMfe y se resume muy brevemente en la Figura 3.1.

\subsection{Imágenes funcionales por RM}

La resonancia magnética funcional del cerebro es una técnica de imagen médica no invasiva pensada para evaluar la función cerebral in vivo mediante el análisis de las variaciones de las imágenes de resonancia magnética asociadas con la actividad neuronal del cerebro. La mayoría de los estudios de RMf utilizan como marcador de la actividad cerebral el contraste endógeno basado en la señal dependiente del nivel de oxigenación sanguínea o BOLD—que se debe a la repercusión hemodinámica y metabólica de las respuestas neuronales [42]. Aunque los mecanismos biofísicos de la técnica y la complejidad de la señal BOLD es elevada, los mapas de activación BOLD o mapas estadísticos paramétricos son ampliamente aceptados [43]. Junto con los mapas de significancia estadística de las respuestas eléctricas evocadas en las electroencefalografías [44], las neuroimágenes funcionales por RM han sido fundamentales para establecer la especialización funcional como principio de organización del cerebro humano. No obstante, el mecanismo de integración de áreas especializadas es un problema mucho más complejo abordado desde multitud de puntos de vista complementarios [45] aunque con un denominador común: la medida de las dependencias estadísticas de las señales BOLD-IRMf de eventos neurofisiológicos remotos [23]. 


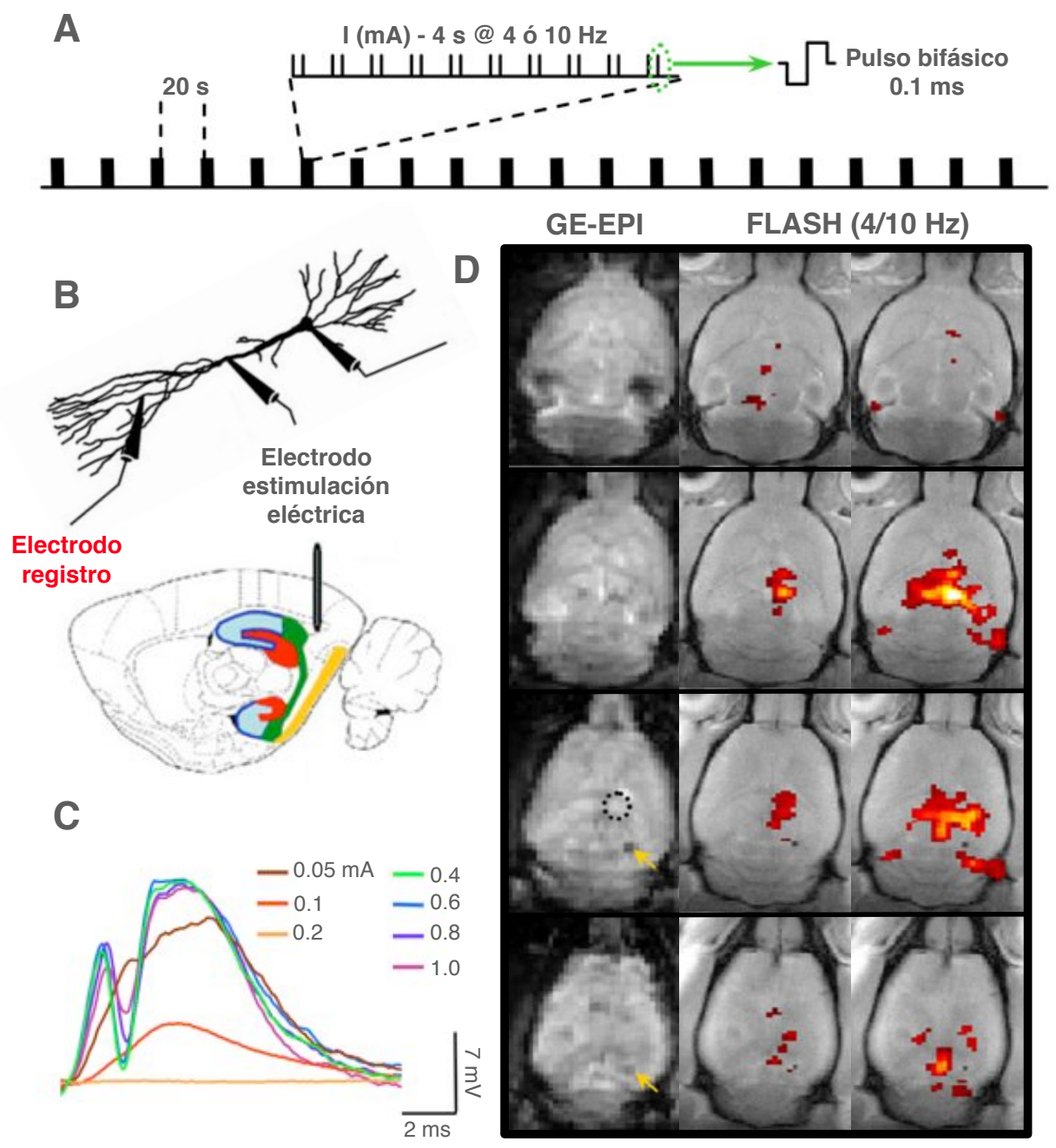

Figura 3.1: Resonancia magnética funcional con estimulación eléctrica (IRMfe) para el estudio del hipocampo (HC, hippocampus) del cerebro de rata. A: estimulación eléctrica que se aplica en el tracto perforante (en amarillo) a distintas frecuencias de estimulación. B: electrodo de estimulación eléctrica, ubicado en el tracto perforante; se utilizan varios electrodos de registro electrofisiológico, uno de ellos ubicado en el giro dentado (DG, dentate gyrus) que aparece en rojo. C: registro electrofisiológico: potenciales de campo del DG tras la estimulación eléctrica de A (evocados para distintas intensidades de estimulación @ $10 \mathrm{~Hz}$ ). D: mapas estadísticos paramétricos que se obtienen al estimular al sujeto mediante la estimulación eléctrica de A (evocados para distintas frecuencias para una intensidad fijada estratégicamente). La primera columna muestra la calidad de las imágenes GE-EPI (por sus siglas en inglés: gradient echo-echo planar imaging). Los mapas estadísticos paramétricos se superponen a una imagen anatómica FLASH (por sus siglas en inglés: fast low angle shot) representativa del experimento. Se detecta actividad funcional en el giro dentado y la corteza entorrinal (EC, entorhinal cortex). Figura basada en [2, 41].

\section{La señal BOLD-IRMf}

La hemoglobina $(\mathrm{Hb})$ es una proteína de la sangre que se encarga del transporte del oxígeno desde los pulmones hasta los tejidos del resto de órganos del cuerpo (como puedan ser el corazón o el cerebro) donde libera el oxígeno para el consumo de las células. En la mayoría de mamíferos, la hemoglobina se encarga también de transportar el $\mathrm{CO}_{2}$ de vuelta desde los tejidos hasta los pulmones. Desde un punto de vista electromagnético, 
la hemoglobina oxigenada (oxihemoglobina, $\mathrm{HbO}_{2}$ ) y desoxigenada (desoxihemoglobina) son respectivamente moléculas diamagnéticas y paramegnéticas debido a la presencia o ausencia de oxígeno en ellas. Dado que la distinta concentración de oxígeno en la sangre implica estados de espín característicos de las moléculas de $\mathrm{Hb}$ [46], la variación de la deoxihemoglobina a lo largo del tiempo produce una alteración sistemática de sus propiedades magnéticas que afectan a los tiempos de relajación de los protones de agua en la sangre, produciéndose una modulación temporal reconocible en la intensidad de las imágenes de resonancia magnética [47]. Los cambios de intensidad en las imágenes por RM debidos a la distinta concentración del oxígeno en la sangre son la base de la señal dependiente del nivel de oxigenación sanguínea (o BOLD) y cuya finalidad principal es el análisis funcional del cerebro [34]. En términos fisiológicos, la señalización BOLD correlaciona con el mayor consumo energético que requieren las células activas y las que están en reposo. Matemáticamente, el balance regional de oxígeno demandado, suministrado y consumido queda establecido por el principio de Fick, que aplicado al régimen neuronal, explica que toda neurona cuya actividad aumenta requiere mayores cantidades de glucosa y oxígeno para funcionar adecuadamente (incrementándose la perfusión regional vascular):

$$
O E=C_{H b} C B F(1-Y)
$$

donde $O E$ es la cantidad de oxígeno que se extrae (por sus siglas en inglés: oxygen extraction), $C B F$ es el flujo sanguíneo cerebral (cerebral blood flow), $C_{H b}$ es la concentración total de hemoglobina e $Y$ su nivel de oxigenación. En dicha situación, se produce un aporte de sangre oxigenada que sobrepasa el consumo metabólico tisular [48]. El incremento del nivel de oxigenación de la hemoglobina enfatiza el carácter diamagnético del área activa, que provoca que se registre una señal mayor en las imágenes por RM que corresponde con una señal BOLD positiva $(\Delta Y>0$, tras manipular la ecuación 3.1). La Figura 3.2 muestra una señal BOLD-IRMf cuando se hace variar el nivel de oxigenación de una región del cerebro de una rata de forma controlada.

\section{Bases neuronales de la señal BOLD}

Si en términos fisiológicos la señal BOLD-IRMf se asocia al consumo energético, en términos neurológicos la señalización BOLD se atribuye al establecimiento de conexiones de las entradas sinápticas en el área activa-dado el correlato neurovascular entre la señal hemodinámica y los potenciales de campo (Figura 3.1, C) o LFP (por sus siglas en inglés: local field potentials) registrados simultáneamente [1]. Esto significa que la señal dependiente de la oxigenación sanguínea refleja la actividad sináptica implicada en el establecimiento de las conexiones en respuesta al estímulo y por lo tanto, que las imágenes por resonancia magnética y los mapas estadísticos paramétricos nos permiten estudiar las respuestas funcionales del cerebro [49]. Además, se ha observado que en las áreas o regiones cerebrales donde se detectan cambios positivos de señal BOLD existe una potenciación a largo plazo o LTP (por sus siglas en inglés: long-term potentiation) debida a la estimulación evocada y asociada al proceso neuronal de modulación sináptica, plasticidad neuronal o conectividad funcional del manejo de la memoria [7].

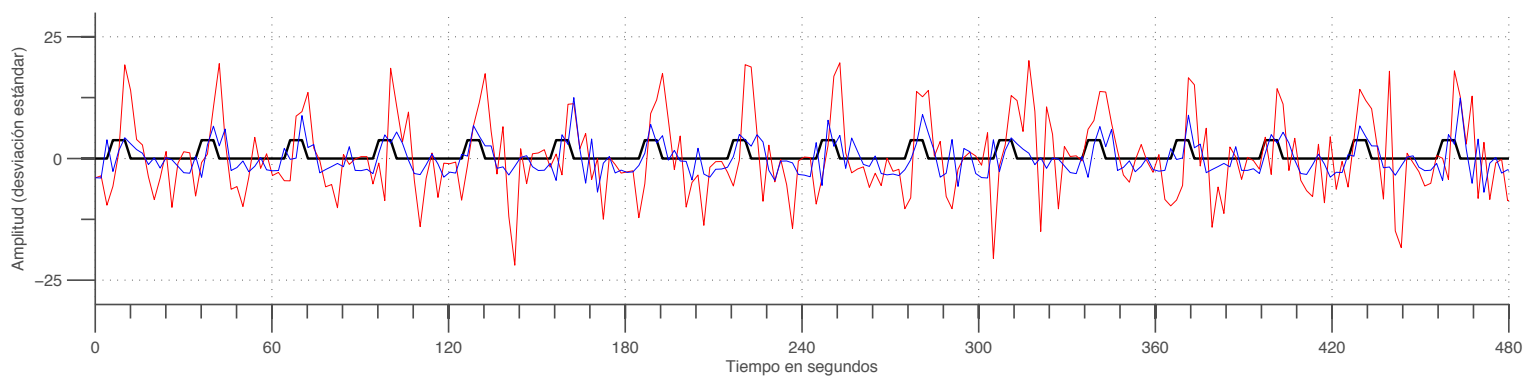

Figura 3.2: Señal BOLD media representativa de los mapas estadísticos de la Figura 3.1 a 4 (azul) y 10 (rojo) Hz. Figura basada en [2]. 
En este punto se hace necesario matizar que la correlación entre la señal BOLD y los potenciales de campo se ha observado únicamente en las regiones cerebrales donde la señal BOLD es positiva. No obstante, no son pocos los casos en los que se observan regiones cerebrales activas donde la respuesta BOLD es negativa. Aunque existen varias teorías al respecto, los mecanismos neurobiológicos para explicar el fenómeno no están claros a día de hoy. Algunos autores achacan el fenómeno a posibles variaciones fisiológicas provocadas por el flujo sanguíneo cerebral [50], aunque en dicho caso los cambios deberían ser mucho más difusos y asíncronos con los eventos neuronales, aunque eso no siempre ocurre-por ejemplo, en el capítulo de resultados asociado al análisis del sistema vestibular, encontramos respuestas hemodinámicas en las que se hace patente una inhibición activa perfectamente sincronizada con el paradigma eléctrico que provoca la actividad neuronal.

Otra limitación importante del modelo IRMf tiene que ver con el hecho que la señal BOLD no está compuesta únicamente por aquellas señales asociadas estrictamente a la activación neuronal, sino también por componentes de ruido. En este sentido se hace necesario conocer qué cantidad de varianza de la señal BOLD-IRMf es atribuible a una actividad neuronal verdadera y se requieren técnicas que minimicen las contribuciones indeseadas, generalmente para reducir los efectos globales [51] o la varianza intrasujeto [52]. En el caso de la experimentación con animales, la mayor resolución espacial de las imágenes funcionales (un orden de magnitud por encima de las imágenes de resonancia magnética en humanos), así como el hecho de utilizar una estimulación mucho más robusta y constante (la estimulación eléctrica consigue una activación directa de las vías nerviosas, no así las activaciones sensoriales o motoras), hacen que algunos de los efectos globales más críticos en la experimentación con humanos (como el problema del volumen parcial) se aligeren o incluso desaparezcan—no obstante, la modelización de los efectos globales se ha demostrado vital para la obtención de buenos análisis estadísticos también en nuestros experimentos IRMfe (Sección 5.3). Por contra, el hecho de que los animales estén anestesiados y las dudas que aún se tienen sobre los mecanismos precisos del acomplamiento neurovascular deberían tenerse en cuenta a la hora de evaluar los resultados que se obtengan con la técnica.

\section{Las secuencias en RM}

La imagen por RM es probablemente la técnica de imagen médica que más se ha beneficiado de la innovación tecnológica actual. Los muchos avances han conducido a mejoras en la calidad y la velocidad de la adquisición de imágenes que han derivado en centenares de secuencias distintas [53]. Cada secuencia se diseña con unas características específicas para favorecer la representación (o señalización) de cierto tipo de tejido o contraste (por ejemplo, un tejido graso o la señal BOLD, respectivamente) y siempre de la forma más rápida posible, minimizando los artefactos (o defectos en la captura de las imágenes) sin perjudicar a la relación señal a ruido. Dos de las modalidades o secuencias de adquisición más utilizadas en la experimentación con animales corresponden a la dupla RARE/GE-EPI. Las secuencias RARE (por sus siglas en inglés: rapid acquisition with relaxation enhancement) suelen utilizarse para la adquisición de imágenes anatómicas, mientras que las secuencias GE-EPI (por sus siglas en inglés: gradient echo-echo planar imaging) se usan habitualmente para la adquisición de las imágenes que debe capturar la señal BOLD. Las imágenes RARE se caracterizan por utilizar una secuencia de codificación de fase que, respecto a las imágenes convencionales de eco de espín, consigue minimizar los artefactos y mejorar la resolución espacial [54] ofreciendo un alto contraste entre las distintas estructuras anatómicas de cerebros como el de la rata. Por su parte, la modalidad GE-EPI corresponde a un tipo secuencia de adquisición de las denominadas rápidas, pues es capaz de adquirir todo el volumen correspondiente a un cerebro en un único disparo [55]. Un volumen del cerebro se puede adquirir en menos de tres segundos, por lo que es la opción ideal para las técnicas que requieren la adquisición de un gran número de imágenes (como en IRMf). En el Capítulo 7 se detallan los parámetros de adquisición configurados para los distintos experimentos que forman parte del presente trabajo de investigación. 


\subsection{Modelos estadísticos}

Desde hace más de dos décadas, las neuroimágenes no invasivas BOLD-IRMf han sido aceptadas como el método de facto para dilucidar las bases neuronales de los procesos motores y mentales que describen el comportamiento humano-muchas veces a través del estudio de animales de experimentación [56]. Por ejemplo, la IRMf se ha utilizado para estudiar la especialización funcional de la agudeza visual en la percepción del color (en el primer mapa cerebral de significancia estadística que se conoce [57]) o en tareas de reconocimiento [58], de la percepción del lenguaje [59] o de la música [60] (entre otras muchas funciones). También ha permitido establecer los principios funcionales de fenómenos psicológicos de orden superior como las emociones y los sentimientos o la moral humana [61]. Un factor importante en el éxito de los estudios de activación BOLD-IRMf debe atribuirse al análisis estadístico específico de los datos funcionales desarrollado por Karl J. Friston [62] en lo que se conoce como mapas estadísticos paramétricos o SPM (por sus siglas en inglés: statistical parametric mapping). Los SPM son una técnica de análisis estadístico creada para examinar las diferencias en la actividad cerebral registrada durante experimentos de neuroimagen funcional como IRMf o la tomografía por emisión de positrones o PET (por las siglas en inglés: positron emission tomography). Las diferencias en la actividad cerebral medida se pueden representar de varias formas, aunque la más útil es sin duda la de los mapas estadísticos paramétricos, quienes representan la actividad cerebral como manchas de color $^{1}$ en degradación sobre una imagen RM anatómica del cerebro, creándose un medio intuitivo y visualmente atractivo para delinear la significancia estadística de una determinada área de la activación, caracterizando (como ya se había comentado anteriormente) la especialización funcional de las distintas regiones del cerebro (Figura 3.1, D). En definitiva, los SPM son una herramienta indispensable para el estudio de la conectividad cerebral dado que permiten la identificación de áreas o regiones segregadas que se activan frente a un estímulo común. Una cuestión diferente consiste en analizar el grado de conectividad entre las distintas áreas o regiones identificadas mediante los SPMs—en una aproximación al estudio de la conectividad e integración funcional.

\subsubsection{Introducción a los mapas estadísticos paramétricos}

Como se ha dicho, los SPM son una herramienta potente en el estudio del cerebro, dado que permiten la inferencia estadística sobre los efectos regionales específicos relativos al principio de especialización funcional [63]. El éxito de los SPM se debe fundamentalmente a la sencillez del modelo matemático en que se basan, y que consiste en asumir que cada vóxel de la serie IRMf se rige por la estadística paramétrica según el modelo lineal generalizado o GLM (por sus siglas en inglés: general linear model). Un análisis SPM típico se reduce a tres pasos ineludibles y esencialmente independientes: normalización espacial (como parte fundamental en el preprocesado de las imágenes funcionales, Capítulo 4), análisis estadístico y evaluación de la significación estadística. Algunas de las limitaciones de los mapas estadísticos paramétricos son:

- Alto tiempo de cálculo.

- Resultados dependientes del preprocesado y sesgo del estimador.

- Pérdida de especificidad por el problema de las comparaciones múltiples.

- El análisis estadístico de volúmenes o cerebros enteros pueden diluir pequeños focos de activación-con la consiguiente pérdida de sensibilidad (Sección 5.3.1).

Todas las manipulaciones u operaciones que se realizan antes y/o después del análisis estadístico son para que los análisis de probabilidad sean de la mayor sensitividad posible [64]. La aportación fundamental de los test de hipótesis (expresados en términos de los parámetros deducidos con GLM) es la de permitir realizar y resolver preguntas estadísticas sobre la manipulación experimental que genera las observaciones-por ejemplo, al estimular mediante una corriente eléctrica una región concreta del cerebro de rata (Figura 3.1). Por ejemplo,

\footnotetext{
${ }^{1}$ Utilizamos la expresión "manchas de color" como traducción literal del término blobs en inglés.
} 
los análisis GLM pueden llevarse a cabo para examinar las diferencias sobre las series de tiempo BOLD-IRMf o la presencia de una o más respuestas funcionales esperadas-en cuyo caso resultan de interés las relaciones causa/efecto entre la percepción de un estímulo y la actividad cerebral localizada en un área determinada. Para ello se utilizan modelos lineales (o dinámicos) de convolución que permiten la realización de pruebas estadísticas que infieren si la señal BOLD-IRMf medida se debe a los cambios neurofisiológicos que provocaría una respuesta funcional establecida previamente. Finalmente, se hace necesario un mecanismo de ajuste para controlar la tasa de falsos positivos de los test de hipótesis, potencialmente causada por la comparación de los niveles de actividad en un gran número de vóxels. En el análisis de la actividad cerebral, un falso positivo se traduciría en una detección erronea de la actividad neuronal subyacente como respuesta a la estimulación. El problema de las comparaciones múltiples se soluciona mediante la teoría de campos aleatorios o RFT (por sus siglas en inglés: random field theory) que permite ajustar de forma apropiada el umbral $p$ para la evaluación de la significancia.

\section{El modelo lineal generalizado}

El modelo lineal generalizado es un modelo estadístico que permite expresar observaciones experimentales como una combinación lineal de un número finito de parámetros (que representan la manipulación experimental) más un coeficiente de ruido o error. La expresión algebraica que representa al modelo suele escribirse en forma matricial [65]:

$$
Y=X \beta+\epsilon
$$

donde $Y$ es una matriz de medidas multivariadas, $X$ es una matriz de que debe ser una matriz de diseño, $\beta$ es un vector de parámetros a estimar y el último término $\epsilon$ corresponde a una matriz de errores. El modelo lineal generalizado permite la diseminación estadística de un gran número de modelos, entre los que encontramos [66]: ANOVA, ANCOVA, MANOVA, MANCOVA o regresión lineal ordinaria entre otros. Los test de hipótesis asociados a dichos modelos pueden realizarse bajo dos enfoques diferentes—según la naturaleza multivariada o univariada que se adopte sobre los datos u observaciones. En la primera variante, las columnas de $Y$ son evaluadas de forma conjunta, mientras que en el caso univariado los datos se evalúan de forma independiente como múltiples test de hipótesis con una matriz de diseño común.

\section{Inferencia clásica}

En su aplicación al análisis de neuroimágenes funcionales por resonancia magnética, GLM se utiliza en su variante univariada para analizar las series de tiempo BOLD-IRMf de cada vóxel $i$ en un problema de regresión lineal múltiple:

$$
Y_{i}=\beta_{0}+\beta_{1} X_{i 1}+\ldots+\beta_{l} X_{i L}+\epsilon_{i}
$$

donde el término de error se distribuye de forma independiente e idéntica bajo una distribución normal (en cuyo caso el modelo lineal generalizado pasa a llamarse modelo lineal general). Las columnas de la matriz de diseño $\left(X_{i j}\right)$ deben contener todos aquellas condiciones (por definición, incorreladas entre sí), causas o efectos que expliquen las observaciones. Por ejemplo, en un experimento IRMfe en cerebros de rata, la condición de mayor relevancia en la matriz de diseño sería aquella que indique en qué volúmenes se están aplicando las descargas eléctricas (describiéndose por tanto el tren de impulsos), mientras que un posible efecto adicional a tener en cuenta serían los movimientos de la cabeza del sujeto al recibir las pequeñas descargas eléctricas (influyendo ruidosamente en las observaciones $Y_{i}$ ). Por último, cada columna de la matriz de diseño se conoce como variable explicatoria o regresor y su contribución relativa a la respuesta observada en los datos queda controlada por el peso estimado de cada parámetro $\beta_{l}$. En cuanto a la inferencia, los test de hipótesis que suelen realizarse sobre los parámetros estimados $\hat{\beta}$ son del tipo $t \mathrm{o} Z$, según la función de densidad de probabilidad que éstos describan: $t$ de Student o normal (respectivamente). 


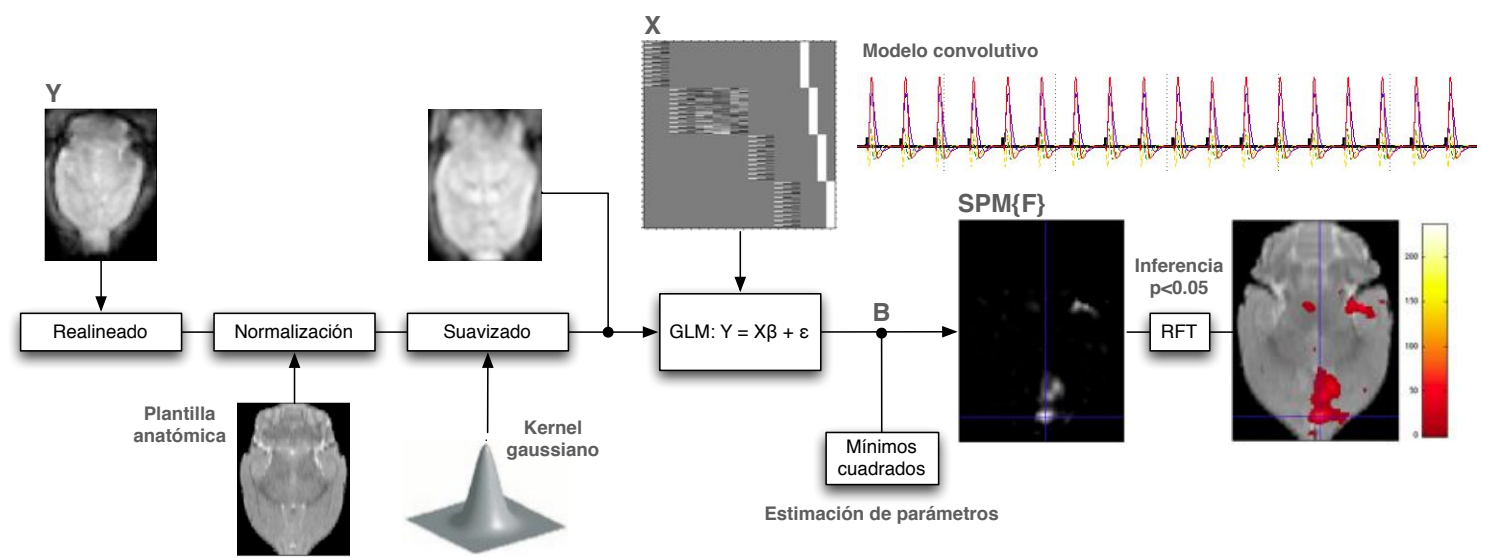

Figura 3.3: Análisis IRMfe del cerebro de rata con GLM. El esquema muestra las transformaciones que permiten obtener un mapa estadístico paramétrico o SPM a partir de una secuencia de imágenes de resonancia magnética (Y). Los análisis vóxel-avóxel requieren que los datos estén registrados en un espacio anatómico común. Con dicho objetivo las imágenes funcionales se preprocesan, realineándose entre sí y normalizándose a una plantilla anatómica. Antes de aplicar el modelo lineal general, las imágenes deben ser suavizadas (normalmente por un filtro de kernel gaussiano). Tras el suavizado, utilizamos GLM para estimar los parámetros del modelo temporal (B) y derivar un SPM (usualmente t, F ó Z) de los parámetros estimados. El último paso consiste en realizar las inferencias estadísticas en base a RFT para caracterizar las respuestas funcionales sobre un sustrato anatómico. Figura basada en [17].

La Figura 3.3 muestra un pequeño ejemplo sobre el análisis GLM de un experimento de estimulación eléctricaIRMf en un cerebro de rata. Como se puede ver en la matriz de diseño de dicha figura, el experimento concierne a cuatro sesiones IRMf en las que los efectos en las imágenes se explican en base a dos familias de condiciones: las sesiones uno, tres y cuatro expresan los efectos en las imágenes únicamente a partir del estímulo eléctrico—en realidad del tren de impulsos suavizado con una respuesta funcional hemodinámica (como se verá en el apartado siguiente), mientras que en la sesión dos (además de los efectos causados por la corriente eléctrica) se tienen en cuenta los seis parámetros de movimiento del espacio tridimensional. La contribución relativa de cada una de las dieciocho columnas (o dieciocho parámetros o regresores) contenidos en la matriz de diseño $\mathbf{X}$ se evalúa mediante el análisis de máxima verosimilitud de mínimos cuadrados. Una vez se hayan estimado, los parámetros del modelo (que representamos como B) se utilizan para obtener un estadístico (para cada vóxel) que representa la evidencia de no activación frente a la hipótesis nula, obteniéndose la imagen o mapa de estadísticos SPM. Finalmente, la imagen estadística paramétrica se infiere limitando la posibilidad de falsos positivos, hecho que se consigue a través de RFT en los supuestos que se explican a continuación.

\section{Modelos dinámicos}

En el ejemplo de la Figura 3.3 se ha obviado hasta el momento la parte identificada como Modelo convolutivo. Cuando a mediados de los noventa aparecieron los paradigmas de estimulación basados en estímulos de corta duración (o eventos) [67], GLM tuvo que refinarse para poder representar en los SPM este tipo de respuestas evocadas. La modificación de GLM para el análisis de la estimulación por eventos (en vez de por bloques [68]) se basa en un simple modelo de convolución temporal, que es la verdadera piedra angular para hacer inferencias sobre activaciones GLM/IRMf basadas en diseños experimentales complejos. En el modelo de convolución se asume que las respuestas neuronales evocadas pueden modelarse como la convolución (o suavizado) del tren de impulsos con una respuesta impulsional finita llamada HRF (por sus siglas en inglés: hemodynamic response function) como la que se muestra en la Figura 3.4.

La selección de una u otra HRF no es una decisión ni mucho menos trivial, sobre todo por el hecho de que 


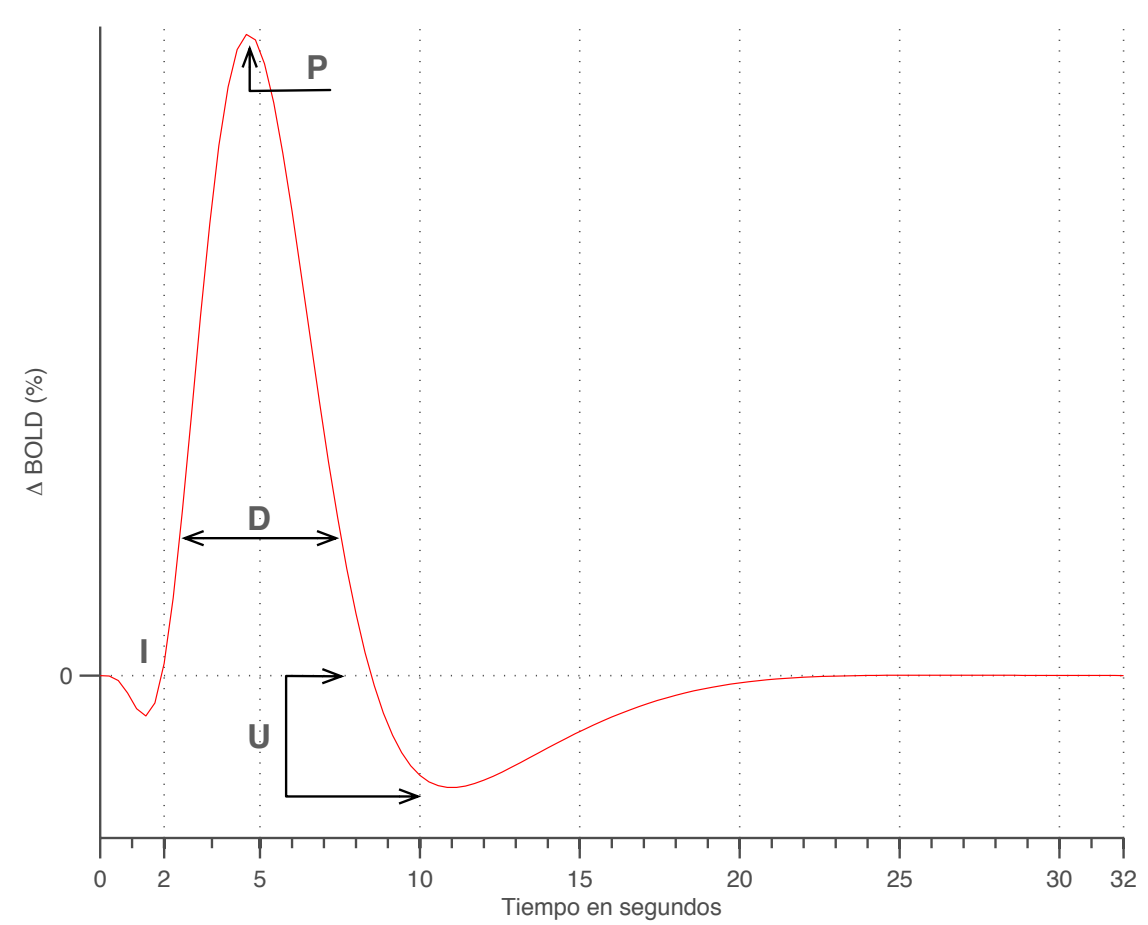

Figura 3.4: Función de respuesta hemodinámica o HRF típica, donde: $\mathbf{I}$ representa un valle inicial, $\mathbf{P}$ es el pico de amplitud de la respuesta, $\mathbf{D}$ la dispersión de la misma y $\mathbf{U}$ o undershoot representa el comportamiento transitorio entre $\mathbf{P}$ y la línea base.

las respuestas hemodinámicas en una parte del cerebro pueden ser diferentes de la respuesta en otra área o región [69], incluso si la actividad neuronal subyacente es exactamente igual—posiblemente debido a las propiedades vasculares características de cada región [70]. Para permitir diferentes HRF en diferentes áreas o regiones del cerebro se introduce el concepto de funciones base temporales [71]. La idea es que cualquier respuesta hemodinámica se puede expresar como una combinación lineal de varias funciones (base) temporales; por lo tanto, la respuesta funcional de un vóxel (área o región) puede depender de uno o más regresores hemodinámicos (tantos como HRFs o funciones base temporales se decida incluir en el modelo). Para mostrar que cualquier modelo convolutivo basado en funciones base temporales puede convertirse en un GLM, resulta útil expresar el modelo lineal general en función del tiempo:

$$
y(t)=X(t) \beta+\epsilon(t)
$$

donde los datos $y(t)$ son series temporales BOLD-IRMf, las variables explicatorias o regresores, $X(t)$, son ahora función del tiempo, $\beta$ son parámetros independientes del tiempo y los errores se distribuyen según $N\left(0, \sigma^{2} \Sigma\right)$, siendo $\Sigma$ la autocorrelación del ruido. Si ahora asumimos que en nuestro diseño experimental sólo tenemos en cuenta los regresores asociados a las funciones temporales, tenemos que la serie temporal BOLD-IRMf del voxel $i$ se puede expresar según la siguiente combinación lineal:

$$
y_{i}(t)=\beta_{0}+\sum_{l=1}^{N}\left[T_{l}(t) \otimes u(t)\right] \beta_{l}+\sum_{l=N+1}^{L} X_{l}(t) \beta_{l}+\epsilon_{i}
$$

donde $T_{1}(t) \ldots T_{N}(t)$ son las $N$ funciones de la base temporal, $u(t)$ representa a los eventos o estímulos (siendo $\otimes$ el operador convolución), el último sumando corresponde a regresores (también temporales) que no dependen 
de las funciones de base temporal, más el término de ruido. Es habitual el uso de una base de tres $(N=3)$ funciones temporales, correspondientes a una HRF canónica (correspondiente a la curva azul en la Figura 3.5, A) y sus derivadas temporal y espacial (en verde y amarillo respectivamente-en la figura recién mencionada).

Retomando el ejemplo de la Figura 3.3, podemos afirmar que los regresores de la matriz de diseño asociados a la estimulación eléctrica corresponden a la convolución del tren de impulsos con la familia de funciones base recién expuestas y no al tren de impulsos en sí. En cuanto a la inferencia estadística de los modelos dinámicos GLM, se puede demostrar que los parámetros que estiman la presencia de varios regresores de forma simultanea describen una función de densidad de probabilidad $F$ o de Fisher (y que es la distribución de la que deriva el mapa estadístico paramétrico SPM $\{\mathbf{F}\}$ del ejemplo). En cuanto al umbral de significancia estadística se asume que para valores suficientemente pequeños (menores a 0,05 ) los efectos funcionales se consideran significativos-en dicho caso establece que la probabilidad de que un vóxel se active por puro azar sea del $5 \%$.
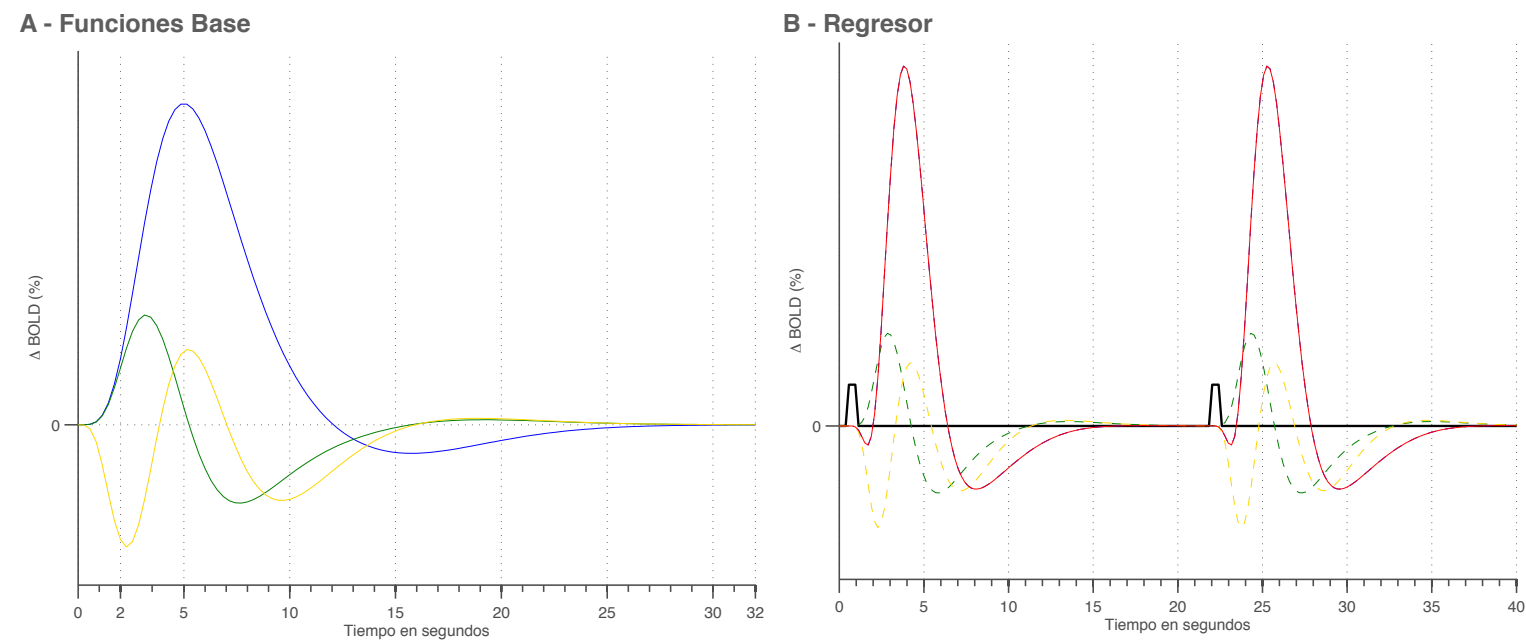

Figura 3.5: El modelo de convolución lineal es el recurso matemático que permite (en sentido práctico) hacer las inferencias en el modelo GLM/IRMf. A: funciones base extraídas a partir de cierta función canónica (en azul) modelada como suma de dos funciones gama (una en representación el pico de la respuesta y otra en representación del undershoot). Las derivadas temporal (en verde) y espacial o dispersiva (en amarillo) reducen el error residual GLM capturando retrasos o deformaciones sistemáticas de la HRF canónica. La suma de las tres funciones base da como resultado la HRF de la Figura 3.4 donde el pico de la respuesta o $\mathbf{P}$ ocurre aproximadamente a los $5 \mathrm{~s}$ después de la estimulación y el undershoot o $\mathbf{U}$ dura menos de $20 \mathrm{~s}$. B: convolución de las funciones base mostradas en A con los dos primeros estímulos eléctricos del paradigma de estimulación eléctrica del experimento de la Figura 3.3.

La asunción del modelo convolutivo implica que cualquier señal BOLD-IRMf es la salida de un sistema lineal invariante (un vóxel o una agrupación de ellos) [72], por lo tanto con duración finita e independiente del tiempo y cuyas respuestas a sucesivos estimulaciones se suman de forma lineal [73, Linear systems]. No obstante, se han encontrado indicios de no linealidad en la amplitud de la señal BOLD-IRMf en experimentos donde bien la duración de los pulsos de estimulación era excesiva, bien cuando la distancia temporal entre eventos o SOA (de sus siglas en inglés: stimulus onset asynchrony) era demasiado corta [74]. Bajo dichos supuestos y en este sentido, no se esperan respuestas no lineales en experimentos como el presentado en [2], donde el modelo convolutivo nos acerca al entendimiento del comportamiento temporal de las respuestas cerebrales inducidas por las manipulaciones experimentales y representa un primer paso hacia los modelos causales de la actividad funcional cerebral para el estudio de la conectividad funcional (Capítulo 6). 


\section{Resumen}

En la primera parte del presente capítulo se ha presentado la señal temporal BOLD-IRMf como un marcador endógeno válido para la actividad neuronal. En concreto, se ha observado que en las áreas o regiones cerebrales donde se detectan cambios positivos de señal BOLD se detectan también variaciones significativas de los potenciales de campo o LFPs, por lo que la señal BOLD-IRMf se asocia al proceso neuronal de modulación sináptica, plasticidad neuronal o conectividad funcional. Además, se presume que la plasticidad evocada por la microestimulación eléctrica tiene mucho que ver en los procesos de potenciación a medio y largo plazo (o LTP), y por tanto en la gestión de la memoria cerebral. Tras el fenómeno de especialización funcional asociado a la señal BOLD positiva, aparece la problemática asociada a la presencia de señales BOLD negativas en no pocos casos de estudio. En la segunda parte del mismo, se ha presentado el modelo lineal general (o GLM) como el mecanismo que soporta el grueso del análisis de las IRMf. GLM permite analizar de forma sencilla los datos funcionales en base a distintas asunciones estadísticas y modelos, permitiendo una gran versatilidad en la planificación de los experimentos funcionales y su análisis. La forma práctica de analizar las IRMf es a través de la versión univariada de GLM (o regresión lineal múltiple) formulado en base a un conjunto de funciones base temporales como punto esencial del modelado dinámico GLM/IRMf. Bajo estos supuestos, los test de hipótesis univariados siguen distribuciones de Fisher ya que las inferencias detectan la presencia de la HRF canónica o alguna de sus derivadas. Como se explica en la Sección 5.3, el uso de las HRF dispersivas es una condición necesaria (aunque insuficiente) para la evaluación de los efectos globales de origen neuronal en el cerebro [75]. Un punto clave para que los SPMs sirvan para el estudio de la conectividad cerebral es el preprocesado de las imágenes de RMf (Figura 3.3, izquierda), que consiste en una manipulación previa al análisis estadístico que asegura que cada vóxel ocupa una misma posición estereotáctica a lo largo de toda la serie de volúmenes-hecho fundamental cuando las inferencias estadísticas se hacen en base a las series de tiempo BOLD-IRMf. 


\section{Capítulo 4}

\section{Preprocesado de las imágenes por RM para estudios funcionales}

\section{Introducción}

En el capítulo anterior se ha introducido a los mapas estadísticos paramétricos GLM/IRMf como una herramienta básica del análisis de la conectividad cerebral, capaz de identificar la anatomía y especialización funcional o la morfometría entre otros [76]. Bajo algunas restricciones biológicas (como la asunción del modelo dinámico/convolutivo) y algunas operaciones adicionales, los mapas estadísticos paramétricos (o SPMs) pueden reflejar de forma eficiente los efectos neuronales globales, soportando el análisis de la integración funcional—que requiere un enfoque complementario de los datos para que permitan modelar la relación entre los cambios de las distintas partes del cerebro que responden a cierto estimulación funcional. Sea cual sea el posterior uso que se haga de los datos, los SPMs se construyen en base a un análisis univariado sobre las series de tiempo BOLDIRMf de cada vóxel. Los análisis vóxel-a-vóxel asumen que los datos de un vóxel dado derivan de una misma región o área del cerebro y cualquier alteración de dicha asunción desvirtúa la extracción de las series temporales BOLD-IRMf, pudiendo afectar gravemente los indicios de actividad neuronal. En este sentido, para que los test estadísticos sobre la actividad reflejen verdaderamente la especialización funcional de las regiones, se requiere de un procesado previo de las imágenes por RM funcional que asegure en la medida de lo posible la asunción indicada. En general, el procedimiento que permite la correcta alineación de la series de tiempo de los vóxels es el preprocesamiento de imágenes. Con dicho objetivo, las imágenes RMf se manipulan iterativamente hasta lograr un mapeado óptimo a un espacio anatómico de referencia. En términos generales, el mapeado o registro de dos imágenes es el procedimiento por el cual una imagen se modifica para adaptarse a otra, generalmente a través de rotaciones, traslaciones y/o pequeñas deformaciones que minimizan la información mutua entre ellas.

\subsection{Preprocesado}

El tema central del modelo lineal general (y por tanto del análisis estadístico de la actividad neuronal) es la inversión de modelos generativos de cómo las imágenes de RMf han sido creadas. La contribución que debe hacer el preprocesamiento a una resolución confiable del problema inverso es para eliminar o modelar las diferencias anatómicas entre imágenes funcionales (ya sea entre volúmenes de un mismo sujeto o entre varios de ellos). La operación más importante en el preprocesamiento es la normalización espacial—una operación que deforma las imágenes funcionales para adaptarlas a un espacio anatómico o plantilla de referencia. Para que dicha operación sea efectiva, por lo general las imágenes deben realinearse y co-registrarse previamente. Finalmente, antes de ser analizadas estadísitcamente, las imágenes suelen suavizarse para mejorar la caracterización espacial de los efectos 
neuronales.

\subsubsection{Realineado}

El realineado de imágenes es una operación de registro utilizada generalmente para reducir los artefactos asociados al movimiento del sujeto a lo largo de las sesiones de adquisición de imágenes funcionales. El movimiento es un efecto global no neuronal que puede tener un alto efecto de confusión en los datos y su modelización es imprescindible en la mayoría de modalidades de imagen cerebral y en especial de las IRMf. El objetivo del realineado es calcular los parámetros de aquella transformación afín (o rígida) que minimiza las diferencias entre cada imagen funcional y una imagen de referencia—en general, la primera de la serie IRMf o la media de todas ellas. Para la deducción de los parámetros de rotación y traslación de la transformación afín, es habitual utilizar el algoritmo de optimización Gauss-Newton. La función que se minimiza puede expresarse como la siguiente serie de Taylor:

$$
b_{i}(\mathbf{q}-\mathbf{t}) \approx b_{i}(\mathbf{q})-b_{1} \frac{\partial b_{i}(\mathbf{q})}{\partial q_{1}} \ldots
$$

donde $b_{i}(\mathbf{q})$ son las diferencias de intensidad del voxel $i$-ésimo entre la imagen original y de referencia cuando los parámetros $q$ se disminuyen en $t$ (hasta la convergencia). Una vez se han deducido los parámetros de la transformación afín, éstos se aplican a las imágenes funcionales en base a un esquema de reescritura por interpolación. Aunque es habitual que los softwares o paquetes de análisis de imágenes de resonancia magnética funcional implementen varios métodos de interpolación, es preferible el uso de métodos generalizados como B-splines.

\subsubsection{Corregistro}

Existen varias razones por las que resulta útil registrar imágenes cerebrales de distintas modalidades. En el análisis de IRMf, el caso de uso más habitual tiene que ver con el registro de imágenes anatómicas y funcionales de un mismo sujeto. Este tipo de corregistros se realizan para propiciar una posterior normalización espacial más precisa: si las imágenes anatómicas y funcionales están registradas, los parámetros que se deriven para la transformación espacial serán mucho mejores si se calculan a partir de la imagen anatómica que si se hace a partir de las propias imágenes funcionales_-dado que la resolución espacial de las primeras debería ser mayor. En el caso de imágenes anatómicas/funcionales de un mismo sujeto, suele bastar un modelo de transformaciones afines para calcular los parámetros que deban usarse para su reescritura. No obstante, en el caso de imágenes funcionales EPI, es posible que la alta heterogeneidad del campo magnético y la baja frecuencia en la codificación de fase impida su buen corregistro [77], en cuyo caso debería recurrirse a un corregistro no lineal [78] o a una normalización espacial directamente. La función que mide las diferencias entre imágenes de distintas modalidades es algo más compleja que la que se utiliza en el realineado. En concreto, la función objetivo que se minimiza en el corregistro es la probabilidad conjunta de las intensidades de las imágenes (usualmente representada como histogramas bidimensionales, Figura 4.1) y se formula en base a la información de Shannon [79].

\subsubsection{Normalización}

En las dos secciones anteriores se han expuesto dos formas no excluyentes que permiten el (co)registrado de imágenes cerebrales de un mismo sujeto donde, dado que se asume que no existen grandes diferencias entre las formas de las imágenes que se toman a lo largo del tiempo, el uso de transformaciones afines se demuestran suficientes. No obstante, esa hipótesis no es válida para la normalización espacial, que es el mecanismo que permite registrar cerebros de sujetos diferentes-por lo tanto, con diferentes tamaños y formas. Dada la mayor dificultad del problema, la normalización espacial requiere de técnicas de registro de imágenes no lineales que sean capaces de deformar las imágenes de varios sujetos individuales a un espacio anatómico estándar [80]. La principal ventaja de la normalización de las imágenes funcionales es la del promediado de las señales BOLDIRMf entre los sujetos, pues permite el análisis post hoc para determinar lo que ocurre de forma genérica sobre 

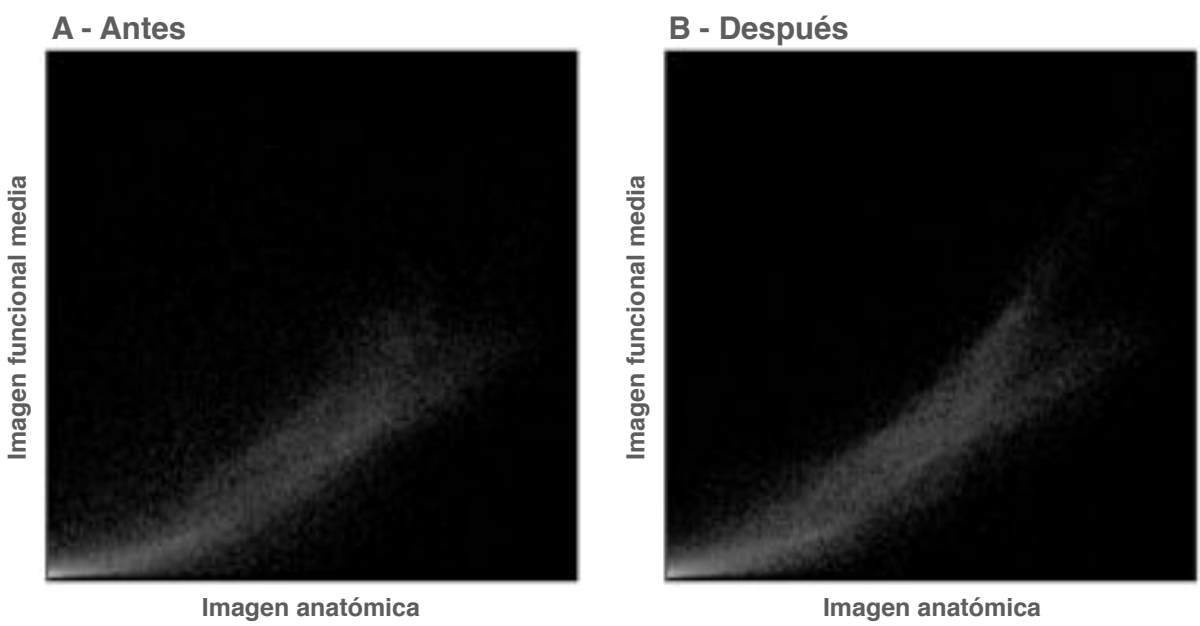

Figura 4.1: Histogramas de la probabilidad conjunta de la intensidad de las imágenes anatómica y la media de las funcionales antes (A) y después (B) del corregistro.

varios individuos. Otra ventaja de la técnica es el poder referir las regiones o áreas activas de las respuestas funcionales a través de las coordenadas euclidianas etiquetadas [81] en lo que se conoce como atlas anatómicos del cerebro. En humanos, el atlas o espacio anatómico coordenado/etiquetado más popular es el que elaboraron en 1988 Talairach y Tournoux. En otros mamíferos, como por ejemplo las ratas, existen atlas anatómicos que también se han convertido en estándares, como es por ejemplo el atlas de Paxinos y Watson (1982). En los últimos años han proliferado las versiones digitales de algunos de estos atlas, tanto en humanos [82] como en ratas [83, 84]. En resumen, en el proceso de normalización se utiliza una imagen funcional realineada (o preferentemente, una imagen anatómica coregistrada de alta definición) para calcular aquellos parámetros de deformación no lineales que mapean las series de imágenes funcionales a un espacio anatómico estándar o plantilla de normalización que, por norma general, está a su vez registrada con un atlas anatómico del modelo cerebral a quien representa. La estimación de parámetros no lineales puede realizarse en base a multitud de combinaciones de algoritmos de minimización y funciones objetivo [85], por ejemplo a partir de un conjunto de funciones base cuyos parámetros a optimizar coinciden con los de una transformada discreta del coseno (o DCT, por sus siglas en inglés: discrete cosine transform). No obstante, la optimización de la mayoría de estas funciones objetivo puede acomodarse bajo el teorema de Bayes y la estima del máximo a posteriori o MAP (por sus siglas en inglés: maximum a posteriori estimation), donde los parámetros de la deformación $\theta$ deben ser los más verosímiles dada la probabilidad $a$ posteriori conocidas las imágenes o datos $D$. En la práctica, la función objetivo se expresa como el logaritmo de la probabilidad a posteriori $p(\theta \mid D)$, en concreto según:

$$
-\log P(\theta, D)=-\log P(D \mid \theta)-\log P(\theta)
$$

donde $P(D \mid \theta)$ es el término de verosimilitud, $P(\theta)$ es la probabilidad a priori de los parámetros y entonces la solución al problema pasa por minimizar el término negativo del logaritmo.

\subsubsection{Suavizado}

En el análisis de las imágenes de RM funcional, es muy común realizar un suavizado de las imágenes funcionales antes del análisis estadístico. La operación de suavizado resulta imprescindible por varias razones. La primera de ellas tiene que ver con mejorar la calidad de la señal BOLD-IRMf. Una proporción del ruido en las imágenes funcionales (en concreto, la varianza $\sigma_{i}^{2}$ ) es independiente entre los vóxels, mientras que la señal de interés se 
extiende usualmente entre varios de ellos. Esto es debido tanto a la naturaleza distribuida de fuentes neuronales como a la homogeneidad de las respuestas funcionales entre los vóxels vecinos de las redes de pequeño mundo. En concordancia con el teorema del filtro adaptado, el suavizado de las imágenes deberá aumentar la relación señal-a-ruido (o RSR) de la señal BOLD [86]. Además de aumentar la relación RSR, el suavizado es un paso fundamental para la posterior inferencia estadística GLM. Cuando los filtros se implementan mediante kernels gaussianos, el suavizado de los datos hará que los términos de error se asemejen a la forma del propio kernel del filtro-según el teorema del límite central. Dado que dicha asunción es una de las columnas sobre las que reposa el análisis de las imágenes de RM funcional con GLM, la operación asegura la validez de los análisis estadísticos basados en los tests paramétricos. Finalmente, para el análisis de grupos de sujetos, el suavizado actúa como mecanismo para difuminar las diferencias de las regiones pareadas que se activan funcionalmente entre los distintos sujetos, mejorando el registro de las imágenes y su posteriores análisis [87].

\section{Resumen}

En este capítulo se han presentado un conjunto de técnicas que, postuladas sobre el mismo modelo generativo asumido por GLM, consiguen acondicionar las imágenes de RM funcional para favorecer su posterior análisis estadístico. Las cuatro operaciones aquí presentadas son el realineado, corregistro, normalización y suavizado. En la práctica, las operaciones de preprocesado son imprescindibles antes de la inversión GLM [88] y es casi una condición sinequanone en la mayoría de softwares que realizan análisis estadísticos GLM/IRMf [89]. Las operaciones de mayor relevancia en el preprocesado son la normalización y el suavizado. No obstante, para conseguir una buena normalización se requiere de un realinado y/o corregistro previo. Por una parte, la normalización resulta fundamental ya que permite el uso de atlas regionales (para la interpretación posterior de resultados y conclusiones de base biológica) así como el análisis de grupos de sujetos entre otros. En cuanto al suavizado, éste resulta también de vital importancia dado que favorece las asunciones sobre las que se postula GLM-fundamentalmente en la modelización del término de error de las series temporales. La Figura 10.6 muestra gráficamente los efectos que causan sobre una imagen funcional el proceso de normalización (cuyos parámetros se extraen a partir de la imagen anatómica Original) y suavizado. 


\section{Capítulo 5}

\section{Mapas estadísticos paramétricos}

\section{Introducción}

Tras su preprocesado, las IRMf están casi listas para el análisis estadístico que permite que los SPMs reflejen de forma fiable las activaciones funcionales que, sin ninguna restricción o información a priori sobre la regionalidad de los efectos, sean capaces de representar las respuestas cerebrales de forma global—que es una propiedad indispensable para poder afrontar el problema de la conectividad cerebral. Las operaciones que complementan al preprocesado son fundamentalmente dos (el modelado de las correlaciones serie y la normalización global para la compensación del efecto de ganancia) y se presumen igualmente imprescindibles para una buena estima de parámetros y una inferencia estadística de calidad. En definitiva, la buena práctica en el análisis de IRMf hacen del modelo convolutivo y del modelado de los efectos globales (de origen neuronal) el puente entre las inferencias clásicas asociadas a los mapas estadísticos paramétricos y un enfoque más próximo al procesamiento de señal que permite la diseminación de relaciones funcionales en base a la detección de patrones correlados en las respuestas neuronales distribuidas por todo el cerebro. En resumidas cuentas, después de la inversión generativa asociada al preprocesamiento y asumiendo como válida la Ecuación 3.5, la construcción de un mapa estadístico paramétrico GLM/IRMf que modele los efectos globales debería fundamentarse en los siguientes pasos:

1. Un diseño experimental que maximice la relación señal a ruido de las series temporales BOLD-IRMf.

2. Una estimación de parámetros que modele las correlaciones serie de los términos de error.

3. Un análisis estadístico que no enmascare ninguna activación neuronal (segregada por cualquier lugar del cerebro) por culpa de otros efectos globales no neuronales.

4. Unos test de hipótesis adecuados al modelo convolucional y al problema de las comparaciones múltiples.

La Figura 5.1 detalla gráficamente el modelo lineal general y sirve como guía para el desarrollo del capítulo. El resultado del proceso descrito son mapas estadísticos paramétricos de primer o segundo nivel (según representen la actividad neuronal de un sujeto aislado o un grupo de ellos) que de forma general infieren sobre la presencia de las funciones de base temporal en los vóxels.

\subsection{Diseño experimental}

Según el modelado experimental asumido, la señal temporal BOLD-IRMf de un vóxel en una serie de imágenes funcionales preprocesadas puede expresarse como una suma de una señal deseada y una señal de ruido, donde: 1) la señal deseada corresponde a los cambios hemodinámicos de origen neuronal modelados como la convolución 


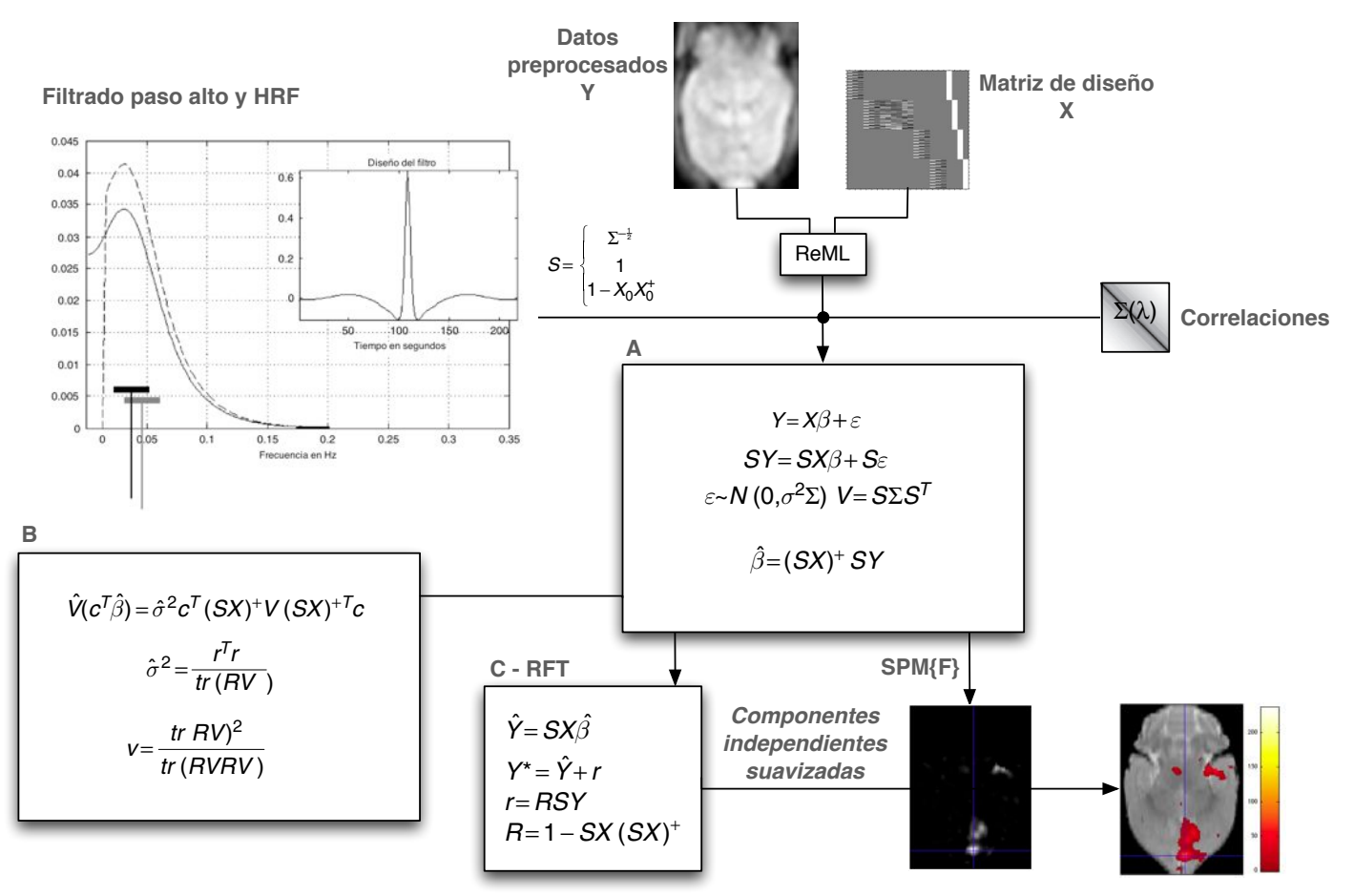

Figura 5.1: El modelo lineal general es una ecuación que expresa las observaciones, datos o imágenes funcionales $Y$ como una combinación lineal de variables explicatorias o regregresores embebidos en una matriz de diseño $X$ más un término de error con una autocorrelación $\Sigma$. En el caso de imágenes funcionales de RM, GLM se modifica para poder modelar la alta correlación espacial en los datos. Dicha modelización se realiza a través de un filtrado especial que decorrela los términos de error según la respuesta en frecuencia dada por $S=\Sigma^{-1 / 2}$. El uso del filtro $S$ permite que la estima por mínimos cuadrados de los parámetros del modelo sea la de máxima verosimilitud o sensitividad—y es gracias a que $S$ se estima en base a un procedimiento de estima ReML (por sus siglas en inglés: restricted maximum likelihood) que proporciona los términos de error de cada vóxel en base a tres hiperparámetros $\lambda$. Los efectos de interés se especifican a través de vectores o matrices de contraste. El cuadro $\mathbf{B}$ muestra a modo de ejmplo algunas de las ecuaciones que permiten calcular los grados de libertad de un estadístico tipo t. Finalmente, las expresiones del cuadro $\mathbf{C}$ muestran algunas de las expresiones que se aplican para estimar el grado de suavizado del campo aleatorio del $\mathbf{S P M}\{\mathbf{F}\}$ y que permite la inferencia estadística para la evaluación de los efectos globales. Figura basada en [17].

de un tren de impulsos (por ejemplo, a partir de la aplicación de descargas eléctricas en un experimento IRMfe) con cierta HRF y 2) la señal ruidosa puede ser a su vez la suma de señales con origen neuronal y no neuronal. Una señal neuronal ruidosa podría ser cualquier señal hemodinámica de base cerebral no incluida como regresor en la matriz de diseño; en el segundo caso, las componentes se deben en su mayoría a ruido de Johnson-Nyquist (el cual es aproximadamente blanco) o al movimiento pulsátil del cerebro según los ciclos cardíacos. Mitra et al. [90] demostraron que la suma de todas las contribuciones ruidosas provocan una correlación temporal de los datos IRMf que afectan a la estima de parámetros del modelo GLM y que para mejorar la sensitividad de su estima es necesario: un buen diseño del experimental (que se centra en la optimización del paradigma temporal en base al contenido espectral de la función de respuesta hemodinámica) y una de-correlación del ruido de las series temporales BOLD-IRMf. 


\subsubsection{Optimización del paradigma temporal}

Para llevar a cabo un buen diseño experimental es necesario adaptar el paradigma temporal y la función de transferencia de la HRF. Dado que la mayoría de herramientas software para el análisis de imágenes de resonancia magnética no están preparados para modificar la función de respuesta hemodinámica que implementan en su núcleo, lo más sencillo es diseñar un protocolo de experimentación en el que los estímulos que inducen la actividad neuronal se apliquen en los instantes temporales adecuados_que son aquellos que maximizan la RSR de la función de transferencia del sistema LTI en su conjunto. Asumiendo como válida la HRF canónica presentada con anterioridad y tras calcular su función de transferencia (Figura 5.2), puede comprobarse que la respuesta del sistema es máxima para la frecuencia $T_{s}^{-1}=0,03 \mathrm{~Hz}$ y por tanto los diseños óptimos son aquellos para los que los eventos se aplican periódicamente cada 30 o $32 \mathrm{~s}$ aproximadamente.

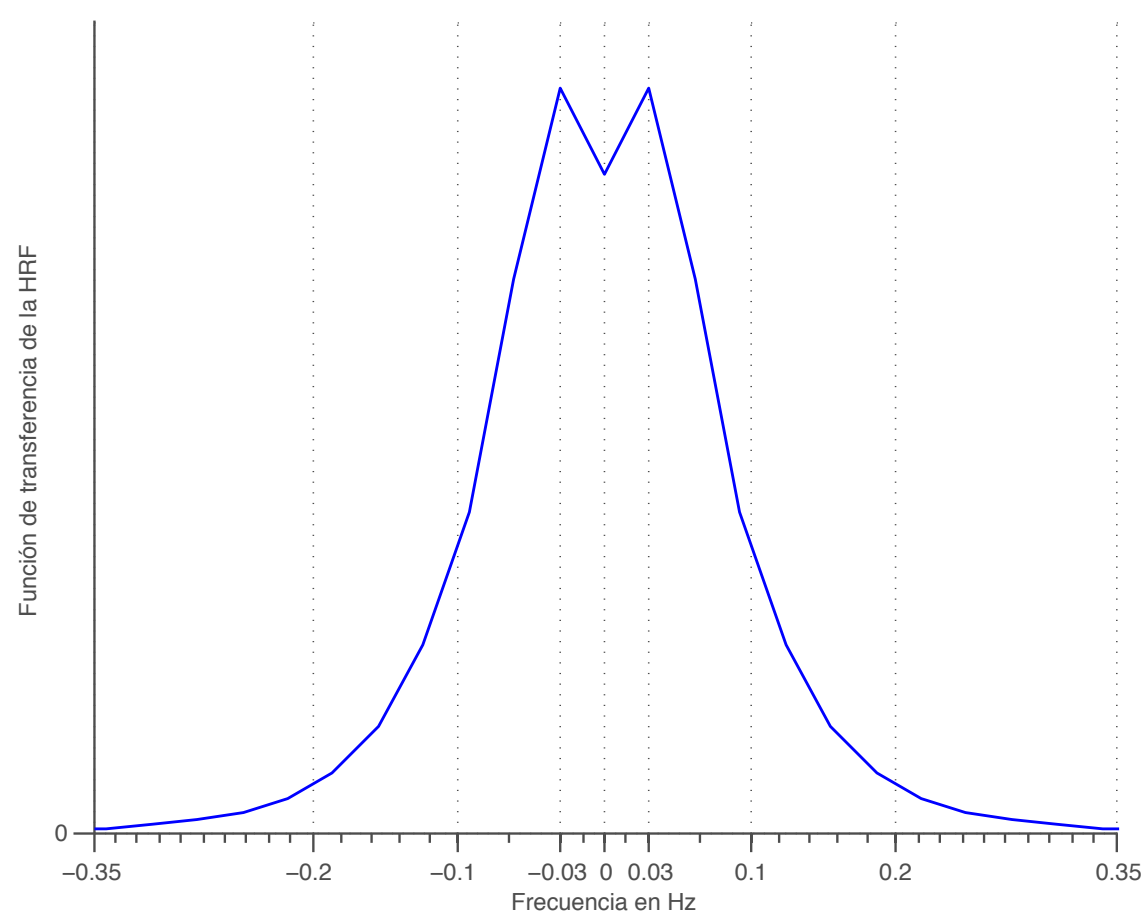

Figura 5.2: Función de transferencia de la HRF canónica de la Figura 3.5 (A, en azul). El máximo de la respuesta del sistema lineal invariante en el tiempo se da para $0,03 \mathrm{~Hz}$.

\subsubsection{Correlaciones y filtrado}

Una vez subsanados los condicionantes que inherentemente impone el modelo convolucional y la asunción de cierta HRF, el siguiente problema a subsanar para no perjudicar a la sensitividad de la estima de parámetros GLM tiene que ver con la alta correlación que existe entre los valores de luminancia de un mismo vóxel entre imágenes funcionales consecutivas. En el entorno GLM/IRMf, las correlaciones temporales se modelan como parte del término de error $\epsilon_{s}$ asociado a cierta imagen $s$ y a sus vecinos temporales. La estima de las correlaciones es un hecho de vital importancia; de hecho, la no modelización de dicho efecto disminuye los grados de libertad de las aproximaciones a las hipótesis nulas y deriva en test de hipótesis incorrectos [91]. Existen varias alternativas a la hora de eliminar las correlaciones de las series de tiempo IRMf. La forma más recurrida consiste en realizar un filtrado (tanto de los datos IRMf como de la matriz de diseño) para el blanqueado (o whitening en inglés) de los 
datos IRMf. Puede demostrarse que el filtro $S$ que optimiza la estima de parámetros es aquél que viene dado por la expresión:

$$
S=\Sigma^{-1 / 2}
$$

donde $\Sigma$ es la matriz de covarianzas del error y debe estimarse. Un modelo que refleja la forma típica de las correlaciones en la series IRMf es el modelo autorregresivo de media móvil AR(1)+wn [92]. No obstante la validez de dicho modelo está sujeta a un filtrado adicional que elimine las bajas frecuencias—pues AR(1)+wn no es válido para dar cuenta de las correlaciones embebidas en variaciones de larga duración. Además, dado que es sabido que la banda de frecuencias inferiores a $1 / 120 \mathrm{~Hz}$ es esencialmente una banda de ruido, el cometido del filtrado es doble. En definitiva, la asunción del modelo autorregresivo y el filtrado paso-alto permiten aproximar las componentes de error de cada vóxel como:

$$
\epsilon_{i} \sim N\left(0, \sigma_{i}^{2} \Sigma\right)
$$

donde $\sigma_{i}^{2}$ y $\Sigma$ se estiman en virtud de un procedimiento de máxima verosimilitud—en concreto de ReML [93]. La estima ReML da como resultado tres hiperparámetros: dos de ellos se utilizan para calcular $\Sigma$ (que como se puede observar en la ecuación anterior, es una constante entre los vóxels) y el tercero se utiliza (junto la recién estimada $\Sigma$ ) para estimar la varianza $\sigma_{i}^{2}[91]$.

\subsection{Estimación de parámetros}

La Ecuación 3.5 del modelo GLM la podemos reformular como:

$$
Y_{s}=\beta_{1} f^{1}\left(t_{s}\right)+\ldots+\beta_{l} f^{l}\left(t_{s}\right)+\ldots+\beta_{L} f^{L}\left(t_{s}\right)+\epsilon_{s}
$$

donde $Y_{1}, \ldots, Y_{s}, \ldots, Y_{N}$ son $N$ observaciones adquiridas en los instantes $t_{s}$ (siendo $s$ el número de imagen funcional de la serie), $\beta_{l}$ son los parámetros a estimar, $f^{1}\left(t_{s}\right), \ldots, f^{L}\left(t_{s}\right)$ son las $L$ funciones base temporales diseñadas para modelar todas las posibles respuestas funcionales IRMf como combinaciones lineales de respuestas HRFs y (como se acaba de explicar) $\epsilon_{s}$ se estima por ReML para construir el filtro que permite la máxima sensitividad en la estima de parámetros. Dado que en la ecuación anterior $L<J$, las ecuaciones del modelo lineal general son irresolubles de forma exacta y se hace necesaria la aplicación de un método de aproximación numérica que estime los parámetros que mejor se ajusten al modelo. Como ya se comentó, esta tarea se lleva a cabo mediante mínimos cuadrados (en concreto mediante OLS, por sus siglas en inglés: ordinary least squares). Supongamos que tenemos un conjunto de parámetros estimados $\tilde{\beta}=\left[\tilde{\beta}_{\tilde{Y}}, \ldots, \tilde{\beta}_{L}\right]^{T}$ que producen unos valores ajustados de las observaciones $\tilde{Y}=\left[\tilde{Y}_{1}, \ldots, \tilde{Y}_{J}\right]^{T}=X \tilde{\beta}$. La estima de parámetros conlleva inevitablemente unos errores residuales $e=Y-X \tilde{\beta}$ cuyo error cuadrático medio $S=e^{T} e$ mide la calidad del ajuste de parámetros del modelo. Como puede adivinarse, el papel de OLS es el de tratar de minimizar dicho error cuadrático según la expresión:

$$
\frac{\partial S}{\partial \tilde{\beta}_{l}}=2 \sum_{s=1}^{N}\left(-f^{l}\left(t_{s}\right)\right)\left(Y_{s}-\tilde{\beta}_{1} f^{1}\left(t_{s}\right)-\ldots-\tilde{\beta}_{L} f^{L}\left(t_{s}\right)\right)
$$

donde $S$ coincide con el filtro de la Ecuación 5.1. La solución de la ecuación anterior viene dada por la expresión analítica:

$$
\hat{\beta}=\left(X^{T} X\right)^{-} X^{T} Y
$$

donde $\left(X^{T} X\right)^{-}$es la pseudoinversa de $X^{T} X, Y$ son las observaciones y $\hat{\beta}$ los parámetros que optimizan el modelo. Finalmente, cabe mencionar que el filtrado adicional que permite la correcta estimación de $S$ es un filtro paso-alto que suele realizarse mediante una DCT. 


\subsection{Análisis estadístico para la caracterización de efectos neuronales glo- bales}

Según el apartado anterior, la solución del modelo GLM/IRMf viene dada por la Ecuación 5.3. Se puede demostrar que los parámetros estimados por OLS siguen la siguiente distribución normal [66, General linear models]:

$$
\hat{\beta} \sim N\left(\beta, \sigma^{2} X^{-} \Sigma X^{-T}\right)
$$

donde $\sigma^{2}$ y $\Sigma$ provienen del procedimiento de estima del error y $X$ es la matriz de diseño. Asumiendo que los parámetros estimados son los de máxima sensitividad, el siguiente paso del análisis corresponde al de la inferencia estadística, que es el proceso que permite determinar los lugares del cerebro en los que los cambios de la señal BOLD-IRMf corresponden a una actividad neuronal subyacente verdadera.

Uno de los puntos clave del análisis estadístico con GLM son sin duda los vectores o matrices de contraste. Los contrastes son el mecanismo matemático que permite configurar los distintos test de hipótesis que se desee inferir sobre los datos $Y$. Además, dichos test se realizan en base a una estima de parámetros fija. Por ejemplo, el contraste según la hipótesis nula $\mathcal{H}_{0}: \mu_{1}=\mu_{2}$ (donde $\mu_{i}$ indica la pertenencia a los grupos) permite calcular la probabilidad de una muestra de pertenecer a una u otra población (en lo que se conoce como prueba estadística t para muestras pareadas). En el análisis de IRMf, los contrastes permiten realizar preguntas estadísticas sobre las condiciones, causas o efectos que expliquen o puedan explicar las observaciones. Por norma general, los regresores de la matriz de diseño en un análisis GLM los podremos separar en dos grupos: uno en representación de los regresores de interés y otro que agrupe los llamados factores de confusión. Lo más habitual en IRMf es generar vectores de contraste para realizar t-test (generalmente para comparar la diferencias entre las respuestas funcionales producidas por dos regresores de interés distintos_-por ejemplo, con el contraste $c=\left[\begin{array}{lllll}1 & -1 & 0 & \ldots\end{array}\right]$ para un experimento en el que se desea evaluar los dos primeros regresores de $X$ ) o matrices de contraste para la generación de F-test (cuando se desea comprobar la presencia de uno o más regresores en la respuesta BOLDIRMf de los vóxels-por ejemplo, para la inferencia de las funciones base temporales).

Para el análisis de la conectividad funcional mediante SPMs, resulta de vital importancia realizar inferencias estadísticas sin ninguna restricción regional sobre dónde puede darse (y dónde no) una respuesta funcional al estímulo. La realización de mapas estadísticos paramétricos basados en hipótesis anatómicamente abiertas conlleva dos problemas de urgencia para el correcto análisis de la actividad neuronal: el problema de las comparaciones múltiples y el de la normalización global [94]. El problema de las comparaciones múltiples aparece en la estadística paramétrica cuando la inferencia requiere que se resuelvan simultáneamente multitud de test estadísticos (como ocurre cuando analizamos todos los vóxels GLM/IRMf de cierto volumen cerebral). Como se comentó con anterioridad, la solución al problema se postula mediante la teoría de campos aleatorios o RFT—un procedimiento matemático que permite ajustar (o corregir) apropiadamente los umbrales de significancia estadística de los test de hipótesis al umbral más alto. Por otra parte, como remarcábamos en el apartado de optimización del diseño, en un experimento típico de IRMf, además de las alteraciones en el flujo sanguíneo causadas por el paradigma de activación, existen otros muchos efectos globales (no neuronales) que como sabemos suponen una fuente extra de varianza que afecta (de forma peyorativa) a la media de la señal entre los volúmenes (y por tanto, a los resultados estadísticos). Algunos de estos efectos globales no neuronales (o factores de confusión) son bien conocidos [95] y la forma en la que los evadimos son de máxima relevancia en el análisis de imágenes de RMf. Básicamente existen dos estrategias para contrarrestar la influencia de éste tipo de efectos globales. Una de las soluciones es la que se suele adoptar respecto al movimiento del cráneo del sujeto mientras se adquieren las imágenes funcionales, y que no es otra que incluir los parámetros de realineado en el propio modelo a través de la matriz de diseño. La otra estrategia (complementaria al modelado explícito de los efectos globales no neuronales) consiste en estimar el factor de confusión y procesar los datos para contrarrestar su efecto. Un ejemplo de esta segunda estrategia seria el filtrado paso bajo de las series BOLD-IRMf que elimina la banda $120 \mathrm{~Hz}$ antes de la estima de parámetros. Otro efecto global no neuronal de gran relevancia en el análisis de IRMf viene dado por la diferente ganancia con la que los amplificadores del sistema de adquisición MRI codifican los momentos magnéticos en cada instante de tiempo. Llamamos escalado o normalización global de las IRMf al modelado de la variación en la intensidad de la 
señal a través de un gran número de vóxels y es un punto indispensable para la evaluación de efectos neuronales globales en análisis de hipótesis regionales abiertas [75].

En conclusión, podemos decir que el uso de las funciones base temporales (en representación de los efectos dispersivos de la HRF canónica) junto con la modelización de los efectos globales no neuronales, permiten la inferencia de mapas estadísticos paramétricos tipo F para la evaluación de los efectos neuronales globales (o respuestas funcionales en todo el cerebro) y habilitan a los SPMs como herramientas de análisis post hoc de la conectividad.

\subsubsection{Normalización global de las IRMf}

Existe una distinción práctica importante entre la evaluación de los efectos regionales y globales en el análisis de IRMf. Como se intuye del apartado anterior, los efectos regionales se refieren a la evaluación de la respuesta funcional en un pequeño conjunto de vóxels y no requieren del modelado de efectos globales (ya sean neuronales o no). Dado que para el análisis de la conectividad funcional es indispensable no asumir ninguna hipótesis sobre la especificidad regional de la actividad neuronal, el modelado del efecto global no neuronal debido a la ganancia de amlificación resulta clave para obtener inferencias estadísticas de confianza [75, 96]. La idea es que antes de la estimación de parámetros se introduzca algún tipo de procedimiento que permita eliminar dicho factor de ganancia en las series de IRMf para así minimizar el riesgo de que los tests estadísticos enmascaren parte de la actividad neuronal. En IRMf, lo más habitual y efectivo para compensar el efecto de la ganancia consiste en realizar dos estimas de dicha variación global: una que divide la intensidad de cada vóxel entre cierto factor (calculado como la intensidad media de los voxels inter-craneales_-de modo que el valor medio de las imágenes sea idéntico) y otra que modela la varianza de intensidad entre sesiones-incluyendo su valor medio en el modelo estadístico a través de la matriz de diseño. Esta implementación puede considerarse una solución mixta entre lo que se conoce como escalado proporcional y un análisis ANCOVA de la ganancia [97] y es la solución adoptada por la mayoría de programas de análisis de IRMf [98]. Aunque el escalado proporcional es indispensable, en ocasiones la parte multiplicativa del modelado puede afectar de forma negativa a los mapas estadísticos paramétricos en una de las siguientes formas: 1) al derivar en una subestimación de los verdaderos niveles de la actividad focal y/o 2) al provocar la aparición de artefactos que se manifiestan como grupos de vóxels que responden de forma inversa al estímulo (Figura 5.3; [75]).

Además, gracias a la normalización efectuada por el procedimiento, las series BOLD-IRMf pueden interpretarse como una magnitud de cambio porcentual sobre cierta media global.

\subsubsection{Teoría de campos aleatorios}

La teoría de campos aleatorios es el procedimiento matemático que se utiliza en el análisis de imágenes de RMf para resolver el problema de las comparaciones múltiples [99]. Dicho problema va asociado irremediablemente a los SPMs en los que se evalua los efectos neuronales globales en hipótesis abiertas, pues en dichos casos es habitual tener varios miles de vóxels en un volumen o imagen funcional y esto significa que hay que realizar varios miles de test estadísticos para determinar qué vóxels están activos y cuáles no. Para aligerar dicho problema, es habitual hacer agrupaciones de vóxels sobre los que evaluar la hipótesis nula. Por lo tanto, en esta redefinición del problema, la pregunta que nos hacemos es qué cantidad de error estamos dispuestos a asumir sobre un conjunto (o familia) de estadísticos de vóxel—en lo que se conoce como umbral FWE (por sus siglas en inglés: family wise error). Existen varias formas de evaluar la hipótesis nula para un conjunto o familia de estadísticos, siendo uno de los métodos más comunes el conocido como el del umbral más alto. Dicho método consiste en hallar un umbral único $\alpha$ que asegure que ningún vóxel de la familia se muestre activo por azar. La solución clásica para hallar un umbral único en el contexto del problema de las comparaciones múltiples y FWE es la corrección de Bonferroni. No obstante, dicha solución no es válida para las imágenes de RMf dada la alta correlación de las series temporales BOLD-IRMf (siendo RFT la solución acertada). Cabe destacar que algunos grupos de investigación utilizan el umbral de significancia sin corrección estadística (o uncorrected) $\mathrm{p}=0,001$ cuando existe algún indicio biológico 

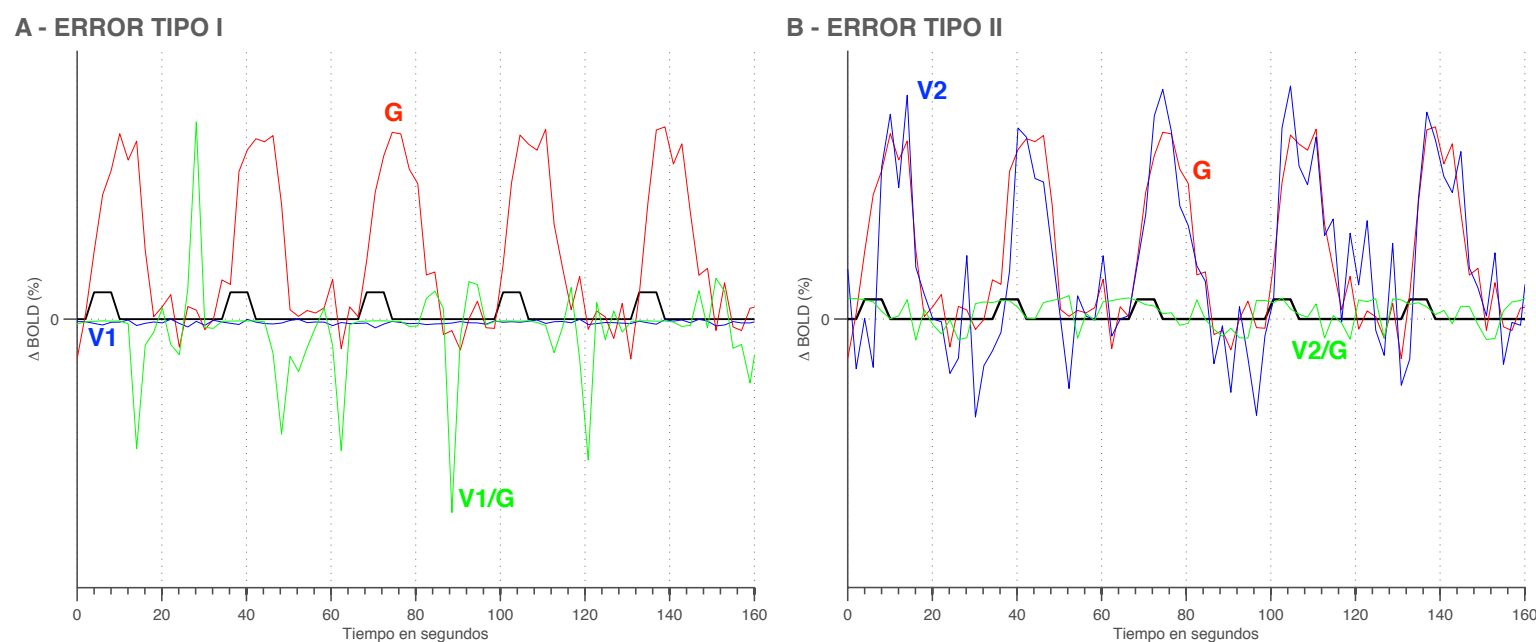

Figura 5.3: Efectos colaterales del escalado proporcional. Existe la posibilidad de que el escalado proporcional induzca a errores de activación en los SPMs cuando la estima del efecto global de la ganancia de los amplificadores (G, en rojo) se correla con el paradigma temporal (en negro). A: dado un vóxel de no interés (que no está respondiendo a la estimulación funcional) es posible que su escalado V1/G provoque una respuesta que induzca a pensar que dicho vóxel sí está respondiendo a la estimulación—además, de forma inversa. B: dado un vóxel de interés (que está respondiendo a la estimulación funcional), es posible que su escalado $\mathbf{V} \mathbf{2} / \mathbf{G}$ provoque una respuesta que induzca a pensar que dicho vóxel no está respondiendo a la estimulación.

que permite adivinar en qué regiones del cerebro puede darse la actividad funcional [17, pp. 229-30: Uncorrected $p$ values and regional hypotheses].

Retomando el problema FWE del umbral más alto, la solución que ofrece la corrección de Bonferroni al problema de las comparaciones múltiples consiste en establecer el umbral de significancia estadística de la hipótesis nula en función del número de vóxels $n$ que deseemos evaluar. Según puede leerse en [100], la tasa FWE cumple la siguiente inecuación:

$$
P^{F W E} \leq n \alpha
$$

donde $n$ es el número de vóxels y el umbral único viene determinado por la expresión: $\alpha=\frac{P^{F W E}}{n}$.

Imaginemos que tenemos una imagen funcional de 100.000 estadísticos $\mathrm{t}$ (de una ditribución $\mathrm{t}$ nula con 40 grados de libertad) y que queremos que la probabilidad de que ningún vóxel del conjunto se active por azar sea de $P^{F W E}=0,05$. Entonces, el umbral único según la corrección de Bonferroni seria $\alpha=0,0000005$ (que corresponde con la entrada 5,77 en la tabla de la distribución t con cuarenta grados de libertad). Entonces, la inferencia estadística en base al umbral calculado nos indicaría que cualquier vóxel (en cualquier lugar del volumen) con un estadístico $t \geq 5,77$ tiene únicamente un $5 \%$ de probabilidad de mostrarse activo por error bajo la hipótesis nula.

Como podemos comprobar por el ejemplo anterior, la corrección de Bonferroni es una corrección estadística FWE demasiado conservadora para los datos de IRMf. Esto se debe a que dicha corrección no tiene en cuenta la alta correlación que hay entre los vóxels de una imagen funcional del cerebro y asume que cada vóxel es independiente de sus vecinos-hecho que no responde a la realidad, entre otras cosas, debido al preprocesado y en especial al suavizado (como sabemos, operación indispensable para difuminar las diferencias residuales entre sujetos). En efecto, la correlación espacial implica que hay menos componentes independientes que vóxels en la imagen. Es en este punto donde se plantea a RFT como una alternativa a la corrección de Bonferroni para poder evaluar eficientemente las tasas FWE en IRMf. El punto clave de RFT es que es capaz de estimar el número de 
componentes independientes que hay realmente en una imagen correlada espacialmente (o suavizada) y calcula el umbral único $\alpha$ en base a dicho número de componentes (que coincide aproximadamente con la característica de Euler de la imagen) [17, pp. 223-31: Parametric procedures].

Además de la corrección FWE/RFT, existen multitud de metodologías que permiten modelar la correlación espacial entre los vóxels de un volumen funcional. Una de las correcciones más conocidas es AFNI-Alphasim (Alphasim, Biophysics Research Institute, Medical College of Wisconsin, Wisconsin, EEUU). La corrección estadística alphasim utiliza una simulación (o método) de Montecarlo para generar una serie de imágenes de RMf sintéticas que permiten establecer el umbral único de significancia estadística a partir de la combinación de un umbral uncorrected sobre cada vóxel, un tamaño mínimo de agrupaciones de vóxels y su frecuencia de aparición en la imagen sintetizada [101]. Una de las características más importantes de la corrección alphasim es que permite evaluar la morfología de la actividad neuronal.

\subsubsection{Inferencia de las funciones base temporales}

Las ecuaciones que mostramos en la Figura 5.1 pueden utilizarse para llevar a cabo un gran número de test o pruebas estadísticas. Como sabemos, cada columna de la matriz de diseño $X$ se asocia a un parámetro desconocido $\beta$. Algunos de dichos parámetros representan efectos o causas que son de interés en el estudio de la actividad neuronal funcional (por ejemplo, las respuestas hemodinámicas esperadas tras una estimulación eléctrica en un cerebro de rata), mientras que el resto de parámetros representan efectos de confusión para el estudio de las respuestas funcionales. Como ya se ha indicado con anterioridad, la inclusión de las derivadas espacio-temporales de la HRF canónica es un punto esencial del análisis GLM/IRMf para resolver el problema de la regionalidad de la función de respuesta hemodinámica y permitir el análisis de los efectos globales neuronales en el cerebro. Por definición, las inferencias que evalúan varios regresores de forma conjunta se llevan a cabo con test de hipótesis (o contrastes) que evalúan la hipótesis nula sobre distribuciones de tipo F [102]. Una matriz de contraste tipo F típica para evaluar la presencia del regresor HRF (o alguna de sus derivadas espacio-temporales) tendría la siguiente forma:

$$
c=\left[\begin{array}{cccc}
1 & 0 & 0 & \ldots \\
0 & 1 & 0 & \ldots \\
0 & 0 & -1 & \ldots
\end{array}\right]
$$

donde el efecto del signo negativo no tiene repercusión alguna dado que (como se verá en la siguiente sección) el estadístico $\mathrm{F}$ se formula en base a la suma de los cuadrados de los parámetros. La inclusión de las funciones de base temporal del modelo convolutivo son esenciales en el análisis GLM/IRMf de la actividad neuronal [103]. En la definición del contraste anterior, resulta de especial interés el uso de la derivada temporal en el modelodado su alto potencial a la hora de poder hacer deducciones biológicas post hoc. Imaginemos que desplazamos cierta señal BOLD $h(t)$ una cierta cantidad $\tau$; entonces la respuesta desfasada $h(t+\tau)$ puede expresarse como la siguiente serie de Taylor:

$$
h(t+\tau) \approx \alpha h(t)+\alpha \tau h^{\prime}(t)
$$

donde $h^{\prime}(t)$ es la derivada temporal y $\alpha$ es un factor de escalado. Por lo tanto, si $h(t)$ (en representación de la HRF canónica) y $h^{\prime}(t)$ son modeladas como regresores o funciones base temporales, el modelo a analizar vendría dado por:

$$
y(t)=\beta_{1} h(t)+\beta_{2} h^{\prime}(t)+\epsilon(t)
$$

y entonces el modelo GLM es capaz de capturar los pequeños desfases $\tau$ en la respuesta funcional-en concreto, según el ratio de parámetros estimados $\tau \approx \frac{\hat{\beta}_{2}}{\hat{\beta}_{1}}[3,104]$. En algunas herramientas software para el estudio de 
las imágenes de RMf (como por ejemplo $\mathrm{SPM}^{1}$ ), la derivada temporal de la función de respuesta hemodinámica canónica se genera desplazando más/menos un segundo la HRF canónica [3]. Esto significa que los mapas estadísticos paramétricos que se realicen con dicho software e incluyan la derivada temporal en su modelo, podrán capturar diferencias en la latencia de la respuesta BOLD-IRMf de hasta $\pm 2 \mathrm{~s}$. De forma similar, la inclusión en el modelo de la derivada espacial permite la captura de desviaciones en la duración del pico de las respuestas [17, Convolution models for fMRI].

Sean cuales sean las funciones de base temporal que se incluyan en el modelo, supongamos ahora que tenemos un modelo con un vector de parámetros $\beta$ que dividimos (según la propuesta anterior) en dos subconjuntos $\beta=$ $\left[\beta_{1}^{T}, \beta_{2}^{T}\right]^{T}$ donde $\beta_{1}$ representa a los parámetros de interés (por ejemplo, las funciones base temporales HRF) y $\beta_{2}$ a los factores de confusión. En base a dicha subdivisión la ecuación GLM podría re-escribirse como:

$$
Y=\left[\begin{array}{lll}
X_{1} & \vdots & X_{2}
\end{array}\right]\left[\begin{array}{c}
\beta_{1} \\
\cdots \\
\beta_{2}
\end{array}\right]+\epsilon
$$

donde la matriz de diseño se ha particionado según el contraste que determina los parámetros de interés. Los mapas estadísticos SPM $\{\mathrm{F}\}$ se derivan siempre respecto a la hipótesis nula

$$
\mathcal{H}_{0}: \beta_{1}=0
$$

(que indica que a priori no hay actividad neuronal en ningún vóxel de un volumen dado). Obviamente, cuando la hipótesis $\mathcal{H}_{0}$ es verdadera el modelo reducido vale: $Y=X_{2} \beta_{2}+\epsilon$. Por tanto, la pregunta estadística que nos hacemos es: ¿cuándo podemos rechazar la hipótesis nula? Si llamamos $S(\beta)$ y $S\left(\beta_{2}\right)$ a la suma de los cuadrados del modelo original y reducido respectivamente, entonces la diferencia entre la suma de cuadrados de $\beta_{1}$ despues que $\beta_{2}$ ocurra es $S\left(\beta_{1} \mid \beta_{2}\right)=S\left(\beta_{2}\right)-S(\beta)$ y entonces la evidencia frente a la hipótesis nula viene dada por:

$$
f_{i}=\frac{\frac{S\left(\beta_{2}\right)-S(\beta)}{p-p_{2}}}{\frac{S(\beta)}{J-p}} \sim F_{p-p_{2}, J-p}
$$

donde $F$ representa una distribución de Fisher con $p-p_{2}$ y $J-p$ grados de libertad y $f_{i}$ representa el estadístico paramétrico del vóxel $i$ que permite rechazar a $\mathcal{H}_{0}$ —cuando su valor es significativamente grande. Por ejemplo, en un experimento IRMfe donde $\beta_{1}$ representa a la función HRF y sus derivadas espacio-temporales, cuanto mayor sea el valor del estadístico $f$ para cierto vóxel en la imagen funcional, más improbable resulta que la hipótesis nula sea cierta y por tanto lo más verosímil es que su actividad funcional se deba a la manipulación experimental que se ha modelado con los regresores $\beta_{1}$.

\section{Análisis clásico de primer nivel y segundo nivel}

En la jerga GLM/IRMf, se recurre al término inferencia clásica para referirse a las pruebas estadísticas t/F que permiten analizar la verosimilitud de la actividad funcional en los SPMs que permiten establecer firmemente la especialización funcional y/o los efectos (neuronales) globales en el cerebro [105]. Existen dos tipos básicos de mapas estadísticos clásicos GLM/IRMf: 1) los que dan cuenta de la actividad neuronal de sujetos individuales (a los que llamamos SPMs de primer nivel) y 2) los que permiten la caracterización de la respuesta funcional de un grupo de sujetos (en lo que se conoce como SPMs de segundo nivel). Actualmente, la mayoría de estudios funcionales que combinan datos de varios sujetos se analizan bajo una estrategia de análisis conocida como análisis de efectos fijos (o FFX, por sus siglas en inglés: fixed effects analysis). Dicha metodología modela únicamente la varianza intrasujeto y su capacidad estadística la habilita únicamente como estrategia para reportar los resultados

\footnotetext{
${ }^{1}$ SPM (SPM8, Wellcome Deparment of Cognitive Neurology, Londres, Reindo Unido) es una de las herramientas software para el análisis de IRMf de cerebros humanos más importantes y más utilizados entre la comunidad científica. Tanto es así que se considera un estándar de facto para la materia.
} 
como casos de estudio. La alternativa al análisis de los efectos fijos es RFX (por sus siglas en inglés: random effects analysis), que es un método de análisis que sí permite realizar inferencias formales sobre poblaciones de sujetos [17, pp. 156-65: Random effects analysis]. Cuando el número de sujetos en un grupo es inferior a 10/12 de ellos, la única opción para la caracterización de la respuesta funcional de segundo nivel debería ser FFX [106]. Afortunadamente, el análisis de múltiples sujetos se acomoda fácilmente en el modelo lineal general, hasta el punto de no existir ninguna diferencia significativa entre el uso de GLM para uno o varios sujetos: simplemente, en lugar de tener datos de un único sujeto para cada vóxel, en un análisis FFX se tienen datos de varios sujetos para un mismo vóxel. Esto significa que las series temporales BOLD-IRMf de los sujetos de un mismo grupo deben concatenarse en un único vector columna de observaciones, debiéndose componer una matriz de diseño aumentada que represente a todos los sujetos del experimento. La Figura 11.3 muestra un ejemplo en el que se analiza un grupo formado por dos sujetos.

\section{Resumen}

En el presente capítulo se han detallado las operaciones más relevantes que permiten sintetizar mapas estadísticos paramétricos GLM para la caracterización de los efectos neuronales globales en IRMf. Todas las operaciones especificadas se orientan a una inferencia de calidad cuando no existen hipótesis regionales sobre la actividad regional-hecho indispensable para habilitar a los SPMs como instrumentos de análisis de la conectividad funcional. Asumiendo que las imágenes del experimento de RMf han sido convenientemente preprocesadas, la solución al problema de determinar las regiones o áreas especializadas -segregadas por cualquier lugar del cerebro- pasa por evaluar la hipótesis nula $\mathcal{H}_{0}: \beta_{1}=0$ para todas las series temporales de todos los vóxels de un volumen dado-donde $\beta_{1}$ representa a los regresores de interés. Para que los test de hipótesis sean de la máxima sensitividad y las manchas de color de los SPMs indiquen la ubicación anatómica de regiones que están respondiendo verdaderamente a la estimulación funcional, es necesario: asumir el modelo convolucional GLM e incluir la función de respuesta hemodinámica canónica y su derivada temporal (como mínimo) en el modelo, realizar una buena estima de los parámetros y realizar test estadísticos tipo $\mathrm{F}$ que no enmascaren la actividad funcional de ninguna región del cerebro. Bajo dichos supuestos, los mapas estadísticos paramétricos inferenciados pueden utilizarse como máscaras que seleccionan los vóxels de aquellas regiones o áreas que están respondiendo al estímulo y dado que dichos vóxels se han modelado como respuestas de un sistema lineal invariante en el tiempo, sus series temporales soportan cálculos de marcadores temporales indicativos de la conectividad. 


\section{Capítulo 6}

\section{Medidas de conectividad funcional mediante imágenes por RM}

\section{Introducción}

Como se dijo en el Capítulo 2, el funcionamiento del cerebro se describe en base a dos principios fundamentales: la especialización y la integración funcional. Dichos principios son complementarios y no pueden entenderse sin la conectividad funcional. En el Capítulo 3 hemos visto como el modelo lineal general, en su versión más elemental, es utilizado para realizar inferencias estadísticas sobre series de imágenes de resonancia magnética funcional, permiténdonos localizar las áreas o regiones cerebrales en las que las respuestas neuronales se expresan de forma estadísticamente significativa, estableciendo firmemente el principio de especialización funcional. No obstante, el estudio o análisis de la integración de las áreas especializadas segregadas por el cerebro supone un problema de mayor dificultad. Hasta la fecha, el análisis de la integración funcional se afronta midiendo la información mútua entre las señales BOLD-IRMf de los modelos dinámicos—que como sabemos miden la actividad neuronal [1]. En la última década han aparecido una gran variedad de técnicas para el estudio de la conectividad funcional y la identificación de redes neuronales, muchos de ellos con un nexo común: el análisis multivariado de las series de tiempo BOLD-IRMf [107]. Las técnicas multivariadas que analizan la conectividad funcional (o patrones de covarianza) mediante imágenes por RM son esencialmente exploratorias, mientras que los modelos que estudian la conectividad efectiva hacen inferencias sobre los parámetros (o medidas temporales indirectas) para determinar la direccionalidad de dichos patrones de covarianza [37]. Las medidas de covarianza, información mútua o conectividad funcional pueden realizarse en el dominio del tiempo o el dominio de la frecuencia, como veremos a continuación.

\subsection{Medidas de conectividad funcional}

En el análisis de imágenes de RMf, se define la conectividad funcional como la información mutua entre entre las series temporales en representación de eventos neurofisiológicos remotos. Esta definición permite una caracterización muy útil de las interacciones corticales (generalmente en ausencia de instrucciones específicas para la realización de tareas) en humanos [108] y más recientemente en monos [109] y ratas [110, 111]. En el caso de experimentos en los que la adquisición de IRM se realiza mientras se lleva a cabo una tarea, se asume que actividad neuronal se deriva fundamentalmente de los cambios provocados por la estimulación inducida en el flujo sanguíneo cerebral o CBF (Ecuación 3.1). Sea como fuere, las señales temporales BOLD-IRMf permiten la identificación de sistemas macroscópicos cuyo flujo sanguíneo cerebral sigue algún patrón de correlación temporal [112]. Cuando los análisis de correlación quedan restringidos a la actividad revelada por mapas estadísticos 
paramétricos, las conclusiones que se obtienen pueden asociarse a estados cerebrales concretos (Figura 6.1).

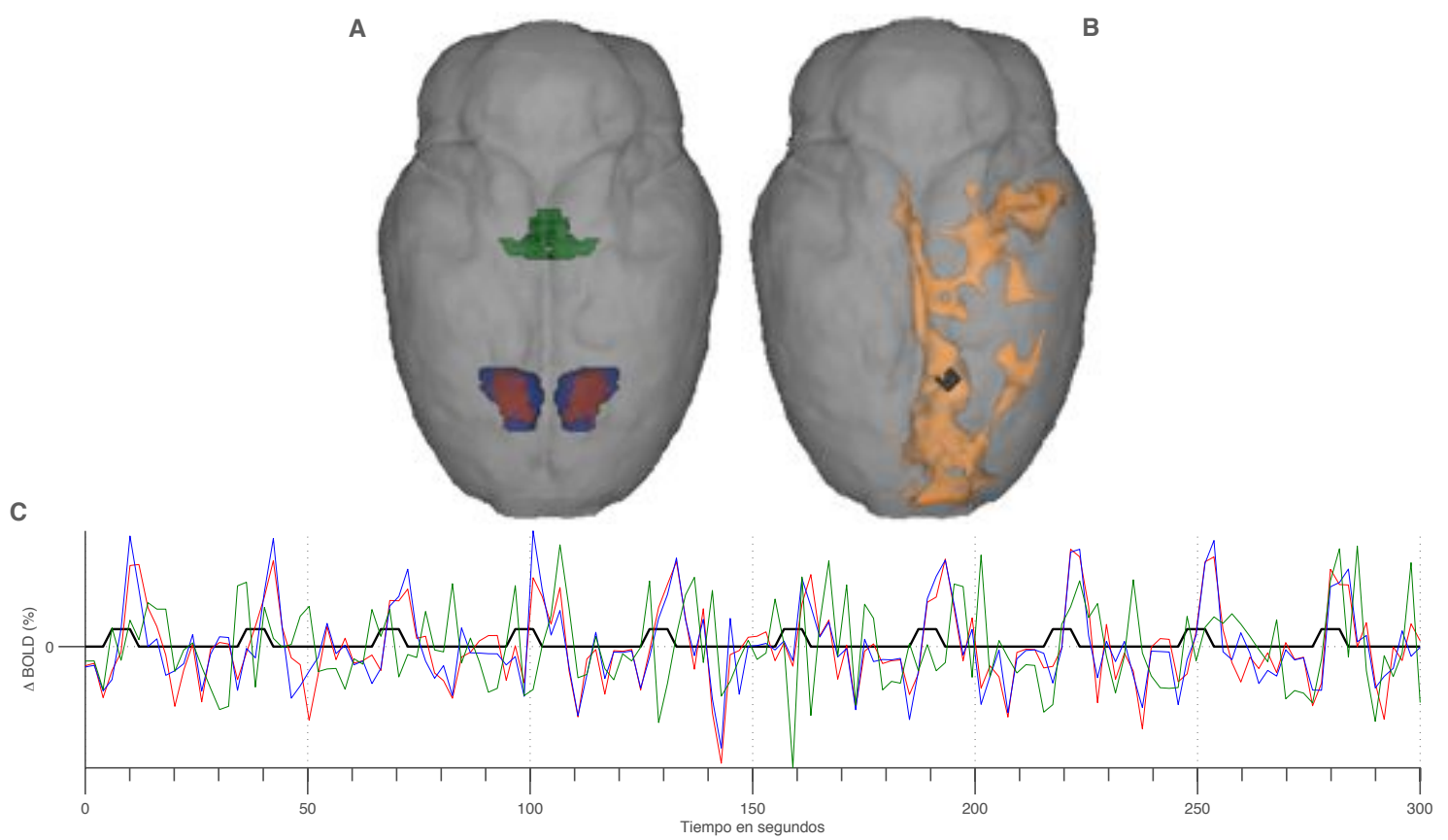

Figura 6.1: Identificación de señales BOLD-IRMf a partir de un mapa estadístico paramétrico asociado a un experimento IRMfe sobre un cerebro de rata. Las señales BOLD-IRMf representan la actividad funcional en tres regiones cerebrales conocidas. A: localización estereotáctica de tres regiones cerebrales conocidas del cerebro de rata: AcbC o accumbens nucleuscore (en rojo), AcbSh o accumbens nucleus - shell (en azul) y VTA o ventral tegmental area (en verde). B: mapa estadístico paramétrico provocado por la estimulación eléctrica inducida a través de un electrodo (en negro) implantado en la zona del núcleo accumbens. C: respuestas BOLD-IRMf inducidas por los impulsos eléctricos (en negro) asociados al paradigma de estimulación eléctrica IRMfe. Las señales BOLD-IRMf son representativas de las tres regiones representadas en a, dado que corresponden a la media de las señales temporales de los vóxeles de cada una de dichas regiones.

\subsubsection{Correlación}

Imaginemos dos series temporales BOLD-IRMf (ambas de $K$ muestras hemodinámicas) de dos vóxeles cualesquiera (a los que llamamos $i$ y $j$ ). En Cao y Worsley [113] se asume que la conectividad funcional entre dichos vóxels puede medirse con la correlación cruzada entre sus series temporales:

$$
\rho_{i j}(\mu)=\frac{\operatorname{Cov}_{i j}(\mu)}{\sqrt{\operatorname{Var}(i) \operatorname{Var}(j)}}
$$

donde $\operatorname{Var}(i)$ y $\operatorname{Var}(j)$ son las varianzas de las series temporales de los vóxels $i$ y $j$ respectivamente y $\operatorname{Cov}_{i j}(\mu)$ es la covarianza de dichas series evaluadas en $\mu$. Entonces si $\rho i j(\mu)$ está por encima de cierto umbral, se considera que las series BOLD-IRMf de $i$ y $j$ están conectadas funcionalmente y la correlación se convierte en el estadístico suficiente para explorar (más que inferir) algo sobre la conectividad funcional de los vóxels bajo estudio. Aunque la Ecuación 6.1 se ha definido para dos vóxels, puede extenderse a dos sistemas distribuidos dado que (como se demostrará más adelante) no hay ninguna diferencia formal entre una señal BOLD-IRMf en representación de un vóxel o de un agrupación de ellos en un sistema macroscópico (Figura 6.2). 


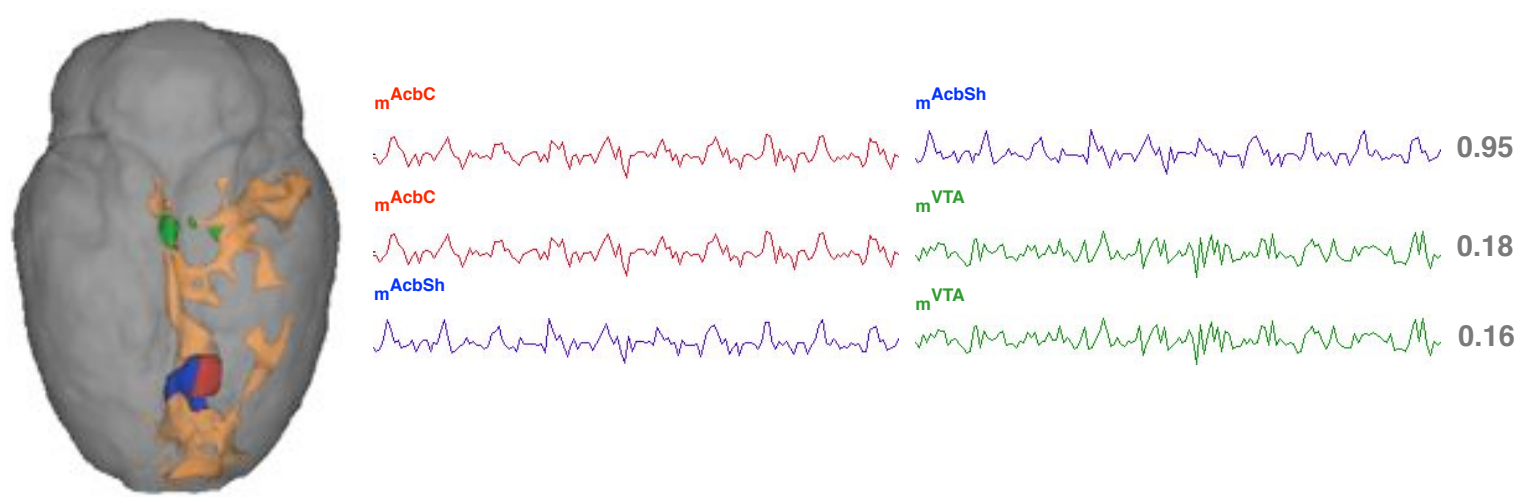

Figura 6.2: Conectividad funcional o correlación $(\mu=0 \mathrm{~s})$ entre las BOLD-IRMf medias representativas de los sistemas macroscópicos identificados por las regiones anatómicas de la Figura 6.1. La correlación entre las regiones AcbC y AcbSh es muy alta $(0,95)$ mientras que entre las regiones del núcleo accumbens y VTA es prácticamente inexistente.

El cálculo de la correlación cruzada para todo $\mu$ haría de la medida de la correlación un cuantificador inviable para la conectividad funcional. Afortunadamente, el modelado de la función de respuesta hemodinámica o HRF hace innecesario el cálculo de $\operatorname{Cov}_{i j}(\mu)$ para todos los valores de la variable independiente y generalmente se utiliza la covarianza como medida de la conectividad para $\mu=0$ [114]. Tradicionalmente, la correlación se ha utilizado como el cuantificador adecuado para la construcción de matrices simétricas de conectividad [115]—en base a un popular método de análisis de la conectividad conocido como CCA (por sus siglas en inglés: crosscorrelation analysis). La Figura 6.2 da una idea visual de dicho método.

\subsubsection{Coherencia}

Pese a que el análisis de la conectividad funcional basado en la Ecuación 6.1 es una técnica ampliamente utilizada en el análisis de IRMf, el uso de la correlación para $\mu=0$ ha despertado recelo entre la comunidad científica [116]. Por una parte, la correlación depende de la forma de la HRF (que como sabemos, puede cambiar no sólo entre distintos sujetos, sino entre distintas regiones o áreas de un mismo cerebro [117]); por otra, existen factores no neuronales que pueden contaminar las medidas de correlación de la conectividad funcional (como por ejemplo el movimiento, la actividad cardíaca [118] o el riego sanguíneo del cerebro [119]). Para solucionar éstos y otros problemas, Sun et al. [24] introdujeron una nueva medida de la conectividad funcional conocida como coherencia, que es el equivalente espectral de la correlación. Dadas las mismas series de tiempo de los vóxels $i$ y $j$, la coherencia se define como:

$$
\operatorname{Cohe}(\lambda)=\frac{\left|F_{i j}(\lambda)\right|^{2}}{F_{i i}(\lambda) F_{j j}(\lambda)}
$$

donde $F_{i j}(\lambda)$ es el espectro definido por la transformada de Fourier de la covarianza:

$$
F_{i j}(\lambda)=\sum_{u} \operatorname{Cov}_{i j}(u) \exp ^{-j \lambda u}
$$

que permite por analogía la definición de los espectros de potencia $F_{i i}(\lambda)$ y $F_{j j}(\lambda)$. Expresar la correlación en el dominio de la frecuencia permite el análisis de la conectividad de una forma más natural. Por ejemplo, el flujo sanguíneo cerebral fluctúa con un período de alrededor de $10 \mathrm{~s}$, por lo que la coherencia a frecuencias por debajo de $0,1 \mathrm{~Hz}$ se relaciona particularmente con la conectividad funcional; en cambio, es sabido que la actividad cardíaca se centra en componentes espectrales alrededor de $5,00 \mathrm{~Hz}$ en ratas $(1,25 \mathrm{~Hz}$ en humanos) y por tanto, la coherencia en dichas bandas frecuenciales deberían ser obviadas para los respectivos análisis de la conectividad. 


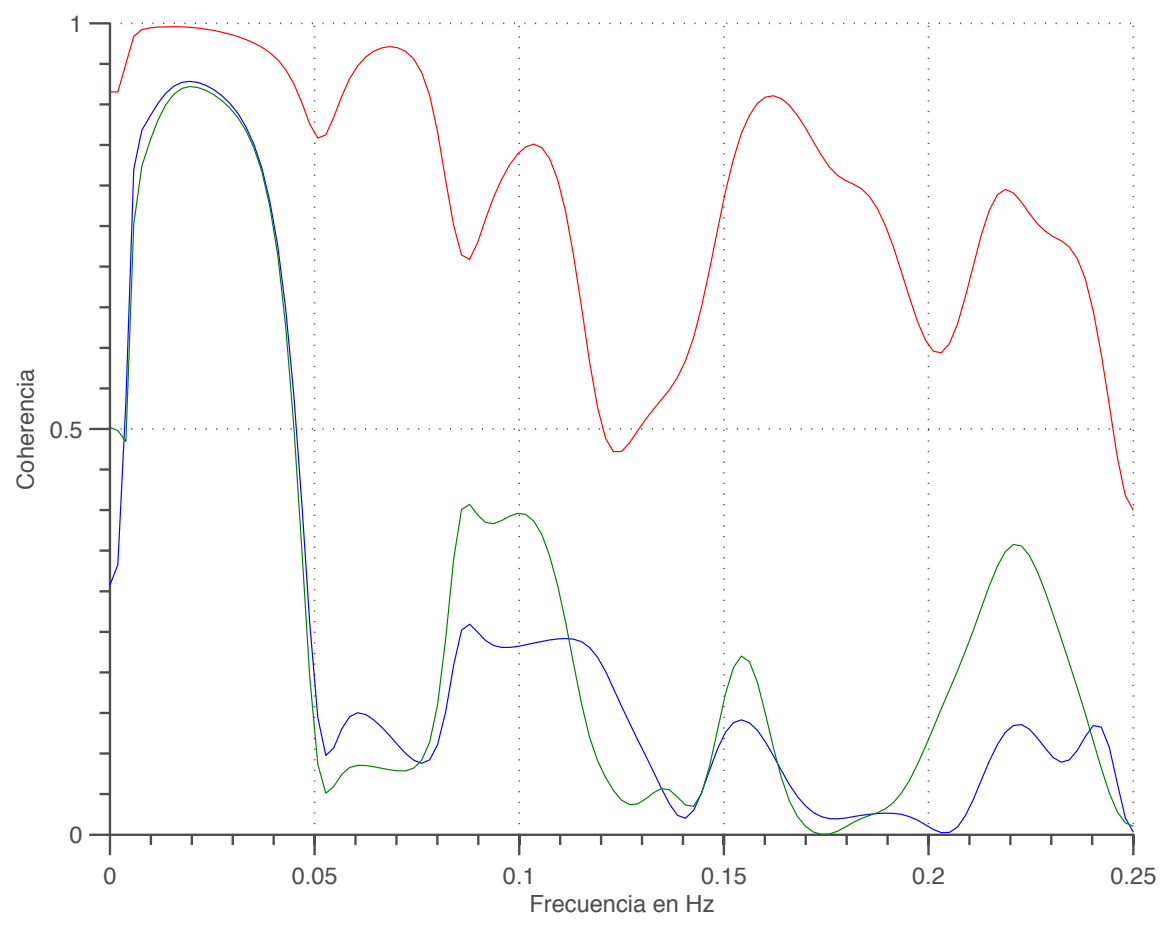

Figura 6.3: Conectividad funcional o coherencia $(\lambda=0,1 \mathrm{~Hz})$ entre los sistemas macroscópicos identificados por las regiones anatómicas de la Figura 6.1. La coherencia entre las regiones AcbC y AcbSh (en rojo) es muy alta para la frecuencia de interés $(0,85)$ mientras que entre las regiones del núcleo accumbens y VTA es prácticamente inexistente: 0,23 (en azul) para AcbC/VTA y 0,40 (en verde) para AcbSh/VTA. Probablemente, una mejor medida de la conectividad funcional consistiría en calcular la coherencia por $\mathrm{Hz}$ para las frecuencias por debajo de $0,1 \mathrm{~Hz}$.

\subsection{Medidas multivariadas}

En la sección anterior se han introducido como medidas de la conectividad funcional la correlación y/o su equivalente espectral: la coherencia. Dado que la conectividad vóxel-a-vóxel resulta de poco interés práctico a la hora de analizar la actividad funcional en todo el cerebro, es necesario utilizar un mecanismo de análisis global que evalúe conjuntamente todos los patrones de varianza/covarianza en los datos IRMf. Una forma sencilla y elegante de caracterizar patrones de covarianza en un conjunto de datos es a través del análisis de componentes principales o PCA (por sus siglas en inglés: principal component analysis). No obstante, en el análisis de neuroimágenes es más habitual utilizar la descomposición en valores singulares o SVD (por sus siglas en inglés: single value decomposition) que permite detectar un conjunto de modos espaciales ortogonales (conocidos como eigenimages) asociados a los patrones temporales de máxima varianza/covarianza (o eigenvariates) [23]. Asumiendo que la covarianza entre distintas regiones cerebrales es equivalente a la conectividad funcional entre ellas, el análisis SVD es de especial interés dado que nos permite estudiar la integración funcional (o lo que es lo mismo, la conectividad) en imágenes de resonancia magnética funcional [120]. La idea subyacente en el análisis SVD es una de las formas de caracterización multivariada más sencillas de las series de tiempo IRMf y junto con las técnicas de análisis de componentes independientes o ICA (por sus siglas en ingles: independent component analysis) [121, 122], una de las herramientas exploratorias más usadas. Precisamente a raíz de su sencillez, las eigenimages son la base para otros procedimientos de análisis de la conectividad funcional, como por ejemplo la clasificación no supervisada o clustering [123] o el análisis de coordenadas principales [124]. 


\subsubsection{Descomposición en valores singulares}

En matemáticas, la descomposición en valores singulares o SVD es una operación de factorización (de una matriz real o compleja) de gran utilidad en diversos campos de la ingeniería, el procesado de señal o imágenes y el análisis estadístico de formas entre otros. Los beneficios de SVD se aprecian desde tres puntos de vista no excluyentes. En primer lugar, SVD puede entenderse como un método para transformar un conjunto de datos de variables correladas en una representación incorrelada de los mismos, sobre la que se asume que pueda representar mejor las relaciones subyacentes en los datos originales. Al mismo tiempo, SVD es un método para identificar y ordenar las dimensiones en las que los datos exhiben mayor información o varianza. Esto encaja con la tercera y última interpretación de SVD: una vez han sido calculadas las direcciones de mayor varianza, es posible realizar la proyección de los datos que mejor se ajustan a los originales-entonces SVD es un método para reducir la dimensionalidad de los datos.

SVD se basa en que una matriz rectangular $A$ con $m$ filas y $n$ columnas $\left(A_{m n}\right)$ puede expresarse como producto de tres matrices: una matriz ortogonal $U_{m m}$, una matriz diagonal $S_{m n}$ y la transpuesta de otra matriz ortogonal $V_{n n}$ según la expresión:

$$
A_{m n}=U_{m m} S_{m n} V_{n n}^{T}
$$

donde las matrices ortogonales son iguales a la identidad: $U^{T} U=I$ y $V^{T} V=I$, las columnas de $U$ son ortonormales a los vectores propios de $A A^{T}$, las columnas de $V$ son ortonormales a los vectores propios de $A^{T} A$ y $S$ es una matriz diagonal que contiene las raíces cuadradas de los valores propios de $U$ y $V$ ordenados de forma decreciente.

\section{Eigenimages}

Imaginemos ahora que queremos cuantificar en qué medida un patrón de actividad (en representación de un sistema macroscópico, región o área cerebral) contribuye a la conectividad funcional (o relaciones de covarianza) en las observaciones de RMf. Entonces, deberíamos descomponer la matriz $M$ (que contiene las series de tiempo originales de las imágenes de RM funcional, normalizadas en media) en sus patrones espaciales $V$ (o eigenimages) y sus patrones temporales $U$ (o eigenvariates). Dado que SVD maximiza el primer valor propio, la primera eigenimage o $V_{1}$ (y su patrón temporal asociado, $U_{1}$ ) dan cuenta de la mayor cantidad de covarianza en las series de tiempo IRMf, seguidos del par $V_{2} / U_{2}$ y así sucesivamente. En este sentido, una posible representación de los datos IRMf podría extraerse de la descomposición $M=U S V^{T}$ y su aproximación según sus dos primeras componentes principales:

$$
\tilde{M}=s_{1} U_{1} V_{1}^{T}+s_{2} U_{2} V_{2}^{T}
$$

La Figura 6.4 representa gráficamente la Ecuación 6.5 mediante un experimento de ejemplo. Imaginemos que se desea analizar los patrones espacio-temporales en un experimento IRMfe en el que se estimula una región del cerebro de rata conocida como nervio vestibular (Figura 6.4, A) a partir de sus eigenimages. Después de preprocesar las imágenes y realizar un filtrado temporal y espacial de las series de tiempo BOLD-IRMf, se utilizaría GLM para obtener aquellos SPMs que mejor representen la actividad neuronal evocada por la estimulación eléctrica (Figura 6.4, B). Si a continuación se sometiese a los vóxels activos (seleccionados mediante cierto SPM-como el de la Figura 6.4, B) a una descomposición SVD, podríamos expresar los datos funcionales como una combinación lineal de valores y vectores propios. En este sentido, supongamos que obtenemos una descomposición en la que únicamente la primera componente $U_{1}$ (Figura $6.4, \mathbf{C}$ ) se correla con el paradigma de estimulación eléctrica por encima del de umbral correlación $(0,35)$ [108]; no obstante, para ejemplificar mejor el concepto, se toman en consideración las dos primeras componentes principales $U_{1}$ y $U_{2}$, de las que se sabe que: 1) se correlan significativamente con el paradigma de estimulación eléctrica $(0,74 / 0,26$ respectivamente) y 2$)$ que sus valores propios asociados acumulan un 32,41\% del total de la varianza (Figura 6.4, E). Esto significaría que la mayor parte de la información funcional queda bien representada en base a las dos primeras componentes principales SVD. La 
descomposición ortogonal de las series de tiempo asociada a las componentes de la Figura 6.4 (D) se conoce como descomposición espectral ya que descompone las series temporales en modos espectrales (que son modos hemodinámicos BOLD-IRMf en nuestro ejemplo).
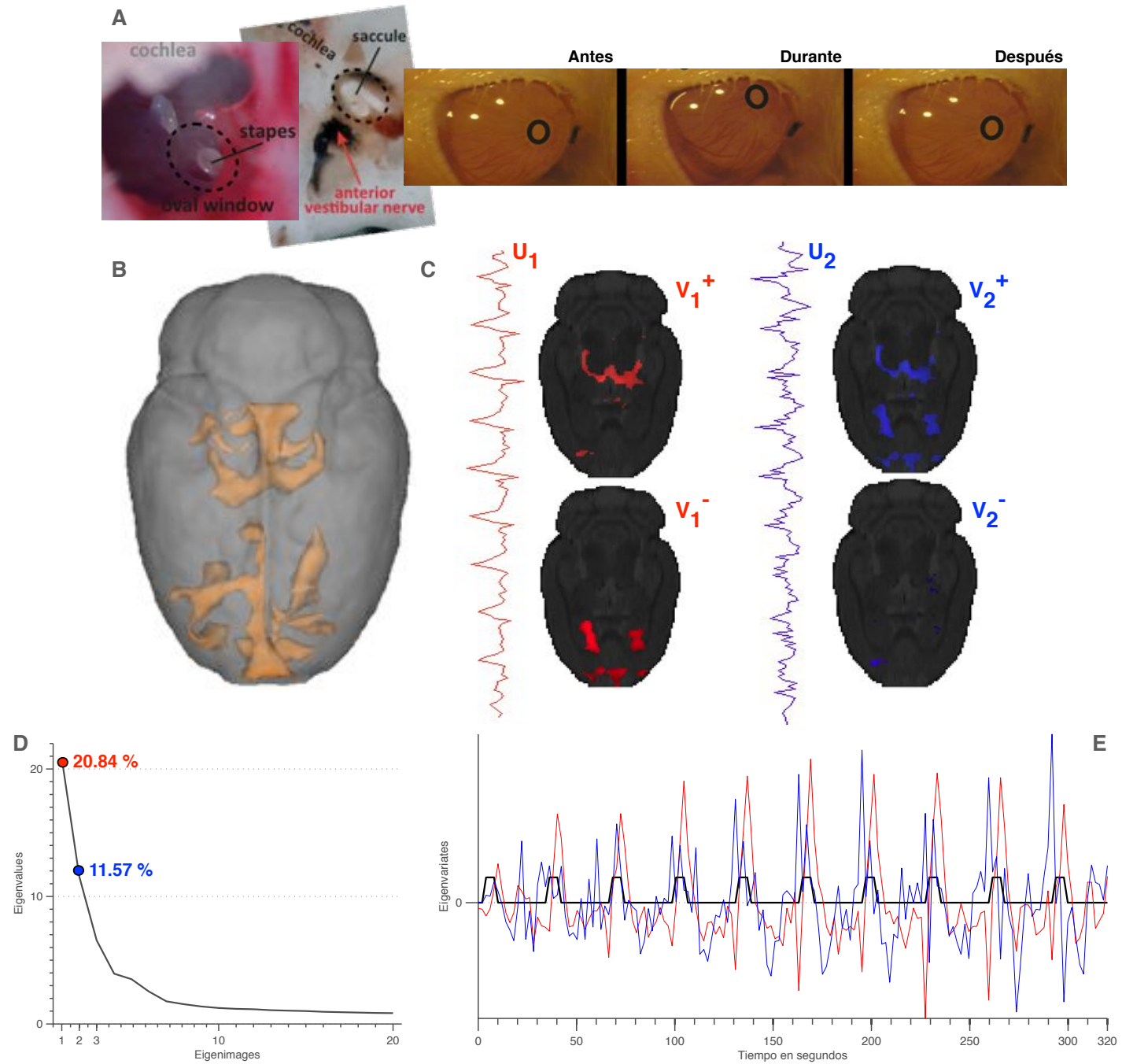

Figura 6.4: Análisis del sistema vestibular. A: acceso quirúrgico al nervio vestibular a través del canal auditivo para la implantación del electrodo de estimulación eléctrica. La correcta implantación del electrodo se comprueba con pequeñas descargas eléctricas que provocan el movimiento vestibo-ocular en el sujeto [125]. B: mapa estadístico paramétrico asociado al experimento IRMfe del sistema vestibular. Los vóxels que forman parte del mapa estadístico son aquellos que componen la matriz de series temporales BOLD-IRMf para el análisis de componentes principales. C: interpretación gráfica de la descomposición SVD asociada a la Ecuación 6.5, donde el total de la actividad neuronal representada por las covarianzas de la matriz de conectividad funcional se aproxima por las dos primeras componentes principales. D: porcentaje de varianza que aporta cada uno de los eigenvalues. E: detalle de las dos primeras componentes principales temporales (o eigenvariates) que representan los dos modos hemodinámicos que mejor representan la actividad neuronal en el sujeto. Los impulsos eléctricos se muestran en negro.

El análisis post hoc de las eigenimages permite asignar una función a un espacio anatómico, generalmente a través de las componentes temporales o eigenvariates [23]. Siguiendo con el ejemplo anterior, la componente 
temporal $U_{1}$ se relaciona claramente con el paradigma de estimulación eléctrico; por tanto las áreas cerebrales representadas en $V_{1}^{+}$y $V_{1}^{-}$se relacionan funcionalmente (de forma clara y concisa) con la actividad estimulada en el nervio vestibular. Respecto a la componente principal $U_{2}$, resulta curioso que esté presente en prácticamente la totalidad del mapa funcional a través de $V_{2}^{+}$. En este punto, la cuestión fundamental a resolver sería conocer qué patrón o modo hemodinámico es el predominante en cada uno de los miles de vóxeles que suelen componer un mapa estadístico paramétrico (14.118 para el de la Figura 6.4, B). De esta forma cada vóxel quedaría asignado a un único sistema macroscópico (el que mejor representa su respuesta hemodinámica) identificable a la vez por una respuesta BOLD-IRMf representativa del sistema.

\subsubsection{Clasificación no supervisada}

La clasificación no supervisada o clustering es la tarea de asignar un conjunto de objetos en grupos de ellos (llamados clusters) de modo que los objetos en el mismo grupo o cluster sean más similares entre sí (en uno $\mathrm{u}$ otro sentido) frente a los objetos que formen parte de otros grupos. El clustering es una herramienta fundamental en la minería de datos y una técnica común para el análisis de datos estadísticos utilizados en muchos campos - incluyendo el aprendizaje o el reconocimiento de patrones entre otros. Existen infinidad de algoritmos de agrupamiento, cada uno con su noción de lo que constituye un cluster. La idea más intuitiva detrás de la mayoría de algoritmos es la evaluación de la cercanía entre los objetos. Esta cercanía se define en términos de una determinada función de distancia, como por ejemplo la soportada en un espacio euclídeo. Otros algoritmos de clustering se postulan en base a la evaluación de las densidades de las distribuciones espaciales de los datos o la caracterización de los mismos en distribuciones de probabilidad bien conocidas. En definitiva, el algoritmo y la configuración del mismo (selección de la función de distancia, umbral de densidad de probabilidad o el número de agrupaciones que deberían hallarse) dependen de los datos en sí y del uso que quiera hacerse de los resultados. En el análisis de IRMf son muchos los algoritmos de clustering utilizados_las primeras aproximaciones de la técnica al problema de la activación funcional ha sido a través del algoritmos basados en la evaluación de la media poblacional (tanto en medidas indirectas [126] como directas [127, 123, 128] de las señales temporales BOLD-IRMf), mientras que en la variante supervisada de la clasificación es habitual el uso de las redes neuronales (artificiales) o las máquinas de soporte vectorial [129].

En el problema de identificar agrupaciones en un conjunto de datos, imaginemos que tenemos $N$ observaciones de una variable aleatoria en un espacio euclídeo $D$-dimensional y que nuestro objetivo es el de particionar los datos en $K$ grupos o clusters. Como ya hemos comentado, intuitivamente debemos pensar en un cluster como un grupo de datos que comprende puntos para los cuales las distancias entre ellos son menores que las distancias hasta otros puntos fuera del cluster. Para formalizar este hecho se introducen un conjunto de vectores $D$-dimensionales $\mu_{k}$, donde cada vector $k=1, \ldots, K$ se conoce como prototipo del cluster $k$-ésimo y representa los centros (o medias) de cada uno de los clusters o grupos. Entonces la partición óptima de los datos será aquella que consiga asignar las $N$ observaciones de nuestros datos a los $K$ vectores, centroides o prototipos que representan nuestros clusters de forma que la suma de la raíz cuadrada de la distancia entre cada punto y su centroide $\mu_{k}$ más cercano sea mínima [130, pp. 423-55: Mixture models and EM]:

$$
J=\sum_{n=1}^{N} \sum_{k=1}^{K} r_{n k}\left|\mathbf{x}_{n}-\mu_{k}\right|^{2}
$$

donde $\mathbf{x}_{n}$ es una observación $D$-dimensional y $\mu_{k}$ es el centroide al que queda asignado el vector según el esquema de codificación binaria $r_{n k}$-cuando una observación $\mathbf{x}_{n}$ se asigna al cluster $k$, entonces $r_{n k}=1$ y $r_{n j}=0$ para $j \neq k$. Las agrupaciones generadas según la Ecuación 6.6 se conocen generalmente como particiones de mínima varianza (dado que buscan el vector óptimo $\mathbf{r}_{n k}$ tal que $J$ sea mínimo) [131, pp. 602-87: Unsupervised learning and clustering] y es la base del método conocido como $k$-medias o $k$-means. El problema de minimización sujeto al algoritmo $k$-means suele llevarse a cabo mediante un procedimiento iterativo para la minimización de funciones multidimensionales conocido como algoritmo esperanza-maximización o EM (por sus siglas en inglés: expectation-maximization algorithm). $K$-means es uno de los algoritmos de clustering más sencillos y recurridos 
y es sin duda el referente bibliográfico para ejemplificar en qué consiste un proceso de clasificación no supervisada. Además de los algoritmos basados en la media poblacional o centroides, existen otros métodos basados en la conectividad (clustering jerárquico), en la caracterización de las funciones de distribución de probabilidad (como EM) o en en la evaluación de las densidades de datos que generan (como DBSCAN [132] o mean shift).

\section{Resumen}

En el presente capítulo se ha descrito dos de las medidas más utilizadas para el análisis de la conectividad funcional en IRMf: la correlación y la coherencia. Definida como la correlación temporal entre eventos neurofisiológicos espacialmente separados, la correlación cruzada se ha venido utilizando como cuantificador de la conectividad funcional desde hace décadas. De hecho, la Ecuación 6.1 suele utilizarse en el popular método de análisis de la conectividad conocido como CCA. Dicho método evalúa la conectividad funcional en dos pasos. En el primero de ellos, se establece la señal BOLD-IRMf media de cierta región o área cerebral (elegida en base a un criterio dado) a modo de patrón o referencia temporal de la actividad neuronal—un patrón al que se conoce como semilla. En la segunda fase, se examina qué otras señales temporales (en representación de otras áreas o regiones cerebrales) se correlan con la semilla por encima de cierto umbral, indicando si la conectividad es significativa o no [133]. No obstante, CCA se considera limitado dado que: 1) el patrón de conectividad funcional que se derive respecto a una semilla en concreto es obviamente sensible a la elección de la semilla y puede derivar a estudios muchas veces inconcluyentes (dado que diferentes semillas pueden conllevar diferentes patrones de conectividad) [134] y 2) el hecho de tener que elegir de forma manual y discreta áreas o regiones cerebrales que presumiblemente se conectan con la semilla puede llevar a ignorar otras partes o funciones del cerebro de máximo interés. En este sentido, técnicas como SVD o el clustering permiten el estudio de la conectividad funcional como un efecto global a partir del análisis de las covarianzas en todo el cerebro. En la Figura 6.4 se presenta una solución intermedia entre el modelo basado en semillas y el análisis exhaustivo de volúmenes y que consiste en analizar únicamente aquellos vóxels que han pasado cierto test estadístico. La utilización de los mapas estadísticos paramétricos GLM como máscaras para la selección de los vóxels de interés (a los que nos podemos referir como supra-vóxels) cobra sentido en el ámbito de la actividad funcional asociada al desarrollo de una tarea o estimulación evocada (como por ejemplo, en la estimulación eléctrica-IRMf). Además, la asunción del modelo SPM/GLM tal y como se ha presentado soslaya las desventajas de la correlación frente a la coherencia, ya que:

1. Las imágenes se manipulan para minimizar los efectos globales no neuronales-por ejemplo, a través del preprocesado o la normalización global.

2. Las series temporales BOLD-IRMf pueden filtrarse para eliminar las frecuencias que no correspondan a la actividad neuronal.

3. El problema de la regionalidad de la función de respuesta hemodinámica se resuelve con la inclusión de las derivadas espacio-temporales de la HRF canónica.

4. En los vóxels que superan el umbral de significancia estadística de los test de Fisher, se espera encontrar únicamente los regresores HRF del modelo convolucional—además, con un alto índice de verosimilitud.

Finalmente se ha sugerido que las técnicas exploratorias basadas en la correlación (ya sea a través de la medida convencional o bien mediante la versión multivariada o SVD) y/o clustering como heramientas válidas para identificar sistemas macroscópicos de la conectividad funcional—o lo que es lo mismo: un conjunto de vóxels cuyas respuestas BOLD-IRMf están correladas entre sí. Además, la identificación de sistemas macroscópicos enmascarados por mapas estadísticos paramétricos puede aplicarse sobre la totalidad del cerebro si se utiliza un umbral de significancia estadística premeditadamente holgado. Como ya se apuntaba al final del capítulo anterior, el uso de mapas SPM $\{F\}$ como máscaras que seleccionan vóxels de interés o supra-vóxels junto con el análisis exploratorio asociado a las técnicas basadas en eigenimages marcan la tónica a seguir en cuanto al análisis de la conectividad funcional en el resto del trabajo de investigación. 


\section{Parte II}

\section{Materiales}





\section{Capítulo 7}

\section{Adquisición de imágenes y herramientas de análisis}

\section{Introducción}

A continuación presentamos el listado de los materiales utilizados para el desarrollo del presente trabajo de investigación para el estudio de la conectividad funcional en animales de experimentación y que podríamos agrupar en tres grandes grupos: 1) las imágenes funcionales por resonancia magnética en cerebros de rata que se estimulan eléctricamente, 2) un atlas anatómico del cerebro de rata bien conocido y validado y 3) la herramienta software que nos permite realizar el análisis de los datos adquiridos según se especifica a continuación.

\subsection{Animales de experimentación}

Todos los protocolos y procedimientos en el manejo de animales de experimentación han sido aprobados por el comité de experimentación animal del Instituto de Neurociencias (CSIC - UMH) y siguen estrictamente todas las directivas de la Comunidad Europea (EUVD 86/609/EEC) para el cuidado y uso de los animales de laboratorio. En los distintos experimentos combinamos la implantación de un electrodo (extraordinariamente dos en el experimento asociado a la demostración práctica de la Sección 10.3) con protocolos de estimulación eléctrica por eventos para provocar una activación neuronal [2] a la vez que se obtienen señales BOLD-IRMf en adquisiciones de resonancia magnética de todo el cerebro. Todas las ratas que utilizamos las sometemos a un protocolo quirúrgico que precede a las sesiones de imágenes RMf, por el cual: 1) anestesiamos a las ratas, 2) las ubicamos en un set quirúrgico para la correcta ubicación de los electrodos de estimulación $[41,135]$ para finalmente implantar los electrodos en la ubicación estereotáctica deseada según Paxinos y Watson [136]—aunque la ubicación final de los electrodos se ajusta hasta inducir máximos en los potenciales evocados [137] respecto a la tierra eléctrica generada por un cable $\mathrm{Ag} / \mathrm{AgCl}$ subcutáneo implantado en el cuello de los animales. Los parámetros de las corrientes de estimulación (amplitud, duración de pulso, duración del tren de pulsos y frecuencia) los controlamos digitalmente con un software, amplificador y sintetizador de onda de elaboración propia [1, 138] (según especificamos en los apartados siguientes). Posteriormente digitalizamos las señales electrofisiológicas (frecuencia de muestreo: $22,3 \mathrm{kHz}$ ) y las almacenamos en un ordenador personal para su posterior análisis.

Por otra parte, el número de experimentos realizados con cada individuo y la duración de los mismos se eligen para maximizar el rendimiento de la preparación y asegurar la obtención de mapas funcionales estadísticamente significativos. Finalmente, el tamaño muestral de cada grupo experimental se seleccionó con el fin de mapear de forma robusta las áreas cerebrales bajo estudio [52] y tratando de minimizar el coste en vidas animales. 
A

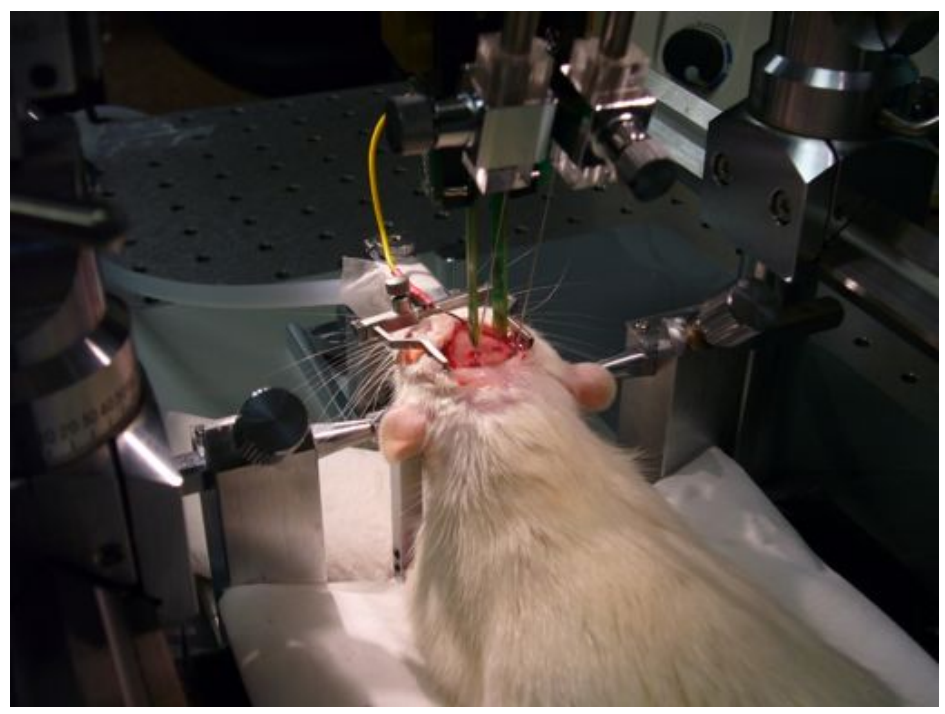

B

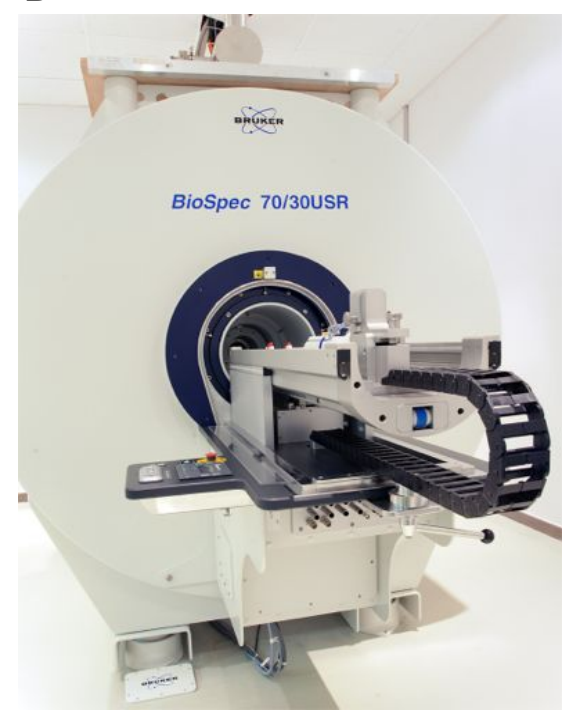

Figura 7.1: Experimentos IRMfe sobre el cerebro de la rata. Combinamos la implantación de uno o dos electrodos (A) con protocolos de estimulación eléctrica que provocan una activación neuronal a la vez que se obtienen señales BOLD-IRMf en sesiones de resonancia magnética de todo el cerebro (B) [2].

\subsubsection{Análisis de la corteza prefrontal}

En el experimento utilizamos diecisiete ratas Sprague-Dawley 250-300 g que anestesiamos con uretano (1,2-1,4 g/kg bw). Los electrodos de estimulación los ubicamos en distintas coordenadas de la corteza prefrontal, incluyendo las regiones infralímbica, prelímbica e insular. El protocolo de estimulación eléctrica consiste en aplicar trenes de impulsos eléctricos bifásicos $(0,1 \mathrm{~ms}, 10 \mathrm{~Hz})$ siguiendo la secuencia 2 OFF/2 ON/11 OFF durante un total de 300 segundos, repitiéndose entre tres y cinco veces por rata y condición. Nos referimos a los sujetos estimulados en la región de la corteza prefrontal como sujetos Pref-1 (P1) a Pref-17 (P17).

\subsubsection{Análisis del núcleo accumbens}

En el experimento utilizamos diez ratas Sprague-Dawley 250-300 g que anestesiamos con uretano $(1,2-1,4 \mathrm{~g} / \mathrm{kg} \mathrm{bw})$. Los electrodos de estimulación los ubicamos en distintas coordenadas anteroposteriores y mediolaterales del núcleo accumbens, incluyendo core y shell. El protocolo de estimulación eléctrica consiste en aplicar trenes de impulsos eléctricos bifásicos (ver Cuadro 7.1) siguiendo la secuencia 3 OFF/3 ON/9 OFF durante un total de 300 segundos, repitiéndose entre tres y cinco veces por rata y condición. Nos referimos a los sujetos estimulados en la región del núcleo accumbens como sujetos Acc-1 (A1) a Acc-10 (A10).

\subsubsection{Análisis del sistema vestibular}

En el experimento utilizamos cinco ratas macho Lister-Hooded (250-300 g) que anestesiamos con uretano (1,2-1,4 g/kg bw); la zona intervenida se anestesia además con lidocaína. Los electrodos de estimulación los ubicamos en el nervio vestibular a través del conducto auditivo [139] (Figura 6.4, A). El protocolo de estimulación eléctrica consiste en aplicar trenes de impulsos eléctricos bifásicos $(0,1 \mathrm{~ms}, 333 \mathrm{~Hz})$ siguiendo la secuencia 2 OFF/3 ON/11 OFF durante un total de 320 segundos, repitiéndose entre tres y cinco veces por rata y condición. La correcta implantación del electrodo se demuestra por la presencia de movimientos vestíbulo-oculares 
Cuadro 7.1: Parámetros de las corrientes de estimulación utilizadas en el experimento del núcleo accumbens: intensidad (Int.), duración (Dur.) y frecuencia (Frec.).

\begin{tabular}{c|c|c|c}
\hline Sujeto & Int. (mA) & Dur. (ms) & Frec. $(\mathbf{H z})$ \\
\hline Acc-1 & 0,5 & 0,2 & 20,0 \\
\hline Acc-2 & 0,5 & 0,2 & 60,0 \\
\hline Acc-3 & 0,5 & 0,2 & 20,0 \\
\hline Acc-4 & 0,1 & 1,0 & 20,0 \\
\hline Acc-5 & 0,5 & 0,2 & 20,0 \\
\hline Acc-6 & 0,5 & 0,2 & 60,0 \\
\hline Acc-7 & 0,5 & 0,2 & 20,0 \\
\hline Acc-8 & 0,5 & 1,0 & 20,0 \\
\hline Acc-9 & 0,5 & 1,0 & 20,0 \\
\hline Acc-10 & 0,5 & 0,2 & 20,0 \\
\hline
\end{tabular}

durante la estimulación (Figura 6.4). Además, en un grupo de experimentos control, registramos simultáneamente la actividad electrofisiológica en la corteza auditiva primaria contralateral al estímulo. Dicha corteza se identificó por la presencia de potenciales evocados por estimulación sonora (ruido blanco). La ausencia de potenciales evocados en la corteza auditiva en respuesta a estimulación eléctrica del nervio vestibular, incluso cuando la intensidad de estimulación es hasta cinco veces la del umbral que provoca movimiento vestíbulo-ocular, demuestra que la estimulación experimental del nervio vestibular no está contaminada por la activación del nervio coclear. Es más, dado que la mayor parte del nervio facial motor discurre cerca del oído interno, monitorizamos con un etéreo-microscopio los movimientos de bigote y nariz del animal durante la estimulación vestibular. La ausencia de contracciones musculares por debajo de un umbral cinco veces superior al vestíbulo-ocular descartan la estimulación cruzada significativa entre el nervio vestibular y el facial [125].

\subsubsection{Estimulación con dos electrodos}

En el experimento utilizamos una rata Sprague-Dawley 250-300 g que anestesiamos con uretano (1,2-1,4 g/kg bw). Los electrodos de estimulación los ubicamos en el hipocampo, concretamente en el tracto perforante: uno en el hemisferio izquierdo y otro en el hemisferio derecho. El protocolo de estimulación eléctrica es diferente en cada uno de los electrodos. En el electrodo del hemisferio derecho aplicamos trenes trenes de impulsos eléctricos bifásicos $(0,1 \mathrm{~ms}, 333 \mathrm{~Hz})$ siguiendo la secuencia 2 ON/13 OFF durante un total de 300 segundos, repitiéndose entre tres y cinco veces por condición. En el electrodo del hemisferio izquierdo aplicamos una corriente eléctrica desfasada respecto a la del electrodo derecho (Cuadro 7.2). Cada desfase introducido conforma un experimento y en el primero de ellos (Doble-1 o D1) aplicamos únicamente una corriente eléctrica (la del hemisferio derecho). En éste caso, nos referimos a los distintos experimentos o desfases estimulados como Doble-2 a Doble-5.

\subsection{Parámetros IRMf}

Para los experimentos MRI, los animales anestesiados se colocan en un sistema de fijación compatible con RM que permite un posicionamiento preciso del animal respecto al imán. La temperatura, el ritmo cardíaco y las concentraciones de $\mathrm{CO}_{2}$ y $\mathrm{SpO}_{2}$ se monitorizan durante la adquisición. Las imágenes de resonancia magnética 
Cuadro 7.2: Desfases relativos entre las corrientes aplicadas como estímulos eléctricos en el experimento de estimulación con dos electrodos.

\begin{tabular}{c|c}
\hline Nombre & Desfase (s) \\
\hline D2 & 4 \\
\hline D3 & 8 \\
\hline D4 & 12 \\
\hline D5 & 16 \\
\hline
\end{tabular}
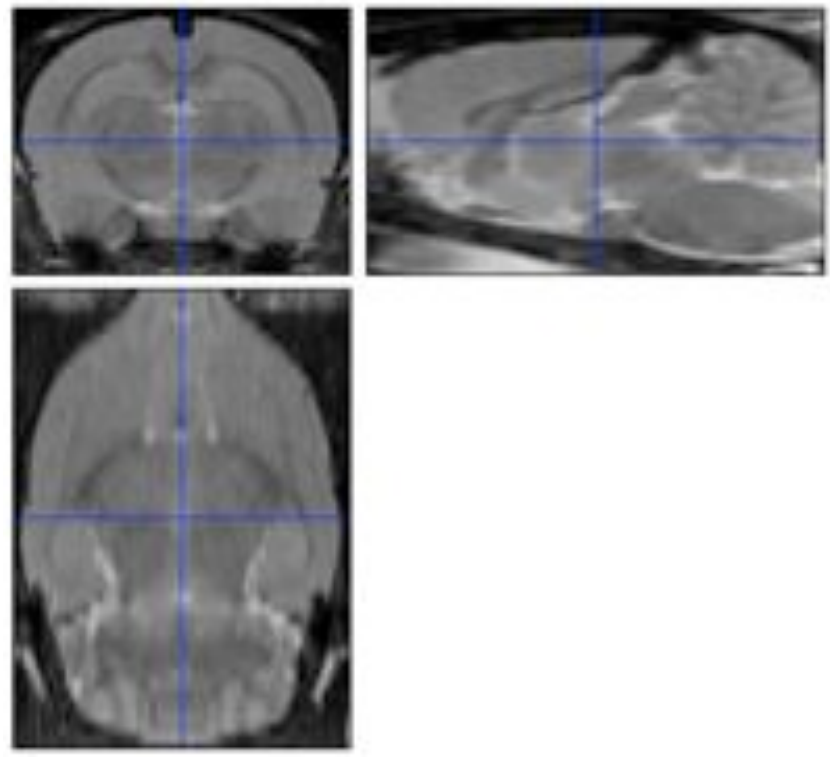

Figura 7.2: Plantilla $T 2$ para la normalización espacial sobre la que definimos el espacio anatómico de referencia de SPMrat [140].

funcional las obtenemos en un escáner de 7 T con un diámetro de núcleo de $30 \mathrm{~cm}$ (Biospec 70/30 v; Bruker Medical, Ettlingen, Alemania) para animales de experimentación (Figura 7.1, B). Se utiliza una bobina acoplada en fase, únicamente para recepción y con sonda $1 \mathrm{H}$, en combinación con un resonador desintonizado de solo transmisión (Bruker BioSpin MRI GmbH, Ettlingen, Alemania). Las imágenes anatómicas las obtenemos potenciadas en T2 con una secuencia RARE, mientras que las imágenes IRMf las obtenemos mediante GE-EPI con un tiempo de repetición o TR de dos segundos. El sistema de resonancia magnética lo controlamos mediante una consola Hewlett-Packard que ejecuta el software ParaVision (Bruker Medical, GmbH, Ettlingen, Alemania) en un entorno Linux.

\subsection{Análisis IRMfe}

Las imágenes las analizamos con un software de elaboración propia desarrollado en MATLAB (R2011a 64bit, Mathworks, Natwick, Massachusetts, EEUU) al que llamamos SPMrat. SPMrat utiliza algunas funciones del paquete de análisis de imágenes de resonancia magnética funcional SPM (SPM8, Wellcome Deparment of Cognitive Neurology, Londres, Reindo Unido; [62]) — en concreto aquellas que tienen que ver con el preprocesado 


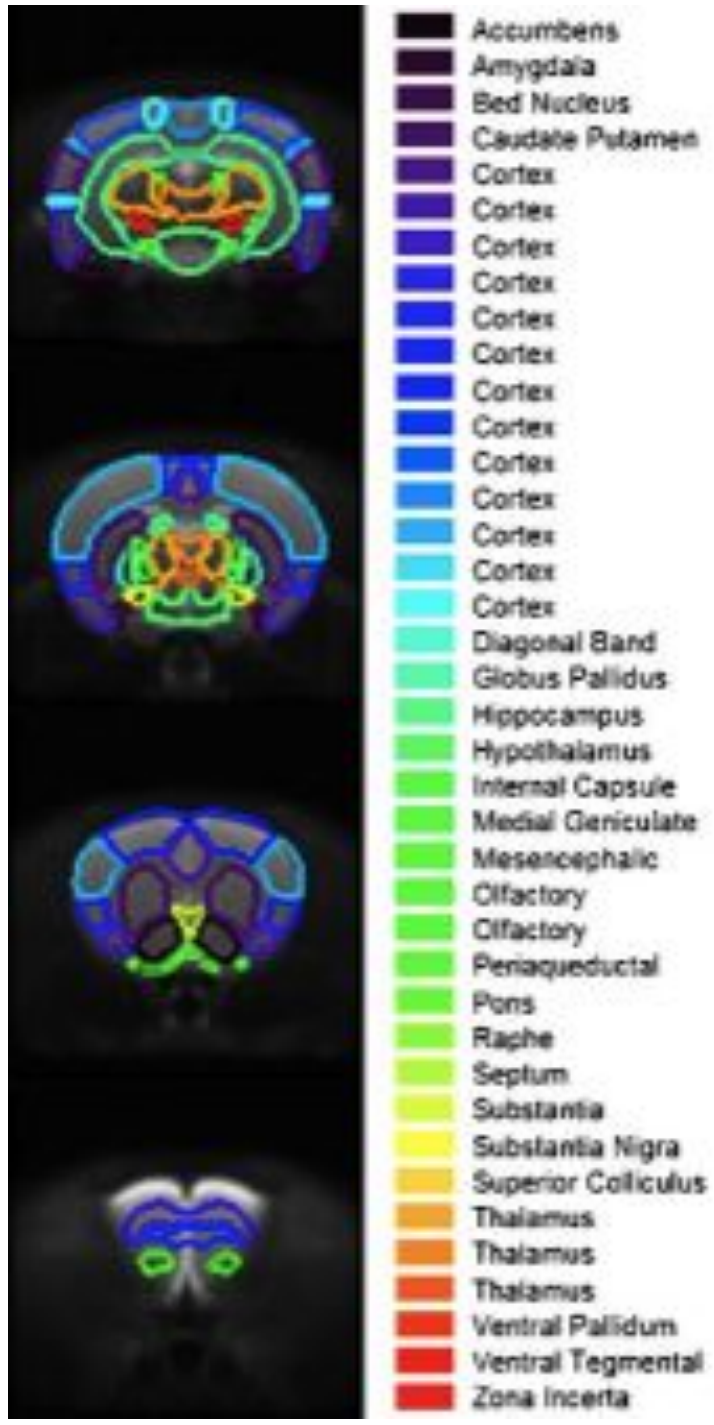

Figura 7.3: Atlas anatómico del cerebro de la rata [83] utilizado para el desarrollo de un atlas multifuncional/tridimensional de elaboración propia. Se muestran algunas de las 38 etiquetas que describen de forma relativamente completa la parte frontal del cerebro de la rata (que cubre desde el hipocampo hasta el borde posterior del bulbo olfatorio).

de imágenes y el análisis estadístico clásico mediante el modelo lineal generalizado, así como las llamadas al sistema para la extracción o segmentación de cerebros del entorno FSL (FSL/BET2, Oxford Centre for Functional Magnetic Resonance Imaging of the Brain, Londres, Reino Unido). Como complemento clave del software y parte esencial de la mayoría de nuestros análisis, SPMrat incorpora un atlas multifuncional del cerebro de rata construido específicamente para nuestros datos. Dicho atlas lo creamos sustituyendo el espacio anatómico original de referencia del atlas Paxinos-Watson descrito en Schwarz et al. [83] (Figura 7.3) por el espacio anatómico de referencia para la normalización espacial que asumimos como propio-y que es una versión segmentada de la plantilla T2 de la Figura 7.2 [140]. Finalmente, los mapas estadísticos paramétricos los visualizamos con SPM8 (para visualizaciones en 2D) y/o FSLview [141] (para visualizaciones tridimensionales). 


\subsubsection{Preprocesado}

El preprocesado de imágenes (Capítulo 4) lo realizamos íntegramente con cuatro funciones del software SPM8 como son las de realineado, co-registro, normalización y suavizado. No obstante, para utilizar éstas y otras funciones es necesario modificar algunos de los parámetros de la configuración software-fundamentalmente para asegurarnos que el tamaño de vóxel de las imágenes de cerebros de rata es equivalente al que SPM8 asume por defecto. Una vez realizados los cambios pertinentes, SPM8 puede utilizarse con normalidad para los datos IRMfe presentados en el Capítulo 7. La metodología de preprocesamiento que presentamos a continuación la aplicamos por separado para cada uno de los animales que analizamos. El punto clave de la metodología es la normalización de todas las imágenes experimentales a una plantilla o referencia anatómica para la normalización espacial. Como acabamos de mencionar, nuestra plantilla para la normalización espacial la obtenemos tras segmentar mediante BET2 la imagen/plantilla T2 para la normalización espacial disponible en [140] (Figura 7.2). La normalización de las imágenes a un espacio común permite las comparaciones entre sujetos, las inferencias de segundo nivel o la extracción de parámetros regionales en base a un atlas sintetizado específicamente para la plantilla según el Capítulo 8. Cabe destacar que la plantilla anatómica que asumimos como referencia se utiliza como base para generar familias de plantillas de normalización que cubren varios tamaños de FOV (para abastecer la variabilidad que pueda haber al respecto en la adquisición de IRMf), tanto para una orientación horizontal (que es la orientación original de la plantilla) como para su equivalente coronal. El atlas multifuncional sintetizado es válido para cualquiera de las plantillas de las familias generadas.

Para el realineado, utilizamos como imagen referencia una versión suavizada (FWHM $=5 \mathrm{~mm}$ ) de la media de las imágenes funcionales, mientras que para las operaciones de interpolación (tanto para la estima como para la escritura) optamos por un esquema 4-spline. Para el corregistro, utilizamos la media de las imágenes funcionales realineadas como imagen origen y la imagen anatómica experimental del sujeto como referencia. Para la normalización espacial, utilizamos un registro no-rígido que utiliza como referencia la versión segmentada de la plantilla para la normalización espacial y como imagen que se deforma para mapearse a la referencia utilizamos una versión sementada (también mediante BET2) de la imagen experimental anatómica T2 del sujeto. Otros ajustes del módulo SPM8 para la normalización espacial son: 1) suavizado de la plantilla y la imagen origen: FWHM $=4 \mathrm{~mm}, 2$ ) frecuencia de corte de las bases DCT: $25 \mathrm{~s}$, rectángulo de selección de valores indeterminados o NaNs y 3) funciones de interpolación spline de cuarto grado (tanto para la estima como para la escritura). Finalmente, como parte del preprocesado, incluimos un módulo que es capaz de generar una imagen NIfTI-1 (corregistrada al espacio normalizado) representación del electrodo de estimulación. Para ello, se requiere que el usuario defina las coordenadas estereotácticas del electrodo (si es que existe). Hecho esto, generamos una imagen binaria (en representación del electrodo en el espacio original) a la que aplicamos los parámetros de la deformación no lineal que ubica el electrodo en el mismo espacio normalizado que el resto de las imágenes IRMf. Después del suavizado (filtro isotrópico gaussiano de dos vóxeles de radio) los datos están listos para la inferencia estadística.

\subsubsection{Inferencia estadística clásica de primer nivel}

Para el análisis estadístico de los datos utilizamos el módulo SPM8/GLM para la especificación, estima y visualización del modelo (Capítulo 5). En cuanto al modelo lineal-invariante para la síntesis del paradigma eléctrico, asumimos como regresores la HRF canónica así como sus derivadas temporal y espacial, por lo que las matrices de diseño incluyen (para cada electrodo y repetición del experimento IRMfe en la sesión) tres columnas correspondientes a los regresores canónico y derivados; ocasionalmente, las matrices de diseño se ampliarán con los parámetros de movimiento del realineado - en concreto, cuando la correlación entre el paradigma y alguno de los tres parámetros de traslación es superior a 0,35 (haciendo válido también para la ocasión el criterio ya utilizado por Biswal et al. [108]). Los parámetros de movimiento también los utilizamos para descartar aquellas repeticiones IRMf en los que uno o más volúmenes deberían desplazarse más allá de la mitad del tamaño de vóxel. En relación a los parámetros temporales, los instantes temporales de muestreo se ajustan para que la primera muestra coincida con el primer corte de la adquisición y la frecuencia de corte del filtro paso-alto que elimina el ruido 
electrónico se establece al doble de la frecuencia del paradigma temporal (o SOA). Finalmente, activamos la normalización global de la intensidad de las imágenes. Después de la estimación de los parámetros, utilizamos las matrices de contraste que infieren como verdaderos positivos aquellos vóxels en los que la HRF o sus derivadas espacio-temporales está presente-por lo tanto, derivándose un F-test [17, pp. 126-39: Contrasts and Classical Inference]. Cuando aplicamos dos corrientes eléctricas, las matrices de contraste se configuran para la búsqueda de la estimulación de referencia (sin el desfase temporal) aunque obviamente las dos corrientes eléctricas (esto es, incluyendo la que se desfasa) se incluyen en la matriz de diseño. Para las correcciones múltiples que determinan los supra-vóxeles de cierta prueba estadística, además de aquellas incluidas por defecto en SPM8 (a saber: uncorrected o FWE/RFT) en SPMrat implementamos el método de Montecarlo para la inferencia según la corrección alphasim. 


\section{Parte III}

\section{Métodos}





\section{Capítulo 8}

\section{Síntesis de atlas tridimensionales para el estudio de la conectividad en cerebros de rata}

\section{Introducción}

Los atlas anatómicos son herramientas indispensables para el estudio de la conectividad (ya sea anatómica, funcional o efectiva). En el caso del cerebro humano, el atlas de Talairach y Tournoux [142] representa una referencia descriptiva ineludible a cualquiera de los tres niveles. Cuando se trata del estudio de la conectividad funcional, los atlas permiten la cuantificación región-a-región de magnitudes que pueden asociarse a la interconexión neuronal, como por ejemplo la correlación cruzada regional de señales BOLD-IRMf medias calculadas por regiones o semillas CCA. El cerebro de rata fue estudiado y publicado por primera vez como atlas anatómico por Paxinos y Watson [136]. Desde entonces, el atlas-Paxinos es la referencia de facto en el cerebro de rata como lo es el atlasTalairach para el cerebro humano. En éste capítulo mostramos una metodología genérica que permite mapear un atlas-Paxinos 2D digitalizado, bien conocido y validado [83] (al que llamamos atlas-Schwarz) a cierta plantilla o espacio anatómico deseado dado. El procedimiento de construcción del atlas consiste fundamentalmente en una normalización no rígida que mapea una a una cada región del atlas-Schwartz de su espacio anatómico original al determinado por el nuevo espacio anatómico que se elija como referencia espacial. Los atlas generados con la metodología que aquí presentamos son una herramienta de propósito general—por ejemplo, son clave para para analizar la conectividad funcional en experimentos IRMfe, pero también pueden utilizarse para localizar máximos de significancia estadística dado cierto mapa analítico e incluso pueden ser válidos para otras modalidades de imagen como puedan ser la de MRI potenciadas en manganeso o MEMRI [143, 144].

\subsection{Análisis regional del cerebro de rata}

Como hemos dicho en la introducción, el atlas-Paxinos marca la referencia en los estudios regionales del cerebro de rata. En su trabajo, Paxinos y Watson describen el cerebro de rata mediante cientos de cortes coronales, sagitales y axiales donde las distintas regiones cerebrales quedan identificadas por etiquetas únicas que se ubican en un sistema coordenado estereotáctico. Además de la versión de A. Schwarz, existen otras versiones digitalizadas del atlas-Paxinos como las que se presentan en Cai et al. [145] o Valdés-Hernández [146] (que intentan mejorar el corregistro del atlas-Schwarz mediante técnicas de análisis de componentes principales). En lo que se refiere a la métodología que aquí presentamos, asumimos el atlas-Schwarz como modelo regional para el estudio de la conectividad en el cerebro de rata. 

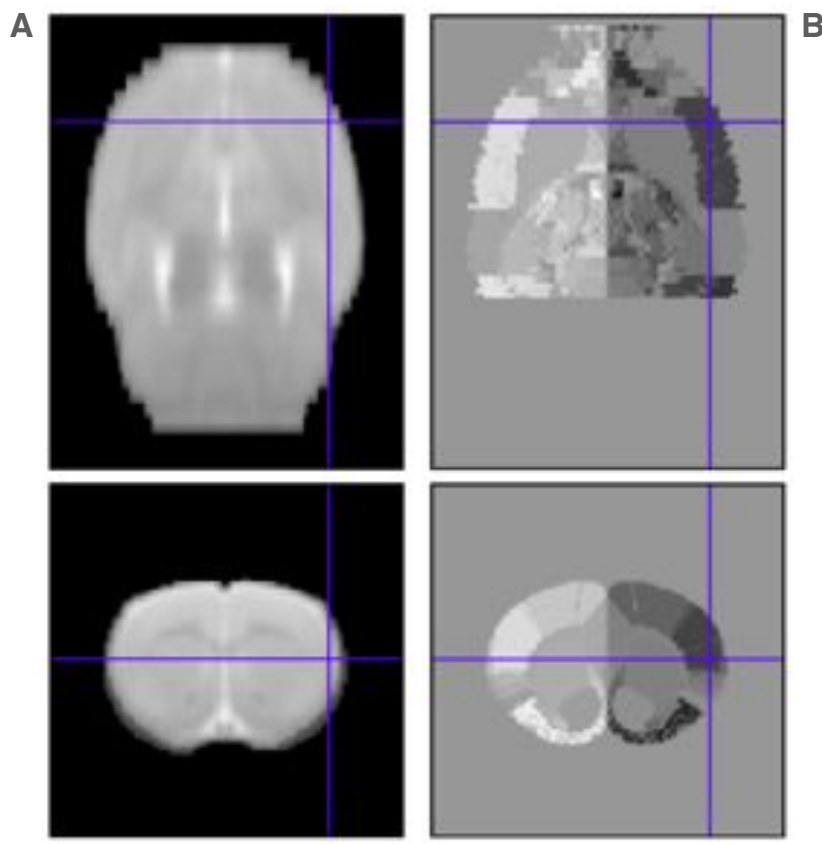

Figura 8.1: Atlas-Schwarz [83]. A: cortes horizontal y coronal del espacio anatómico T2 incluido como una de las referencias del marco de trabajo asociado al atlas original. B: cortes horizontal y coronal del atlas anatómico compuesto por 492 etiquetas identificadas unívocamente por diferentes valores de gris.

\subsubsection{Registro del atlas y las imágenes experimentales}

Para poder llevar a cabo cualquier análisis regional mediante cualquier tipo de atlas anatómico es indispensable registrar las imágenes experimentales en el mismo espacio anatómico en el que el atlas esté definido. El registro de las imágenes experimentales y el atlas como volúmenes tridimensionales no es una tarea sencilla. Por ejemplo, en Hjornevik et al. [147] las imágenes experimentales se corregistran en base a puntos de referencia reconocibles del cerebro y/o cráneo, por lo que la calidad del registro (y por tanto, del análisis regional) reside fundamentalmente en la habilidad de encontrar buenos puntos de referencia. Aunque la utilidad de los análisis regionales que utilicen un corregistro manual no se pone en duda [148] la tendencia actual es la de realizar un corregistro automático mediante algún software específico (por ejemplo, mediante SPM8) de las imágenes experimentales y el espacio anatómico de referencia. Una solución intermedia (y que inspira en parte nuestro método) es la que se presenta en [149], donde se utiliza SPM99 (una versión anterior de SPM8) para realizar una normalización de las imágenes tomando como referencias o imágenes objetivo ciertas correspondencias entre puntos anatómicos medidos en varias imágenes T2. Un enfoque más sencillo (pero también soportado por un registro automático de imágenes) es el que presentan Lu et al. [150], donde simplemente se hace una traslación o transformación rígida asumiendo que el tamaño y la forma del cráneo de rata es excepcionalmente heterogéneo.

\subsubsection{El atlas-Schwarz}

Según lo indicado, nuestra metodología para la construcción de atlas tridimensionales de propósito general asume como válido el proceso de digitalización del atlas-Paxinos llevado a cabo por Schwartz y sus colaboradores. De todos los ficheros disponibles en el entorno de trabajo relacionado con dicho modelo de atlas, utilizamos únicamente los siguientes tres ficheros: 1) el espacio o modelo anatómico T2 del atlas (Figura 8.1, A), 2) el atlas propiamente dicho (Figura 8.1, B) y 3) un fichero en representación de las estructuras cerebrales que componen el 
atlas y que identifica unívocamente las 492 regiones cerebrales en base a otras tantas etiquetas. Finalmente, cabe destacar que todas las imágenes del marco de trabajo del atlas-Schwarz corresponden a una orientación coronal.

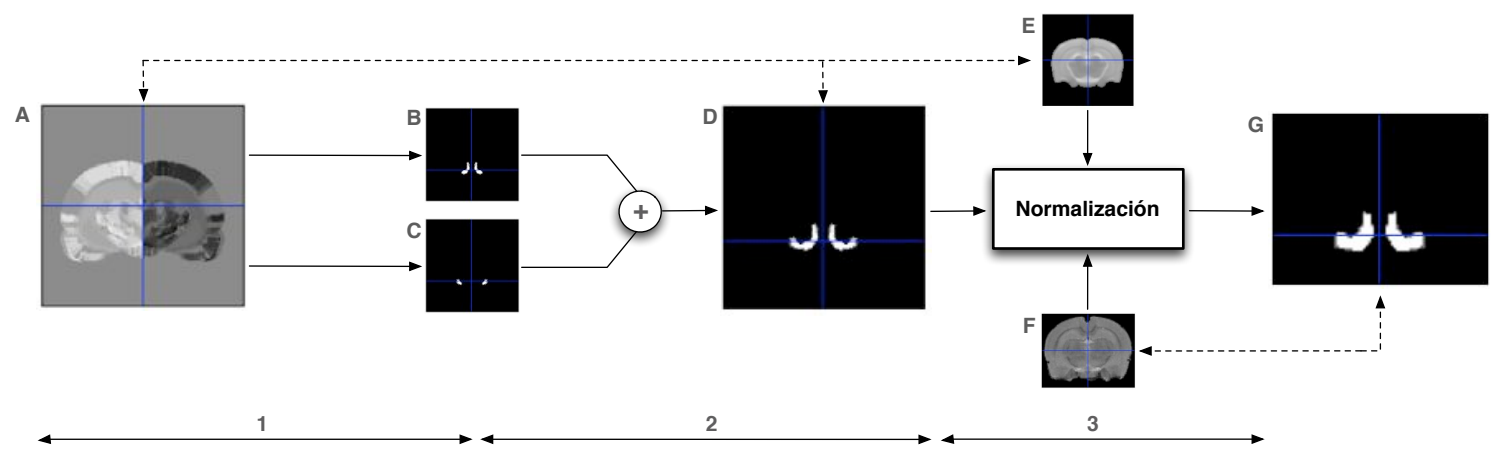

Figura 8.2: Síntesis de la región cerebral AcbSh (accumbens nucleus shell). Después de tres operaciones podemos trasladar las regiones/etiquetas $\mathbf{B}$ y $\mathbf{C}$ de su espacio anatómico original $(\mathbf{E})$ a la referencia anatómica deseada $\mathbf{F}$ (que deberá coincidir con el espacio anatomico para la normalización espacial asumido como propio). El procedimiento descrito para la etiqueta AcbSh se repite para todas y cada una de las 492 regiones/etiquetas del atlas-Schwarz (sujetos al paso 2 de agrupación). Las líneas discontinuas unen imágenes registradas entre sí.

\subsection{Síntesis de atlas de propósito general}

El procedimiento para sintetizar un nuevo atlas tridimensional del cerebro de rata consiste en una normalización que reescribe todas y cada una de las regiones del atlas-Schwartz de su espacio anatómico original al nuevo espacio anatómico o referencia anatómica deseada. Los parámetros de deformación de la normalización son fijos y vienen determinados por la minimización del error al comparar las imágenes del espacio anatómico original (Figura 8.1, A) y la del espacio anatómico deseado (como por ejemplo el que mostramos en la Figura 7.2). Adicionalmente, el procedimiento de síntesis requiere de algunas operaciones básicas en la manipulación de imágenes como sumas y binarizaciones [151] o de tipo morfológico. Un punto crítico para que la metodología de síntesis funcione es que el espacio anatómico original y el de la referencia anatómica deseada deben ser congruentes en cuanto a la modalidad de imagen, la orientación y el origen de la cabecera NIfTI ${ }^{1}$ (por ejemplo, ambas referencias anatómicas deben estar potenciadas en T2, coronales y centradas en el origen espacial). Este hecho no debe suponer ningún problema a priori, dado que el atlas-Schwartz ofrece varias referencias espaciales con diferentes modalidades de imagen además de la que hemos asumido. Otro punto muy relevante en nuestro desarrollo es la agrupación de etiquetas que pueden considerarse subdivisiones de otras regiones mayores; en base a nuestro criterio de agrupación de regiones, nuestro atlas sintetizado contiene 149 regiones etiquetadas en vez de las 492 del atlas original.

La Figura 8.2 muestra un ejemplo de normalización que permite trasladar la región cerebral AcbSh (accumbens nucleus shell) de la referencia anatómica original del atlas-Schwartz a un nuevo espacio anatómico. En el primer paso del procedimiento (1) utilizamos el módulo Imcalc de SPM8 para extraer cada región del atlas original por separado y construir una imagen NIfTI-1 por cada una de ellas (B y C). El segundo paso (2) corresponde a la agrupación de etiquetas recién mencionada-por ejemplo, las regiones/etiquetas originales LAcbSh (lateral accumbens shell) y AcbSh (accumbens shell nucleus) se suman para formar una única etiqueta y/o región. En el paso tres (3) cada etiqueta agrupada (si es el caso) es sometida a un proceso de normalización no-rígida en el que la imagen referencia es aquella que representa al espacio anatómico deseado (F) y la imagen que se deforma o source es la imagen anatómica original a la que va asociado el atlas-Schwarz (E). Finalmente, en aquellos casos

\footnotetext{
${ }^{1}$ NIfTI (neuroimaging informatics technology initiative; http://nifti.nimh.nih.gov/) es un formato de imagen médica utilizado comúnmente como soporte IRMf [152].
} 
en los que detectamos que la normalización con re-escritura del paso tres degrada la apariencia de la imagen como etiqueta, llevamos a cabo una binarización por Otsu y una apertura morfológica (con un elemento estructurante circular con $r=5$ ) para restaurarlas.

\subsection{Demostraciones prácticas}

Como comentamos al principio, los atlas que aquí derivamos podrían ser calificados como multifuncionales (en el sentido que permiten el análisis regional de varias modalidades de imagen). Por ejemplo, Moya et al. [153] utilizan la metodología aquí presentada para generar un atlas que se aplica en el estudio de la conectividad funcional en IRMfe a través de unas matrices que representan las conexiones funcionales entre regiones cerebrales moduladas por una corriente eléctrica. Otra aplicación de un atlas sintetizado según la metodología aquí presentada es la del estudio de la conectividad funcional en MEMRI [154].

\section{Resumen}

Según el procedimiento mostrado esquemáticamente en la Figura 8.2, hemos desarrollado una metodología por la cual somos capaces de sintetizar atlas anatómicos de propósito general que se pueden mapear a casi cualquier espacio anatómico deseado o plantilla anatómica para la normalización. Dado que nuestra metodología se basa fundamentalmente en una normalización no-rígida (en lugar de rotaciones y traslaciones), los atlas que conseguimos sintetizar guardan una correspondencia óptima entre las regiones cerebrales sintetizadas y algunos puntos de referencia que testeamos durante el desarrollo del método. Además son de propósito general dado que sirven para estudiar la conectividad en varias modalidades de imagen. 


\section{Capítulo 9}

\section{Huellas de conectividad y análisis de grupos}

\section{Introducción}

En el Capítulo 6 hemos presentado el análisis PCA/SVD como alternativa a los análisis de la conectividad funcional CCA [113] basados en el análisis de la correlación cruzada entre regiones y semillas. Los estudios CCA los considerábamos limitados por dos razones: en primer lugar, los patrones de conectividad funcional dependerán de la semilla; en segundo lugar, la selección manual y discreta de la semilla puede llevar a ignorar regiones clave en el funcionamiento del cerebro. Un enfoque diferente y muy práctico de los análisis clásicos CCA basados en semilla [133] es el que aquí presentamos a través de lo que llamamos huellas de conectividad-unas estructuras de datos que representan las correlaciones cruzadas entre todas las regiones activas (asociadas a cierto mapa estadístico paramétrico) identificadas automáticamente como semillas según cierto atlas anatómico del cerebro de rata (por ejemplo, uno que se haya sintetizado según la metodología presentada con anterioridad) [153]. Por lo tanto, las huellas de conectividad serán aquellas matrices cuadradas que representan las conexiones funcionales que se establecen entre cualesquiera de las regiones activas o moduladas por la estimulación eléctrica aplicada a cierto sujeto. Las huellas de conectividad representan uno de los pilares de la presente Tesis Doctoral: dado que revelan in vivo y dinámicamente el sustrato anatómico de un conjunto específico de conexiones funcionales junto con sus pesos (correlaciones o conectividad funcional) y que un mismo paradigma de estimulación eléctrica aplicado sobre un mismo núcleo cerebral debe producir respuestas funcionales similares (que no idénticas, pues obviamente las respuestas funcionales están sujetas a la variabilidad inherente que muestre cada sujeto), podemos considerar que las huellas de conectividad representan unívocamente a los distitntos sistemas cerebrales que estimulamos y por tanto pueden utilizarse para generar agrupaciones de sujetos con una respuesta al estímulo similar. Éste hecho sugiere la utilización de algún algoritmo de clasificación/clustering tras el cual puedan realizarse mapas estadísticos paramétricos en representación de la respuesta media del grupo (o de segundo nivel).

\subsection{Huellas de conectividad}

En el ejemplo de uso de la correlación como medida de conectividad funcional del Capítulo 6, obteníamos las señales BOLD-IRMf medias para tres regiones-semilla (AcbC, AcbSh y VTA) para cierto mapa estadístico paramétrico (en concreto, del sujeto Acc-1 para una corrección alphasim y un umbral p =0,05, Figura 6.1-C). Los coeficientes de correlación de las señales BOLD-IRMf medias entre dichas regiones nos revelaban que las regiones AcbC y AcbSh (accumbens nucleus core y shell respectivamente) sí estaban conectadas funcionalmente (correlación: 0,95) mientras que la región VTA (ventral tegmental area) no mostraba una conexión funcional sig- 
nificativa ni con AcbC (correlación: 0,18) ni con AcbSh (correlación: 0,16)—pese a que dicha conexión anatómica es de sobras conocida y de vital importancia. Imaginemos que llevamos al extremo el procedimiento anterior y calculamos las correlaciones cruzadas o conectividad funcional entre todas las regiones activas que identifiquemos en el mapa funcional que nos ocupa; entonces estamos obteniendo la huella de conectividad del sujeto en representación del patrón de modulación sináptica (o de conexiones funcionales) inducidas tras la estimulación (Figura 9.1). En los últimos años han aparecido multitud de representaciones de la correlación regional cerebral de todo el cerebro $[5,155]$ de las que se espera poder sacar un gran rendimiento en el estudio de la conectividad funcional [6] (por ejemplo, a través del clasificador de la actividad funcional que aquí presentamos). Una representación matricial similar a la presentada en las huellas de conectividad es la que encontramos en el trabajo de Pawela et al. [156] — no obstante, con tres marcadas diferencias: 1) las matrices de conectividad se calculan para experimentos en reposo y no para estimulación evocada, 2) las señales temporales de las regiones se extraen mediante PCA y no mediante la señal BOLD-IRMf media y 3) la identificación de las regiones o semillas se realiza de forma manual y no mediante un reconocimiento automático sustentado en la síntesis de un atlas anatómico diseñado específicamente para la referencia anatómica del sujeto bajo análisis (que como ya hemos dicho, presentamos en el Capítulo 8). El proceso de construcción de las huellas de conectividad lo resumimos en cuatro pasos:

1. Calculamos la intersección entre el mapa estadístico paramétrico de interés y cada una de las regiones cerebrales incluidas en cierto atlas tridimensional del cerebro de rata (asociado a la referencia anatómica que tenga el sujeto).

2. Si el área activa ocupa más de un $5 \%$ del área de la región cerebral, entonces la región pasa a formar parte de la huella de conectividad.

3. Para todas las regiones extraídas según los pasos 1 y 2, calculamos la señal BOLD-IRMf media de todos sus vóxeles.

4. Calculamos las correlaciones cruzadas entre todas las señales BOLD medias entre los pares regionales combinados.

El criterio de inclusión del $5 \%$ se introdujo tras comprobar que era el adecuado para eliminar de la huella de conectividad a aquellas regiones cuyas señales hemodinámicas medias se correlaban con el resto por debajo del umbral de correlación definido en [108]. Finalmente, cabe destacar que, aunque las huellas de conectividad pueden calcularse para cualquier corrección estadística, establecemos la corrección alphasim como la corrección por defecto para el cálculo de las huellas dada su capacidad intrínseca de representar la morfología del mapa estadístico paramétrico correspondiente.

\subsection{Análisis de grupos}

Como decíamos en la introducción y a la vista de la huella de conectividad de la Figura 9.1, dado que la conectividad anatómica es muy similar entre individuos y que unas mismas condiciones experimentales (en el ámbito de la microestimulación eléctrica-incluyendo la posición del electrodo) deben producir unas respuestas funcionales similares entre distintos sujetos (y por tanto, unos mapas estadísticos paramétricos y huellas de conectividad características), podemos decir que, pese a la presencia indeseada de ciertas contribuciones ruidosas (como la que produce el latido cardíaco) y la variabilidad inherente a la respuesta funcional de cada sujeto, las huellas de conectividad son a la conectividad funcional lo que las huellas dactilares a la biometría: una herramienta apropiada para el reconocimiento de sistemas cerebrales funcionalmente activos. De este modo, después de obtener las respuestas funcionales de tres o más sujetos individuales (la clasificación $k$-means de dos muestras es siempre la trivial [131, p. 614: Unsupervised learning and clustering]—en este caso, dos grupos de un sujeto cada uno), nuestro objetivo es el de utilizar sus correspondientes huellas de conectividad para tratar de identificar patrones de modulación sináptica comunes entre ellos para permitir su ordenación en grupos funcionales de sujetos. Una 


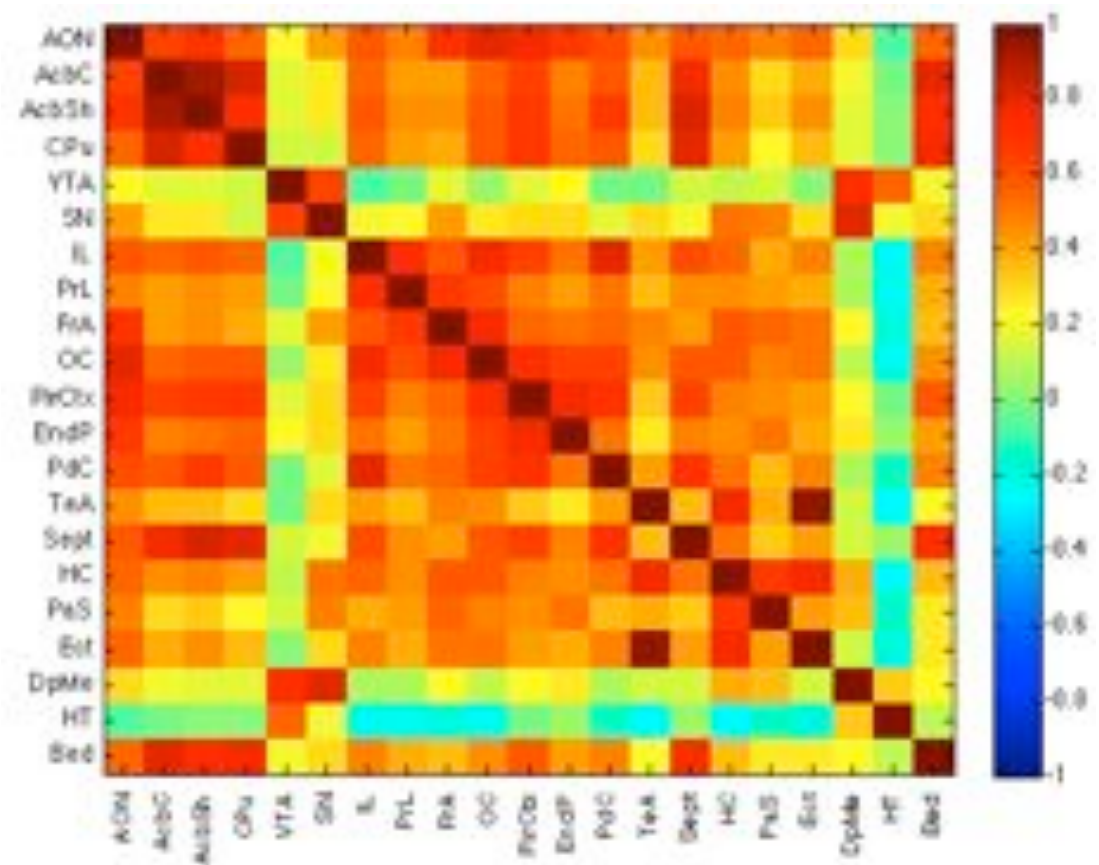

Figura 9.1: Huella de conectividad asociada al mapa estadístico paramétrico del sujeto Acc-1 (alpha., 0,05). Las regiones cerebrales etiquetadas se extraen de un atlas sintetizado específicamente para la referencia anatómica del sujeto. En la huella de conectividad observamos que las regiones del núcleo accumbens (AcbC y AcbSh, accumbens nucleus core y shell respectivamente) presentan un gran peso de conectividad, dado que la correlación entre sus series de tiempo BOLD-IRMf está cercana al 0,95 (rojo oscuro). En cambio, la relación de conectividad entre el núcleo accumbens y VTA (ventral tegmental area) existe pero su peso es mucho menor y corresponde a tonos verdes claros.

vez organizados en grupos, seremos capaces de obtener mapas estadísticos paramétricos en representación de la actividad media de los sujetos a través de las inferencias de segundo nivel o GLM/FFX. Con dicho propósito diseñamos un clasificador en base a las huellas de conectividad, PCA y $k$-means.

\subsubsection{Clasificador de la actividad funcional}

La definición de grupos no es una tarea sencilla. En el contexto de IRMf con estimulación eléctrica es habitual agrupar los sujetos tomando como único criterio para la agrupación las coordenadas estereotácticas de los electrodos de estimulación. No obstante dicha hipótesis puede ser demasiado liviana dado que la implantación quirúrgica de los electrodos está sujeta al error experimental al que además hay que sumar la variabilidad biológica interindividual. En esta sección presentamos un clasificador de la actividad funcional que nos permite generar grupos de sujetos teniendo en cuenta tanto las coordenadas estereotácticas normalizadas de los electrodos implantados en los sujetos, así como los patrones de modulación sináptica después de la estimulación individual de cada sujeto a través de sus huellas de conectividad.

Como podemos ver en el diagrama de flujo de la Figura 9.2 (a la cual nos referimos mediante letras en negrita en este párrafo), el módulo clasificador (B) recibe como entrada cierto número de huellas de conectividad (A) y las clasifica según la similitud de los patrones subyacentes CCA embebidos en las huellas de conectividad de los sujetos, generando grupos funcionales de sujetos (C). El algoritmo de clasificación utilizado para esta tarea es $k$-means (Capítulo 6) y la matriz de características (o clasificación) es aquella para la que el número de filas u observaciones coincide con el número de sujetos a clasificar y el número de columnas depende del procedimiento que describimos a continuación. En primer lugar procedemos a determinar ciertas regiones de interés a partir de 


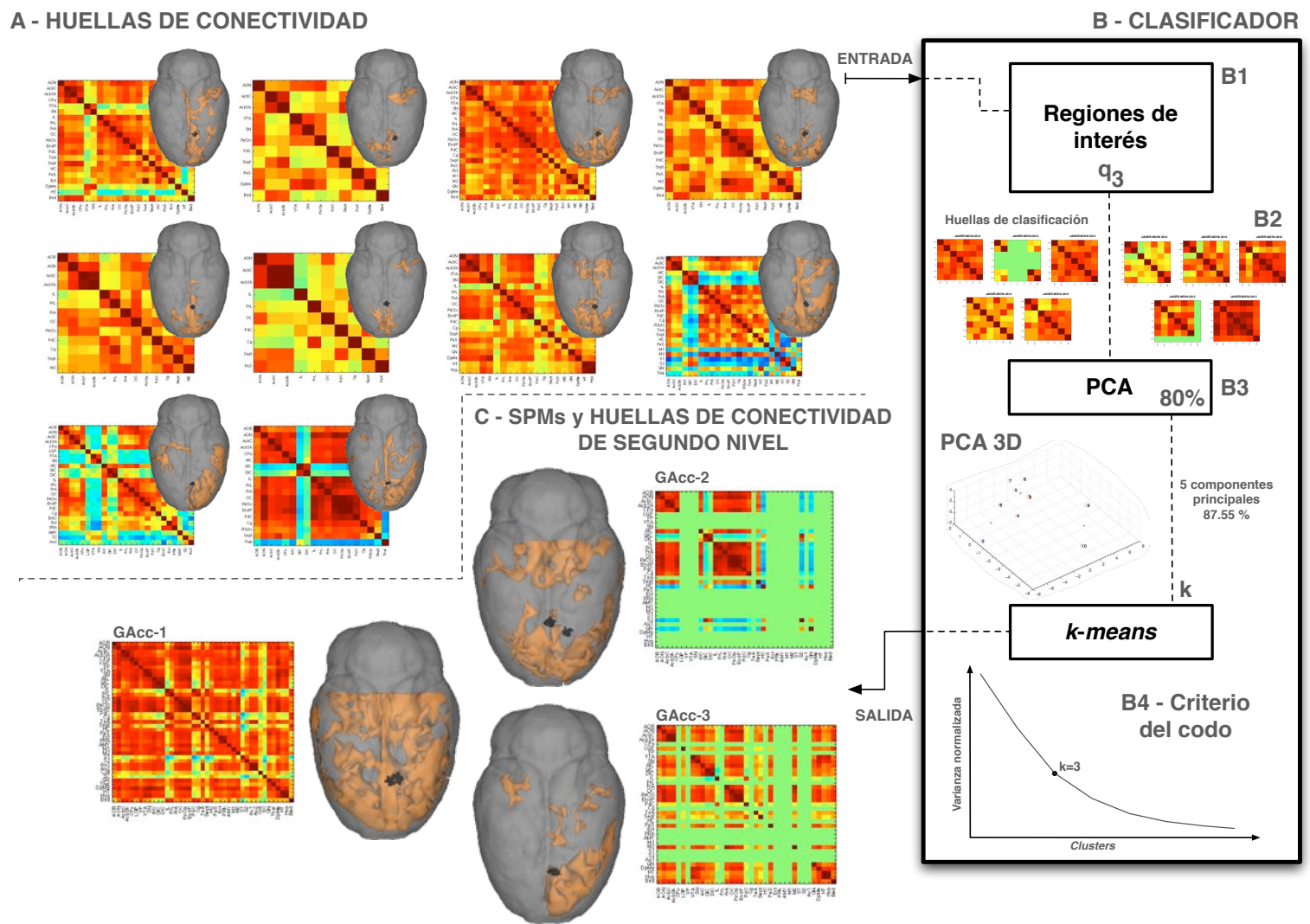

Figura 9.2: Clasificador de la actividad funcional para el análisis de grupos. El clasificador (B) recibe a su entrada huellas de conectividad (A) de sujetos individuales y entrega a su salida un listado de grupos de sujetos que permite obtener mapas estadísticos paramétricos de grupo (o segundo nivel) así como las correspondientes huellas de conectividad (C) en representación de la actividad neuronal subyacente de dichos grupos. En PCA 3D mostramos una representación tridimensional del hiperespacio de clasificación que forman las huellas de clasificación.

la selección de características que realizamos en dos pasos (B1):

1. De cada huella de conectividad de cada sujeto seleccionamos las diez mejores relaciones de correlación cruzada regional.

2. De todos los pares de regiones seleccionados en el paso anterior, establecemos como regiones de interés a aquellas cuyo porcentaje de área activa esté por encima del tercer cuartil $\left(\mathbf{q}_{3}\right)$.

Nuestro procedimiento de selección que establece las regiones de interés se diseña para evitar el fenómeno de Hughes (más comúnmente conocido como la maldición de la dimensionalidad), por lo que nos permite ajustar la dimensionalidad del espacio de clasificación de forma acorde al número de muestras (o sujetos, en nuestro caso) a clasificar [157]. Una vez hemos determinado las regiones de interés (que son una versión hipodimensional de las huellas de conectividad), añadimos las coordenadas de los electrodos (una columna por cada coordenada cartesiana) y obtenemos lo que llamamos huellas de clasificación (B2). Después concatenamos apropiadamente las distintas huellas de clasificación, aplicamos una reducción PCA y seleccionamos como entrada al clasificador las componentes principales que acumulan como mínimo el $80 \%$ de la varianza del espacio de las huellas de clasificación (B3). Antes de proceder a la clasificación, necesitamos establecer el número de grupos o clusters $k$ (un parámetro indispensable para el funcionamiento del algoritmo de clasificación seleccionado) y que establecemos a partir del criterio del codo [158] — que establece como número óptimo de grupos aquel entero en el 
que se detecta el mayor salto de porcentaje de varianza intragrupo (B4). Una vez el clasificador haya generado las agrupaciones, el siguiente paso del análisis de los mapas estadísticos paramétricos de segundo nivel (y las correspondientes huellas de conectividad) en representación de la actividad funcional o respuesta media de los grupos.

\subsubsection{Respuesta media de los grupos: análisis clásico de segundo nivel}

Como ya se mencionó en su momento, las inferencias estadísticas que involucran a más de un sujeto suelen llevarse a cabo mediante un análisis de efectos fijos o FFX, una variante del análisis clásico de segundo nivel que permite obtener la respuesta funcional media de un grupo de sujetos. Es por ello que consideramos el análisis de segundo nivel GLM/FFX casi como una parte más del clasificador de la actividad neuronal, dado que es el mecanismo por el cual vamos a poder visualizar las respuestas funcionales medias que el propio clasificador haya determinado. Finalmente, cabe comentar que del mismo modo que hemos generado huellas de conectividad para sujetos individuales, podemos hacer lo propio para mapas estadísticos paramétricos de segundo nivel para representar las relaciones de conectividad funcional establecidas en la media poblacional (Figura 9.2, C).

\section{Resumen}

En el presente capítulo hemos presentado unas estructuras de datos (a las que llamamos huellas de conectividad) que permiten representar de una forma compacta la conectividad funcional entre todas las regiones activas (asociadas a cierta prueba estadística del diseño experimental) identificadas automáticamente a partir de un atlas normalizado a cierta referencia anatómica común y un análisis CCA iterativo. Después de algunas modificaciones para la reducción de su dimensionalidad, utilizamos las huellas de conectividad para clasificar sujetos individuales en clusters o grupos de sujetos—en virtud de la homogeneidad de sus patrones de modulación sináptica. Como demostraremos más adelante, los grupos generados con el clasificador de la actividad funcional revelan una asociación precisa y robusta de la localización de los electrodos de estimulación con las respuestas funcionales de segundo nivel. Este hecho podría resultar de máxima relevancia en aquellos casos en los que las huellas de conectividad representen la actividad funcional de sujetos con algún trastorno neurológico, ya que en dicho caso la relación llave/cerradura entre las localizaciones de la estimulación eléctrica y las huellas de conectividad podrían ayudar a la consolidación de las bases neurfisiológicas de la estimulación cerebral profunda (Capítulo 15-Principios funcionales de la ECP). 


\section{Capítulo 10}

\section{Sistemas funcionales}

\section{Introducción}

Como sabemos, la descomposición SVD/PCA se ha utilizado recurrentemente en el análisis de la conectividad funcional IRMf $[159,160]$. En este capítulo presentamos una nueva metodología para la cuantificación de la conectividad funcional basada en el análisis de los sistemas macroscópicos o patrones de covarianza identificados en las eigenimages y en técnicas de clasificación no supervisada [161]. En primer lugar, construimos un espacio multidimensional (conocido como espacio funcional) en el que la distancia euclidiana entre las representaciones de las series de tiempo de los supra-vóxels tiene connotaciones directas de conectividad funcional. Dado que la conectividad entre puntos o vóxels en el espacio funcional es inversamente proporcional a la distancia entre ellos, la aplicación de un algoritmo de clustering nos permite agrupar vóxels conectados funcionalmente. Es por ello que como segundo paso del procedimiento, aplicamos sobre el espacio funcional un algoritmo de clasificación no supervisada conocido como mean shift. Dicho algoritmo fija como prototipos de los clusters o grupos a aquellos puntos que representan mínimos locales en la función de densidad de probabilidad de las muestras del propio espacio funcional. Obviamente, los vóxels se asignan a los prototipos por proximidad y entonces las agrupaciones del espacio funcional representan a vóxels que se conectan funcionalmente entre sí. Una vez formados los sistemas macroscópicos (o clusters) de actividad funcional correlada, podremos derivar las conclusiones oportunas a partir de dos representaciones que se complementan, bien a nivel hemodinámico (a partir de cierto patrón BOLD-IRMf que represente al conjunto de vóxels_como por ejemplo, la señal BOLD media de todos los vóxels del cluster o la señal propia del centroide) o bien a nivel espacial (a través de unos mapas analíticos multiparamétricos del módulo y la fase que generamos a partir del propio espacio funcional particionado). A los sistemas macroscópicos identificados mediante clusters mean shift los llamamos sistemas funcionales, dado que agrupan vóxels que están conectados funcionalmente. En cierto modo, los sistemas funcionales permiten expresar la respuesta funcional global como una suma de varias respuestas hemodinámicas parciales. Además, dadas las propiedades del espacio funcional, somos capaces de establecer la conectividad entre los distintos sistemas funcionales que identifiquemos. Finalmente, presentamos un ejemplo práctico en el que mostramos los datos IRMf que utilizamos para el diseño de nuestra metodología. Dadas las características experimentales del protocolo IRMf de dichas imágenes podemos poner en valor las bondades del procedimiento que permite extraer los sistemas funcionales en experimentos de estimulación eléctrica en cerebros de rata.

\subsection{Actividad correlada}

La descomposición en componentes principales es una herramienta ampliamente utilizada para representar las variaciones temporales observadas en datos IRMf. En la Figura 6.4 utilizamos SVD para descomponer los datos IRMf de cierto experimento (en concreto, del segundo de los sujetos estimulados en la región vestibular o Vest-2_ 
para una corrección alphasim y un umbral $\mathrm{p}=0,05$ ) en una combinación lineal de eigenimages y eigenvariates. Las limitaciones asociadas a la descomposición de las series de tiempo en eigenimages [159, 162] se aprecian claramente en el punto $\mathbf{C}$ de dicha figura: somos capaces de identificar las regiones o áreas cerebrales donde la actividad neuronal (o patrón de covarianza) es mayor, pero no podemos poner en contexto qué condición, regresor, eignevariate o componente principal $U$ contribuye de forma predominante en cierto patrón de covarianza. Dicho de otro modo, en el análisis post hoc de las imágenes SVD no hay una interpretación biológica clara cuando se observa que un mismo vóxel recibe contribuciones de varios patrones temporales o columnas de $U$ (además, moduladas de forma poco intuitiva por los valores propios y las contribuciones $V^{+}$y $V^{-}$de cada sumando de la descomposición). La cuestión es: dada la serie temporal BOLD-IRMf de un vóxel, ¿con qué patrón o modo hemodinámico de todos los presentes en la respuesta funcional del cerebro debería asociarse su comportamiento? Para solucionar la pregunta anterior y como hemos comentado en la introducción, hemos desarrollado un método en el que sometemos al espacio funcional de Friston et al. [124] a un algoritmo de clustering por el cual cada vóxel de un mapa estadístico paramétrico es asignado por verosimilitud a un cluster que agrupa vóxels con un comportamiento hemodinámico similar (o conectados funcionalmente) y por lo tanto: 1) un vóxel solo puede pertenecer a un cluster o sistema funcional, 2) cada vóxel contribuye por igual a la respuesta BOLD-IRMf media del cluster y 3) es posible definir la conectividad funcional entre dos sistemas funcionales a través de la evaluación de la conectividad de sus centroides (o puntos estacionarios en la jerga específica del algoritmo de clustering seleccionado).

La construcción del espacio funcional se fundamenta en el análisis de coordenadas principales o escalado multidimensional de las series temporales [163]. Aunque en la referencia principal se pone especial cuidado en describir el escalado multidimensional, existe una interpretación mucho más intuitiva del espacio funcional. Normalmente hemos considerado los datos IRMf como $K$ observaciones o imágenes IRMf de $N$ vóxels cada una, esto es: $M$ es una matriz $K \times N$ en un espacio $N$-dimensional. No obstante, no hay impedimento para considerar la representación completamente equivalente que consiste en $N$ puntos o vóxels en un espacio $K$-dimensional, es decir: $M^{T}$. Asumiendo que la conectividad funcional entre $i$ y $j$ es igual a la conectividad entre $j$ e $i$, esta puede asociarse a la distancia euclidiana entre los puntos en el espacio $K$-dimensional y por tanto $M^{T}$ es directamente un espacio métrico [164] de la conectividad en base a la siguiente medida de similitud:

$$
d_{i j}=\sqrt{\sum_{k}\left(m_{i}^{k}-m_{j}^{k}\right)^{2}}
$$

donde $d_{i j}$ es la distancia o conectividad funcional entre los vóxels $i$ y $j$ siendo $m_{i}^{k}$ y $m_{j}^{k}$ sus series temporales BOLD-IRMf respectivamente. Si desarrollamos el binomio de la expresión anterior, obtenemos que:

$$
d_{i j}=\sqrt{\left|m_{i}^{k}\right|+\left|m_{j}^{k}\right|-2 \sum_{k} m_{i}^{k} \cdot m_{i}^{k}}
$$

siendo $\left|m_{i}^{k}\right|=\sum_{k}\left(m_{i}^{k}\right)^{2}$ el módulo de $m_{i}^{k}$.

\subsubsection{Espacio funcional}

El espacio funcional es una representación compacta de las correlaciones cruzadas de todos y cada uno de los supra-vóxels de cierto mapa estadístico paramétrico respecto a ciertos patrones o modos hemodinámicos tomados como referencias-representando la conectividad funcional relativa entre cualesquiera dos vóxels del espacio funcional. Imaginemos que tomamos la matriz de datos $M^{T}$. Si normalizamos las series de tiempo BOLD-IRMf (media cero y módulo unidad: $\left|m_{i}^{k}\right|=\left|m_{j}^{k}\right|=1$ ) entonces la distancia, similitud o conectividad funcional se convierte en:

$$
d_{i j}=\sqrt{2} \sqrt{1-\cos \phi}
$$


donde $\cos \phi$ es el coeficiente de correlación de Pearson y $\phi$ se convierte en un estadístico suficiente para la caracterización de la conectividad funcional. Además, dado que la rotación de un espacio vectorial no modifica las distancias relativas entre los puntos (muestras o vóxels) representados en él, la construcción del espacio métrico de la conectividad contempla una transformación del espacio que permite visualizar los datos desde la orientación de máxima varianza o simplemente a través de sus coordenadas principales. Dicha rotación se consigue a través de la base vectorial formada por los vectores propios del producto escalar $K \times K$ de $M M^{T}$ [165] o lo que es lo mismo: los eigenvariates $U$ asociados a la descomposición SVD de la Ecuación 6.4. Por lo tanto, el espacio funcional $Q$ queda expresado según:

$$
Q=M^{T} U
$$

De este modo, como puede leerse en [17, pp. 496-7: Mapping anatomy into functional space - multidimensional scaling]: dos vóxels con una respuesta BOLD-IRMf idéntica ocuparán el mismo punto en $Q$; dos vóxels cuyas series de tiempo estén decorreladas estarán separados por $\pi / 2$ rad y dos vóxels separados por $\pi$ rad tendrán unas respuestas hemodinámicas perfectamente anticorreladas.

De forma extraordinaria, vamos a ir complementando la explicación de cada etapa de la metodología para la detección de patrones de varianza/covarianza de la actividad correlada con el análisis del espacio funcional de uno de nuestros experimentos de imágenes RMfe en cerebros de rata, de forma que podamos acompañar las explicaciones teóricas del método con figuras que ilustren el procedimiento. Como hemos comentado al principio del apartado, el sujeto que elegimos para el análisis de la actividad correlada es el Vest-2 (que es el mismo que utilizamos en su momento para ejemplificar las limitaciones del análisis SVD/eigenimages). De este modo, la Figura 10.1 muestra el espacio funcional asociado al mapa estadístico de la Figura 6.4. Como ya se demostró en su momento, la información asociada a la actividad cerebral inducida en el sujeto Vest-2 queda resumida suficientemente en las dos primeras componentes principales o eigenvariates $U_{1}$ y $U_{2}$ (Ecuación 6.5) y el espacio funcional es esencialmente bidimensional.

Cabe destacar, como parte de nuestra metodología de extracción de la actividad correlada, una etapa adicional de selección de datos, por la cual eliminamos de $Q$ todos los vóxels que, pese a ser supra-vóxels de cierta prueba estadística, están por debajo del umbral de ruido de coherencia [166].

\subsection{Análisis de la conectividad con mean shift}

En la sección anterior hemos presentado el espacio funcional como una representación hipo-dimensional de los datos IRMf en la que las distancias euclidianas significan conectividad funcional. Dado que dos vóxels con la misma respuesta al estímulo ocuparán un mismo punto en el espacio funcional, podemos identificar regiones o áreas con patrones de activación similares (y por tanto conectados funcionalmente) mediante el uso de técnicas de clustering. En su aplicación al análisis de datos IRMf, el objetivo fundamental de la clasificación no supervisada es la de particionar los datos en diferentes clusters en base a la intensidad de la proximidad de las series de tiempo, es decir: series temporales BOLD-IRMf suficientemente cercanas formarán parte del mismo cluster. No obstante el análisis basado en la intensidad de las series temporales no es suficiente para el estudio de la conectividad funcional [114] (ya sea en cuantificaciones directas [127, 123, 128] o indirectas de las mismas [126]) y por lo que se propone el uso de la similitud (en el sentido del escalamiento multidimensional presentado en [37]) de las series temporales como medida de la distancia [167]. En el método novel que presentamos utilizamos como métrica para realizar las agrupaciones las proyecciones $Q$ del espacio funcional, que son las correlaciones de las series temporales de cada vóxel con las componentes $U$ o eigenvariates; el algoritmo de clasificación que proponemos es conocido como mean shift y por lo que conocemos, nunca ha sido utilizado en el análisis de datos IRMf. 


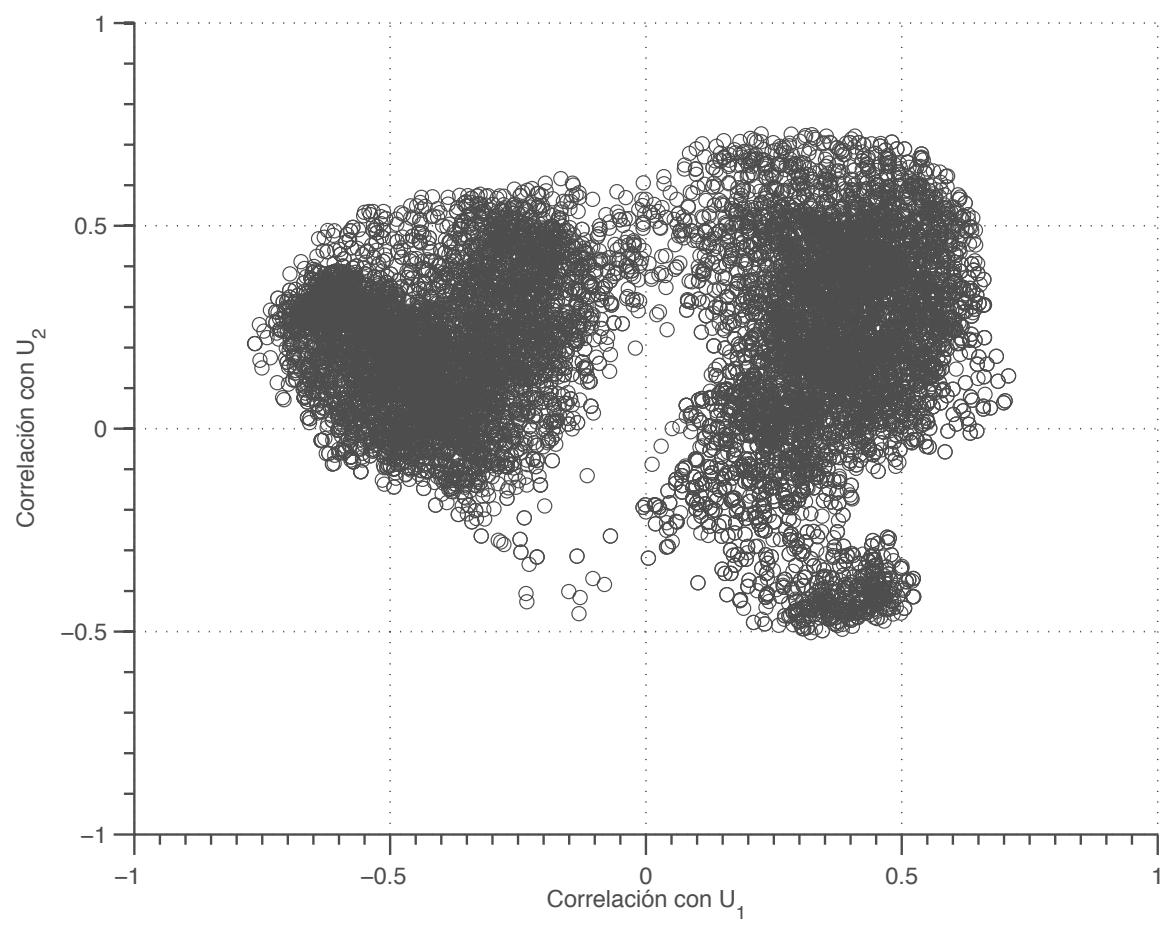

Figura 10.1: Espacio funcional del mapa estadístico paramétrico del sujeto Vest-2 (alpha., $\mathrm{p}=0,05)$. El espacio que describe la conectividad funcional inducida por estimulación eléctrica es esencialmente bidimensional debido a las contribuciones de las componentes principales $U$ o eigenvariates.

\subsubsection{Algoritmo mean shift}

Mean shift es un método no paramétrico de propósito general que puede utilizarse como algoritmo de clustering. En contraste al algoritmo de $k$-medias (Capítulo 6), mean shift no necesita realizar ninguna asunción sobre la forma de la distribución subyacente o del número de clusters [168] (siendo esta una limitación considerable de la técnica [169]). La idea principal detrás del algoritmo viene de asumir que las observaciones $K$-dimensionales (puntos o muestras) que conforman los datos a analizar provienen de una mixtura de funciones de densidad de probabilidad que generan altas concentraciones de muestras alrededor de sus máximos locales o modos y que por tanto cada muestra puede asociarse al modo o máximo (mínimo) global más cercano. Como puede intuirse, el cálculo de las particiones óptimas según mean shift se engloba dentro de los métodos de optimización del gradiente de funciones multidimensionales para identificar cuántos modos, puntos singulares o clusters hay en la distribución subyacente. Imaginemos que tenemos $N$ puntos u observaciones de cierta variable aleatoria en un espacio $K$-dimensional. Entonces la densidad de la distribución alrededor de cierto punto $\mathrm{x}$ del espacio de características es:

$$
F(\mathbf{x})=\frac{1}{n h^{d}} \sum_{n=1}^{N} \mathcal{K}\left(\frac{\mathbf{x}-\mathbf{x}_{i}}{h}\right)
$$

donde $\mathcal{K}$ representa cierta función kernel y $h$ es un parámetro conocido como ancho de banda (o bandwidth) que representa el radio (o ventana) de $\mathcal{K}$. Si a continuación, para cada punto u observación se aplica una optimización por descenso de gradiente (Figura 10.2) sobre la densidad estimada $F(\mathbf{x})$ para la ventana del kernel $\mathcal{K}$ y se itera hasta la convergencia, se puede demostrar que [170]: 
1. Los puntos estacionarios del procedimiento de descenso representan uno o más modos de la distribución de probabilidad subyacente.

2. Las observaciones, puntos o muestras asociadas a un mismo punto estacionario se consideran miembros del mismo grupo o cluster.

Puesto que el espacio funcional representa series de tiempo del consumo de oxígeno en la sangre, el punto estacionario o centroide de cada cluster es un modo hemodinámico. Finalmente, una limitación del procedimiento mean shift estándar es que el valor del parámetro $h$ o bandwidth debe especificarse. No obstante existen reglas básicas concretas para su correcta configuración [171].

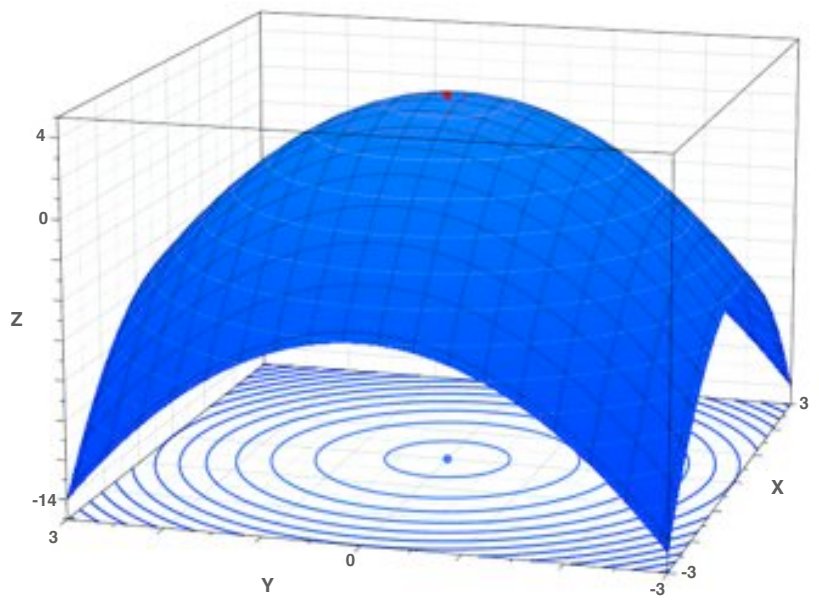

Figura 10.2: Los algoritmos de descenso de gradiente buscan el mínimo local de una función multivariada en base a la resolución secuencial de una serie de problemas unidimensionales. Figura basada en [172].

Siguiendo con el análisis del sujeto Vest-2, la Figura 10.3 muestra el espacio funcional particionado de dicho sujeto. Si comparamos la figura anterior con la del espacio original (Figura 10.1) observamos como efectivamente mean shift detecta como puntos estacionarios o modos aquellos lugares del espacio de características donde la densidad de datos es mayor y por tanto, somos capaces de identificar sistemas macroscópicos de vóxels como clusters o sistemas funcionales de flujo sanguíneo correlado (o funcionalmente conectados) que nos permiten asociar un evento neurofisiológico (o estimulación eléctrica) a un estado cerebral macroscópico determinado.

Dado que no hay diferencia formal entre las señales que representan las series temporales de vóxels aislados o de un conjunto de ellos [17, p. 497: Functional connectivity between systems-partial least squares] (fundamentalmente dada la independencia controlada de vóxels por encima de cierto umbral estadístico [173]), es posible definir la conectividad funcional entre dos sistemas funcionales o clusters en base al desfase de sus centroides. El Cuadro 10.1 resume las relaciones de conectividad entre los distintos sistemas funcionales detectados en la actividad cerebral del sujeto Vest-2-por ejemplo, el cluster uno (en rojo) está conectado funcionalmente al cluster tres (en verde) dado que el desfase relativo entre sus puntos estacionarios o centroides en el espacio funcional es $\phi_{13}=153,70^{\circ}\left(\rho_{13}=-0,89\right)$. Por otra parte, los modos hemodinámicos característicos de cada cluster (en este caso, en base al promedio de las señales temporales BOLD-IRMf) los mostramos en la Figura 10.4 (C). Podemos comprobar que la pobre extensión del cluster tres (verde) justifica una respuesta temporal tan ruidosa y sugiere su omisión en el resto del análisis. Para la descripción cuantitativa de la actividad neuronal sintetizamos unos mapas analíticos del módulo y la fase-una forma equivalente de representar la conectividad funcional del sistema funcional sobre un sustrato anatómico. 


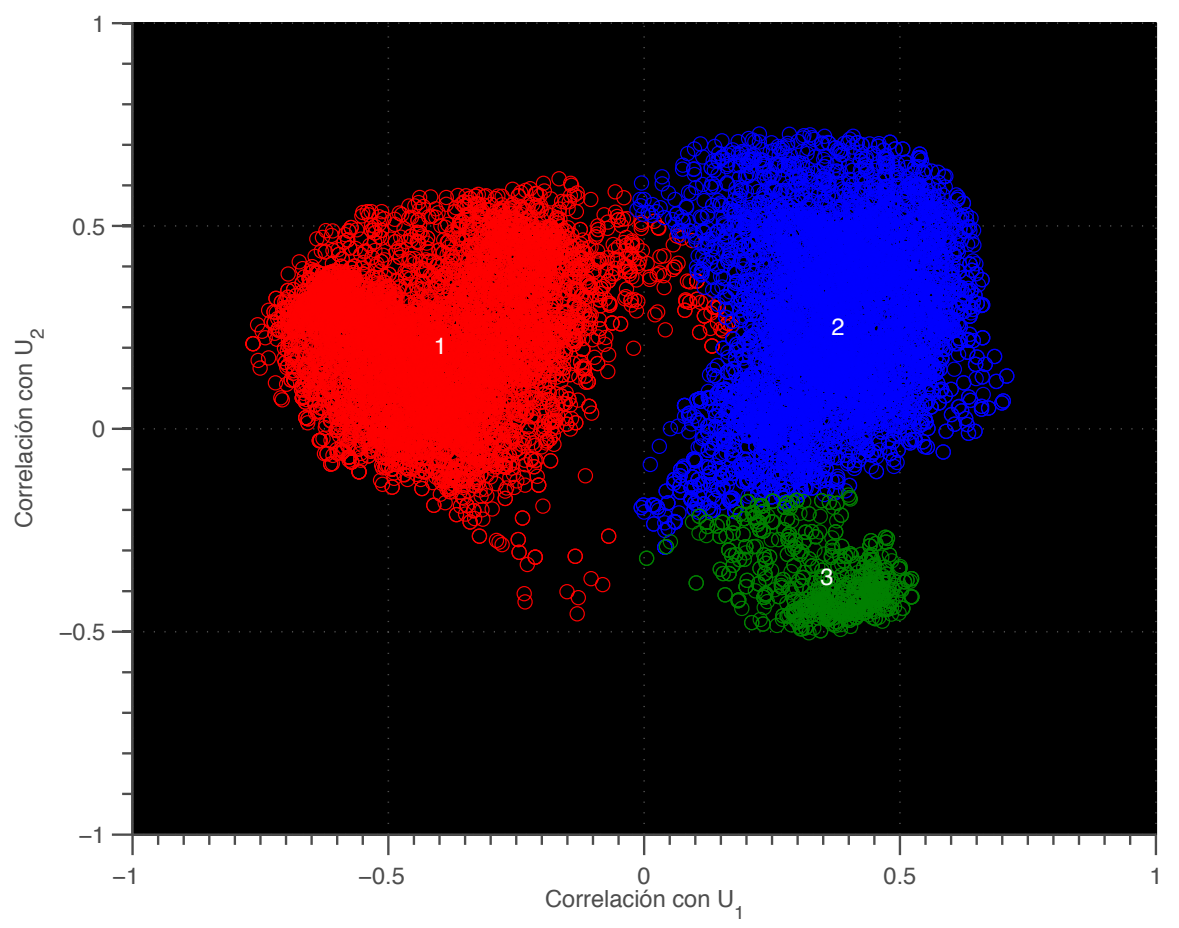

Figura 10.3: Clusters o sistemas funcionales identificados al aplicar el algoritmo mean shift sobre el espacio funcional del sujeto Vest-2.

Cuadro 10.1: Desfases relativos ( $\phi_{\mathbf{i j}}$, en grados) y correlaciones (o conectividad funcional, $\rho_{\mathbf{i j}}$ ) entre los clusters del espacio funcional particionado de la Figura 10.3.

\begin{tabular}{c|c|c}
\hline Clusters i-j & Desfase $\phi_{\mathbf{i j}}($ grad) & $\rho_{\mathbf{i j}}$ \\
\hline $1-2$ & 123,56 & $-0,55$ \\
\hline $1-3$ & 153,70 & $-0,89$ \\
\hline $2-3$ & 82,74 & 0,13 \\
\hline
\end{tabular}

\subsubsection{Mapas analíticos del espacio funcional}

En el espacio funcional de la Figura 10.3 hemos representado la conectividad funcional de los supra-vóxels de cierto mapa estadístico paramétrico en una base vectorial bidimensional, en concreto mediante las coordenadas $\left(M^{T} U_{1}, M^{T} U_{2}\right)$ de cada vóxel, que podrían interpretarse como los argumentos real e imaginario de un número complejo. Imaginemos que el vóxel $i$-ésimo queda representado por las coordenadas $\left(q_{1}^{i}, q_{2}^{i}\right)$; entonces podemos definir su módulo como:

$$
x_{i}=\frac{1}{\sqrt{2}}\left|q_{1}^{i}+j q_{2}^{i}\right|
$$

(donde el factor $\sqrt{2}$ nos asegura que $x_{i}$ queda definido en los mismos límites que la correlación), mientras que su fase (o $y_{i}$ ) la definimos como el ángulo que forma $q_{1}^{i}+j q_{2}^{i}$ con el eje de abscisas.

$\mathrm{Si}$ a continuación calculamos el módulo de todos los supra-vóxels de cierto mapa estadístico paramétrico según 


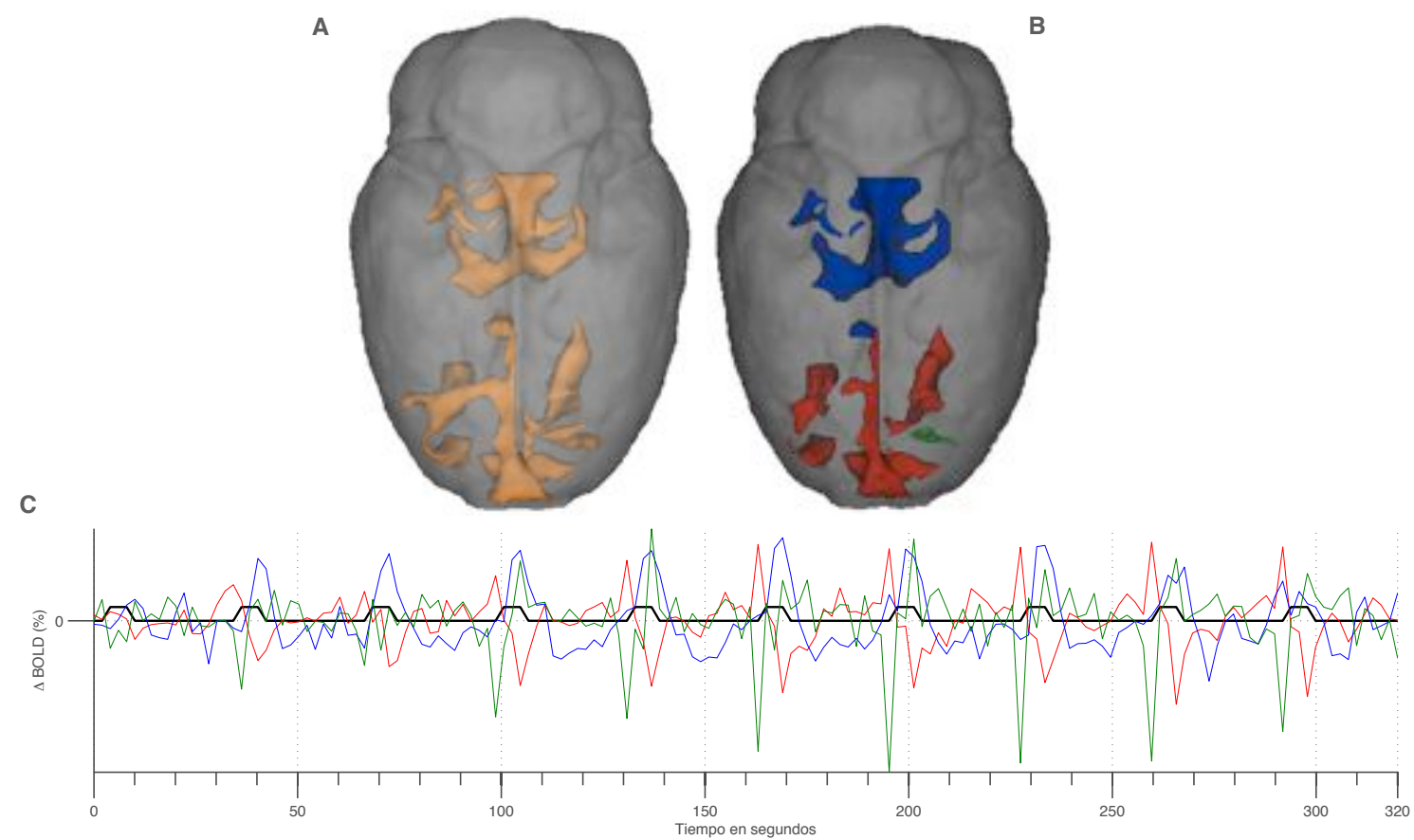

Figura 10.4: Análisis del espacio funcional del sujeto Vest-2. Una vez identificados los clusters, podemos asociar regiones o áreas cerebrales aisladas (cluster uno, en rojo; cluster dos, en azul; cluster tres, en verde) a un comportamiento que queda descrito de forma inherente por las series temporales BOLD-IRMf que las representan. A: mapa estadístico paramétrico del sujeto Vest-2 (alpha., $\mathrm{p}=0,05)$. B: espacio anatómico particionado según el algoritmo de clustering mean shift sobre el espacio funcional del sujeto bajo análisis. C: señales BOLD-IRMf representativas de los clusters hallados—según la codificación de color anterior.

la Ecuación 10.6 y lo almacenamos en el vector $\mathrm{x}$ y dado que de cada vóxel conocemos sus coordenadas estereotácticas, podemos generar fácilmente mapas de módulo asociados a cierto espacio funcional sin más que aplicar la transformación $\mathrm{Z}$ de Fischer [174] sobre el vector de pseudo-correlaciones $\mathbf{x}$ para generar mapas de estadísticos analíticos para inferir algo sobre la conectividad funcional.

Como penúltimo paso del análisis, la Figura 10.5 (A) muestra el mapa de módulo asociado al espacio funcional del sujeto Vest-2. De forma similar podemos utilizar $\phi$ (Ecuación 10.3) para obtener el mapa de fase que nos permita analizar sobre el sustrato anatómico la distribución de los desfases en la respuesta funcional (Figura 10.5, B). Podemos comprobar como efectivamente la fase $\phi$ (calculada a partir de los dos primeros modos ortonormales $U_{1}$ y $U_{2}$ ) puede considerarse la característica separable del espacio funcional.

Finalmente, podemos combinar ambos mapas analíticos para localizar los puntos en los que la correlación alcanza máximos locales de significación estadística. Por ejemplo, el máximo de correlación en el cluster uno se localiza en una región del cerebro de rata conocida como corteza orbital $(Z=1,90)$; en el cluster dos, el máximo $(\mathrm{Z}=1,98)$ corresponde a la región conocida como corteza retrosplenial. La identificación de regiones es posible gracias al mismo atlas tridimensional de propósito general utilizado para generar las huellas de conectividad presentadas en el capítulo anterior. 

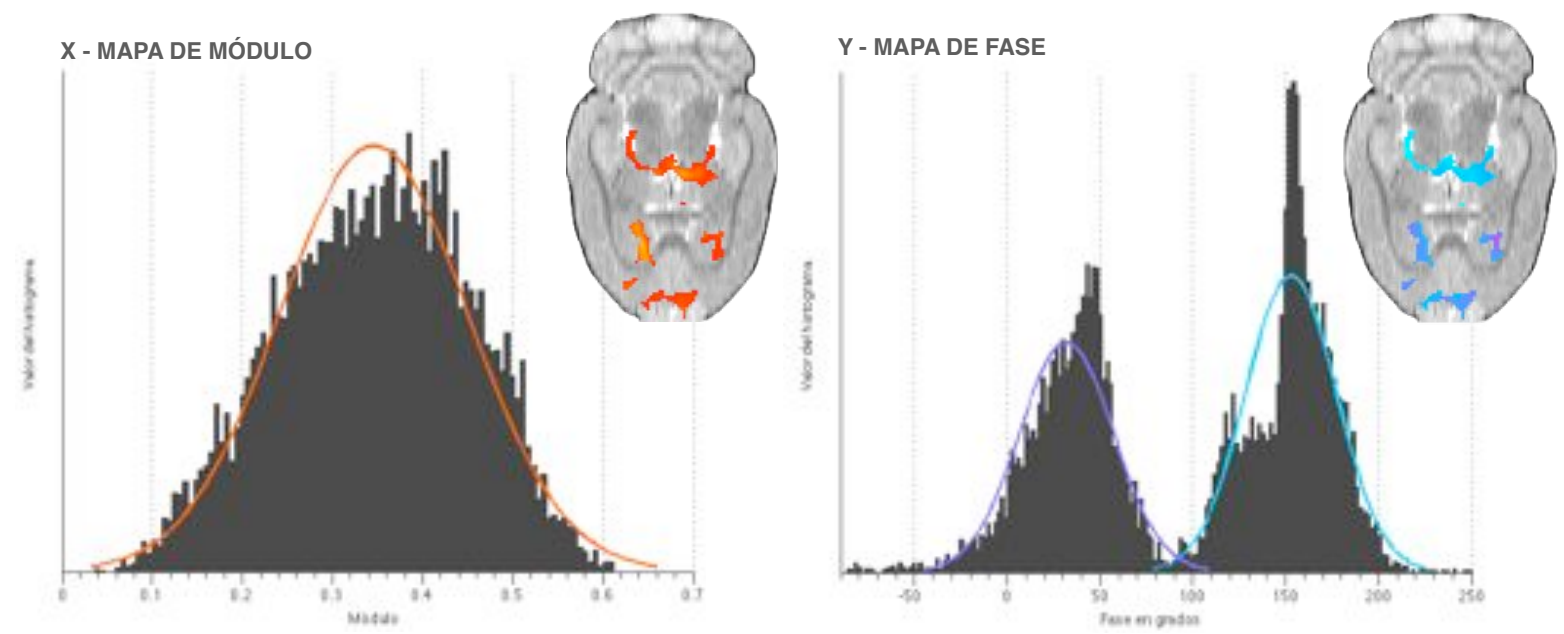

Figura 10.5: Los mapas analíticos del módulo $(\mathbf{X})$ y la fase $(\mathbf{Y})$ de cierto espacio funcional nos permiten la cuantificación estadística/multiparamétrica de los distintos modos hemodinámicos que aparecen como parte de la respuesta funcional.

\subsection{Demostración práctica}

El experimento de estimulación con dos electrodos presentado en la Sección 7.1.4 se pensó específicamente para el diseño y test de la metodología mean shift aquí presentada. Después de preprocesar las imágenes (Figura 10.6), utilizamos GLM para obtener los mapas estadísticos paramétricos de los sujetos. Las matrices de diseño de los sujetos contienen, por cada sesión y electrodo, los tres regresores correspondientes a la forma canónica de la HRF y a sus dos derivadas, y ocasionalmente, los parámetros de movimiento (en concreto cuando en aquellas sesiones en las que se detecte una relación directa entre el movimiento del sujeto con las descargas eléctricas; ver la Figura 10.7).
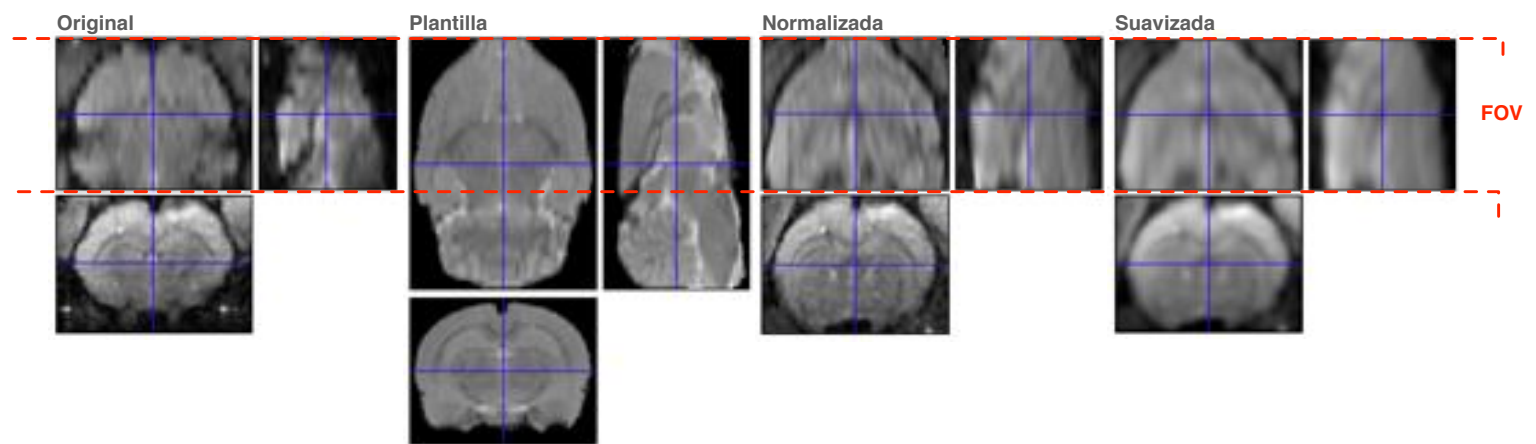

Figura 10.6: Preprocesado de las imágenes de resonancia magnética funcional para el experimento de estimulación con dos electrodos. Las imágenes suavizadas son la entrada al módulo GLM para la síntesis de mapas estadísticos paramétricos. La línea roja discontínua indica el campo de visión o FOV (por sus siglas en inglés: field of view).

Tras especificar los modelos, procedemos a la estima de parámetros y la obtención de los mapas estadísticos paramétricos para cierto nivel de inferencia (Figura 10.8). Como se especificó en el Capítulo 7, el sujeto Doble-1 o D1 se estimula únicamente a través del electrodo implantado en el hemisferio derecho. Dada la extensión de la actividad evocada, se espera que la respuesta funcional media en los sujetos en los que se aplican dos corrientes 


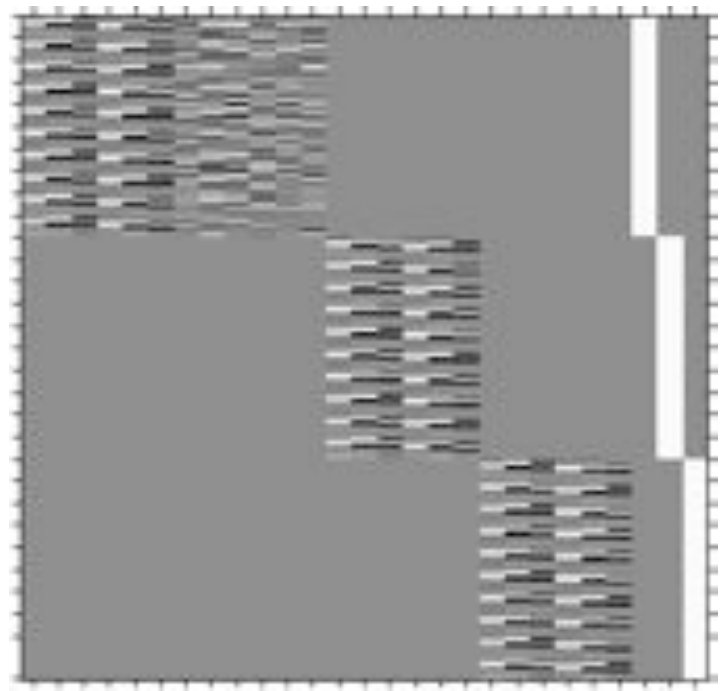

Figura 10.7: Matriz de diseño del sujeto Doble-1. La primera sesión (de un total de tres) incluye los seis parámetros de movimiento extraídos en la etapa de realineado de las imágenes.

(D2 a D5) sea una suma interferente de sendas respuestas funcionales.
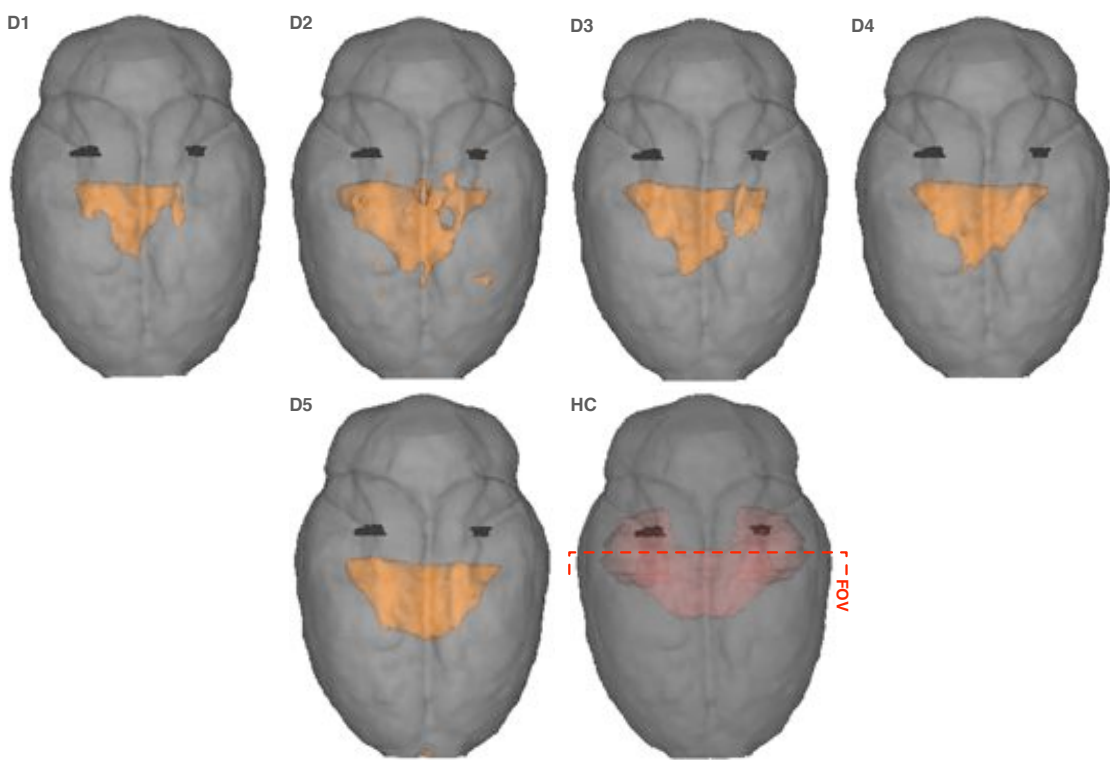

Figura 10.8: Mapas estadísticos paramétricos de primer nivel family wise error $(\mathrm{p}=0,05)$ de los cinco sujetos del experimento de estimulación con dos electrodos. Los electrodos de estimulación los mostramos en negro junto cada mapa estadístico; en el último cerebro (HC) se muestran junto al área cerebral donde se implantan y que es conocida como hipocampo (y que queda en parte fuera del FOV de los datos).

A continuación, calculamos los cinco espacios funcionales sobre los que aplicar el algoritmo mean shift con la intención de demostrar que con la metodología presentada somos capaces de identificar (para cada uno de los 
sujetos D2 a D5) los sistemas funcionales asociados a cada uno de los electrodos. El resultado de los análisis mean shift los mostramos en la Figura 10.9 y el Cuadro 10.2, a partir de los cuales podemos concluir:

1. Que el algoritmo de clasificación no supervisada mean shift aplicado al análisis de los espacios funcionales permite identificar respuestas funcionales que se retrasan sistemáticamente [3].

2. Que es posible la cuantificación del retardo relativo entre las respuestas funcionales (según el principio del reposo inicial de los sistemas lineales invariantes en el tiempo) dada la relación causal inherente que provoca la estimulación eléctrica.

3. Que en experimentos donde se utilicen varios electrodos de estimulación eléctrica, podría sugerirse un posible procedimiento experimental para estudiar la conectividad efectiva (dado que la aplicación de dos o más corrientes eléctricas simultáneamente generan respuestas evocadas que se interifieren asimétricamente). Por ejemplo, en el caso del experimento D2, la mayor intensidad de la respuesta funcional asociada al cluster dos (Figura 10.9, Sujeto Doble-2, HRF en azul) resultaría consistente con el hecho que alrededor del $s e-$ gundo electrodo (o por el que se aplica la corriente desfasada) las funciones de respuesta hemodinámica se interfieren constructivamente (puesto que la segunda respuesta al estímulo o HRF causa efecto antes de que la respuesta hemodinámica asociada a la corriente de referencia empiece a decrecer). En el caso del experimento D5, el segundo tren de impulsos se aplica con un desfase temporal suficiente para que los estados transitorios (o lapso temporal entre $\mathbf{P}$ y la línea base; Figura 3.4) asociados a cada respuesta funcional de cada electrodo no afecten a la señal inducida del eletrodo vecino y por tanto el desfase entre sendas HRFs es el predecible $\left(\Delta t_{D 5}=15,00 \mathrm{~s}\right.$ para un desfase entre las corrientes de dieciséis segundos).

Cuadro 10.2: Medidas cuantitativas del experimento de estimulación con dos electrodos: desfase ( $\Delta \mathbf{t}_{\mathbf{D i}}$, en segundos) y diferencia de amplitud ( $\Delta$ BOLD ${ }_{\mathbf{D i}}$, en tanto por cien) entre los clusters detectados en la metodología mean shift.

\begin{tabular}{c|c|c}
\hline Sujeto (Di) & $\Delta \mathbf{t}_{\mathbf{D i}}(\mathbf{s})$ & $\boldsymbol{\Delta} \mathbf{B O L D}_{\mathbf{D i}}(\boldsymbol{\%})$ \\
\hline D1 & - & - \\
\hline D2 & 2,14 & 48,45 \\
\hline D3 & 6,43 & 49,00 \\
\hline D4 & 10,71 & 44,58 \\
\hline D5 & 15,00 & 35,49 \\
\hline
\end{tabular}

Dados los resultados del experimento de la demostración práctica, asumimos que cuando nuestro método se aplique a experimentos en los que se utilice un único electrodo de estimulación, seremos capaces de aislar aquellos modos hemodinámicos o clusters que se puedan inducir como respuesta funcional al único estímulo eléctrico, es decir: seremos capaces de descomponer la señal neuronal global o integrada como una suma de respuestas funcionales parciales. Esto podría ser de interés, por ejemplo, para diferenciar respuestas directas e indirectas o monosinápticas vs. polisinápticas. Además, aunque siempre debamos comprobar las relaciones de correlación entre el regresor principal y cada eigenvariate [108], dado el caso podríamos sintetizar espacios funcionales que combinen otras respuestas que no sean las de máxima varianza (como por ejemplo $U_{1}$ con $U_{3}$ ) para un análisis de mayor profundidad.

\section{Resumen}

En el presente capítulo hemos presentado un método para agrupar aquellos supra-vóxels cuya respuesta funcional o actividad neuronal (caracterizadas por las series de tiempo BOLD-fMIR) está correlada entre sí. Las 
A - Resumen del procedimiento mean shift
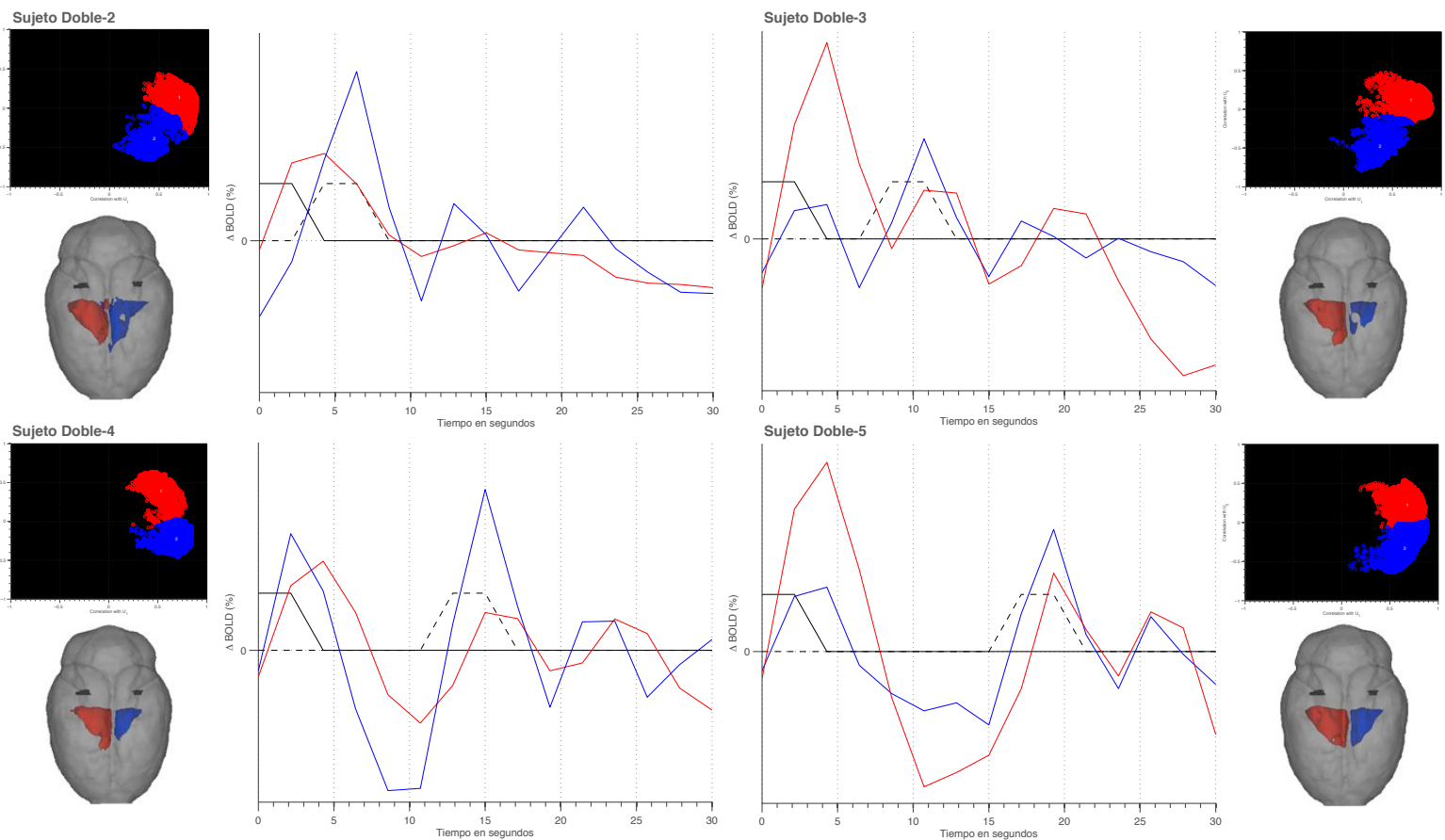

B - Respuesta hemodinámica del sujeto Doble-5 al tren de impulsos

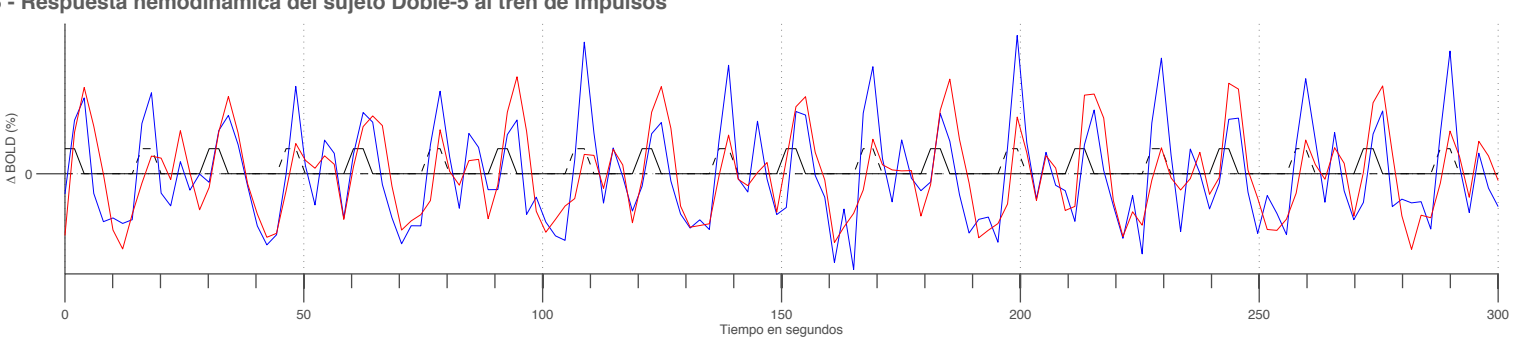

Figura 10.9: A: análisis mean shift de los espacios funcionales de los experimentos con estimulación bilateral D2 a D5. La respuesta funcional de cada experimento corresponde a la interferencia de sendas respuestas a los dos estímulos eléctricos aplicados, donde el estímulo de referencia se muestra con una línea continua en negro y el desfasado con una línea discontinua. En todos los experimentos se detectan dos sistemas funcionales o clusters, cuyas respuestas medias y/o localización espacial quedan codificadas por los colores rojo (cluster 1) y azul (cluster 2). Según el desfase introducido, la respuesta funcional se puede interpretar de forma más o menos clara. Por ejemplo, en el experimento D2 la estimulación con desfase se aplica antes del undershoot asociado al estímulo de referencia, y la amplitud de la segunda respuesta funcional puede explicarse por la suma constructiva de las intensidades de ambas corrientes; algo similar ocurre con el experimento D5, donde la estimulación con desfase se aplica cuando las neuronas asociadas al cluster uno (o rojo) ya están en estado basal, por lo que el desfase temporal entre las respuestas es predecible. Los experimentos D3 y D4 son casos intermedios en los que las interferencias son menos predecibles. B: respuesta al tren de impulsos del experimento D5-donde se aprecia claramente la interferencia entre las respuestas. Pese a ello, el procedimiento mean shift consigue aislar las respuestas de forma acorde a la ubicación estereotáctica de los electrodos de estimulación.

agrupaciones de vóxels las hacemos en el espacio de características definido por el espacio funcional presentado en [124], que (como ya se ha comentado con anterioridad) no es más que un espacio métrico en el que la proximidad (o distancia euclidiana) entre sus puntos, muestras o vóxels implica el grado de conectividad funcional 
entre ellos. El concepto clave en el que se sustenta nuestro método de identificación de sistemas macroscópicos o funcionales es que en el espacio funcional, los vóxels segregados anatómicamente por todo el cerebro ocupan un mismo lugar del espacio funcional cuando están conectados funcionalmente, y es por ello que las agrupaciones o clusters identifican a vóxels con una respuesta funcional al estímulo conectada o coherente. Mediante sendos ejemplos prácticos (correspondientes al análisis del sujeto Vest-2 y a los datos con estimulación eléctrica bilateral) conseguimos justificar que mean shift es el algoritmo adecuado para la clasificación no supervisada del espacio funcional. En aplicaciones reales de estimulación cerebral mediante un único electrodo (como la de la Figura 6.4), los espacios funcionales que representan los supra-voxeles suelen provenir (y así es en todos los experimentos de este trabajo de investigación) de un F-test en el que se incluyen las derivadas temporales y espaciales del regresor canónico. La inclusión de la derivada temporal es especialmente importante dado que permite capturar los retrasos sistemáticos de la HRF canónica asumida en el modelo GLM. Según puede leerse en Henson et al. [3] (y como se ha explicado en la sección Inferencia de las funciones base temporales del Capítulo 5), las respuestas funcionales que se retrasan $\tau \approx \pm 2 \mathrm{~s}$ respecto a la HRF canónica serán capturadas como respuestas que responden al estímulo positivamente. En este sentido, la metodología mean shift aquí presentada es capaz de identificar dichos desfases como distintos puntos estacionarios y sugiere la posibilidad de realizar medidas del retardo entre las distintas respuestas funcionales BOLD-IRMf representativas de los clusters. En la misma línea, el experimento de estimulación con dos electrodos puede sugerir un método de análisis de la causalidad de las respuestas funcionales para el estudio de la conectividad efectiva — en base a la influencia asimétrica que un electrodo de estimulación puede ejercer respecto al resto de núcleos neuronales estimulados y del resto con éste. En cualquier caso, somos capaces de crear mapas analíticos que identifican sistemas macroscópicos conectados funcionalmente y que nos permiten inferir sobre la diferencia de magnitud o módulo y la latencia, retardo o desfase. Por desgracia, la interpretación de los mapas de fase queda limitada por la dificultad de extrapolar la señalización BOLD-IRMf a las características de la actividad neuronal subyacente [175]. 


\section{Parte IV}

\section{Resultados y discusión}





\section{Capítulo 11}

\section{Análisis de la conectividad funcional en cerebros de rata: SPMrat}

\section{Introducción}

En la parte de métodos hemos presentado diferentes alternativas para el análisis de la conectividad funcional a varios niveles. En concreto, en el Capítulo 9-Huellas de conectividad y análisis de grupos, hemos presentado una representación matricial de los datos (a la que llamamos huellas de conectividad) que permite caracterizar un estado funcional de un experimento IRMf con estimulación eléctrica. En ese mismo capítulo presentábamos un clasificador de la actividad funcional capaz de realizar agrupaciones de sujetos en base a los patrones de modulación sináptica embebidos en las huellas de conectividad. La clasificación de sujetos en grupos funcionales nos motivaba a realizar un análisis de segundo nivel para obtener mapas estadísticos paramétricos en representación de la respuesta media de los grupos a la salida del clasificador. Por otra parte, en el Capítulo 10 (Sistemas funcionales), utilizábamos las eigenimages PCA/SVD para construir un espacio funcional capaz de representar las relaciones de conectividad vóxel-a-vóxel. Dadas las propiedades del espacio de la conectividad funcional y del algoritmo de clasificación no supervisada mean shift, elaborábamos una metodología para: 1) identificar clusters de vóxels como sistemas funcionales que contribuyen a la respuesta funcional integrada mediante una respuesta BOLD-IRMf correlada que es representativa de su respuesta al impulso, 2) establecer la relación de conectividad funcional y/o causalidad entre los clusters o sistemas funcionales y 3) sintetizar unos mapas analíticos multiparamétricos en representación del espacio funcional que nos permiten localizar las distintas regiones cerebrales según su conectividad funcional.

Las huellas de conectividad y los sistemas funcionales tienen mucho en común—no en vano representan una visión complementaria de una misma realidad. Por una parte, tanto las huellas de conectividad como los sistemas funcionales asumen como medida de conectividad funcional la correlación de las series temporales BOLD-IRMf, ya sea como característica regional (las huellas de conectividad representan las señales BOLD-IRMf extraídas con un atlas multifuncional) o como característica hipodimensional de la conectividad de vóxels aislados (dado que los espacios funcionales representan la correlación de cada vóxel respecto a las componentes principales SVD). Además, ambas estructuras representan únicamente las relaciones de conectividad que atañen a aquellos vóxeles que previamente han pasado una prueba estadística definida en el seno del modelo lineal general y, por tanto, representan de forma conjunta la conectividad anatómica y funcional. En este sentido, el camino que nos lleva hasta la obtención de las huellas y sistemas de la conectividad funcional es también común, dado que todos los mapas estadísticos paramétricos que determinan los supra-vóxels de cierta prueba estadística se derivan bajo una misma metodología de análisis_que implica tanto al preprocesamiento de las imágenes como al análisis estadístico. Todos estos hechos hacen que la información representada en las huellas y en los sistemas funcionales deba ser compatible en ciertos aspectos. Por ejemplo, se debería poder comprobar que los vóxels de aquellas regiones de 


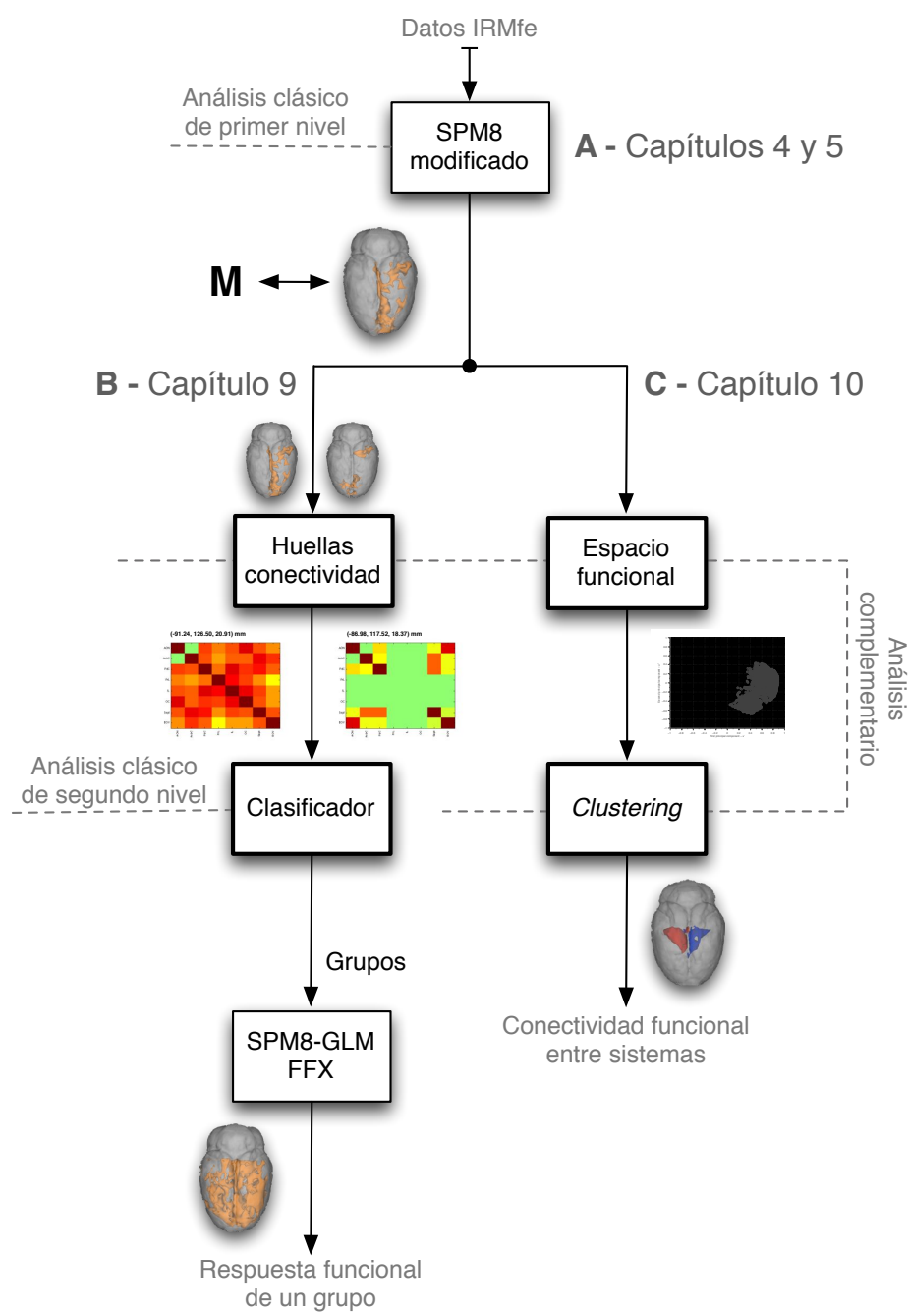

Figura 11.1: Diagrama de flujo simplificado del software SPMrat. El módulo A se encarga de preprocesar las imágenes funcionales y de derivar los mapas estadísticos paramétricos que representan la respuesta global neuronal a la estimulación eléctrica. Los módulos con el marco en negrita se ocupan de realizar medidas de la correlación de señales BOLD-IRMf como indicadores de la conectividad. En la rama $\mathbf{B}$ las huellas de conectividad son las muestras de entrada de un clasificador de la actividad neuronal que es capaz de agrupar sujetos según la conectividad funcional entre las distintas regiones que han sido moduladas de forma similar por la estimulación eléctrica. En la rama $\mathbf{C}$ sometemos al espacio funcional a un algoritmo de clustering que nos permite identificar clusters de vóxels que responden de forma sincronizada al estímulo eléctrico. Las huellas de conectividad y los espacios funcionales representan de forma complementaria las series temporales BOLD-IRMf de los supra-vóxels de un mapa estadístico paramétrico dado. De alguna forma, las primeras nos permiten delinear el network, mientras que los espacios funcionales nos permiten identificar los puntos donde las conexiones funcionales son más robustas.

las huellas de conectividad que no estén conectadas funcionalmente entre sí deberán quedar identificadas en clusters distintos del espacio funcional o que aquellas regiones que se correlan positivamente entre sí y negativamente respecto a otras, deben quedar identificadas por clusters de vóxels cuya respuesta BOLD-IRMf media tenga cierto carácter inhibitorio. Estos hechos se observan claramente si comparamos la Figura 14.5 (que muestra algunas huellas de conectividad de segundo nivel del grupo formado por los sujetos estimulados en el nervio vestibular) 
con la Figura 14.6 (que muestra el análisis del espacio funcional asociado al mismo SPM sobre el que se deriva la huella de la Figura 14.5, B). Como decíamos, si comparamos ambas figuras, se puede comprobar: 1) que las regiones que se correlan de forma positiva entre sí, pero de forma negativa con el resto (como puedan ser PrL, OC o FrA) forman parte de un mismo cluster (el número dos, en azul en la Figura 14.6), 2) que el resto de regiones (como HC, Thal o RSctx) forman parte de un cluster que responde de forma directa al estímulo y 3) que sendos clusters se ordenan en el espacio funcional formando dos polos.

En el presente capítulo presentamos el software de elaboración propia (al que llamamos SPMrat) que implementa en MATLAB todos los programas, funciones o métodos que permiten el estudio de la conectividad funcional en cerebros de rata según los metodologías diseñadas en la Parte II y que acabamos de mencionar brevemente. Dicho software no ha sido aun liberado a la comunidad científica, hecho que sucederá de forma simultánea a la publicación del primer trabajo científico fruto de esta Tesis Doctoral. No obstante, el software está siendo validado por nuestro laboratorio en varias líneas de investigación cuyos resultados ya han sido presentados en congresos nacionales e internacionales $[153,176]$.

\subsection{SPMrat}

En los últimos años, las técnicas de imagen no invasivas han conducido a un importante avance en el estudio de la estructura cerebral y su funcionalidad tanto en humanos como en animales de experimentación. En el último caso, técnicas de imagen por resonancia magnética como la de estimulación eléctrica funcional o IRMfe [2] es probablemente la herramienta más importante en el estudio de la conectividad funcional dado que permite la puesta en práctica de complejos diseños experimentales. Una vez los datos IRMf han sido adquiridos, es necesario el uso de programas para la corrección de movimiento y/o registro, normalización, suavizado y análisis estadístico. La Figura 11.1 muestra un diagrama simplificado del software de análisis post hoc que presentamos como SPMrat y que tiene como objetivo fundamental el estudio de la conectividad funcional en cerebros de rata. En base a la figura anterior, el módulo A modifica algunas del software SPM8 para permitir el preprocesado de imágenes del cerebro de rata (mucho menores que las imágenes correspondientes a cerebros humanos, para los que se diseñó SPM8) y también maneja la parte GLM de ese mismo software para la obtención de mapas estadísticos paramétricos de los sujetos individuales o de primer nivel. Como podemos ver, a cada mapa estadístico se le asocia la matriz de series temporales BOLD-IRMf $\mathbf{M}$ que representa las respuestas hemodinámicas de todos los supravóxeles que están por encima del umbral de cierta prueba estadística (así como sus coordenadas estereotácticas). La rama $\mathbf{B}$ del bloque resume gráficamente el procedimiento para el cálculo de las huellas de conectividad que permite generar grupos de sujetos y mapas estadísticos paramétricos de segundo nivel en representación de las respuestas funcionales de las agrupaciones. Por otra parte, la rama $\mathbf{C}$ del diagrama utiliza la matriz $\mathbf{M}$ para el análisis de los sistemas funcionales según se explicó en el capítulo correspondiente. Finalmente, aunque no se indique en el diagrama y como ya mostramos en su momento, no hay impedimento para obtener las huellas de conectividad de los mapas estadísticos paramétricos así como los mapas analíticos del espacio funcional para el análisis de la conectividad funcional de segundo nivel-y así lo permite el software SPMrat.

La utilidad de la herramienta SPMrat será contrastada en los siguientes cuatro capítulos, en los que se hace uso de los diferentes módulos para obtener conclusiones acerca de la conectividad funcional en otros tantos experimentos IRMfe en cerebros de rata. El resto del este capítulo se centra en detallar cómo SPMrat configura los módulos de SPM8 que permiten la obtención de los mapas estadísticos paramétricos de primer nivel y segundo nivel. El detalle de la implementación del resto de módulos (que son aquellos enmarcados con un cuadro en negrita en la Figura 11.1) se obvia_-dado que una vez explicada la metodología en los capítulos correspondientes, el detallar su programación no contribuiría en nada al objetivo del presente trabajo.

\subsubsection{Análisis clásico de primer nivel}

Nos referimos al análisis clásico de primer nivel como el procedimiento que nos permite obtener los mapas estadísticos paramétricos GLM de las respuestas individuales de los sujetos aislados. La obtención de mapas es- 
tadísticos paramétricos requiere de una buena práctica tanto en el preprocesamiento de las imágenes de resonancia magnética como en su posterior análisis de la significación estadística (más si cabe cuando resulta de interés caracterizar la presencia de patrones comunes de modulación sináptica entre varios sujetos) y es con dicho propósito que definimos los pasos ya descritos en la Sección 7.3.
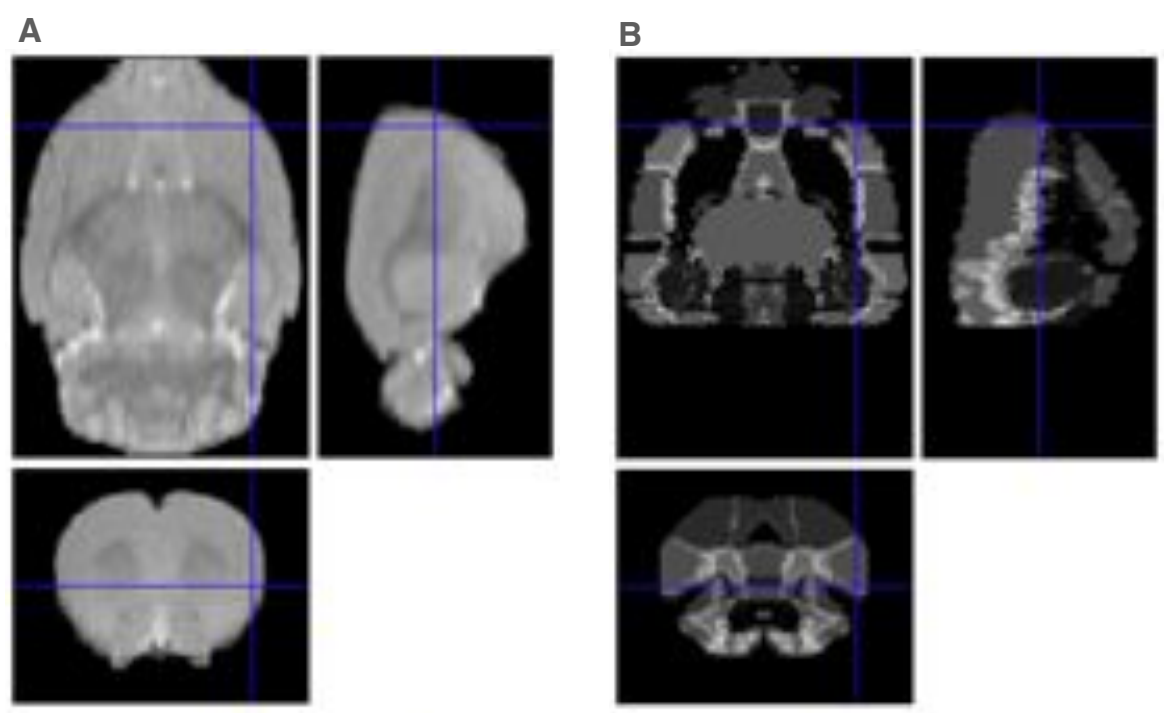

Figura 11.2: Atlas tridimensional para el estudio de la conectividad en cerebros de rata. A: plantilla para la normalización espacial utilizada como referencia deseada para la síntesis del atlas SPMrat. Como podemos comprobar, la referencia anatómica que elegimos para la síntesis del atlas es una versión segmentada de la plantilla anatómica T2 que presentábamos en la Figura 7.2. B: atlas anatómico compuesto por 149 etiquetas identificadas unívocamente por diferentes valores de gris y que componen nuestro atlas de propósito general que utilizamos para el estudio de la conectividad funcional.

\subsubsection{Atlas anatómico SPMrat}

Para poder calcular las huellas de conectividad, los máximos estadísticos asociados a los mapas analíticos del espacio funcional o cualquier otra cuantificación regional sobre la conectividad, es indispensable el uso de atlas anatómicos del cerebro de rata. En SPMrat incorporamos un atlas a la plantilla para la normalización espacial según la metodología que hemos expuesto en el Capítulo 8 y cuyo resultado mostramos en la Figura 11.2. Como sabemos, el atlas anatómico es fundamental para el cálculo de las huellas de conectividad (y por tanto, para la generación de grupos) y para el análisis de los espacios funcionales.

\subsection{Análisis de la conectividad funcional con SPMrat}

Como dijimos en la introducción, SPMrat es la herramienta de elaboración propia programada en MATLAB con la que estudiamos la conectividad funcional en los experimentos descritos en el Capítulo 7-Material. SPMrat implementa los programas necesarios para calcular los mapas estadísticos paramétricos de primer nivel sobre imágenes previamente preprocesadas, huellas de conectividad (Capítulo 9) o sistemas funcionales (Capítulo 10). Una función muy interesante incluida en SPMrat es que implementa un clasificador de la actividad funcional (Sección 9.2.1) que permite generar grupos de sujetos a partir de las huellas de conectividad individuales y el posterior análisis de segundo nivel GLM/FFX para la caracterización de las respuestas medias funcionales. 


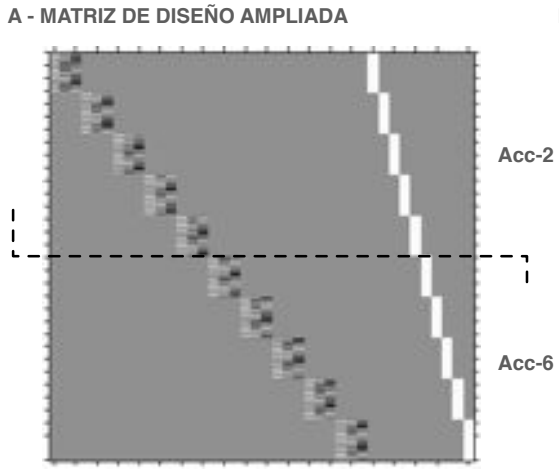

B - SPMS DE PRIMER Y SEGUNDO NIVEL

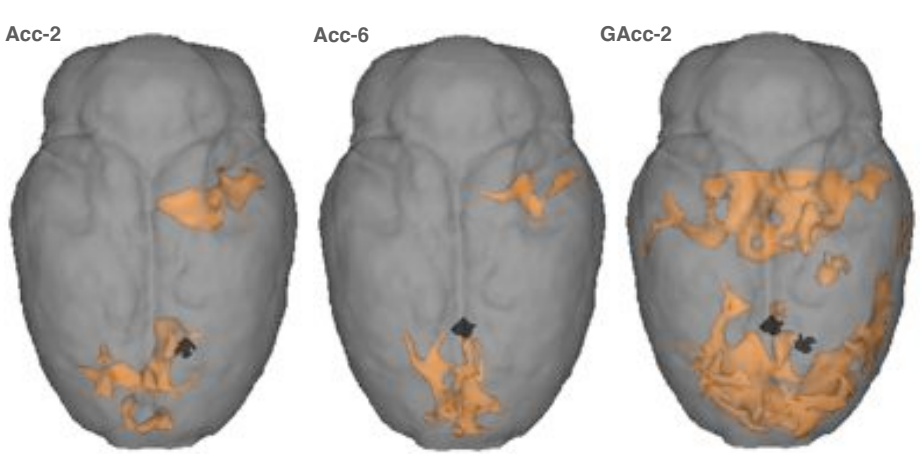

Figura 11.3: Análisis clásico de segundo nivel. La dificultad en la caracterización de las respuestas medias no reside en el cálculo del mapa estadístico paramétrico del grupo, sino en cómo deben realizarse las agrupaciones. A: matriz de diseño ampliada para el análisis GLM/FFX de los sujetos Acc-2 (arriba de la línea discontinua) y Acc-6 (abajo de la misma). B: mapas estadísticos paramétricos (alpha., $\mathrm{p}=0,05)$ para los sujetos individuales Acc-2 y Acc-6 y para la respuesta media de grupo (GAcc-2).

\subsubsection{Análisis clásico de segundo nivel}

Después de obtener las respuestas individuales mediante el análisis clásico de primer nivel, ahora nos ocupa el problema de la realización de inferencias estadísticas que implican a varios sujetos, en lo que se conoce como inferencias de segundo nivel. En SPMrat, las inferencias a nivel de grupo las realizamos en base a la estrategia de análisis de efectos fijos. Según se desprende de la Sección 5.3.3, la dificultad de dicho análisis no reside ni mucho menos en el proceso GLM/FFX para la obtención de los mapas estadísticos paramétricos de los grupos, y sí en cómo éstos son creados-por ejemplo, mediante la clasificación de huellas de conectividad, es decir: no formulando los grupos únicamente en base a las coordenadas estereotácticas de los electrodos de estimulación (en lo que sería una decisión demasiado liviana), sino teniendo presente los patrones de modulación sináptica que se derivan al aplicar un protocolo de estimulación eléctrica determinado en intensidad, frecuencia, etcétera, junto con la ubicación concreta del implante. En la Figura 11.3 (A) podemos ver una matriz de diseño FFX ampliada para modelar la actividad neuronal de dos sujetos. En dicha figura, la línea discontinua separa las cinco sesiones de imágenes adquiridas sobre los sujetos Acc-2 y Acc-6 respectivamente.

\section{Resumen}

En el presente capítulo hemos presentado un software que hemos elaborado específicamente para el análisis de la conectividad funcional en cerebros de rata. El software (al que llamamos SPMrat) analiza la conectividad funcional en base a los patrones de correlaciones o covarianzas encontrados en las series temporales BOLD-IRMf de los supra-vóxels de un mapa estadístico paramétrico dado. El análisis individual de las correlaciones de los vóxels en un análisis CCA entre regiones cerebrales del atlas-SPMrat (que también diseñamos de forma específica) permite la generación de grupos de sujetos a partir de un clasificador de lo que llamamos huellas de conectividadunas estrucutras de datos que diseñamos (junto al clasificador) para cuantificar los estados funcionales. Por otra parte, si analizamos las series temporales bajo una visión multivariada de las mismas podemos aplicar SVD y mean shift para hallar los distintos clusters o modos hemodinámicos en los que se descompone la respuesta al estímulo. Después de realizar los análisis que conciernen a sujetos individuales, utilizamos el resultado de la clasificación no supervisada de las huellas de conectividad para derivar mapas estadísticos paramétricos de segundo nivel en representación de las respuestas medias de los grupos. 


\section{Capítulo 12}

\section{Análisis de la corteza prefrontal}

\subsection{La corteza prefrontal}

La corteza prefrontal localizada en la parte anterior del neocortex está formada por multitud de regiones cerebrales como el córtex orbitofrontal (OC, orbitofrontal cortex), la corteza prelímbica, infralímbica, e insular. En términos generales la corteza prefrontal está involucrada en la planificación de comportamientos cognitivamente complejos, los procesos de toma de decisiones, la atención, en la adecuación del comportamiento al entorno y sobre todo, a la coordinación de la función ejecutiva. Cabe mencionar que algunas regiones de la corteza prefrontal presentan relación funcional con el sistema límbico. Por ejemplo, el córtex orbitofrontal (fundamentalmente asociado con la toma de decisiones y con la definición social del individúo) muestra también cierta sensibilidad funcional a la emoción o la recompensa-de hecho, el OC junto con el núcleo accumbens y la amígdala (AMY, amygdala) se han identificado como regiones que se activan con el consumo de drogas [177].

\subsubsection{Regiones que forman la corteza prefrontal}

La corteza prefrontal está fuertemente interconectada con gran parte del cerebro, incluyendo conexiones con otras regiones corticales y regiones subcorticales. La corteza prefrontal dorsal está especialmente interconectada con regiones cerebrales implicadas en procesos como la atención, la cognición y la acción, mientras que la corteza prefrontal ventral se interconecta con regiones asociadas a la emoción. La corteza prefrontal también recibe información de los sistemas que controlan el grado de activación fisiológica y psicológica del tronco del encéfalo, definiendo la coordinación entre el grado arousal (o la activación del cuerpo en general) y el estado mental. Según Uylings et al. [178], los cerebros de rata tendrían una corteza prefrontal cuya estructura (en especial a lo que se refiere a la parte dorsomedial y dorsolateral) es muy similar a la que se encuentra en primates y hombres.

\subsection{Descripción del experimento}

En el presente experimento tratamos de extraer y analizar los posibles patrones de conectividad funcional inducidos en los diecisiete sujetos a los que hemos implantado electrodos de estimulación a lo largo de la corteza prefrontal y sometido a un estudio IRMfe_-Pref-1 a Pref-17, según lo descrito en el Capítulo 7. El primer paso del análisis consiste en obtener los SPMs de primer nivel de todos y cada uno de los sujetos. Hecho esto, utilizamos el atlas-SPMrat para extraer las señales BOLD-IRMf de las regiones activas de cada respuesta funcional y construir una huella de conectividad por cada sujeto. La Figura 12.1 muestra un análisis regional de cierta respuesta funcional a modo de ejemplo. Después, utilizamos el clasificador de huellas de conectividad para agrupar aquellos patrones de modulación que muestran una actividad subyacente similar y finalmente, obtenemos los mapas es- 
tadísticos y las huellas de conectividad de segundo nivel en representación de la respuesta funcional de los grupos que hayamos podido sintetizar.
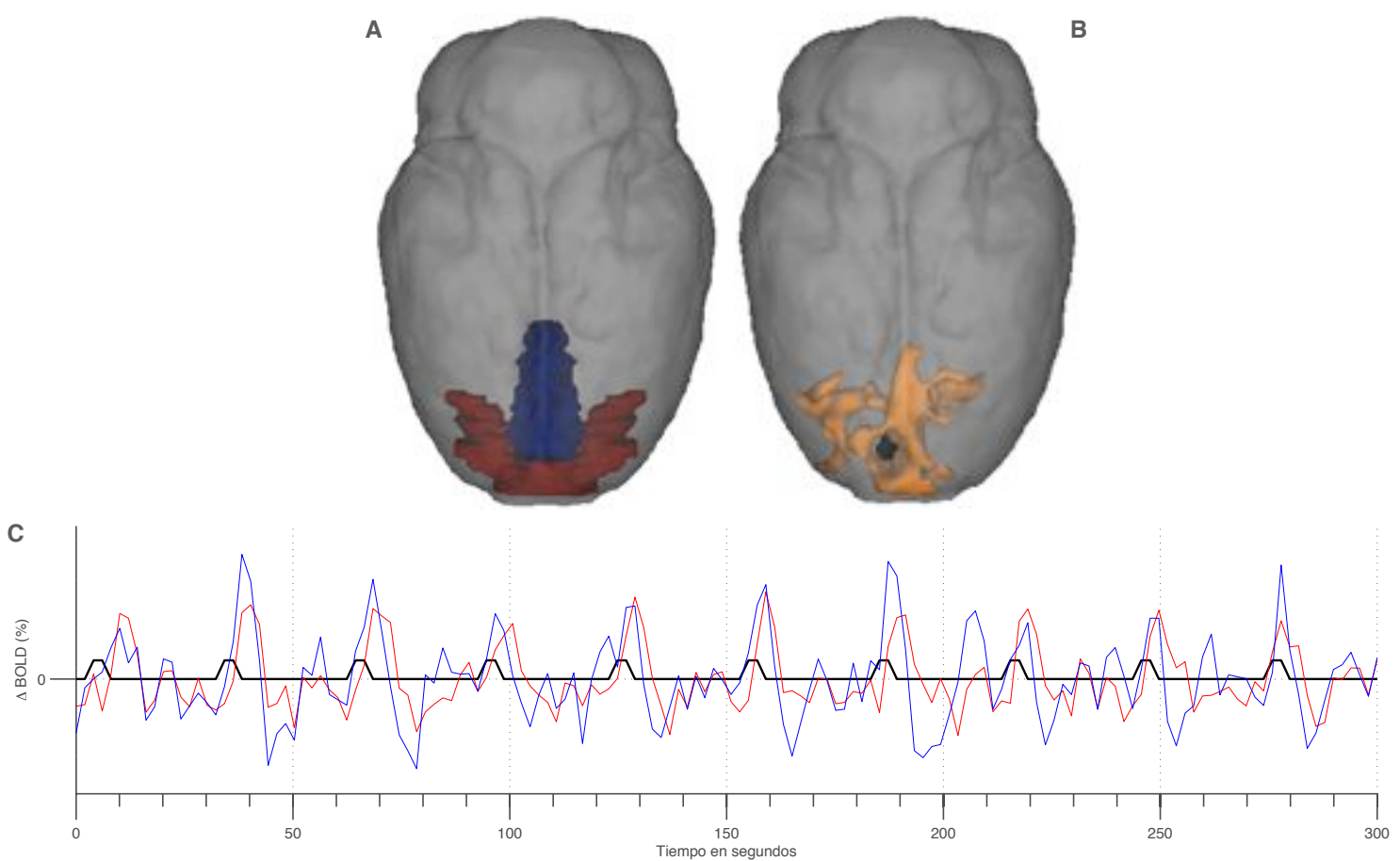

Figura 12.1: Análisis regional de la actividad funcional del sujeto Pref-3. A: córtex orbitofrontal (en rojo) y la corteza cingulada (en azul) según el atlas tridimensional de propósito general desarrollado para el cerebro de rata. B: mapa estadístico paramétrico del sujeto Pref-3 para una corrección alpashim $(\mathrm{p}=0,05)$ junto con su electrodo de estimulación (en negro). C: señal BOLD-IRMf media en el córtex orbitofrontal (OC, orbitofrontal cortex) y la corteza cingulada $(\mathrm{Cg}$, cingulate cortex) en rojo y azul respectivamente.

\subsection{Desarrollo y resultados}

Los mapas estadísticos paramétricos de la actividad neuronal en el experimento de estimulación de la corteza prefrontal los mostramos en la Figura 12.2. La huella de conectividad correspondiente al SPM de la Figura 12.1 (B) la mostramos en la Figura 12.3. En dicha huella de conectividad apreciamos que el sujeto Pref-3 presenta una conectividad funcional alta entre todas las regiones activas, incluyendo algunas conexiones que esperábamos a priori (por ejemplo las que involucran a las regiones $\mathrm{Cg}$, OC y PrL). Las huellas de conectividad del resto de sujetos las mostramos en la Figura 12.4.

Una vez hemos calculado las huellas de conectividad de los diecisiete sujetos, las introducimos en el clasificador para tratar de identificar patrones subyacentes de conectividad funcional. El clasificador determina de forma automática que las conexiones funcionales más significativas son, no sorprendentemente, las que se dan entre las regiones activas IL, PrL, FrA, OC y Cg. De este modo, las huellas de conectividad de la Figura 12.4 evaluadas para dichas regiones de interés (junto con las coordenadas estereotácticas de los electrodos de estimulación) se convierten en las huellas de clasificación que mostramos en la Figura 12.5 y que son los datos sobre los que el clasificador es capaz de realizar agrupaciones de sujetos.

En concreto, el clasificador selecciona las cinco primeras componentes principales (que acumulan un 82,73\% 


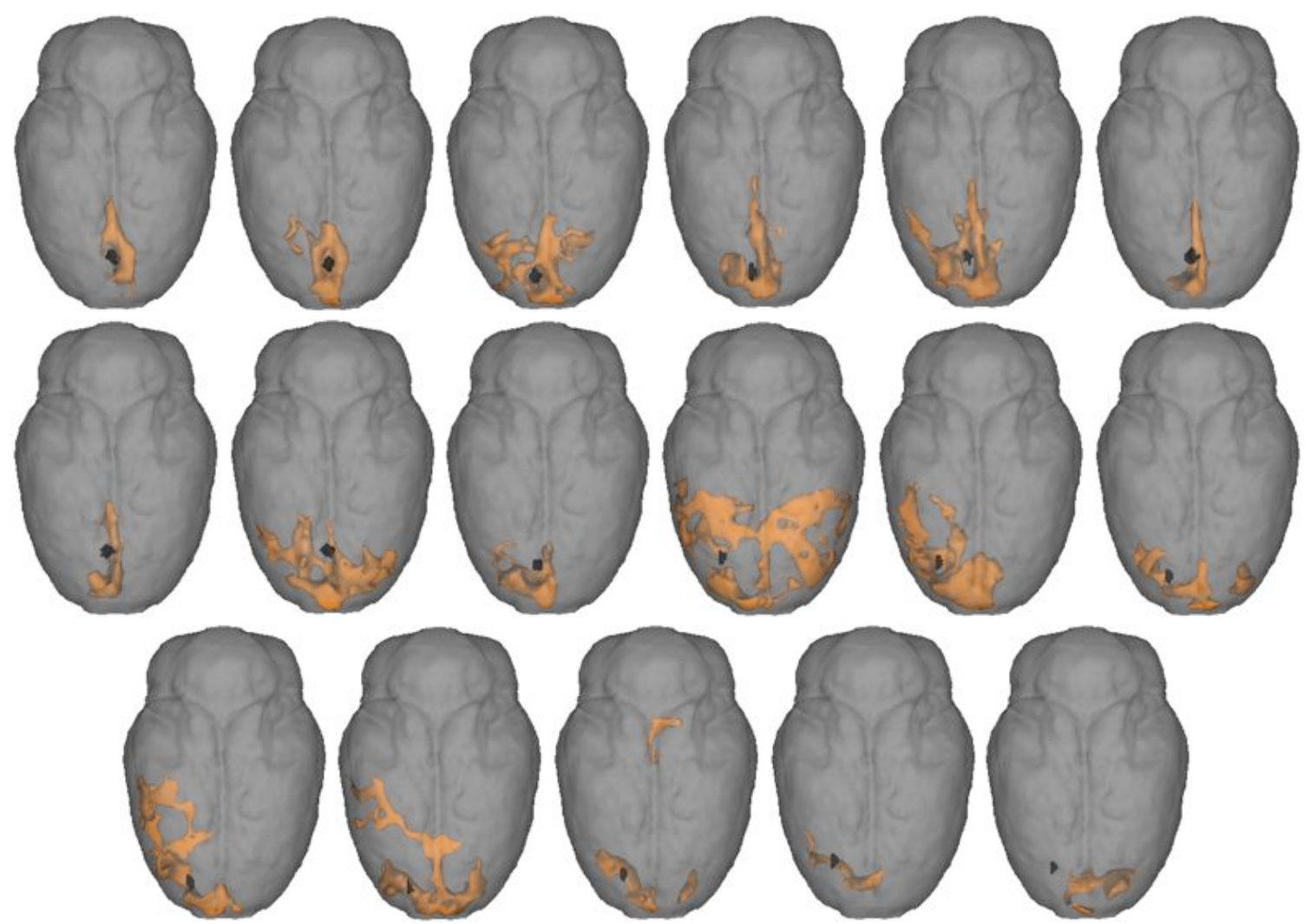

Figura 12.2: Mapas estadísticos paramétricos de primer nivel alphasim $(\mathrm{p}=0,05)$ de los diecisiete sujetos del experimento de la corteza prefrontal (Pref-1 a Pref-17, de izquierda a derecha, de arriba a abajo). Los electrodos de estimulación los mostramos en negro junto con el mapa estadístico.

del total de la varianza) como la representación adecuada de los datos sobre la que aplicar k-means y generar los grupos. La Figura 12.6 (A) muestra una representación tridimensional PCA del espacio de clasificación así como la varianza que aportan las distintas componentes principales que componen el espacio de clasificación para la generación de grupos funcionales-donde el criterio del codo ha establecido que el número óptimo de centroides o grupos es $k=5$. Los agrupaciones generadas las mostramos en la Cuadro 12.1.

El siguiente paso de nuestro análisis consiste en obtener los mapas estadísticos de segundo nivel, que como sabemos, son aquellos que representan la respuesta funcional media de los grupos (Figura 12.6, B). Finalmente, obtenemos las huellas de conectividad de los grupos en representación global del experimento (Figura 12.7).

\subsection{Discusión}

A la vista del Cuadro 12.1, entre los diecisiete sujetos estimulados en la corteza prefrontal detectamos cinco patrones subyacentes diferenciables de actividad funcional. Observamos algunas particularidades interesantes entre las distintas agrupaciones (las cuales, justifican la esencia de los grupos como tales):

- En los grupos GPref-1 y GPref-5 observamos una alta conectividad entre regiones de la corteza insular (granular, agranular y disgranular). Esta actividad correlaciona perfectamente con el hecho que los electrodos estén implantados en zonas laterales de la corteza prefrontal. Además, el grupo refleja un alto grado de 


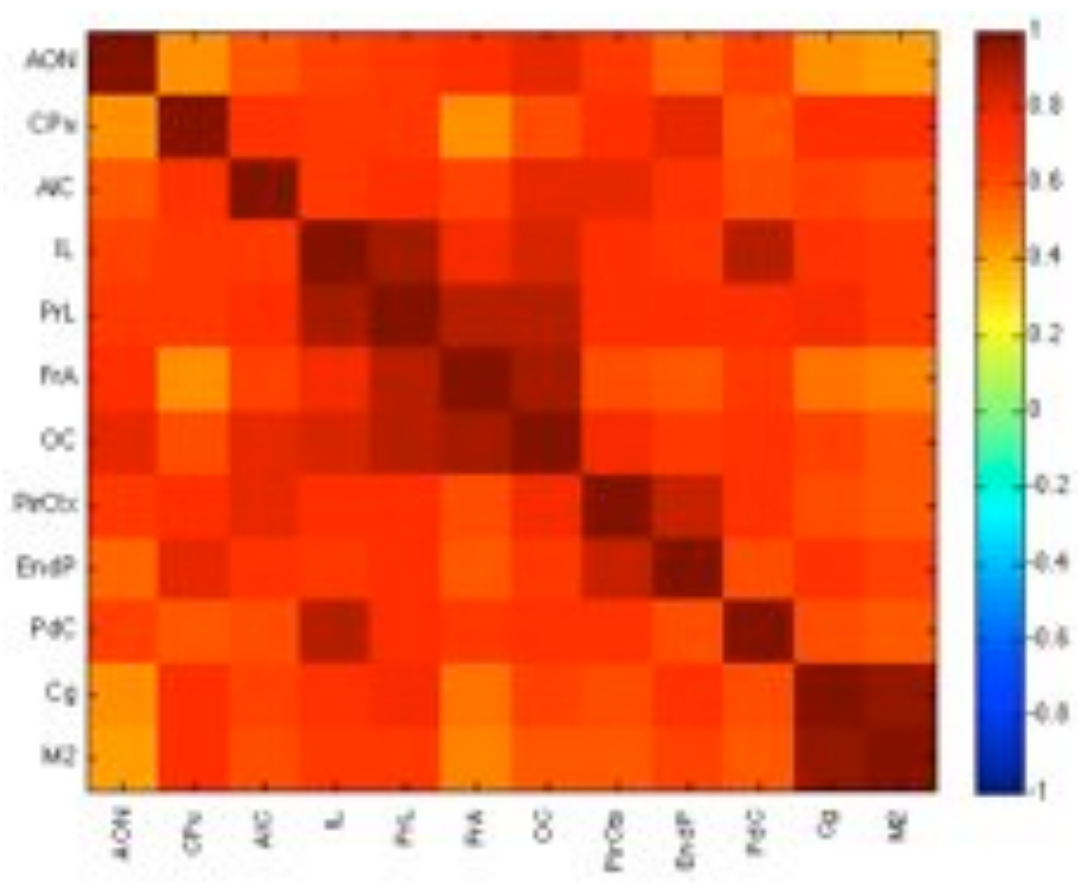

Figura 12.3: Huella de conectividad (alpha., 0,05) del sujeto Pref-3. La relación de conectividad más alta se da entre la corteza cingulada $(\mathrm{Cg}$, cingulate cortex) y la corteza motora secundaria (M2, secondary motor cortex) con una correlación de 0,95 (rojo oscuro). La corteza prelímbica (PrL, prelimbic cortex) también muestra una alta conectividad (del orden de 0,90$)$ con las regiones IL (infralimbic cortex), FrA (frontal association cortex) y OC (orbital cortex). El resto de regiones activas en respuesta al estímulo son: AON (anterior olfactory nucleus), $\mathrm{CPu}$ (caudate putamen), AIC (agranular insular cortex), PirCtx (piriform cortex) y EndP (endopiriform nucleus).

conectividad funcional entre la corteza insular, prelímbica y orbital (OC).

- Las huellas de conectividad de los grupos GPref-2 y GPref-3 tienen unas huellas muy similares, lo cual es consistente con la localización contigua de los electrodos en la corteza prefrontal. En el caso del grupo GPref-3, la posición más ventral del electrodo de microestimulación recluta zonas frontales de la corteza como FrA y OC.

- Los electrodos del GPref-4, ubicados en la zona medial de la corteza prefrontal (OC y PrL), generan una huella de conectividad muy extensa que relaciona todas las regiones de la corteza prelímbica e infralímbica con la corteza frontal de asociación e insular.

Finalmente, cabe destacar que la codificación de colores utilizada en el último cerebro de la Figura 12.6 muestra de forma clarividente una asociación robusta de las localizaciones estereotácticas de los electrodos y los patrones de conectividad funcional interindividual de los sujetos. 

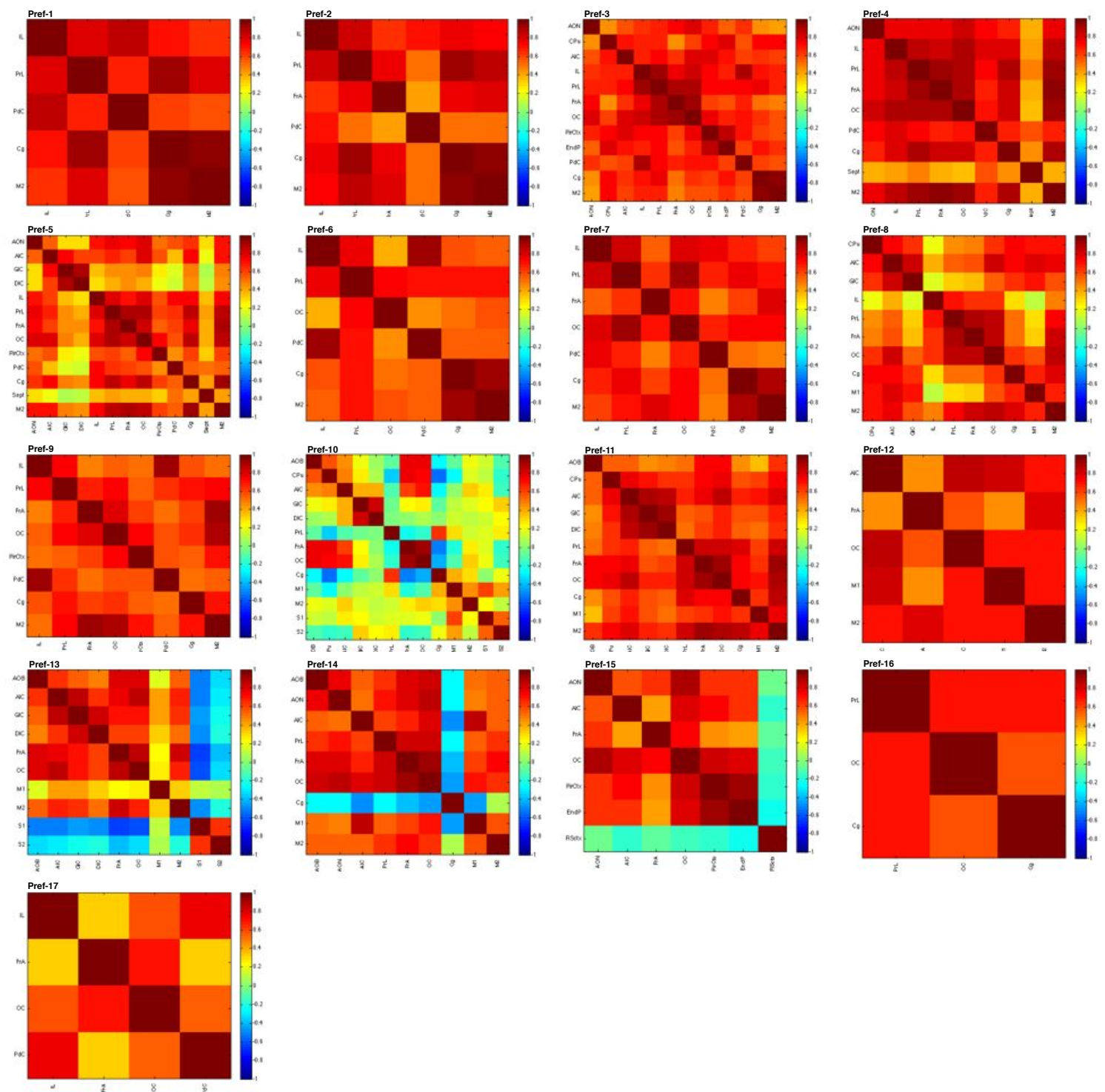

Figura 12.4: Huellas de conectividad (alpha., 0,05) de los sujetos Pref-1 a Pref-17. Dado que es altamente improbable que dos sujetos muestren un mismo patrón de modulación sináptica, en la práctica consideramos que cada huella de conectividad es única e identifica unívocamente al sujeto a quien representa. Regiones activas en uno o más de los diecisiete sujetos: AOB (accessory olfactory bulb), AON (anterior olfactory nucleus), CPu (caudate putamen), AIC (agranular insular cortex), GIC (granular insular cortex), DIC (dysgranular insular cortex), IL (infralimbic cortex), PrL (prelimbic cortex), FrA (frontal association cortex), OC (orbital cortex), PirCtx (piriform cortex), EndP (endopiriform nucleus), PdC (peduncular cortex), $\mathrm{Cg}$ (cingulate cortex), RSctx (retrosplenial cortex), Sept (septal nucleus), M1 (primary motor cortex), M2 (secondary motor cortex), S1 (primary somatosensory cortex) y S2 (secondary somatosensory cortex). 

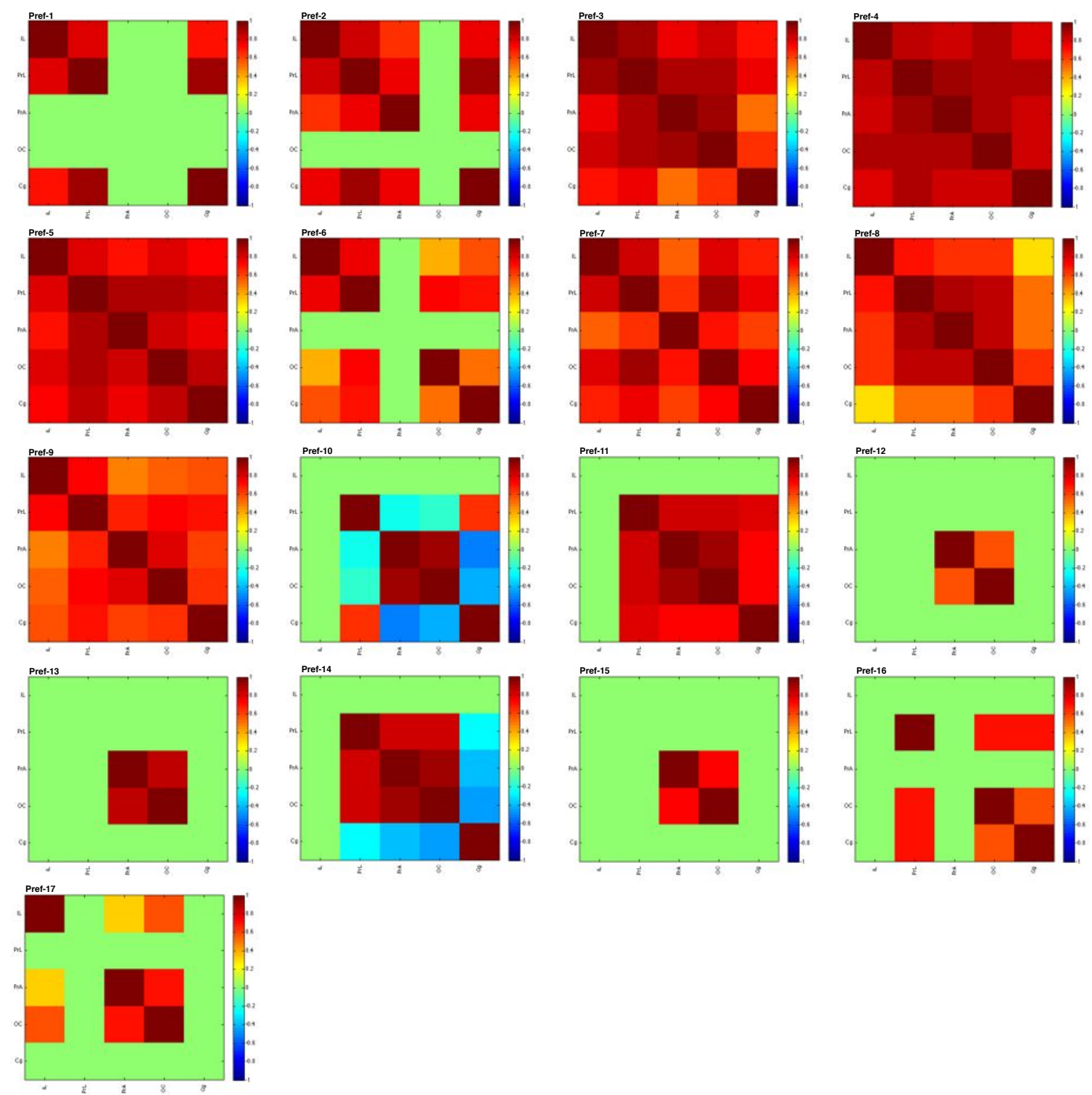

Figura 12.5: Huellas de clasificación de los diecisiete sujetos del experimento que analiza la corteza prefrontal. Las huellas de clasificación son una versión hipodimensional de las huellas de conectividad. Las huellas de clasificación se acompañan con las coordenadas estereotácticas normalizadas de los electrodos de estimulación. Regiones de interés: IL (infralimbic cortex), PrL (prelimbic cortex), FrA (frontal association cortex), OC (orbital cortex) y Cg (cingulate cortex). 
Cuadro 12.1: Grupos generados por el clasificador de huellas de conectividad entre todos los sujetos del experimento de la corteza prefrontal.

\begin{tabular}{c|c}
\hline Grupo funcional & Sujetos del grupo \\
\hline GPref-1 & $\begin{array}{c}\text { Pref-10, Pref-12, Pref-13 } \\
\text { Pref-14, Pref-15 y Pref-17 }\end{array}$ \\
\hline GPref-2 & Pref-1, Pref-2 y Pref-6 \\
\hline GPref-3 & Pref-7, Pref-8 y Pref-9 \\
\hline GPref-4 & Pref-3, Pref-4 y Pref-5 \\
\hline GPref-5 & Pref-11 y Pref-16 \\
\hline
\end{tabular}
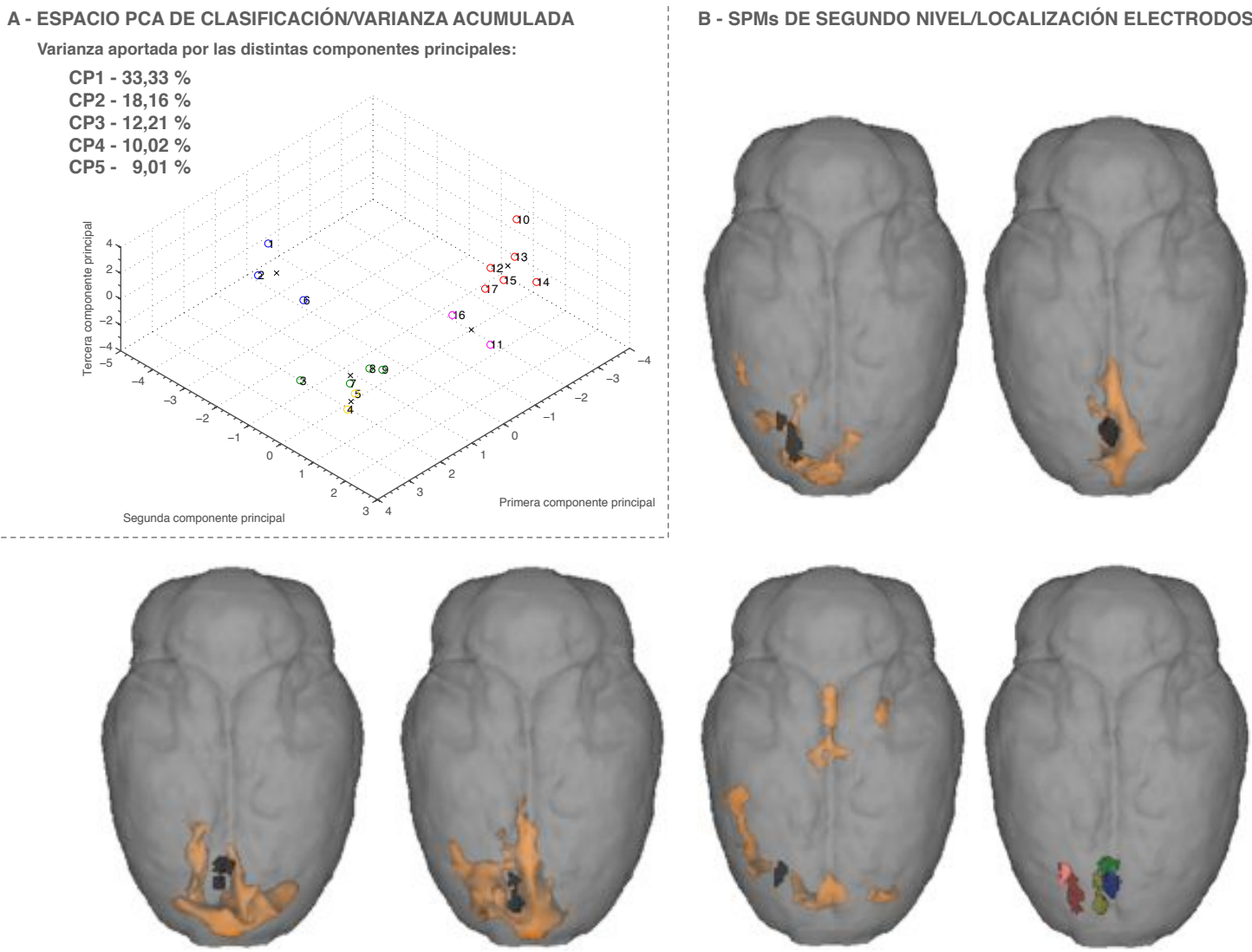

Figura 12.6: A: representación tridimensional del espacio de clasificación y varianza que aportan las distintas componentes principales (CP) a dicho espacio. Cada punto del espacio representa una huella de clasificación o sujeto individual. B: mapas estadísticos paramétricos de segundo nivel (alpha., 0,05) de los cinco grupos del experimento de la corteza prefrontal (GPref-1 a GPref-5, de arriba a abajo, de izquierda a derecha) en representación de las respuestas funcionales medias de las agrupaciones halladas en el espacio de clasificación A. Los electrodos de estimulación de los sujetos que forman los grupos se muestran en negro junto con el mapa estadístico y con la siguiente codificación de colores (según la pertenencia a los grupos) en el último cerebro: rojo para GPref-1, azul para GPref-2, verde para GPref-3, amarillo para GPref-4 y rosa para el último grupo. 

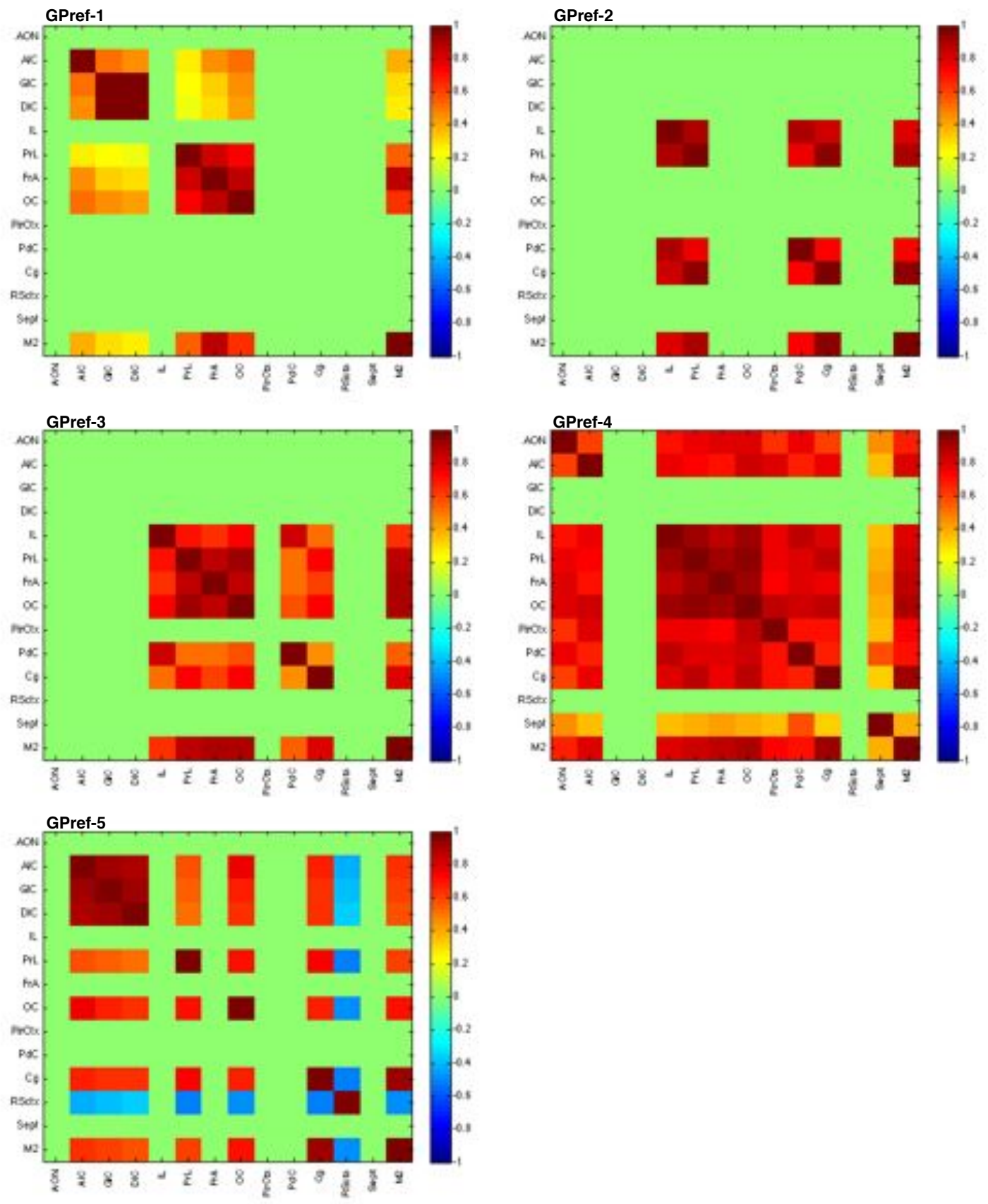

Figura 12.7: Huellas de conectividad de las respuestas medias funcionales de los grupos GPref-1 a GPref-5 halladas entre los diecisiete sujetos del experimento de la corteza prefrontal. Las regiones representadas en las huellas de conectividad quedan fijadas por el total de las que aparecen entre todos los grupos, en aras de facilitar la comparación entre los patrones de conectividad de los grupos. Regiones activas en uno o más de los cinco grupos: AON (anterior olfactory nucleus), $\mathrm{CPu}$ (caudate putamen), AIC (agranular insular cortex), GIC (granular insular cortex), DIC (dysgranular insular cortex), IL (infralimbic cortex), PrL (prelimbic cortex), FrA (frontal association cortex), OC (orbital cortex), PirCtx (piriform cortex), $\mathrm{PdC}$ (peduncular cortex), Cg (cingulate cortex), RSctx (retrosplenial cortex), Sept (septal nucleus), M1 (primary motor cortex) y M2 (secondary motor cortex). 


\section{Capítulo 13}

\section{Análisis del núcleo accumbens}

\subsection{El accumbens}

El núcleo accumbens (o accumbens por simplificación) es un grupo de neuronas del encéfalo localizadas desde el lugar donde el núcleo estriado y la porción anterior del putamen confluyen lateralmente hasta el septum (de hecho, en latín, accumbens significa núcleo que yace sobre el septum). El núcleo accumbens es la parte más importante del estriado ventral y junto con el bulbo olfatorio (AOB, accessory olfactory bulb) conforman el ganglio basal. Cada mitad del cerebro tiene un núcleo accumbens, y cada núcleo accumbens está formado por dos estructuras: una zona central conocida como AcbC (por sus siglas en inglés: accumbens nucleus core) y una región periférica conocida como AcbSh (accumbens nucleus shell). Se piensa que el núcleo accumbens juega un papel importante en el comportamiento, en concreto en la recompensa y el placer [179], la adicción, la agresividad, el efecto placebo e incluso el miedo [180].

\subsubsection{Aferencias y eferencias}

El término aferencia se relaciona con la recepción de conexiones nerviosas que provienen de una parte remota del cerebro, mientras que la eferencia se refiere a la emisión de conexiones nerviosas desde una parte del cerebro a otra que con respecto a ella es considerada periférica. Ocasionalmente nos referimos a las aferencias y eferencias como canales de entrada y salida respectivamente.

\section{Canales de entrada al accumbens}

La mayor parte de las aferencias del accumbens provienen de las regiones que conforman la corteza prefrontal, junto con la parte basolateral de la amígdala (AMY, amygdala) y ciertas neuronas dopaminérgicas localizadas en el área tegmental ventral (VTA, ventral tegmental area). Se considera que las entradas dopaminérgicas provenientes del área tegmental ventral son las que modulan la actividad de las neuronas del núcleo accumbens. Dichas terminales son el sitio de acción de drogas altamente adictivas como la cocaína y la anfetamina-las cuales provocan un aumento en la liberación de dopamina en el núcleo accumbens [181]. Otro conjunto importante de aferencias del núcleo accumbens provienen del hipocampo (HC, hippocampus) [182]. Las terminales que provienen del HC tienen un papel importante en la despolarización de las células del núcleo accumbens.

\section{Canales de salida del accumbens}

Las neuronas eferentes del núcleo accumbens proyectan sus axones fundamentalmente hacia sus análogas de la parte ventral del pálido ventral (VP, ventral pallidum). Éste a su vez proyecta sus axones hacia el núcleo medio dorsal del tálamo (Thal, thalamic nucleus), que proyecta hacia la corteza prefrontal y al núcleo estriado o $\mathrm{CPu}$ 


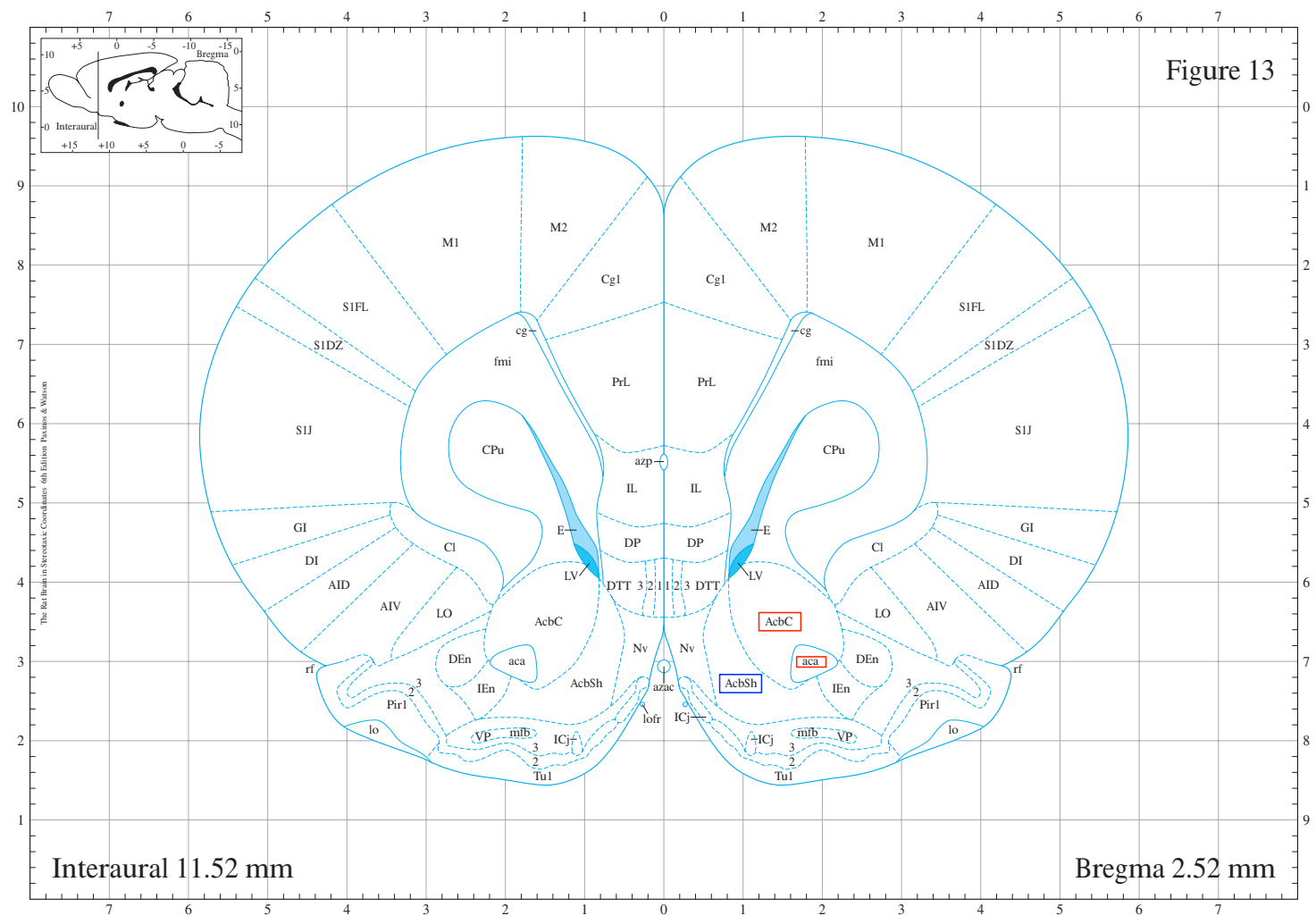

Figura 13.1: Núcleo accumbens y algunas de sus aferencias/eferencias más importantes en el cerebro de la rata [136]. En nuestros experimentos resultan de especial interés el nucleus accumbens core (AcbC) y shell (AcbSh) y la comisura anterior (aca).

(caudate putamen, striatum). Otras eferencias relevantes en el núcleo accumbens incluyen las conexiones con la sustancia negra (SN, substantia nigra) y la formación pontina reticular (Pons, pontine nuclei).

\subsection{Descripción del experimento}

Como ya hicimos en el capítulo anterior, en el presente experimento tratamos de extraer y analizar los patrones de conectividad funcional inducidos en los diez sujetos a los que hemos implantado electrodos de estimulación en las inmediaciones del núcleo accumbens y sometido a un estudio IRMfe-Acc-1 a Acc-10, según lo descrito en el Capítulo 7. El primer paso del análisis consiste en obtener los SPMs de primer nivel de todos y cada uno de los sujetos. Hecho esto, utilizamos el atlas-SPMrat para extraer las señales BOLD-IRMf de las regiones activas de cada respuesta funcional y construir una huella de conectividad por cada sujeto. La Figura 13.2 muestra un análisis regional de cierta respuesta funcional a modo de ejemplo. Después, utilizamos el clasificador de huellas de conectividad para agrupar aquellos patrones de modulación que muestran una actividad subyacente similar y finalmente, obtenemos los mapas estadísticos y las huellas de conectividad de segundo nivel en representación de la respuesta funcional de los grupos que hayamos podido sintetizar. 


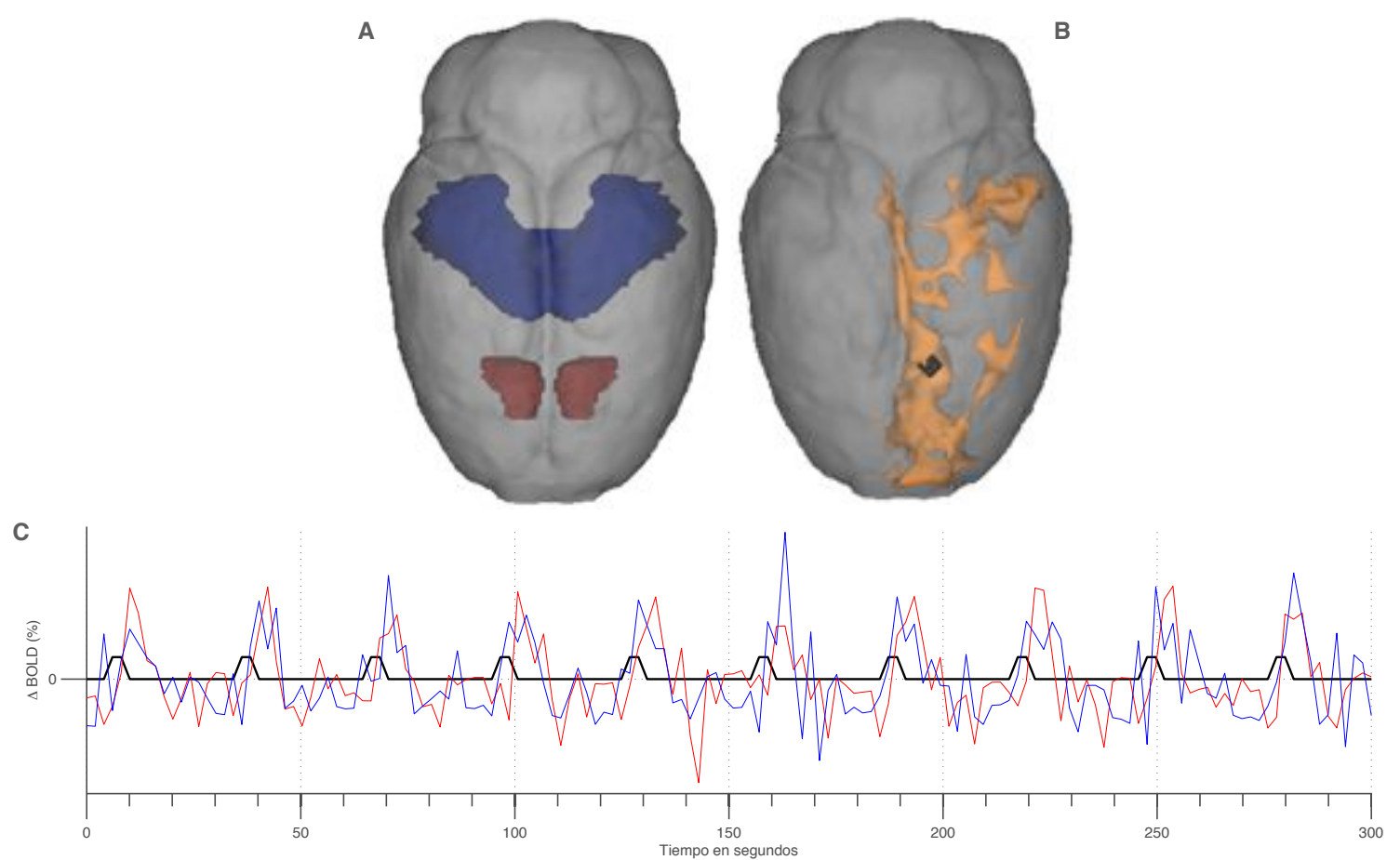

Figura 13.2: Análisis regional de la actividad funcional del sujeto Acc-1. A: núcleo accumbens (en rojo) e hipocampo (en azul) según el atlas tridimensional de propósito general desarrollado para el cerebro de rata. B: mapa estadístico paramétrico del sujeto Acc-1 para una corrección alpashim $(\mathrm{p}=0,05)$ junto con su electrodo de estimulación (en negro). C: señal BOLD-IRMf media en el núcleo accumbens (es decir: AcbC y AcbSh) y el hipocampo (HC, hippocampus) en rojo y azul respectivamente.

\subsection{Desarrollo y resultados}

Los mapas estadísticos paramétricos de la actividad neuronal en el experimento de estimulación del núcleo accumbens los mostramos en la Figura 13.3. La huella de conectividad correspondiente al SPM de la Figura 13.2 (B) la mostramos en la Figura 13.4. Podríamos calificar dicha huella de conectividad como una estructura representativa del experimento, dado que aparecen como regiones activas algunas de las aferencias y eferencias que presuponíamos como activas en la introducción del capítulo (por ejemplo: VTA, HC y SN). Las huellas de conectividad del resto de sujetos se muestran en la Figura 13.5.

Una vez hemos calculado las huellas de conectividad de los diez sujetos, las introducimos en el clasificador de huellas de conectividad para tratar de identificar patrones subyacentes de conectividad funcional. El clasificador determina de forma automática que las conexiones funcionales más significativas son las que se dan entre las regiones activas AON, AcbC, IL, PrL, OC, PdC y Sept.

De este modo, las huellas de conectividad de la Figura 13.5 evaluadas para las regiones de interés (junto con las coordenadas estereotácticas de los electrodos de estimulación) se convierten en las huellas de clasificación que mostramos en la Figura 13.6 y que son los datos sobre los que el clasificador es capaz de realizar agrupaciones de sujetos. En concreto, el clasificador selecciona las cinco primeras componentes principales (que acumulan un $87,55 \%$ del total de la varianza) como la representación adecuada de los datos sobre la que aplicar $k$-means y generar los grupos. Tras evaluar la curva de la varianza intragrupo normalizada [158], obtenemos que el número óptimo de centroides que deberíamos establecer para agrupar a los diez sujetos es de $k=3$ (ver Cuadro 13.1).

Finalmente obtenemos los mapas estadísticos y las huellas de conectivida de segundo nivel, que como sabemos, son aquellos que representan la respuesta funcional media de los grupos en representación global del experimento 

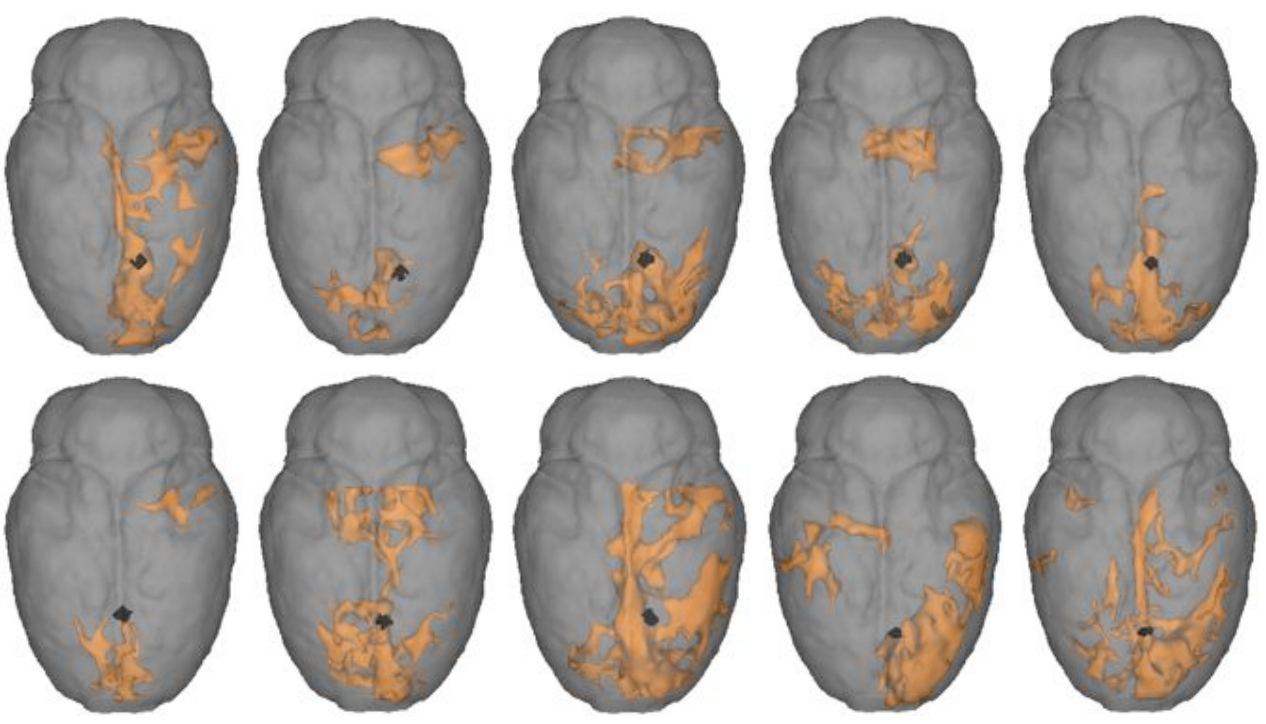

Figura 13.3: Mapas estadísticos paramétricos de primer nivel alphasim $(\mathrm{p}=0,05)$ de los diez sujetos del experimento del núcleo accumbens (Acc-1 a Acc-10, de izquierda a derecha, de arriba a abajo). Los electrodos de estimulación los mostramos en negro junto con el mapa estadístico.

Cuadro 13.1: Grupos generados por el clasificador de huellas de conectividad entre todos los sujetos del experimento del núcleo accumbens.

\begin{tabular}{c|c}
\hline Grupo funcional & Sujetos del grupo \\
\hline GAcc-1 & $\begin{array}{c}\text { Acc-1, Acc-3, Acc-4 } \\
\text { Acc-5, Acc-7 y Acc-8 }\end{array}$ \\
\hline GAcc-2 & Acc-2 y Acc-6 \\
\hline GAcc-3 & Acc-9 y Acc-10 \\
\hline
\end{tabular}

(Figura 13.7).

\subsection{Discusión}

A la vista del Cuadro 13.1, entre los diez sujetos del núcleo accumbens detectamos tres patrones subyacentes diferenciables de actividad funcional. La huella de conectividad del grupo GAcc-1 es consistente con el hecho de haber ubicado el electrodo de microestimulación en el accumbens nucleus core (AcbC), dado que es la única huella que incluye conexiones con la amígdala (AMY). No obstante, su gran extensión nos hace pensar sobre la posibilidad de haber podido estimular la comisura anterior (aca, anterior commissure), que es un haz de fibras que proyecta de forma dispersa en toda la región frontal y subcortical. En cualquier caso, dichas opciones no son excluyentes si tenemos en cuenta que la comisura anterior forma parte del núcleo accumbens (como puede observarse en la Figura 13.1). En cuanto al grupo GAcc-2, tanto por la ubicación de los electrodos de estimulación eléctrica (que de alguna forma parecen envolver a los electrodos sobre el núcleo accumbens core; Figura 13.7-B, electrodos en rojo vs. electrodos en azul), como por presentar conexiones funcionales con la corteza prefrontal, frontal y con el hipocampo (HC), resulta consistente con el hecho que el núcleo cerebral activado sea el accumbens 


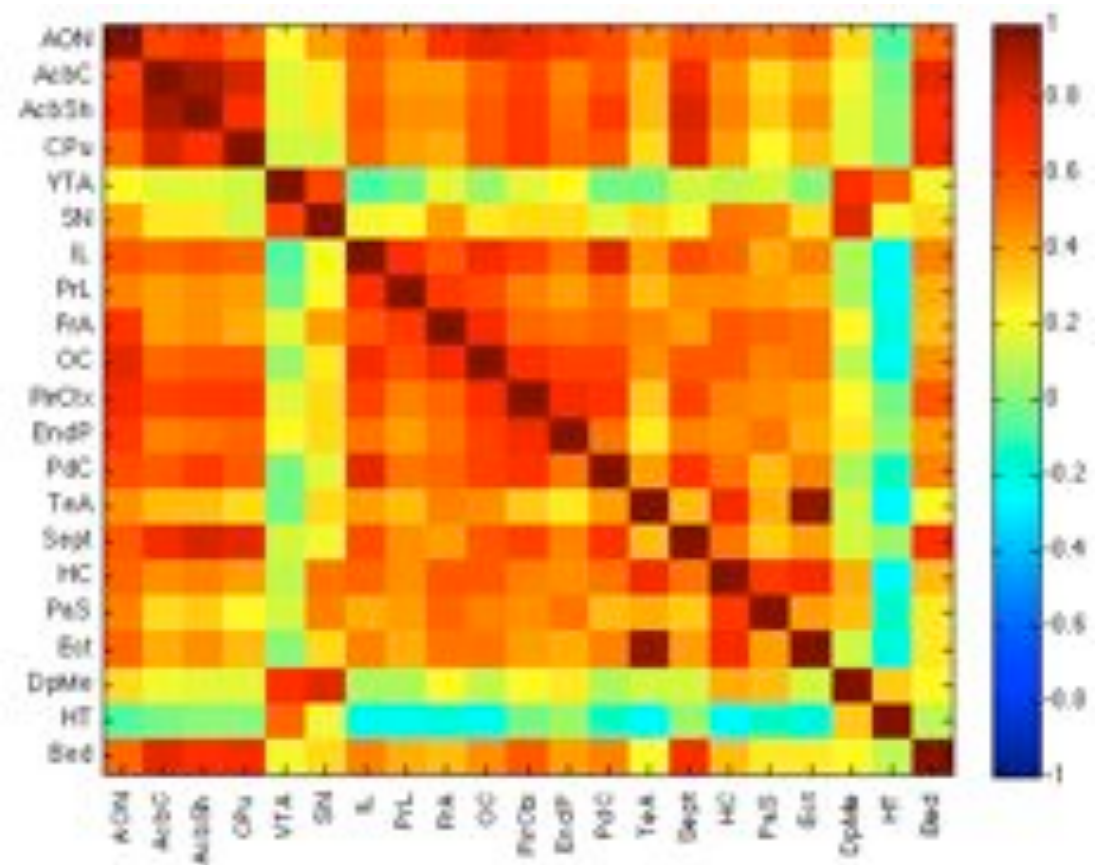

Figura 13.4: Huella de conectividad (alpha., 0,05) del sujeto Acc-1. Las regiones del núcleo accumbens (AcbC y AcbSh, accumbens core y shell respectivamente) presentan (como era de esperar) el mayor peso de conectividad, dado que la correlación entre sus series de tiempo BOLD-IRMf está cercana al 0,95 (rojo oscuro). En cambio, la relación de conectividad entre el núcleo accumbens y la aferencia VTA (ventral tegmental area) existe, pero su peso es mucho menor $(0,17$, verde claro). El resto de regiones activas en respuesta al estímulo son: AON (anterior olfactory nucleus), $\mathrm{CPu}$ (caudate putamen), SN (substantia nigra), IL (infralimbic cortex), PrL (prelimbic cortex), FrA (frontal association cortex), OC (orbital cortex), PirCtx (piriform cortex), EndP (endopiriform nucleus), PdC (dorsal peduncular cortex), TeA (temporal association cortex), Sept (septal nucleus), HC (hippocampus), PaS (parasubiculum), Ect (ectorhinal cortex), DpMe (deep mesencephalic), HT (hypothalamus) y Bed (bed nucleus of the stria terminalis).

core shell (AcbSh). Además observamos que las respuestas funcionales de los sujetos individuales que contribuyen al grupo GAcc-2 (es decir: Acc-2 y Acc-6) se caracterizan por una conectividad prácticamente nula entre las regiones IL, PrL y OC (dado que las correlaciones cruzadas entre ellas son inferiores a 0,16). Finalmente, las conexiones funcionales representadas en la huella de conectividad del grupo GAcc-3 parecen proyectar de forma mayoritaria, si no exclusiva, a la cortez prefrontal, frontal, prelímbica, infralímbica y cingulada $(\mathrm{Cg}$, cingulate cortex) que podría ser una actividad funcional más característica de los electrodos en una región más anterior del núcleo accumbens (Figura 13.7-B, en verde). 

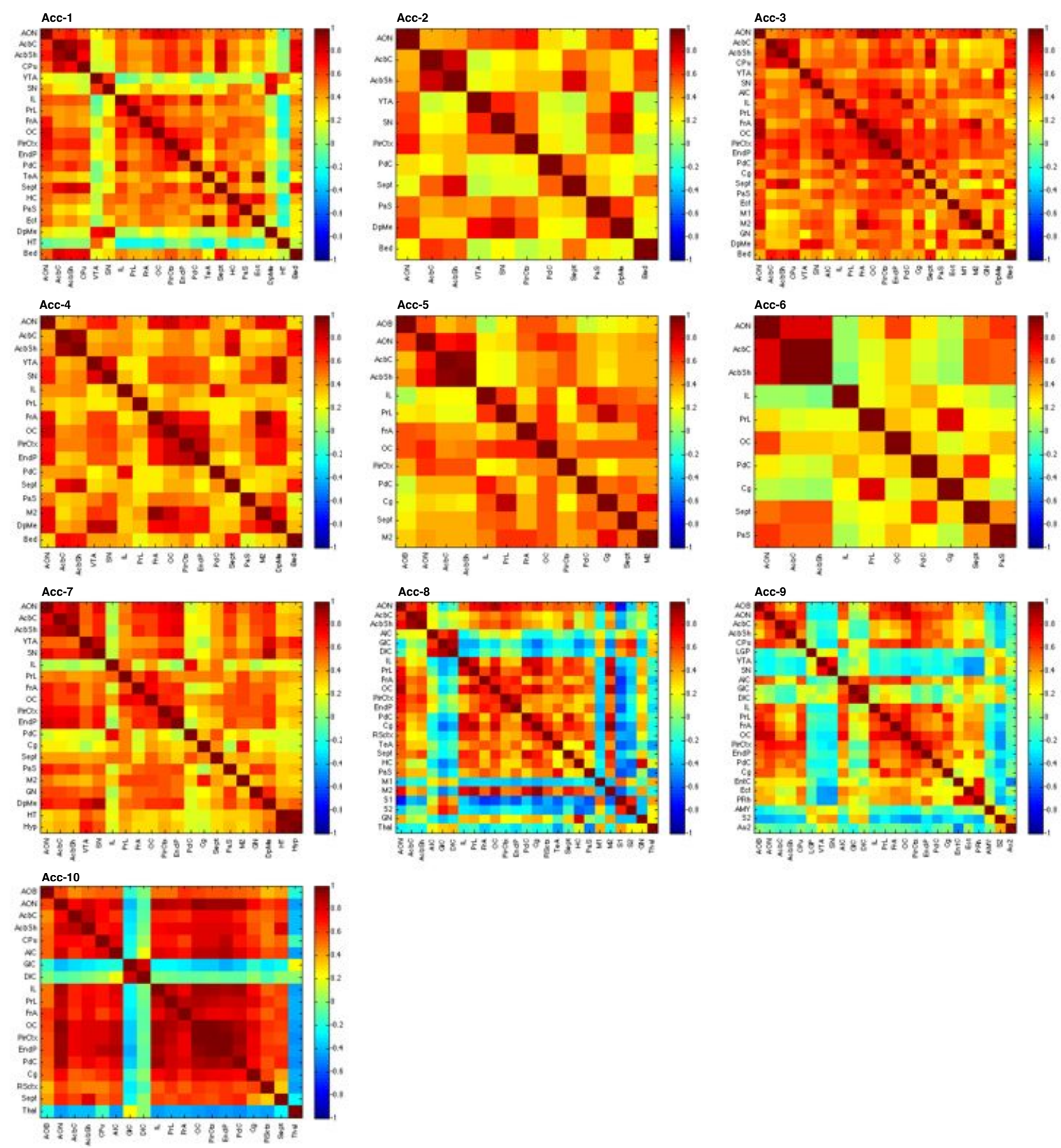

Figura 13.5: Huellas de conectividad (alpha., 0,05) de los sujetos Acc-1 a Acc-10. Dado que es altamente improbable que dos sujetos muestren un mismo patrón de modulación sináptica, en la práctica consideramos que cada huella de conectividad es única e identifica unívocamente al sujeto a quien representa. Regiones activas en uno o más de los diez sujetos: AOB (accessory olfactory bulb), AON (anterior olfactory nucleus), AcbC (accumbens core), AcbSh (accumbens shell), CPu (caudate putamen), VTA (ventral tegmental area), SN (substantia nigra), AIC (agranular insular cortex), GIC (granular insular cortex), DIC (dysgranular insular cortex), IL (infralimbic cortex), PrL (prelimbic cortex), FrA (frontal association cortex), OC (orbital cortex), PirCtx (piriform cortex), EndP (endopiriform nucleus), PdC (dorsal peduncular cortex), Cg (cingulate cortex), RSctx (retrosplenial agranular cortex), TeA (temporal association cortex), Sept (septal nucleus), HC (hippocampus), PaS (parasubiculum), EntC (entorhinal cortex), Ect (ectorhinal cortex), PRh (perirhinal cortex), AMY (amygdala), M1 (primary motor cortex), M2 (secondary motor cortex), S1 (primary somatosensory cortex), S2 (secondary somatosensory cortex), Au2 (secondary auditory cortex), GN (geniculate nucleus), Thal (thalamic nucleus),DpMe (deep mesencephalic), HT (hypothalamus), Hyp (hypothalamic area) y Bed (bed nucleus of the stria terminalis). 

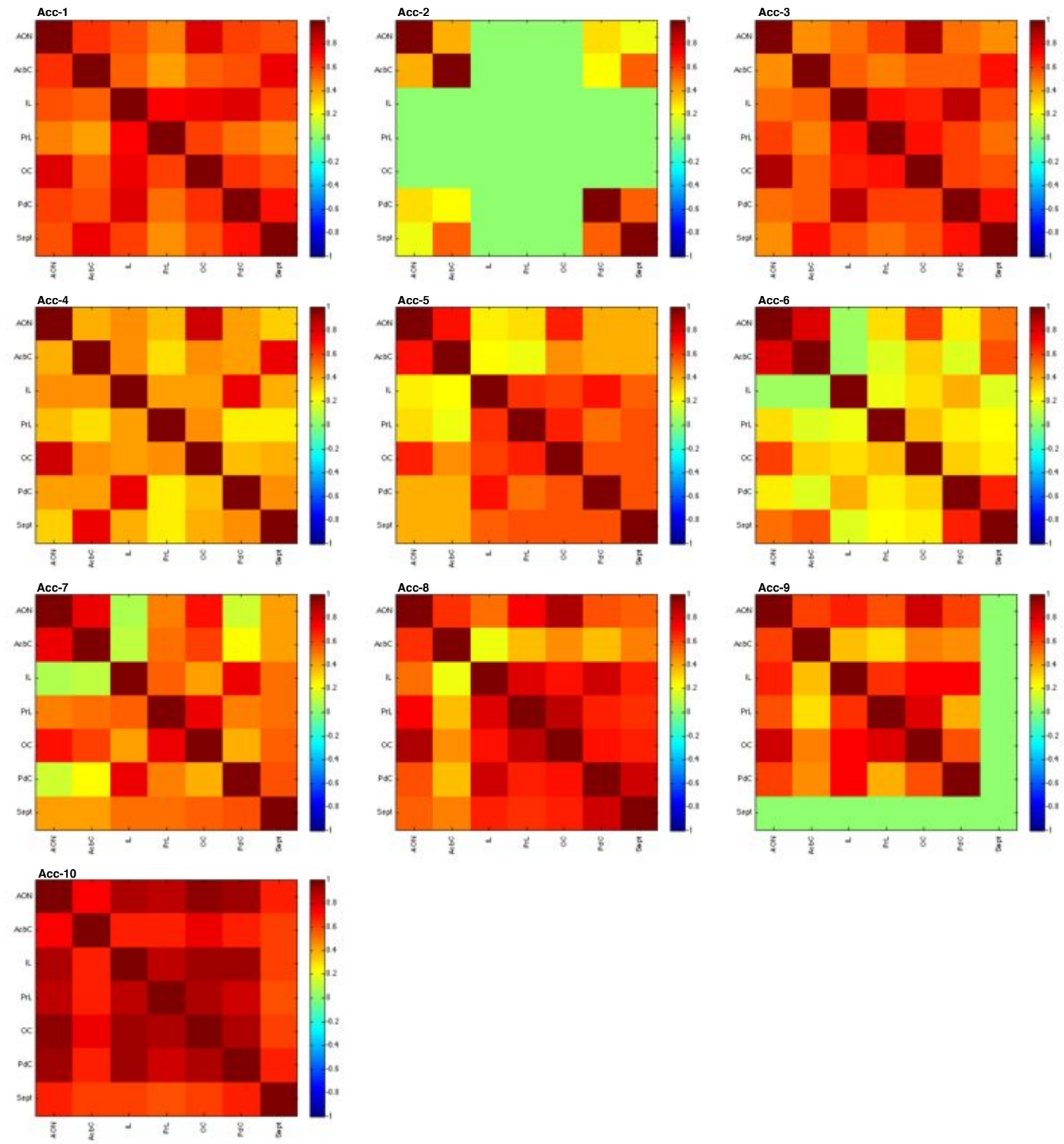

Figura 13.6: Huellas de clasificación de los nueve sujetos del experimento que analiza el núcleo accumbens. Las huellas de clasificación son una versión hipodimensional de las huellas de conectividad y se acompañan con las coordenadas estereotácticas normalizadas de los electrodos de estimulación. Regiones de interés: AON (anterior olfactory nucleus), AcbC (accumbens core), IL (infralimbic cortex), PrL (prelimbic cortex), OC (orbital cortex), PdC (dorsal peduncular cortex) y Sept (septal nucleus). 
A - ANÁLISIS DE SEGUNDO NIVEL
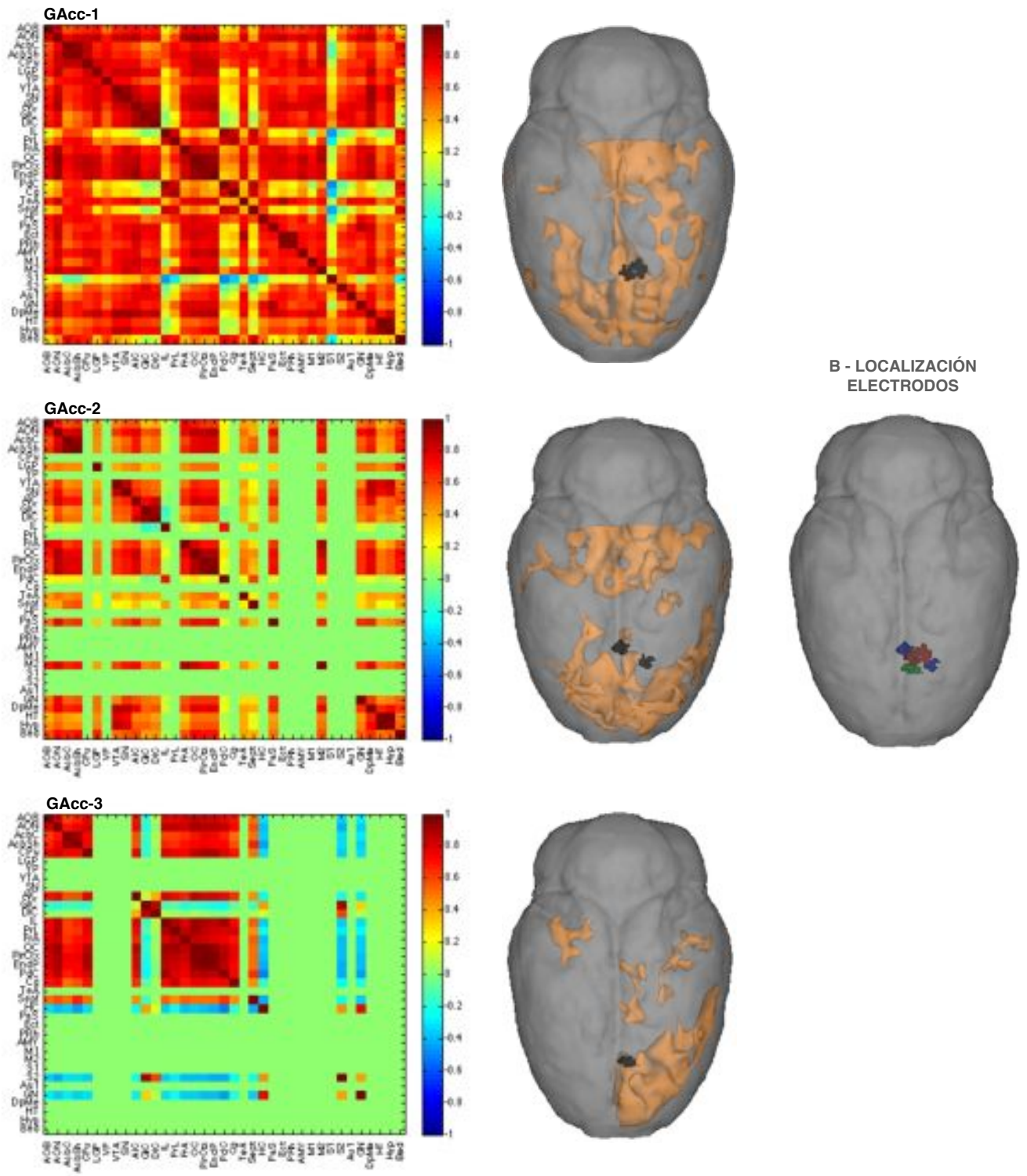

Figura 13.7: A: mapas estadísticos paramétricos y huellas de conectividad de segundo nivel (alpha., 0,05), en representación de las respuestas funcionales medias de las agrupaciones halladas entre los diez sujetos del experimento del núcleo accumbens. Los electrodos de estimulación de los sujetos que forman los grupos se muestran en negro junto con el mapa estadístico. Las regiones representadas en las huellas de conectividad quedan fijadas por el total de las que aparecen entre todos los grupos, en aras de facilitar la comparación entre los patrones de conectividad de los grupos. Regiones activas en uno o más de los tres grupos: AOB (accessory olfactory bulb), AON (anterior olfactory nucleus), AcbC (accumbens nucleus core), AcbSh (accumbens nucleus shell), CPu (caudate putamen), LGP (lateral globus pallidus), VP (ventral pallidum), VTA (ventral tegmental are), SN (ubstantia nigra), AIC (agranular insular cortex), GIC (granular insular cortex), DIC (dysgranular insular cortex), IL (infralimbic cortex), PrL (prelimbic cortex), FrA (frontal association cortex), OC (orbital cortex), PirCtx (piriform cortex), EndP (endopiriform nucleus), PdC (peduncular cortex), Cg (cingulate cortex), RSctx (retrosplenial cortex), TeA (temporal association cortex), Sept (septal nucleus), HC (hippocampus), PaS (parasubiculum), Ect (ectorhinal cortex), PRh (perirhinal cortex), AMY (amygdala), M1 (primary motor cortex), M2 (secondary motor cortex), S1 (primary somatosensory cortex), $\mathrm{S} 2$ (secondary somatosensory cortex), Au1 (primary auditory cortex), GN (geniculate nucleus), DpMe (deep mesencephalic), HT (hypothalamus), Hyp (hypothalamic area) y Bed (bed nucleus of the stria terminalis). B: electrodos de estimulación codificados en colores según la pertenencia a los grupos: rojo para GAcc-1, azul para GAcc-2 y en verde para el último grupo. 


\section{Capítulo 14}

\section{Análisis del sistema vestibular}

\subsection{El sistema vestibular}

Uno de los problemas más importantes (y fascinantes) a los que se enfrenta la neurociencia es la forma en la que el cerebro representa el entorno. El sistema vestibular (formado por dos ensanchamientos: el utrículo y el sáculo) es posiblemente el de mayor influencia funcional en el sistema nervioso central pues además de ser el responsable de coordinar nuestra orientación y movimientos en el espacio [183] se sospecha que influye en la visión, la escucha, la cognición, el sueño, la digestión y el aprendizaje y la memoria. No obstante, pese a la importancia de la información vestibular en la mayoría de las acciones que realizamos a diario, los principios funcionales que permiten su representación y procesamiento cortical están por esclarecer-registros electrofisiológicos de la información extracelular y estudios basados en neuroimágenes muestran un sistema vestibular muy complejo en los primates, incluyendo al ser humano [184]. En el caso de los roedores, como es habitual, muy poco se sabe sobre cómo las áreas de la corteza prefrontal responden a la estimulación del sistema vestibular.

\subsubsection{Aferencias}

El sistema vestibular está formado por tres acelerómetros angulares (los canales semicirculares) y dos acelerómetros lineales (los otolitos). Sus células sensoriales generan impulsos que llegan hasta el cerebelo, lo que nos permite mantener el equilibrio a pesar de que realicemos desplazamientos, giros o aceleraciones. Por lo tanto cada estímulo generado en el sistema vestibular queda descrito por seis parámetros (tres aceleraciones axiales y tres lineales), cuyas combinaciones pueden estimularse de forma aislada mostrando aferencias que controlan el movimiento de la cabeza [185]. Dichas aferencias convergen en las neuronas del núcleo vestibular, que son las que se interconectan con el tálamo (Thal, thalamic nucleus) y el cerebelo [186].

\subsection{Descripción del experimento}

En el presente experimento tratamos de establecer qué otros canales de comunicación (además de con el tálamo y el cerebelo) se establecen en las áreas corticales cuando se estimula el sistema vestibular. La localización (o mapeo) de las aferencias y eferencias del sistema vestibular es un punto clave para entender el cómo nuestro sistema nervioso procesa la información sensorial. Para ello, y en colaboración con el grupo del Dr. Troy W. Margrie del University College of London, hemos desarrollado una metodología para estimular el nervio vestibular en las ratas [125].

Con dicho objetivo nos valemos de algunas huellas de conectividad y del análisis mean shift del espacio funcional de ciertos mapas estadísticos paramétricos seleccionados estratégicamente. La descomposición de la respuesta global integrada en sistemas funcionales de vóxels y el cálculo de los mapas multiparamétricos asociados 


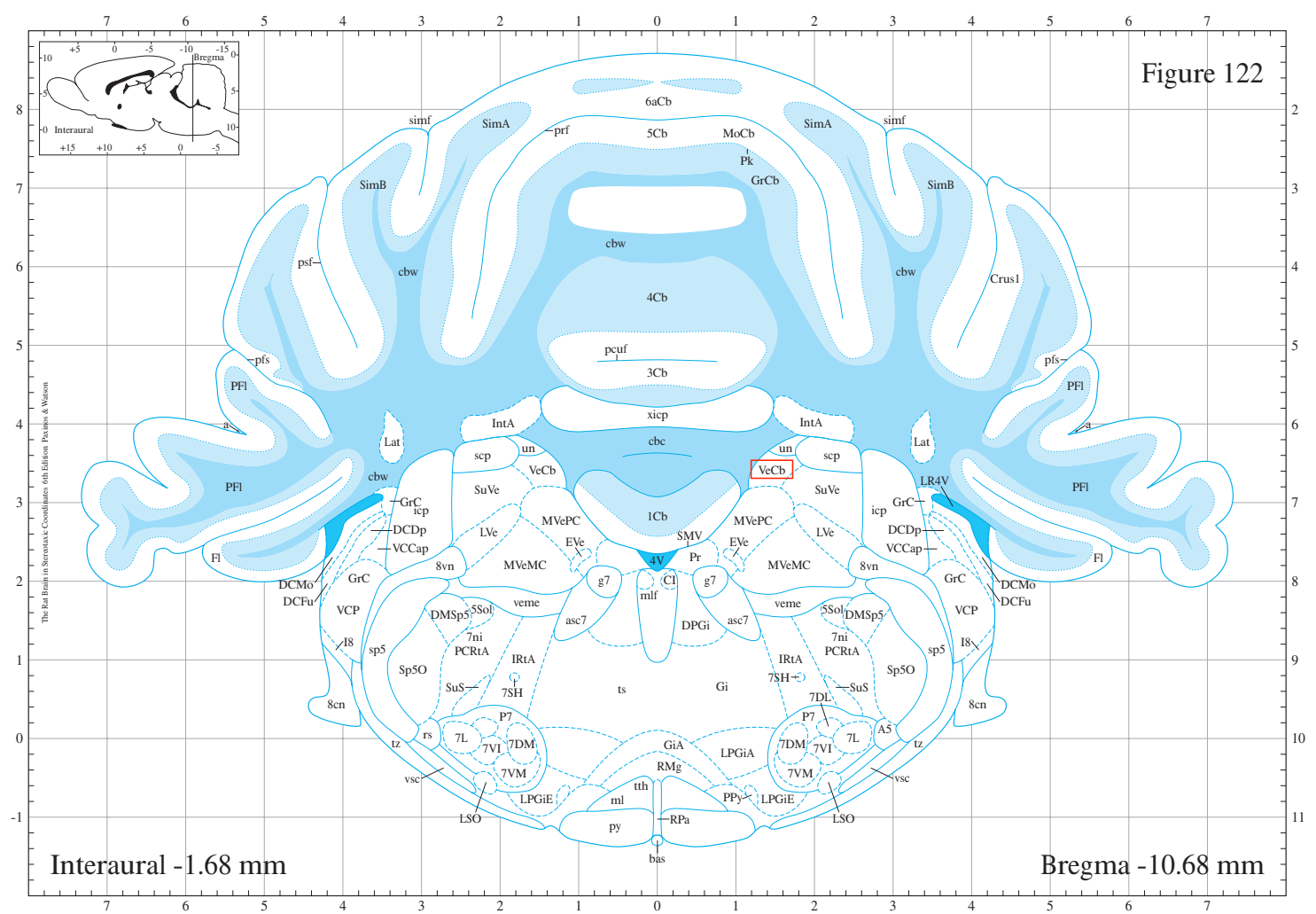

Figura 14.1: Localización del nervio vestibular (VeCb, vestibulocerebellar nucleus) en el cerebro de la rata [136].

al módulo y la fase del espacio funcional (similares a los de la Figura 10.5) nos permiten localizar los máximos de significancia estadística de cada cluster (o grupo de vóxels con una respuesta al estímulo correlada), que a su vez nos indican las coordenadas estereotácticas donde registrar los potenciales de campo y disparos neuronales para verificar la presencia de conexiones vestibulares.

\subsection{Desarrollo y resultados}

\subsubsection{Mapas estadísticos paramétricos y huellas de conectividad}

Los mapas estadísticos paramétricos de la Figura 14.2 sugieren la existencia de un patrón de modulación sináptica muy claro y conciso, por lo que decidimos analizar todos los sujetos como un único grupo funcional sin necesidad de utilizar el clasificador de huellas de conectividad. No obstante, calculamos las huellas de conectividad de los cinco sujetos (Figura 14.3) con el ánimo de verificar dicha hipótesis, la cual confirmamos tras comprobar que los patrones de modulación sináptica subyacente de los sujetos comparten la mayoría de las relaciones de conectividad funcional (Cuadro 14.1).

Contrastada la esencia de grupo entre los sujetos (llamamos al grupo GVest), procedemos a obtener la respuesta de segundo nivel con un análisis GLM/FFX. La respuesta media del grupo la mostramos en la Figura 14.5 para tres correcciones diferentes: family wise error $(\mathrm{p}=0,05)$, uncorrected $(\mathrm{p}=0,001)$ y alphasim $(\mathrm{p}=0,05)$. Si observamos las huellas de conectividad del grupo para las tres correcciones estadísticas, encontramos que en las tres pruebas estadísticas (incluyendo la más restrictiva) aparecen como regiones activas no únicamente las que se 

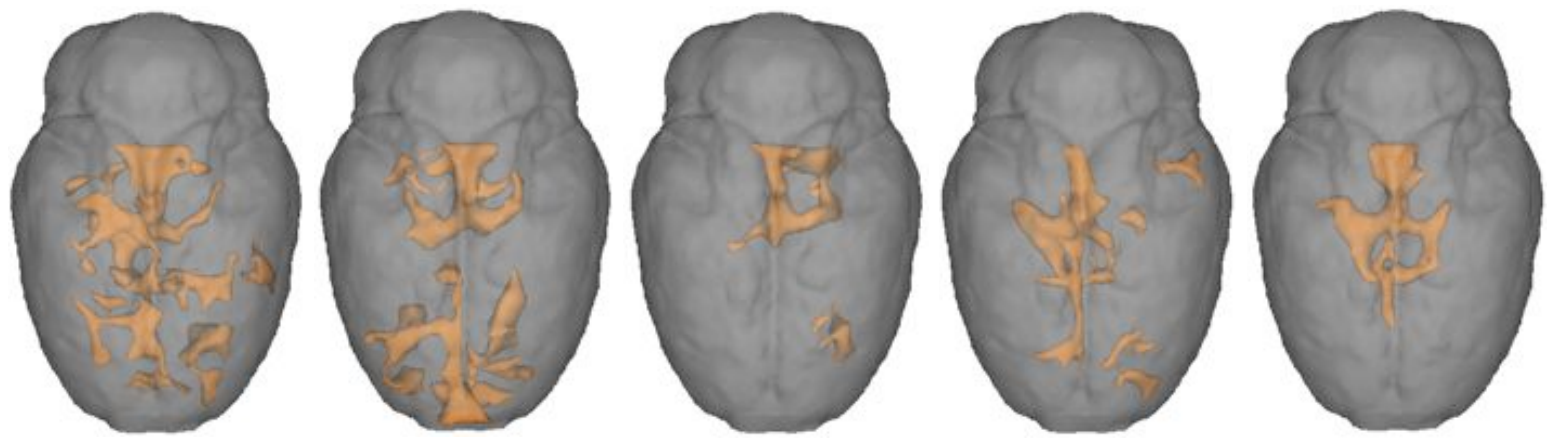

Figura 14.2: Mapas estadísticos paramétricos de primer nivel (alpha., $\mathrm{p}=0,05)$ ) de los cinco sujetos del experimento del sistema vestibular (Vest-1 a Vest-5, de izquierda a derecha).
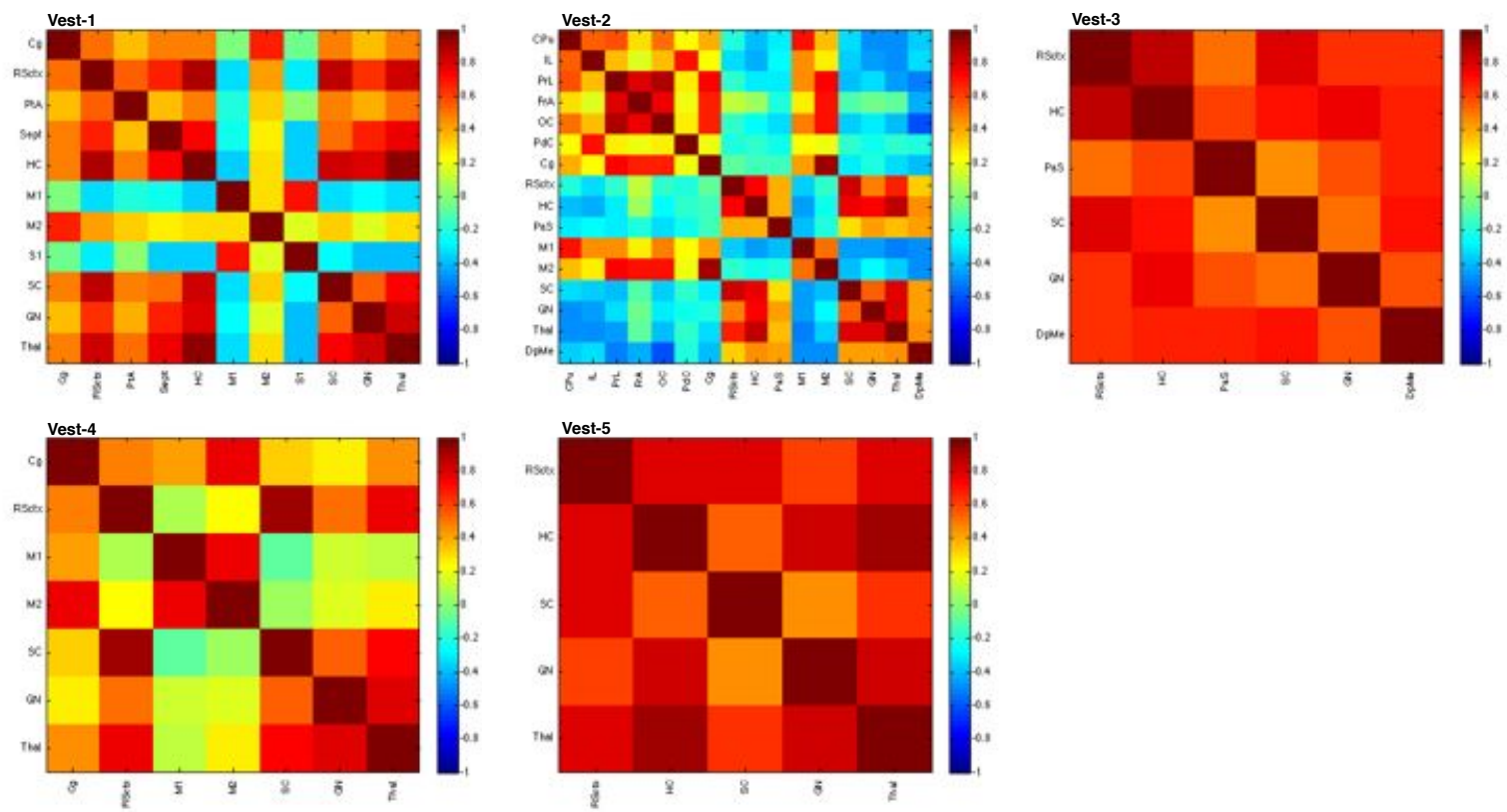

Figura 14.3: Huellas de conectividad (alpha., 0,05) de los sujetos Vest-1 a Vest-5. Regiones activas en uno a más de los cinco sujetos: $\mathrm{CPu}$ (caudate putamen), IL (infralimbic cortex), PrL (prelimbic cortex), FrA (frontal association cortex), OC (orbital cortex), PdC (peduncular cortex), Cg (cingulate cortex), RSctx (retrosplenial cortex), PtA (parietal association cortex), Sept (septal nucleus), HC (hippocampus), PaS (parasubiculum), M1 (primary motor cortex), M2 (secondary motor cortex), S1 (primary somatosensory cortex), SC (superior colliculus), GN (geniculate nucleus), Thal (thalamic nucleus) y DpMe (deep mesencephalic).

preveían según el análisis de primer nivel (por ejemplo: Rsctx, HC, SC o Thal) sino que además encontramos una respuesta funcional estadísticamente relevante (soportada por un análisis de efectos fijos e inferencias restrictivas) en regiones de la corteza prefrontal como PrL (prelimbic cortex), OC (orbital cortex) o PdC (peduncular cortex). Como era de esperar por los colores azulados de las huellas de conectividad de segundo nivel, las respuestas funcionales medias de las regiones localizadas en la corteza prefrontal parecen responder de forma inversa al 
Cuadro 14.1: Regiones activas en cuatro o más sujetos del experimento del nervio vestibular. Algunas regiones están activas en el $100 \%$ de los sujetos: RSctx (retrosplenial cortex), SC (superior colliculus) y GN (geniculate nucleus).

\begin{tabular}{c|c}
\hline $\begin{array}{c}\text { Región } \\
\text { Activa }\end{array}$ & $\begin{array}{c}\text { Sujeto } \\
\text { no activo }\end{array}$ \\
\hline RsCtx & - \\
\hline HC & Vest-4 \\
\hline SC & - \\
\hline GN & - \\
\hline Thal & Vest-3 \\
\hline
\end{tabular}

estímulo (Figura 14.4).

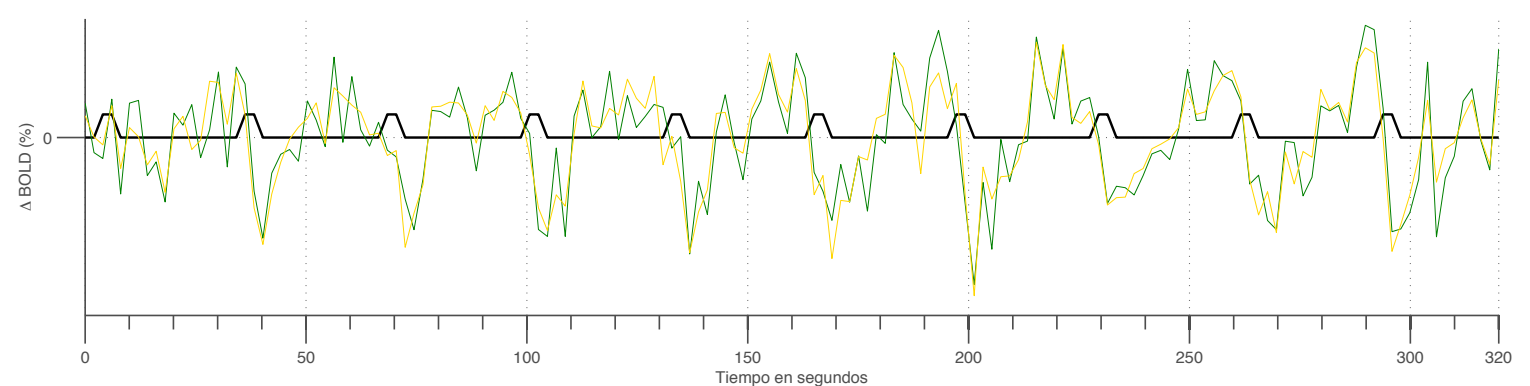

Figura 14.4: Señales medias BOLD-IRMf del grupo GVest (unc., $\mathrm{p}=0,05$ ) en las regiones de la corteza prefrontal PrL o prelimbic cortex (en verde) y OC u orbital cortex (en amarillo). Como era de prever por las huellas de conectividad calculadas, las respuestas funcionales de dichas regiones parecen ser inhibiciones al estímulo.

\subsubsection{Registro electrofisiológico}

Para localizar estereotácticamente los puntos donde ubicar los electrodos para el registro electrofisiológico, utilizamos el análisis mean shift de los espacios funcionales para identificar como dianas los puntos de mayor significancia estadística de cada cluster o sistema funcional.

\section{Sistemas funcionales y dianas para el registro}

Si asumimos como respuesta funcional media del grupo la correspondiente al mapa estadístico uncorrected (Figura 14.5, centro) y aplicamos el algoritmo de clustering mean shift sobre el espacio métrico de la conectividad funcional (o espacio funcional), obtenemos que existen dos sistemas funcionales (Figura 14.6, A y B) formados por clusters de vóxels cuyas series temporales BOLD-IRMf en respuesta al estímulo están correladas entre sí, formando los modos hemodinámicos que mostramos en la Figura 14.6 (C y D).

Cuando analizamos el mapa de estadísticos $\mathrm{Z}$ asociado al módulo de los vóxeles del cluster uno, obtenemos que el máximo global de significancia estadística está en la región del hipocampo (HC), seguido del tálamo (Thal) o la corteza retrosplenial (RSctx) entre otros-Cuadro 14.2. En el caso del cluster dos, el máximo global lo localizamos en la corteza prelímbica o PrL (Cuadro 14.3). 

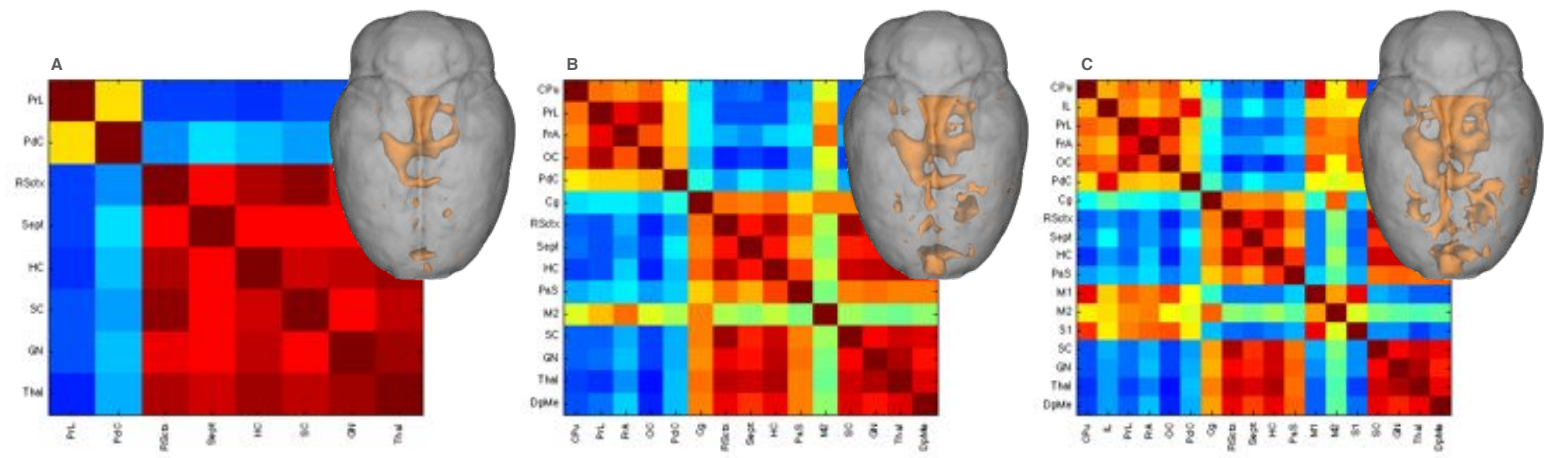

Figura 14.5: Huellas de conectividad (y respuestas funcionales medias) del grupo GVest para las correcciones estadísticas (de izquierda a derecha): family wise error $(\mathrm{p}=0,05)$, uncorrected $(\mathrm{p}=0,001)$ y alphasim $(\mathrm{p}=0,05)$. Regiones activas en las distintas pruebas estadísticas: CPu (caudate putamen), IL (infralimbic cortex), PrL (prelimbic cortex), FrA (frontal association cortex), OC (orbital cortex), PdC (peduncular cortex), Cg (cingulate cortex), RSctx (retrosplenial cortex), Sept (septal nucleus), HC (hippocampus), PaS (parasubiculum), M1 (primary motor cortex), M2 (secondary motor cortex), S1 (primary somatosensory cortex), SC (superior colliculus), GN (geniculate nucleus), Thal (thalamic nucleus) y DpMe (deep mesencephalic).

Cuadro 14.2: Valores estadísticos máximos para el cluster uno. El máximo global se da para el hipocampo (HC, hippocampus). El resto de regiones son (por orden de aparición): Thal (thalamic nucleus), RSctx (retrosplenial cortex), GN (geniculate nucleus) y $\mathrm{Cg}$ (cingulate cortex)

\begin{tabular}{c|c|c}
\hline ROI & Coordenada $\mathbf{z}$ & Estadístico $\mathbf{Z}$ \\
\hline HC & 24 & 2,23 \\
\hline Thal & 18 & 1,98 \\
\hline RSctx & 29 & 1,94 \\
\hline GN & 20 & 1,78 \\
\hline Cg & 30 & 1,14 \\
\hline
\end{tabular}

Cuadro 14.3: Valores estadísticos máximos para el cluster dos. El máximo global se da para la corteza prelímbica (PrL, prelimbic cortex). El resto de regiones son (por orden de aparición): OC (orbital cortex) y FrA (frontal association cortex).

\begin{tabular}{c|c|c}
\hline ROI & Coordenada $\mathbf{z}$ & Estadístico $\mathbf{Z}$ \\
\hline PrL & 16 & 2,60 \\
\hline OC & 16 & 2,58 \\
\hline FrA & 28 & 1,53 \\
\hline
\end{tabular}

Estos resultados nos indican las coordenadas z donde implantar los electrodos de registro electrofisiológico que puedan corroborar la existencia de actividad neuronal apuntada por el sistema funcional analizado. En este sentido, el trabajo de registro electrofisiológico realizado por Rancz et al. [125] bajo las hipótesis aquí apuntadas permite afirmar que el nervio vestibular se conecta funcionalmente con el tálamo (como era de esperar) [187], pero también con la corteza retrosplenial (Figura 14.7). Finalmente, con la intención de arrojar luz sobre las respuestas 


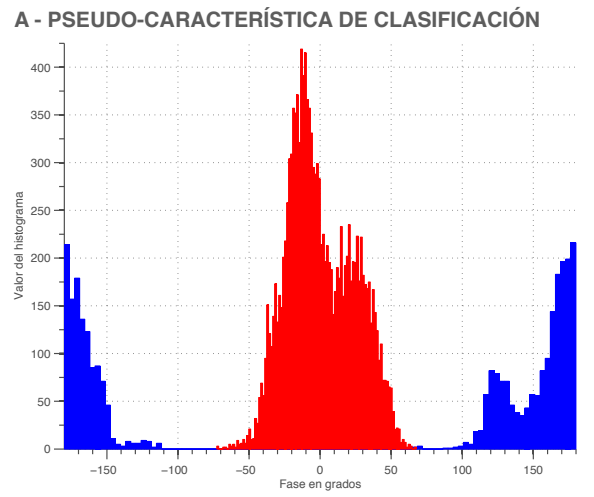

B - ESPACIO FUNCIONAL AGRUPADO
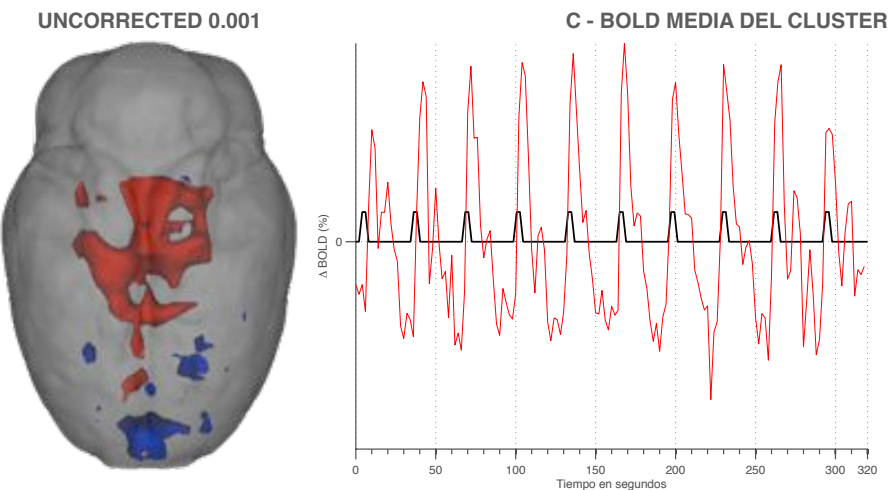

D - BOLD MEDIA DEL CLUSTER 2
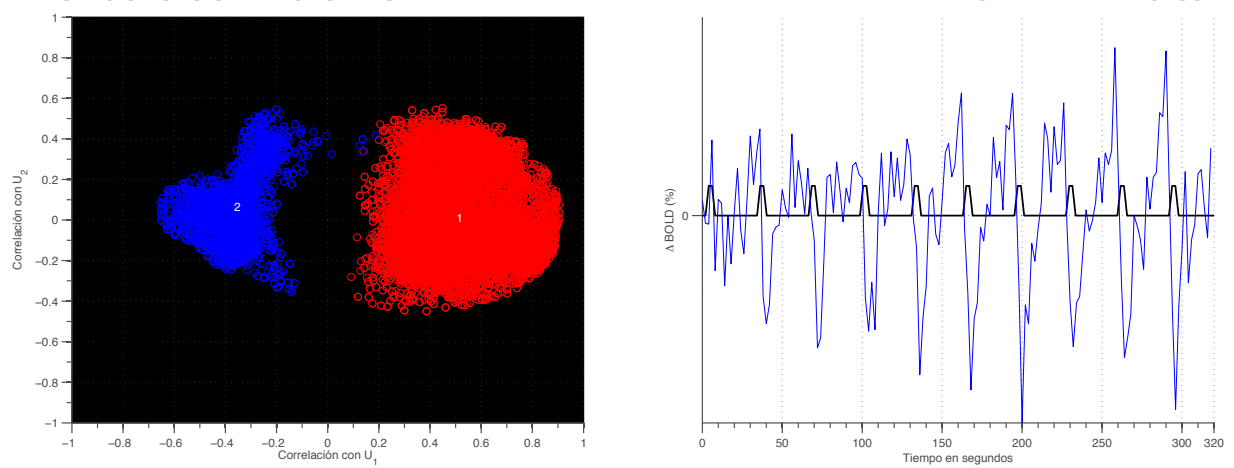

Figura 14.6: Análisis del sistema funcional del grupo GVest (unc., $\mathrm{p}=0,001$ ). A y B: mediante el algoritmo mean shift somos capaces de detectar dos agrupaciones de supra-vóxeles (cluster uno, en rojo; cluster dos, en azul) cuyas series temporales BOLD-IRMf están acopladas temporalmente, formando sendos sistemas funcionales. Las subfiguras C y D muestran las señales BOLD-IRMf representativas de dichos clusters, destacando sobremanera la respuesta funcional inversa del modo hemodinámico del cluster dos.

BOLD negativas (o negativamente correladas con el estímulo) halladas en la corteza prefrontal, será interesante en el futuro proceder a la implantación de un electrodo en la región PrL—dada la ambigüedad que a día de hoy todavía existe sobre el origen biológico de estas respuestas funcionales negativas [50, 126]. En esta línea, existe la posibilidad que la respuesta BOLD-IRMf negativa (y su inclusión como supra-vóxels en el SPM) se deba a la compensación del efecto global no neuronal de la ganancia (Figura 5.3). No obstante, la presencia de actividad PrL en la huella de conectividad de grupo más restrictiva (Figura 14.5, A) respalda la necesidad de realizar un registro electrofisiológico en la zona.

\subsection{Discusión}

Los resultados obtenidos con nuestra metodología mean shift de descomposición de la respuesta neuronal integrada es útil no solo para corroborar conocimientos anatómicos previos, si no sobre todo para identificar nuevas áreas conectadas funcionalmente, de manera indirecta, por otros territorios cerebrales. Por ejemplo, hasta día de hoy era desconocida la conexión entre el nervio vestibular y la corteza retrosplenial-hecho que nos indican los mapas estadísticos paramétricos, las huellas de conectividad y los espacios/sistemas funcionales y que nos corrobora la electrofisiología. Además, este estudio nos confirma que nuestros métodos de análisis se complementan de 
A - Resultados RMf: señales BOLD medias en el tálamo y corteza retrosplenial

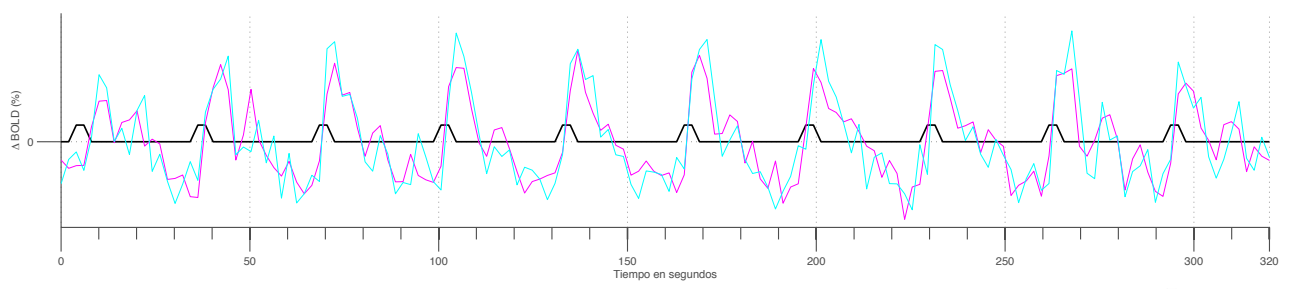

B - Coordenadas z y resultados registro electrofisiológico
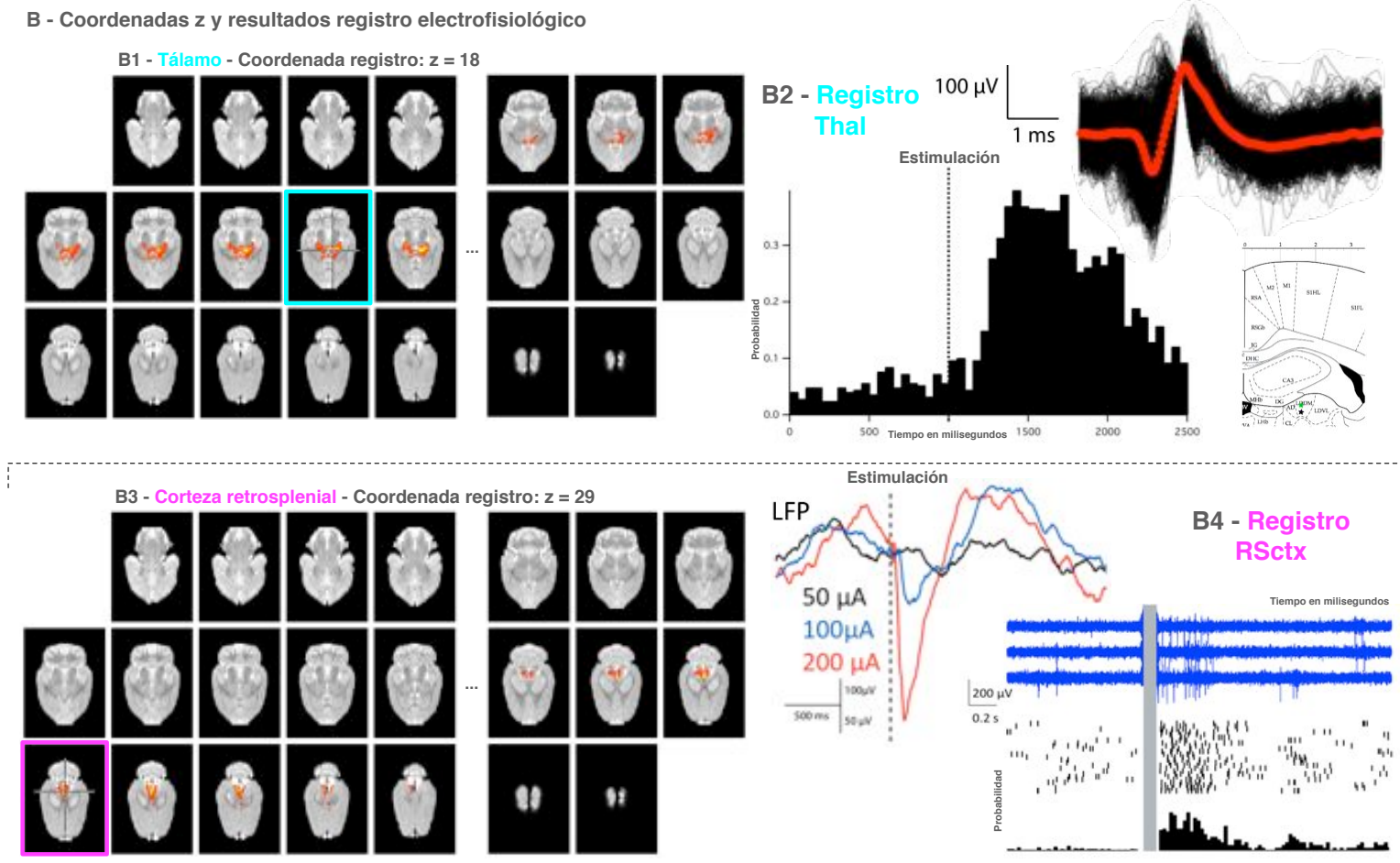

Figura 14.7: Registro electrofisiológico de las regiones Thal (thalamic nucleus) y RSctx (retrosplenial cortex). A: la respuesta funcional del cluster uno (Figura 14.6, en rojo) es una respuesta hemodinámica BOLD-IRMf que responde positivamente al estímulo e incluye las respuestas del tálamo (en cian) y de la corteza retrosplenial (en magenta). B1 y B2: registro electrofisiológico del tálamo. El recuadro cian indica la coordenada z que localiza el máximo local que corresponde al tálamo $(\mathrm{Z}=1,98$, z=18). B3 y B4: registro electrofisiológico de la corteza retrosplenial. El recuadro magenta indica la coordenada z que localiza el máximo local que corresponde a la corteza retrosplenial $(\mathrm{Z}=1,94, \mathrm{z}=29)$.

forma muy satisfactoria. En este sentido, las huellas de conectividad funcional nos permiten delinear el network, mientras que los espacios funcionales nos permiten identificar los puntos donde las conexiones son más robustas. En el experimento desarrollado en el presente capítulo, el análisis de los modos hemodinámicos de la descomposición mean shift nos han permitido: 1) evaluar por primera vez el peso de la conexión vestíbulo-talámica y 2) identificar nuevas áreas influenciadas por el nervio vestibular, destacando sobremanera una actividad BOLD negativa que se estudiará en profundidad en futuros experimentos. 


\section{Capítulo 15}

\section{Principios funcionales de la ECP}

\subsection{Estimulación cerebral profunda}

La estimulación cerebral profunda o $\mathrm{ECP}^{1}$ es un tratamiento neuroquirúrgico usado para tratar gran variedad de transtornos neurológicos en humanos-aunque los más comunes son aquellos relacionados con la enfermedad de Parkinson, la distonía, el temblor esencial, los dolores de cabeza crónicos o la epilepsia [188]. La estimulación cerebral profunda usa un dispositivo médico conocido como neuroestimulador (similar a un marcapasos cardíaco y aproximadamente del tamaño de un cronómetro), el cual se implanta quirúrgicamente bajo la piel del paciente y es controlado por una batería que envía estímulos eléctricos a las áreas específicas del cerebro (aquellas que se asuman como responsables de los síntomas que limitan al enfermo) para así bloquear las señales nerviosas anormales que los causen-por ejemplo, la sustancia negra (SN, substantia nigra) para tratar la enfermedad de Parkinson (Figura 15.1). Muchos de los ensayos clínicos de ECP se realizan en cerebros de ratas [189]. Antes del procedimiento, un neurocirujano suele hacer uso de técnicas como la captación de imágenes por resonancia magnética o la tomografía computarizada para identificar la coordenadas cerebrales exactas donde las señales eléctricas nerviosas generan los síntomas de la enfermedad (probablemente ayudándose de registros electrofisiológicos para una mejor identificación) y ubicar el electrodo en la diana cerebral que será estimulada. Evidentemente, la selección estratégica de los puntos de estimulación establece una relación directa causa-efecto entre la localización de los electrodos, el tipo paradigma de estimulación que debe programarse en el neuroestimulador y la enfermedad del paciente. Las primeras aplicaciones reales de la ECP datan de los años noventa, cuando un grupo de profesores de la Universidad de Grenoble en Francia (liderados por Alim-Louis Benabid) consiguen resultados satisfactorios en el tratamiento de trastornos del movimiento [190]. La terapia de control para dicha enfermedad tiene como puntos diana en el cerebro el núcleo subtalámico (Sth, subthalamic nucleus), el núcleo palidal y/o la cápsula interna (dependiendo de si se trata de distonía o de una enfermedad mental). Desde entonces multitud de desórdenes neurológicos y psiquiátricos se han propuesto como patologías susceptibles de ser tratadas con ECP. Por ejemplo, se han añadido como dianas para la estimulación cerebral profunda el hipotálamo y el núcleo accumbens para tratar cefaleas en racimo [191, 192], el trastorno obsesivo-compulsivo [193], la obesidad o la adicción [194]. No obstante, a pesar de la larga historia de la ECP, su mecanismo de acción o principios funcionales nunca ha sido claramente establecido. La falta de base en el conocimiento de la técnica la condena a una práctica ineficiente, y a veces cuestionable, basada en procesos de prueba y error en pacientes. Esta ambigüedad afecta la consolidación de la ECP como una solución clínica real y actualmente se usa solamente en pacientes cuyos síntomas no pueden ser controlados adecuadamente con medicamentos.

${ }^{1}$ En inglés, el término ECP (o estimulación cerebral profunda) corresponde al término DBS (deep brain stimulation). 


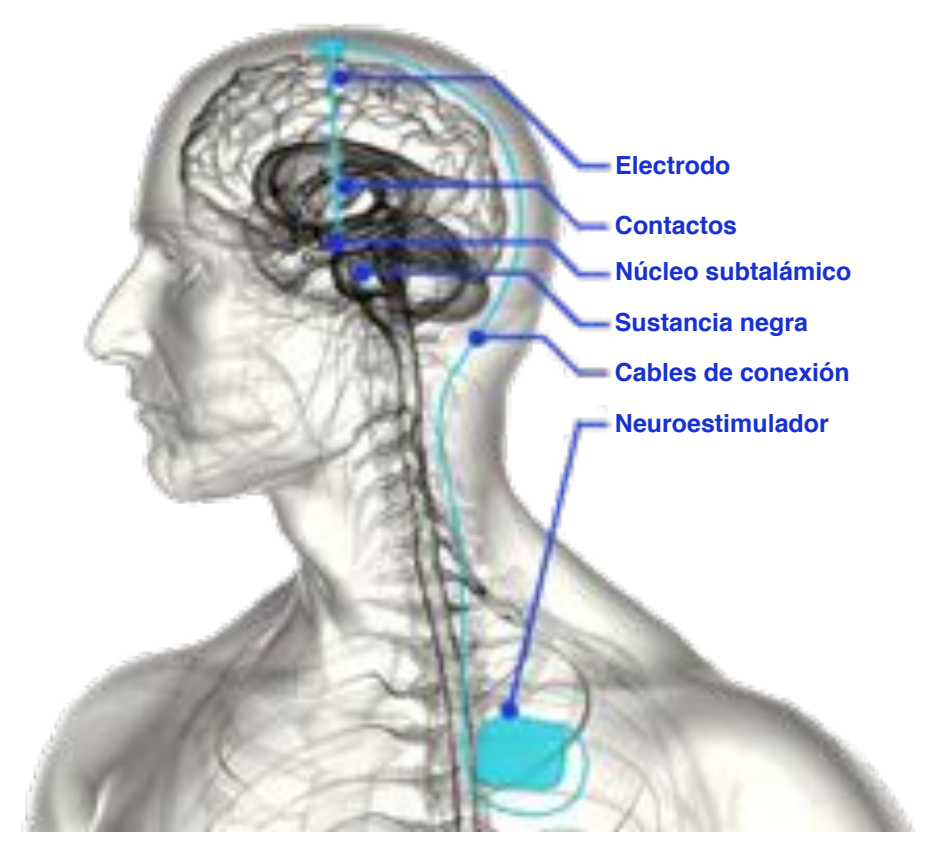

Figura 15.1: ECP aplicada al tratamiento de la enfermedad de Parkinson. El sistema de estimulación cerebral profunda consta de tres componentes: el electrodo, los contactos y el neuroestimulador. El electrodo se inserta a través de una pequeña abertura en el cráneo y se implanta en el cerebro. La punta del electrodo se posiciona dentro de la región objetivo en el cerebro en lo que se conoce como contacto principal. El neuroestimulador generalmente se implanta bajo la piel cerca de la clavícula. Figura basada en [195].

\subsection{Descripción del experimento}

En el presente experimento tratamos de caracterizar cómo afecta la localización de los electrodos y el paradigma eléctrico de estimulación (supuestamente inducido por un neuroestimulador) a la respuesta funcional evocada. Nuestro objetivo es el diseño de una metodología que permita establecer las dianas terapéuticas antes de empezar la intervención quirúrgica para la implantación de los electrodos, así como su posterior verificación. Con dicho objetivo utilizamos el clasificador de huellas de conectividad para generar los mapas funcionales de segundo nivel que representen de forma global al experimento e intentamos asociar dichas respuestas con las coordenadas estereotácticas de los electrodos implantados (así como con los protocolos eléctricos utilizados). Los electrodos los implantamos en diferentes zonas de la corteza prefrontal y del núcleo accumbens.

\subsection{Desarrollo y resultados}

Para el estudio de la ECP hacemos uso de los mapas GLM que obtuvimos para los diecisiete sujetos del experimento en que estimulábamos la corteza prefrontal (Figura 12.2) junto con los diez SPMs de los sujetos que estimulábamos en el núcleo accumbens (Figura 13.3). Las huellas de conectividad alphasim las mostramos en las figuras 12.4 y 13.5 respectivamente. En esta ocasión, para tratar de identificar patrones subyacentes de conectividad funcional entre los veintisiete sujetos, configuramos las regiones de interés manualmente y las establecemos como aquellas que el clasificador estableció automáticamente en cada uno de los experimentos por separado, es decir: AON, AcbC, IL, PrL, FrA, OC, PdC, Cg y Sept (Figura 15.2). De este modo, las huellas de conectividad de los sujetos involucrados en el experimento de la ECP se convierten en las huellas de clasificación de la Figura 15.3. 


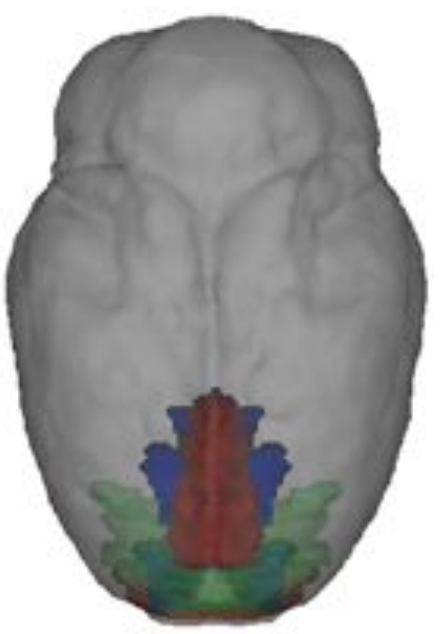

Figura 15.2: Regiones de interés configuradas para el uso del clasificador de huellas de conectividad en el experimento de la ECP. Rojo: regiones extraídas automáticamente por el clasificador en el experimento de la corteza prefrontal—Fra (frontal association cortex) y Cg (cingulate cortex). Azul: regiones extraídas automáticamente por el clasificador en el experimento del núcleo accumbens-AON (anterior olfactory nucleus), AcbC (accumbens core), PdC (dorsal peduncular cortex) y Sept (septal nucleus). Verde: regiones de interés (extraídas automáticamente por el clasificador) comunes en los experimentos de la corteza prefrontal y del núcleo accumbens-IL (infralimbic cortex), PrL (prelimbic cortex) y OC (orbital cortex).

En concreto, el clasificador selecciona las once primeras componentes principales (que acumulan un $80,70 \%$ del total de la varianza) como la representación adecuada de los datos sobre la que aplicar $k$-means y generar los grupos. En este caso el criterio del codo establece que el número óptimo de centroides es $k=7$. Entre las agrupaciones que se generan, se da la circunstancia que uno de los grupos está formado por un único sujeto (en concreto el Acc-10 — cuya exclusión es entendible en vista de su huella de clasificación, Figura 15.3) y, por tratarse de un sujeto aislado, no se considera como respuesta funcional representativa del experimento (Cuadro 15.1).

Cuadro 15.1: Grupos generados por el clasificador de huellas de conectividad entre todos los sujetos del experimento sobre los principios funcionales de la ECP.

\begin{tabular}{c|c}
\hline Grupo funcional & Sujetos del grupo \\
\hline GECP-1 & Acc-1 y Acc-4 \\
\hline GECP-2 & Acc-2 y Acc-6 \\
\hline GECP-3 & $\begin{array}{c}\text { Pref-1, Pref-2, Pref-6, } \\
\text { Pref-7, Pref-8 y Pref-9 }\end{array}$ \\
\hline GECP-4 & $\begin{array}{c}\text { Acc-3, Acc-5, Acc-7, } \\
\text { Acc-8 y Acc-9 }\end{array}$ \\
\hline GECP-5 & Pref-3, Pref-4 y Pref-5 \\
\hline GECP-6 & Pref-10 a Pref-17 \\
\hline
\end{tabular}

Respecto a las agrupaciones que el clasificador de huellas de conectividad realiza para los experimentos de la corteza prefrontal y del núcleo accumbens por separado, observamos que: 
- Los sujetos estimulados en la corteza prefrontal y en el núcleo accumbens no se mezclan en ningún grupo.

- Los grupos GECP-2 y GECP-5 son exactamente iguales a los grupos GAcc-2 y GPref-4 respectivamente.

- El grupo GECP-3 es la unión de los grupos GPref-2 y GPref-3; por su parte el GECP-6 lo es de los grupos GPref-1 y GPref-5. Este hecho no resulta sorprendente ya que sus huellas de conectividad solo se diferencian en dos posiciones: la corteza frontal asociativa y la orbital.

- Finalmente, los grupos GECP-1 y GECP-4 se distribuyen los sujetos que pertenecían a los grupos GAcc-1 y GAcc-3 (teniendo en cuenta la exclusión del suejeto aislado Acc-10), hecho que resulta obvio por las huellas de clasificación de la Figura 13.6.

Como ya hiciéramos en los capítulos anteriores, el siguiente paso del análisis de los datos es el de obtener los mapas estadísticos de segundo nivel para representar las respuesta funcionales medias de los grupos. Tras observar los SPMs y huellas de conectividad de segundo nivel (Figura 15.4), nuevamente podemos afirmar que las respuestas funcionales de los grupos muestran patrones funcionales identificables, cuya morfología es consistente con las ubicaciones de los electrodos de estimulación.

\subsection{Discusión}

Como ya ocurría con los experimentos de clasificación de las huellas de conectividad de la corteza prefrontal y el accumbens por separado, la clasificación de las 27 huellas de conectividad de la región frontal del cerebro de la rata permite la doble localización espacial/funcional de las respuestas al estímulo eléctrico de los núcleos cerebrales estimulados. Además de predecir la localización de los electrodos que las generan, el clasificador es capaz de distinguir respuestas funcionales generadas a partir de unas mismas coordenadas estereotácticas del electrodo de microestimulación pero con unas características diferentes en el patrón temporal de estimulación. Por ejemplo, las huellas de clasificación de los sujetos Acc-1 y Acc-2 están definidas para una misma localización en el set estereotáctico ${ }^{2}$ ( $\mathrm{AP}=1,6, \mathrm{ML}=0,8, \mathrm{DV}=6,8$, en milímetros) pero la respuesta funcional del Acc-2 se agrupa con el sujeto Acc-6, con quien comparte la frecuencia de estimulación eléctrica (en concreto $60 \mathrm{~Hz}$, Cuadro 7.1) pero no la localización espacial del electrodo (Figura 15.5).

\footnotetext{
${ }^{2} \mathrm{La}$ localización de los electrodos en el set quirúrgico las expresamos en base a las coordenadas anteroposterior (AP), mediolateral (ML) y dorsoventral (DV)—generalmente en milímetros.
} 


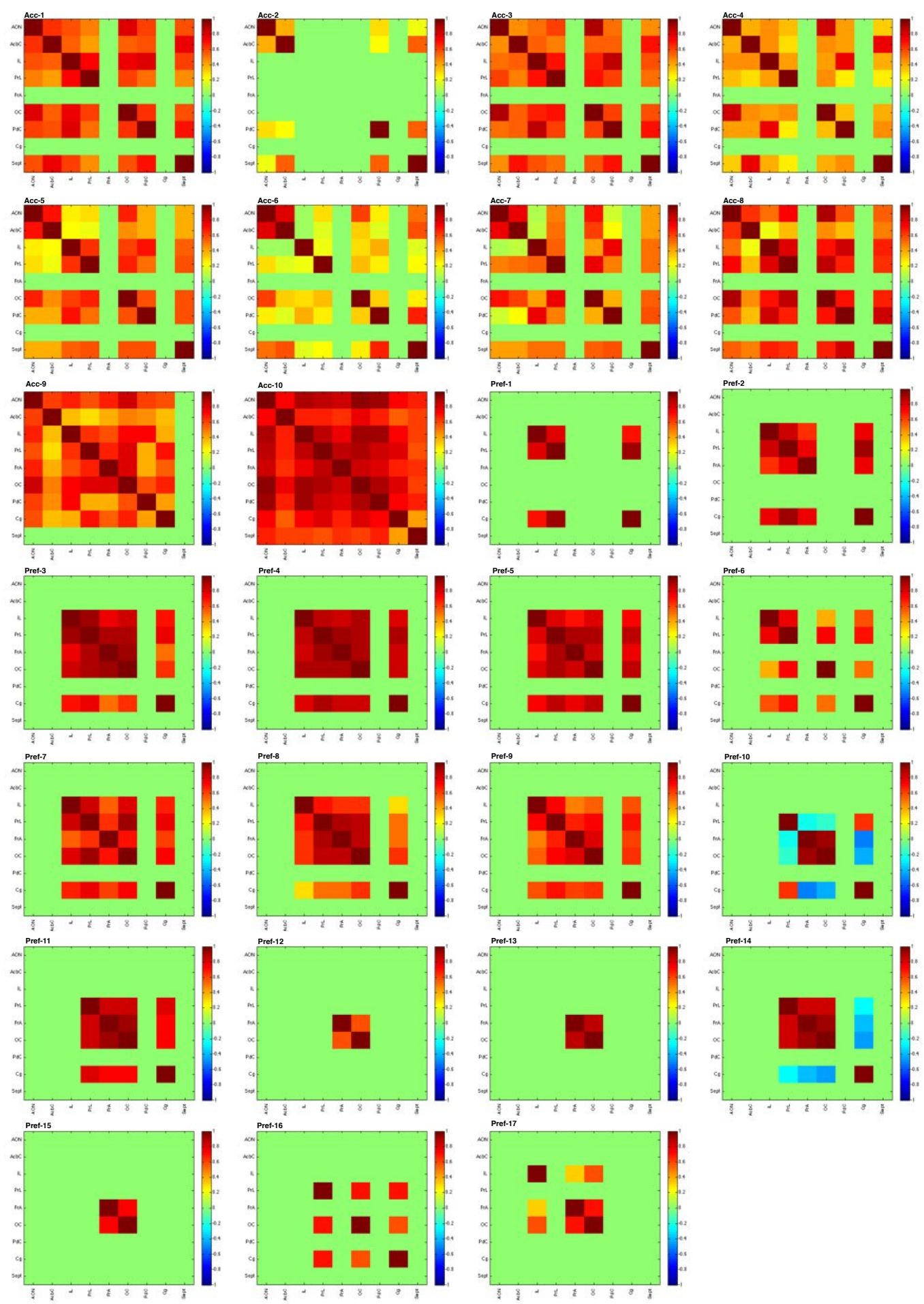

Figura 15.3: Huellas de clasificación de los veinticinco sujetos del experimento que analiza los principios funcionales de la ECP. Las huellas de clasificación son una versión hipodimensional de las huellas de conectividad a las que se le añaden las coordenadas estereotácticas normalizadas de los electrodos de estimulación. 

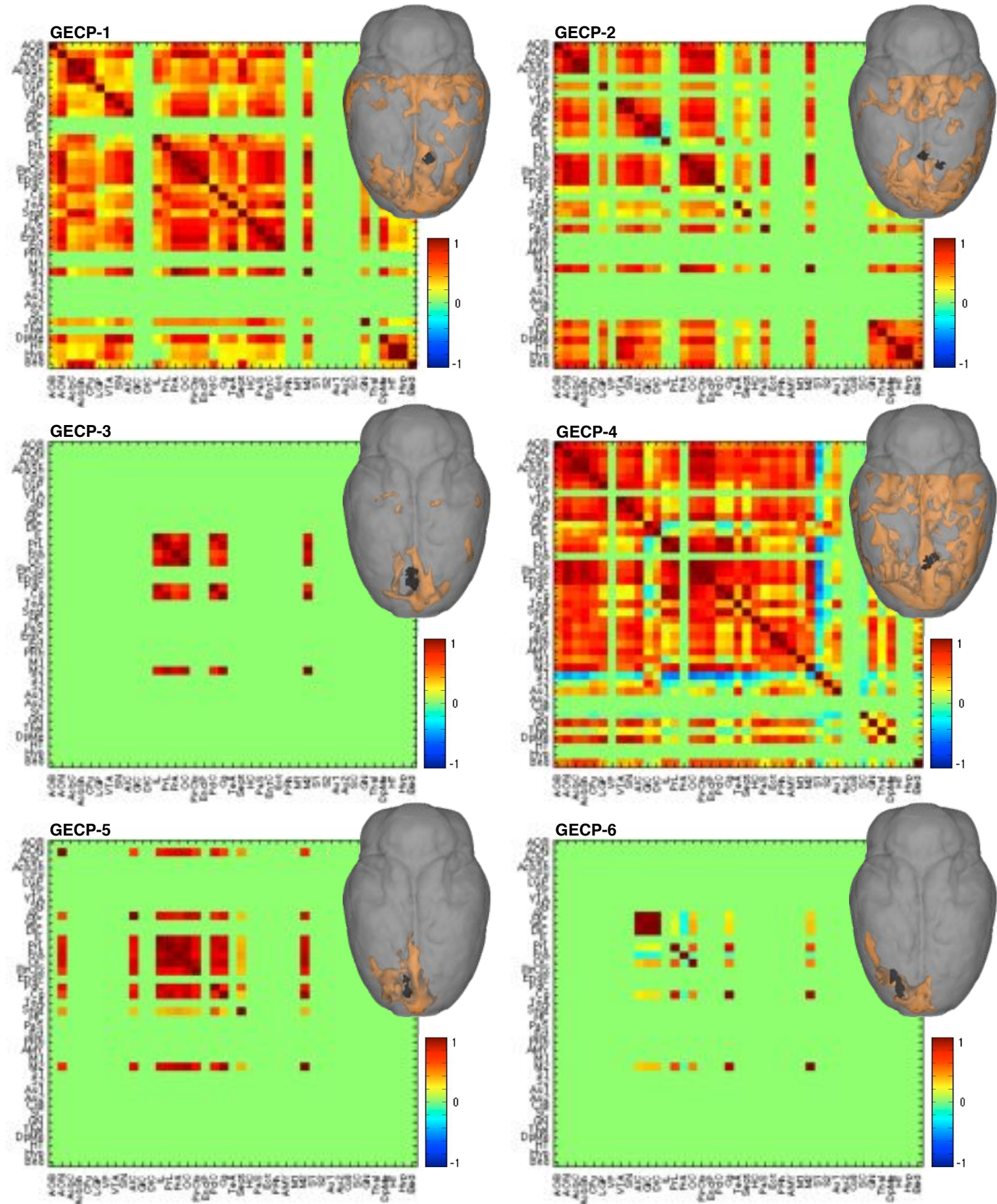

Figura 15.4: Mapas estadísticos paramétricos y huellas de conectividad de segundo nivel (alpha., 0,05) de los seis grupos del experimento de los principios funcionales de la ECP (GECP-1 a GECP-6, de arriba a abajo, de izquierda a derecha) en representación de las respuestas funcionales medias de las agrupaciones halladas entre los veintisiete sujetos que forman parte del experimento. Los electrodos de estimulación de los sujetos que forman los grupos se muestran en negro junto con el mapa estadístico. Las regiones representadas en las huellas de conectividad quedan fijadas por el total de las que aparecen entre todos los grupos, en aras de facilitar la comparación entre los patrones de conectividad de los grupos. 
A

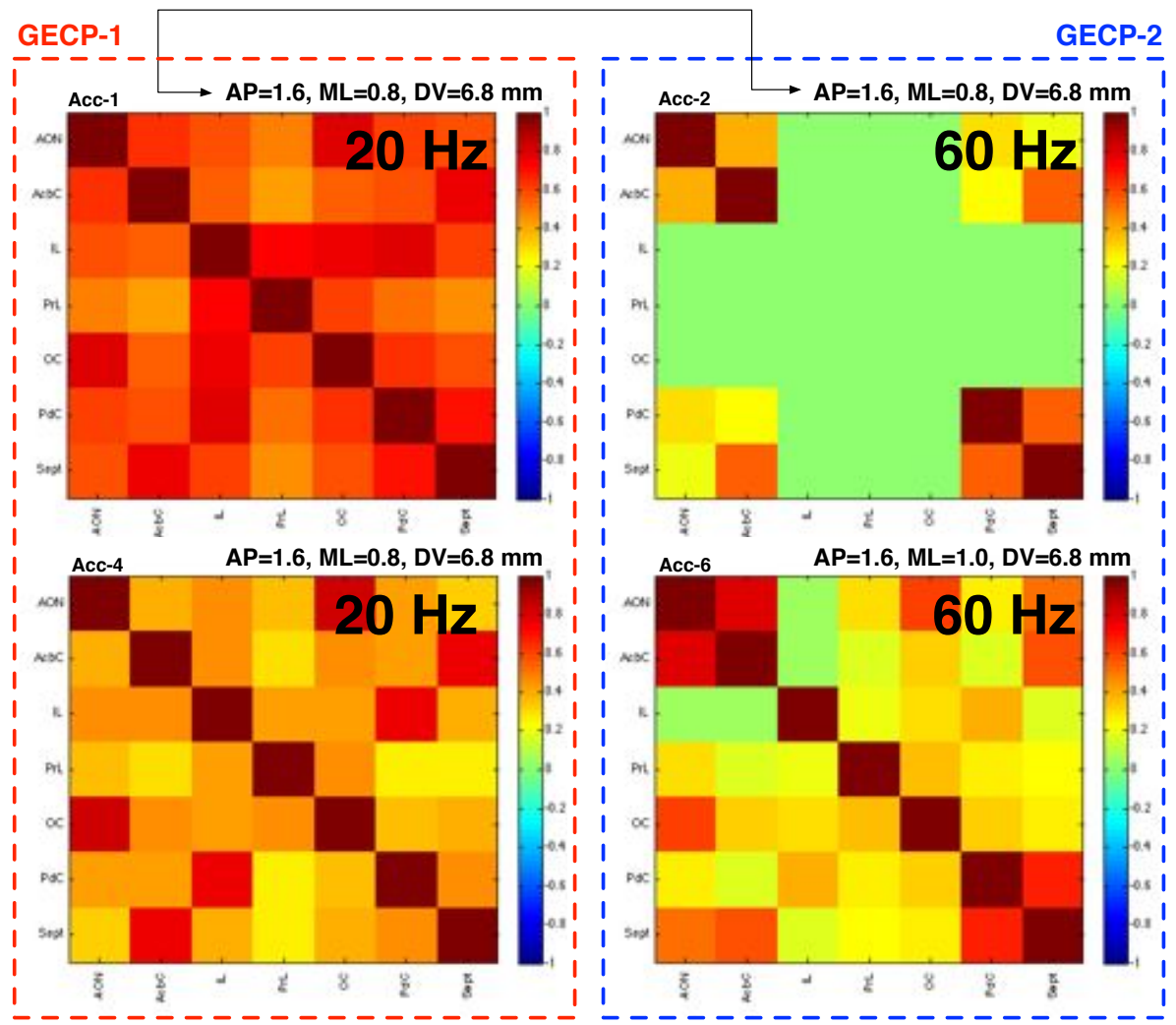

B
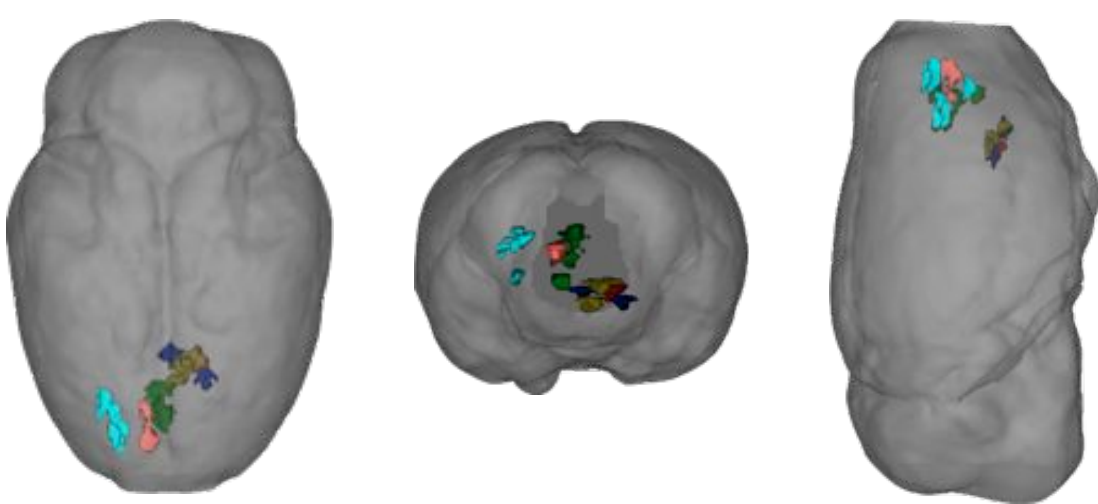

Figura 15.5: A: además de predecir la localización de los electrodos que las generan, el clasificador de huellas de conectividad es capaz de distinguir respuestas funcionales generadas a partir de una misma localización anatómica del electrodo de microestimulación pero con unas características diferentes en el patrón temporal de estimulación. Por ejemplo, la implantación de los electrodos de los sujetos Acc-1 y Acc-2 se planifica en base a unas mismas coordenadas estereotácticas (expresadas en milímetros: anteroposterior o $\mathrm{AP}=1,6$, mediolateral $\mathrm{o} \mathrm{ML}=0,8$ y dorsoventral o $\mathrm{DV}=6,8$ ) pero se asignan a grupos diferentes. En este sentido, la combinación de IRMf con ECP puede ayudar a definir los protocolos de estimulación adecuados. B: proyecciones horizontal, coronal y sagital de las localizaciones de los electrodos de microestimulación codificados en colores según la pertenencia a los grupos: rojo para GECP-1, azul para GECP-2, verde para GECP-3, amarillo para GECP-4, rosa para GECP-5 y cian para el último grupo. 


\section{Parte V}

\section{Conclusiones}





\section{Conclusiones}

El procesamiento de información en el cerebro no puede entenderse de forma completa a partir de imágenes estáticas de conectividad. Si bien las proyecciones neuronales marcan el camino por el cual fluye la información, son las sinapsis, estructuras dinámicas, las que transmiten el mensaje. La intensidad con que las sinapsis se activan, o peso sináptico, depende de su historial de activación, sustancias neuromoduladoras y diversos procesos plásticos que varían con, por ejemplo, la atención y el aprendizaje. Por tanto, un mismo sustrato anatómico puede contener diversos mapas de conectividad funcional que se suceden temporalmente en virtud del estado de sus sinapsis. La imagen funcional no invasiva del cerebro ofrece nuevas oportunidades para estudiar mapas dinámicos de conectividad neuronal. El estudio de la conectividad anatómica, funcional y efectiva se realiza mediante softwares que fuera de línea analizan las series de imágenes de resonancia magnética funcional.

En la presente Tesis Doctoral se han definido dos grandes bloques de métodos que se ocupan de analizar y estudiar la conectividad funcional en cerebros de ratas de experimentación. Dichos bloques permiten el análisis de la conectividad funcional a partir de la correlación bajo dos puntos de vista:

- El que determinan las huellas de conectividad.

- El que determina el análisis mean shift de los espacios funcionales.

Las huellas de conectividad son unas matrices de conectividad simétricas que permiten identificar in vivo el conjunto específico de conexiones funcionales que se establecen al estimular eléctricamente (en base a unos parámetros eléctricos que se conocen a priori) cierto núcleo cerebral y, dado que unas mismas condiciones experimentales deben generar huellas de conectividad que representen de forma unívoca a los sistemas cerebrales (asumiendo entre otros el error debido a la implantación del electrodo y la propia variabilidad biológica interindividual), las huellas de conectividad pueden utilizarse para generar agrupaciones de sujetos con una respuesta al estímulo similar. Las agrupaciones de sujetos las realizamos con un clasificador $k$-means que tiene en cuenta tanto las huellas de conectividad como las coordenadas etereotácticas de los electrodos de microestimulación. A la vista de los resultados, el clasificador llega a una solución muy buena que predice la localización de los electrodos que las generan, de forma que huellas similares localizan sus electrodos en sitios comparables. La robusta identificación entre los pesos funcionales y la ubicación del electrodo (o del núcleo o sistema cerebral que se estimula) hacen de las huellas de conectividad y del clasificador una herramienta muy interesante para el estudio de la estimulación cerebral profunda. De hecho, los resultados revelados por las huellas de conectividad de los grupos generados por el clasificador permiten llegar a varias conclusiones de interés:

1. La combinación de un protocolo concreto de estimulación y una localización cerebral definida modula la actividad cerebral de una forma robusta e identificable, a la que llamamos huella de conectividad funcional.

2. Distintas localizaciones cerebrales originan huellas de conectividad características.

3. Una misma localización puede dar lugar a huellas de conectividad diferentes dependiendo del patrón temporal de estimulación (llave-cerradura). 
Por lo tanto, la combinación de IRMfe con DBS puede ayudar a definir las dianas terapéuticas y los protocolos de estimulación adecuados en base a su correlato funcional, en lugar de simples criterios anatómicos. Es importante destacar que un mismo electrodo de estimulación genera mapas funcionales diferentes en función de los parámetros precisos de estimulación. No es aventurado imaginar una situación en la que, de las posibles huellas funcionales evocadas por un electrodo, solo una de ellas correlacione con un efecto clínico deseado y las demás quizá resulten inefectivas o incluso contraproducentes. De esta forma la selección informada de protocolos clínicos sustituiría la estrategia actual de ensayo error con pacientes.

Por su parte, el análisis de la conectividad funcional en base a la clasificación no supervisada de los espacios funcionales permite asignar cada supra-vóxel representado en el espacio funcional a un cluster o sistema funcional de forma única y, dado que la métrica o función de distancia del espacio funcional es la conectividad funcional, los clusters agrupan vóxels que están conectados funcionalmente. La definición de los sistemas funcionales nos permite descomponer la respuesta funcional integrada en una suma de varias respuestas funcionales según los patrones de actividad neuronal correlada de la respuesta funcional, los cuales representan los retrasos sistemáticos y los cambios de intensidad de la actividad neuronal capturada por el modelo lineal generalizado. Por lo tanto, el análisis mean shift de los espacios funcionales nos proporciona una serie de evidencias que derivan en una serie de conclusiones que complementan a las obtenidas con las huellas de conectividad, como puedan ser:

4. Que es posible cuantificar la causalidad o el retardo sistemático de los distintos modos hemodinámicos que puedan componer la respuesta funcional integrada.

5. Que en modelos causales donde se utilicen dos o más electrodos de microestimulación, la identificación de los sistemas funcionales permite caracterizar las respuestas funcionales como sumas interferentes de las distintas respuestas evocadas. En este sentido, la cuantificación del grado de las interferencias podría sugerir un procedimiento empírico para medir la conectividad efectiva entre los sistemas cerebrales estimulados.

6. Que la interpretación del módulo y la fase de los espacios funcionales particionados permite la construcción de unos mapas analíticos multiparamétricos mediante los cuales es posible identificar anatómicamente las distintas respuestas funcionales que integran la respuesta global funcional, permitiendo diferenciar las regiones cerebrales que puedan responder de forma monosináptica/polisináptica o como una inhibición al estímulo eléctrico. 


\section{Parte VI}

\section{Publicaciones derivadas}





\section{Publicaciones derivadas}

El software que desarrolla los métodos que presentamos en el presente trabajo de investigación ha sido presentado y usado con éxito en varios casos de estudio, trabajos y artículos.

Por ejemplo, los casos de estudio expuestos en las reuniones anuales de la Sociedad Española de NeuroCiencia y la FENS (Federation of European Neuroscience Societies) nos han permitido verificar el alto potencial de la clasificación de las huellas de conectividad en el estudio de la estimulación cerebral profunda:

- [153] J. Moya, J.M. Pascual, R. Prieto, D. Moratal, and S. Canals. Functional principles of deep brain stimulation (DBS). XIV Congreso Nacional Sociedad Española de NeuroCiencia, Salamanca, 2011.

- [176] C. Quesada, J. Moya, J.M. Pascual, R. Prieto, D. Moratal, and S. Canals. Mechanisms of action of Deep Brain Stimulation. 8th FENS Forum of Neuroscience, Barcelona, 2012.

En colaboración con E.A. Rancz, se ha utilizado la descomposición mean shift de los espacios funcionales para identificar posibles conexiones entre la corteza prefrontal y la región vestibular:

- [125] E.A. Rancz, S. Canals, J. Moya, N.K. Logothetis, D. Moratal, A.M. Brichta, and T.W. Margrie. A map of vestibular representation in the rodent brain revealed by functional imaging and electrophysiology. MRC-National Institute for Medical Research/Wellcome Trust Conference, London, 2010.

Además, la metodología presentada para la construcción de atlas multifuncionales del cerebro de la rata ha sido utilizada con éxito par sintetizar atlas cerebrales que forman parte de otras herramienta de análisis de imágenes funcionales (en concreto, potenciadas en manganeso):

- [154] V. Pallarés. Directores: D. Moratal, S. Canals, J. Moya. Estudio de la conectividad cerebral a partir de imágenes de RM potenciadas con manganeso. Desarrollo de un atlas cerebral para un análisis tridimensional. Proyecto Final de Carrera, Escuela Técnica Superior de Ingenieros de Telecomunicación, Universitat Politècnica de València, 2010.

- V. Pallarés, F. Samper-Belda, J. Moya, S. Canals, and D. Moratal. Experimental Neurosurgery Planning in Rats Using a Magnetic Resonance Imaging Assisted Framework. Submitted to IEEE Transactions on Biomedical Engineering, 2012.

Finalmente, cabe mencionar que se está trabajando en los siguientes trabajos científicos para mandar a revista:

- J. Moya, D. Moratal, and S. Canals. Unsupervised classification framework for evaluating structural and functional connectivity in rat brains MRI.

- J. Moya, D. Moratal, and S. Canals. Synthesis of three-dimensional brain atlases for the study of connectivity in rat brains. 


\section{Parte VII}

\section{Líneas futuras}





\section{Líneas futuras}

A lo largo de esta Tesis Doctoral se ha podido constatar la existencia de ciertas limitaciones de la metodología desarrollada entre las que cabría destacar:

1. El proceso por el cual establecemos las regiones de interés (como etapa previa a la clasificación de las huellas de conectividad).

2. La forma en la que construimos los espacios funcionales - donde nos ceñimos exactamente al procedimiento estándar descrito en la referencia bibliográfica correspondiente.

Para suplir estas limitaciones se podría trabajar en el desarrollo de:

1. Un procedimiento de selección de regiones de interés que añada o combine criterios complementarios a los relativos al área de las regiones con respuesta funcional positiva (por ejemplo, aquellos que evalúen umbrales mínimos de correlación y/o de ruido de coherencia) o incluso permitir la incorporación (o exclusión) manual de ciertas regiones cerebrales al proceso de clasificación.

2. Espacios funcionales tridimensionales en representación de las tres primeras componentes/coordenadas principales de la descomposición SVD.

3. Una función que implemente el algoritmo mean shift para que funcione en el nuevo espacio vectorial según el punto anterior-que es de orden superior al utilizado en la versión actual de las funciones implementadas.

Finalmente, el trabajo desarrollado en la presente Tesis Doctoral plantea las siguientes líneas futuras de trabajo:

- Tratar de combinar la información de base temporal que aporta el análisis el mean shift del espacio funcional a las huellas de conectividad.

- Verificar mediante registros electrofisiológicos en las zonas de la corteza prefrontal PrL, OC y FrA la presencia de una conexión vestibular.

- Aplicar las huellas de conectividad, el clasificador de huellas de conectividad y el análisis mean shift del espacio funcional a experimentos que estudien el aprendizaje a partir de la potenciación sináptica del hipocampo.

- Extender la clasificación de las huellas de conectividad a experimentos resting state. En este caso, las huellas de conectividad podrían componerse como estructuras de clasificación multiespectrales, donde cada elemento de la matriz representaría la conectividad funcional a partir de la coherencia de la señal BOLD de las regiones a distintas bandas frecuenciales.

- Extender el análisis mean shift a espacios funcionales resting state. Cabe mencionar que ya se han realizado algunas pruebas en este sentido y que los resultados de los que se dispone hasta la fecha son prometedores. 
- Desarrollar en profundidad la metodología que permitiría medir la conectividad efectiva en base a la cuantificación de señales interferentes generadas por dos o más electrodos de microestimulación, posiblemente aplicando métodos de análisis como ICA a las respuestas funcionales medias de los clusters o sistemas funcionales previamente identificados con la metodología aquí presentada. 
Parte VIII

Bibliografía 



\section{Bibliografía}

[1] N.K. Logothetis, J. Pauls, M. Augath, T. Trinath, and A. Oeltermann. Neurophysiological investigation of the basis of the fMRI signal. Nature, 412(6843):150-157, 2001.

[2] S. Canals, M. Beyerlein, Y. Murayama, and N.K. Logothetis. Electric stimulation fMRI of the perforant pathway to the rat hippocampus. Magnetic resonance imaging, 26(7):978-86, 2008.

[3] R.N.A. Henson, C.J. Price, M.D. Rugg, R. Turner, and K.J. Friston. Detecting latency differences in eventrelated BOLD responses: application to words versus nonwords and initial versus repeated face presentations. NeuroImage, 15(1):83-97, 2002.

[4] E.R. Kandel, J.H. Schwartz, and T.M. Jessell. Principles of Neural Science. McGraw-Hill, New York, United States of America, 2000.

[5] M. Liang, Y. Zhou, T. Jiang, Z. Liu, L. Tian, H. Liu, and Y. Hao. Widespread functional disconnectivity in schizophrenia with resting-state functional magnetic resonance imaging. NeuroReport, 17(2):209-213, 2006.

[6] M. Siegel, T.H. Donner, and A.K. Engel. Spectral fingerprints of large-scale neuronal interactions. Nature reviews. Neuroscience, 13(2):121-34, 2012.

[7] S. Canals, M. Beyerlein, H. Merkle, and N.K. Logothetis. Functional MRI evidence for LTP-induced neural network reorganization. Current biology, 19(5):398-403, 2009.

[8] G. Buzsaki. Hippocampus. Scholarpedia, 6(1):1-10, 2011.

[9] S. Ogawa, R.S. Menon, S.G. Kim, and K. Ugurbil. On the characteristics of functional magnetic resonance imaging of the brain. Annual Review of Biophysics and Biomolecular Structure, 27(1):447-74, 1998.

[10] J.M. Harlow. Passage of an iron rod through the head. Boston Medical and Surgical Journal, 39(20):389393,1848 .

[11] J.M. Harlow. Recovery from the passage of an iron bar through the head. History of Psychiatry, 4(14):274281,1993

[12] D. Ferrier. The Goulstonian Lectures on the Localisation of Cerebral Disease. British medical journal, 1(899):591-595, 1878.

[13] J.M. Fuster. The Prefrontal Cortex-Anatomy Physiology, and Neuropsychology of the Frontal Lobe. The American Journal of Psychiatry, 157(6):1038-1038, 1997.

[14] S. Ramon y Cajal. Histologie du systeme nerveux de l'homme et des vertebres, volume 1. Maloine, Paris, France, 1909. 
[15] R.W. Tsien and R. Yuste. Nature Reviews Neuroscience - Highlights. Nature Reviews Neuroscience, 4(1):1-7, 2003.

[16] S. Ramon y Cajal. Textura del sistema nervioso del hombre y de los vertebrados, volume 2. Imprenta Nacional del Boletín Oficial del Estado, Madrid, España, 1904.

[17] K.J. Friston. Statistical parametric mapping. The analysis of functional brain images. Academic Press, London, United Kingdom, 2007.

[18] D.A. Drachman. Do we have brain to spare? Neurology, 64(12):2004-2005, 2005.

[19] G. Jefferson. Localization of function in the cerebral cortex. British medical bulletin, 6(4):333-340, 1950.

[20] C.G. Phillips, S. Zeki, and H.B. Barlow. Localization of function in the cerebral cortex. Past, present and future. Brain: A journal of neurology, 107(1):327-361, 1984.

[21] J.R. Absher and D.F. Benson. Disconnection syndromes: an overview of Geschwind's contributions. Neurology, 43(5):862-867, 1993.

[22] G. Tononi, O. Sporns, and G.M. Edelman. A measure for brain complexity: relating functional segregation and integration in the nervous system. Proceedings of the National Academy of Sciences of the United States of America, 91(11):5033-7, 1994.

[23] K.J. Friston, C.D. Frith, P.F. Liddle, and R.S.J. Frackowiak. Functional connectivity: the principalcomponent analysis of large (PET) data sets. Cerebral Blood Flow and Metabolism, 13(4):5-14, 1993.

[24] F.T. Sun, L.M. Miller, and M. D’Esposito. Measuring interregional functional connectivity using coherence and partial coherence analyses of fMRI data. NeuroImage, 21(2):647-58, 2004.

[25] S. Greenland and B. Brumback. An overview of relations among causal modelling methods. International Journal of Epidemiology, 31(5):1030-1037, 2002.

[26] J.R. Sato, E.A. Junior, D.Y. Takahashi, M. De Maria Felix, M.J. Brammer, and P.A. Morettin. A method to produce evolving functional connectivity maps during the course of an fMRI experiment using waveletbased time-varying Granger causality. NeuroImage, 31(1):187-196, 2006.

[27] A. Roebroeck, E. Formisano, and R. Goebel. Mapping directed influence over the brain using Granger causality and fMRI. NeuroImage, 25(1):230-242, 2005.

[28] S.M. Smith, K.L. Miller, G. Salimi-Khorshidi, M. Webster, C.F. Beckmann, T.E. Nichols, J.D. Ramsey, and M.W. Woolrich. Network modelling methods for FMRI. NeuroImage, 54(2):875-891, 2010.

[29] B. Horwitz. The elusive concept of brain connectivity. NeuroImage, 19(2):466-470, 2003.

[30] O. Sporns. Brain connectivity. Scholarpedia, 2(10):4695, 2007.

[31] O. Sporns, G. Tononi, and R. Kötter. The Human Connectome: A Structural Description of the Human Brain. PLoS Computational Biology, 1(4):11-18, 2005.

[32] P. Hagmann, L. Jonasson, T. Deffieux, R. Meuli, J. Thiran, and V. J. Wedeen. Fibertract segmentation in position orientation space from high angular resolution diffusion MRI. NeuroImage, 32(2):665-675, 2006.

[33] V.J. Wedeen, D.L. Rosene, R. Wang, G. Dai, F. Mortazavi, P. Hagmann, J.H. Kaas, and W.Y.I. Tseng. The Geometric Structure of the Brain Fiber Pathways. Science, 335(6076):1628-1634, 2012.

[34] S. Ogawa. Brain Magnetic Resonance Imaging with Contrast Dependent on Blood Oxygenation. Proceedings of the National Academy of Sciences, 87(24):9868-9872, 1990. 
[35] S. Achard, R. Salvador, B. Whitcher, J. Suckling, and E. Bullmore. A resilient, low-frequency, small-world human brain functional network with highly connected association cortical hubs. Journal of Neuroscience, 26(1):63-72, 2006.

[36] A. Brovelli, M. Ding, A. Ledberg, Y. Chen, R. Nakamura, and S.L. Bressler. Beta oscillations in a largescale sensorimotor cortical network: directional influences revealed by Granger causality. Proceedings of the National Academy of Sciences of the United States of America, 101(26):9849-9854, 2004.

[37] K.J. Friston, J.B. Poline, A.P. Holmes, C.D. Frith, and R.S. Frackowiak. A multivariate analysis of PET activation studies. Human Brain Mapping, 4(2):140-151, 1996.

[38] G. Tononi and O. Sporns. Measuring information integration. BMC Neuroscience, 4(1):31, 2003.

[39] E. Bullmore and O. Sporns. Complex brain networks: graph theoretical analysis of structural and functional systems. Nature Reviews Neuroscience, 10(3):186-198, 2009.

[40] K.J. Friston, P. Jezzard, R.S.J. Frackowiak, and R. Turner. Characterizing focal and distributed physiological changes with MRI and PET. Functional MRI of the Brain Society of Magnetic Resonance in Medicine, 1994.

[41] S. Canals, I. Makarova, L. López-Aguado, C. Largo, J.M. Ibarz, and O. Herreras. Longitudinal depolarization gradients along the somatodendritic axis of CA1 pyramidal cells: a novel feature of spreading depression. Journal of neurophysiology, 94(2):943-51, 2005.

[42] S. Ogawa and Y. Sung. Functional magnetic resonance imaging. Scholarpedia, 2(10):3105, 2007.

[43] G.G. Brown, J.E. Perthen, T.T. Liu, and R.B. Buxton. A primer on functional magnetic resonance imaging. Neuropsychology Review, 17(2):107-125, 2007.

[44] F.H. Duffy, P.H. Bartels, and J.L. Burchfiel. Significance probability mapping: an aid in the topographic analysis of brain electrical activity. Electroencephalography and Clinical Neurophysiology, 51(5):455-462, 1981.

[45] K.J. Friston. Functional and effective connectivity: a review. Brain Connectivity, 1(1):13-36, 2011.

[46] L. Pauling and C.D. Coryall. The magnetic properties and structure of hemoglobin, oxyhemoglobin and carbonoxyhemoglobin. Proceedings of the National Academy of Sciences of the United States of America, 22(3):210-216, 1936

[47] K.R. Thulborn, J.C. Waterton, P.M. Matthews, and G.K. Radda. Oxygenation dependence of the transverse relaxation time of water protons in whole blood at high field. Biochimica et Biophysica Acta, 714(2):265$270,1982$.

[48] P.T. Fox, M.E. Raichle, M.A. Mintun, and C. Dence. Nonoxidative glucose consumption during focal physiologic neural activity. Science, 241(4864):462-464, 1988.

[49] M.E. Raichle. A brief history of human brain mapping. Trends in Neurosciences, 32(2):118-126, 2009.

[50] P. Born, E. Rostrup, H. Leth, B. Peitersen, and H.C. Lou. Change of visually induced cortical activation patterns during development. Lancet, 347(9000):543, 1996.

[51] M. Raemaekers, S. du Plessis, N.F. Ramsey, J.M.H. Weusten, and M. Vink. Test-retest variability underlying fMRI measurements. NeuroImage, 60(1):717-27, 2012. 
[52] B.B. Zandbelt, T.E. Gladwin, M. Raemaekers, M. van Buuren, S.F. Neggers, R.S. Kahn, N.F. Ramsey, and M. Vink. Within-subject variation in BOLD-fMRI signal changes across repeated measurements: quantification and implications for sample size. NeuroImage, 42(1):196-206, 2008.

[53] P. Jezzard, P.M. Matthews, and S.M. Smith. Functional MRI: An introduction to methods. Oxford University Press Inc., London, United Kingdom, 2001.

[54] J. Hennig, A. Nauerth, and H. Friedburg. RARE imaging: a fast imaging method for clinical MR. Magnetic Resonance in Medicine, 3(6):823-833, 1986.

[55] M.S. Cohen. Echo-planar imaging (EPI) and functional MRI. Functional MRI, 1998.

[56] E.A. Phelps and J.E. LeDoux. Contributions of the amygdala to emotion processing: from animal models to human behavior. Neuron, 48(2):175-187, 2005.

[57] C.J. Lueck, S. Zeki, K.J. Friston, M.P. Deiber, P. Cope, V.J. Cunningham, A.A. Lammertsma, C Kennard, and R S Frackowiak. The colour centre in the cerebral cortex of man. Nature, 340(6232):386-389, 1989.

[58] J. Wang, T. Zhou, M. Qiu, A. Du, K. Cai, Z. Wang, C. Zhou, M. Meng, Y. Zhuo, S. Fan, and L. Chen. Relationship between ventral stream for object vision and dorsal stream for spatial vision: an fMRI + ERP study. Human Brain Mapping, 8(4):170-181, 1999.

[59] J.F. Demonet, G. Thierry, and D. Cardebat. The renewal of the neurophysiology of language: Functional neuroimaging. Physiological Reviews, 85(1):49-95, 2005.

[60] R. Ramirez. An fMRI Study on Attentive Music Listening. In The Neurosciences and Music, Montreal, 2008.

[61] J. Greene and J. Haidt. How (and where) does moral judgment work? Trends in Cognitive Sciences, 6(12):517-523, 2002.

[62] K.J. Friston, A.P. Holmes, K.J. Worsley, J.P. Poline, C.D. Frith, and R.S.J. Frackowiak. Statistical parametric maps in functional imaging: A general linear approach. Human Brain Mapping, 2(4):189-210, 1995.

[63] K.J. Friston, C.D. Frith, P.F. Liddle, and R.S. Frackowiak. Comparing functional (PET) images: the assessment of significant change. Journal of cerebral blood flow and metabolism official journal of the International Society of Cerebral Blood Flow and Metabolism, 11(4):690-699, 1991.

[64] C. Davatzikos, H.H. Li, E. Herskovits, and S.M. Resnick. Accuracy and sensitivity of detection of activation foci in the brain via statistical parametric mapping: a study using a PET simulator. NeuroImage, 13(1):176$184,2001$.

[65] K.V. Mardia, J.T. Kent, and J.M. Bibby. Multivariate Analysis. Academic Press, London, United Kingdom, 1979.

[66] P. McCullagh and J.A. Nelder. Generalized linear models. Chapman \& Hall/CRC, London, United Kingdom, 1989.

[67] O. Josephs, R. Turner, and K.J. Friston. Event-Related fMRI. Human brain mapping, 5:243-248, 1997.

[68] M.W.L. Chee, V. Venkatraman, C. Westphal, and S.C. Siong. Comparison of block and event-related fMRI designs in evaluating the word-frequency effect. Human brain mapping, 18(3):186-93, 2003.

[69] D.L. Schacter, R.L. Buckner, W. Koutstaal, A.M. Dale, and B.R. Rosen. Late onset of anterior prefrontal activity during true and false recognition: an event-related fMRI study. NeuroImage, 6(4):259-269, 1997. 
[70] A.T. Lee, G.H. Glover, and C.H. Meyer. Discrimination of large venous vessels in time-course spiral bloodoxygen-level-dependent magnetic-resonance functional neuroimaging. Magnetic Resonance in Medicine, 33(6):745-754, 1995.

[71] K.J. Friston, C.D. Frith, R. Turner, and R.S. Frackowiak. Characterizing evoked hemodynamics with fMRI. NeuroImage, 2(2):157-165, 1995.

[72] G.M. Boynton, S.A. Engel, G.H. Glover, and D.J. Heeger. Linear systems analysis of functional magnetic resonance imaging in human V1. Journal of Neuroscience, 16(13):4207-4221, 1996.

[73] A.V. Oppenheim, A.S. Willsky, and S.H. Nawab. Signals and Systems. Prentice Hall Signal Processing Series. Prentice Hall, New Jersey, United States of America, 1997.

[74] A.L. Vazquez and D.C. Noll. Nonlinear aspects of the BOLD response in functional MRI. NeuroImage, 7(2):108-118, 1998.

[75] G.K. Aguirre, E. Zarahn, and M. D'Esposito. The inferential impact of global signal covariates in functional neuroimaging analyses. NeuroImage, 8(3):302-6, 1998.

[76] J. Ashburner and K.J. Friston. Voxel-based morphometry-the methods. NeuroImage, 11(1):805-821, 2000.

[77] P. Jezzard and S. Clare. Sources of distortion in functional MRI data. Human Brain Mapping, 8(2-3):80-85, 1999.

[78] J. Kybic, P. Thevenaz, A. Nirkko, and M. Unser. Unwarping of unidirectionally distorted EPI images. IEEE Transactions on Medical Imaging, 19(2):80-93, 2000.

[79] W.M. Wells III, P. Viola, H. Atsumi, S. Nakajima, and R. Kikinis. Multi-Modal Volume Registration by Maximisation of Mutual Information. Medical Image Analysis, 1(1):35-51, 1996.

[80] J. Ashburner and K.J. Friston. Nonlinear spatial normalization using basis functions. Human Brain Mapping, 7(4):254-266, 1999.

[81] P.T. Fox. Spatial normalization origins: Objectives, applications, and alternatives. Human Brain Mapping, 3(3):161-164, 1995.

[82] A.C. Evans, D.L. Collins, S.R. Mills, E.D. Brown, R.L. Kelly, and T.M. Peters. 3D statistical neuroanatomical models from 305 MRI volumes. Construction, 3(31):1813-1817, 1993.

[83] A.J. Schwarz, A. Danckaert, T. Reese, A. Gozzi, G. Paxinos, C. Watson, E.V. Merlo-Pich, and A. Bifone. A stereotaxic MRI template set for the rat brain with tissue class distribution maps and co-registered anatomical atlas: application to pharmacological MRI. NeuroImage, 32(2):538-50, 2006.

[84] P.A. Valdés-Hernández, A. Sumiyoshi, H. Nonaka, R. Haga, E. Aubert-Vásquez, T. Ogawa, Yasser IturriaMedina, Jorge J Riera, and Ryuta Kawashima. An in vivo MRI Template Set for Morphometry, Tissue Segmentation, and fMRI Localization in Rats. Frontiers in neuroinformatics, 5(26):1-10, 2011.

[85] S. Robbins, A.C. Evans, D.L. Collins, and S. Whitesides. Tuning and comparing spatial normalization methods. Medical Image Analysis, 8(3):311-23, 2004.

[86] J.D. Carew, G. Wahba, X. Xie, E.V. Nordheim, and M.E. Meyerand. Optimal spline smoothing of fMRI time series by generalized cross-validation. NeuroImage, 18(4):950-961, 2003.

[87] M. Mikl, R. Marecek, P. Hlustík, M. Pavlicová, A. Drastich, P. Chlebus, M. Brázdil, and P. Krupa. Effects of spatial smoothing on fMRI group inferences. Magnetic Resonance Imaging, 26(4):490-503, 2008. 
[88] S.C. Strother. Evaluating fMRI preprocessing pipelines. IEEE Engineering in Medicine and Biology Magazine, 25(2):27-41, 2006.

[89] S. Gold, B. Christian, S. Arndt, G. Zeien, T. Cizadlo, D.L. Johnson, M. Flaum, and N.C. Andreasen. Functional MRI statistical software packages: a comparative analysis. Human brain mapping, 6(2):73-84, 1998.

[90] P.P. Mitra, S. Ogawa, X. Hu, and K. Uğurbil. The nature of spatiotemporal changes in cerebral hemodynamics as manifested in functional magnetic resonance imaging. Magnetic Resonance in Medicine, 37(4):511-518, 1997.

[91] K.J. Worsley and K.J. Friston. Analysis of fMRI time-series revisited-again. NeuroImage, 2(3):173-181, 1995.

[92] P.L. Purdon and R.M. Weisskoff. Effect of temporal autocorrelation due to physiological noise and stimulus paradigm on voxel-level false-positive rates in fMRI. Human Brain Mapping, 6(4):239-249, 1998.

[93] D.A. Harville. Maximum Likelihood Approaches to Variance Component Estimation and to Related Problems. Journal of the American Statistical Association, 72(358):320-338, 1977.

[94] G. Flandin and K.J. Friston. Statistical parametric mapping (SPM). Scholarpedia, 3(4):6232, 2008.

[95] J.L.R. Andersson, C. Hutton, J. Ashburner, R. Turner, and K.J. Friston. Modeling geometric deformations in EPI time series. NeuroImage, 13(5):903-919, 2001.

[96] A.S. Lowe, G.J. Barker, J.S. Beech, M.D. Ireland, and S.C.R. Williams. A method for removing global effects in small-animal functional MRI. NMR in Biomedicine, 21(1):53-58, 2008.

[97] J.D. Gispert, J. Pascau, S. Reig, P. García-Barreno, and M. Desco. Mapas de estadísticos paramétricos (SPM) en medicina nuclear. Rev. Esp. Med. Nuclear, 1(1):43-53, 2003.

[98] M. Gavrilescu, M.E. Shaw, G.W. Stuart, P. Eckersley, I.D. Svalbe, and G.F. Egan. Simulation of the effects of global normalization procedures in functional MRI. NeuroImage, 17(1):532-542, 2002.

[99] R.J. Adler. The Geometry of Random Fields. Wiley-Interscience, New York, United States of America, 1981.

[100] P. Sedgwick. Multiple significance tests: the Bonferroni correction. Journal of Public Health Medicine, 344(25):509-12, 2012.

[101] B.D. Ward. Simultaneous Inference for FMRI data. AFNI Documentation, Medical College, 1(11):1829_ 1841,2000

[102] C. Büchel, R.J. Wise, C.J. Mummery, J.B. Poline, and K.J. Friston. Nonlinear regression in parametric activation studies. NeuroImage, 4(1):60-6, 1996.

[103] R. Henson, M.D. Rugg, and K.J. Friston. The choice of basis functions in event-related fMRI. NeuroImage, 13(6):149, 2001.

[104] C.H. Liao, K.J. Worsley, J.B. Poline, J.A.D. Aston, G.H. Duncan, and A.C. Evans. Estimating the delay of the fMRI response. NeuroImage, 16(3):593-606, 2002.

[105] K.J. Friston, W. Penny, C. Phillips, S. Kiebel, G. Hinton, and J. Ashburner. Classical and Bayesian inference in neuroimaging: theory. NeuroImage, 16(2):465-483, 2002. 
[106] J.P. Gallivan, C. Cavina-Pratesi, and J.C. Culham. Is that within reach? fMRI reveals that the human superior parieto-occipital cortex encodes objects reachable by the hand. The Journal of neuroscience: the official journal of the Society for Neuroscience, 29(14):4381-91, 2009.

[107] D.S. Margulies, J. Böttger, X. Long, Y. Lv, C. Kelly, A. Schäfer, D. Goldhahn, A. Abbushi, M.P. Milham, G. Lohmann, and A. Villringer. Resting developments: a review of fMRI post-processing methodologies for spontaneous brain activity. Magma, 23(5-6):289-307, 2010.

[108] B. Biswal, F.Z. Yetkin, V.M. Haughton, and J.S. Hyde. Functional connectivity in the motor cortex of resting human brain using echo-planar MRI. Magnetic resonance in medicine, 34(4):537-41, 1995.

[109] A. Shmuel and D.A. Leopold. Neuronal correlates of spontaneous fluctuations in fMRI signals in monkey visual cortex: Implications for functional connectivity at rest. Human Brain Mapping, 29(7):751-761, 2008.

[110] H. Lu, Y. Zuo, H. Gu, J.A. Waltz, W. Zhan, C.A. Scholl, W. Rea, Y. Yang, and E.A. Stein. Synchronized delta oscillations correlate with the resting-state functional MRI signal. Proceedings of the National Academy of Sciences of the United States of America, 104(46):18265-18269, 2007.

[111] C.P. Pawela, B.B. Biswal, Y.R. Cho, D.S. Kao, R. Li, S.R. Jones, M.L. Schulte, H.S. Matloub, A.G. Hudetz, and J.S. Hyde. Resting-state functional connectivity of the rat brain. Magnetic Resonance in Medicine, 59(5):1021-1029, 2008.

[112] R.S. Menon, J.S. Gati, B.G. Goodyear, D.C. Luknowsky, and C.G. Thomas. Spatial and temporal resolution of functional magnetic resonance imaging. Biochemistry and cell biology Biochimie et biologie cellulaire, 76(2-3):560-571, 1998.

[113] J. Cao and K. Worsley. The geometry of correlation fields with an application to functional connectivity of the brain. The Annals of Applied Probability, 9(4):1021-1057, 1999.

[114] K. Li, L. Guo, J. Nie, G. Li, and T. Liu. Review of methods for functional brain connectivity detection using fMRI. Computerized medical imaging and graphics, 33(2):131-9, 2009.

[115] A. Aertsen and G. Gerstein. Evaluation of Neuronal Connectivity: Sensitivity of Cross-Correlation. Brain Research, 340(4):341-354, 1985.

[116] G.A. Cecchi, A.R. Rao, M.V. Centeno, M. Baliki, A.V. Apkarian, and D.R. Chialvo. Identifying directed links in large scale functional networks: application to brain fMRI. BMC Cell Biology, 8(1):S5, 2007.

[117] D.R. Gitelman, W.D. Penny, J. Ashburner, and K.J. Friston. Modeling regional and psychophysiologic interactions in fMRI: the importance of hemodynamic deconvolution. NeuroImage, 19(1):200-207, 2003.

[118] C. Chang, J.P. Cunningham, and G.H. Glover. Influence of heart rate on the BOLD signal: the cardiac response function. NeuroImage, 44(3):857-69, 2009.

[119] S.P. Lee, T.Q. Duong, G. Yang, C. Iadecola, and S.G. Kim. Relative changes of cerebral arterial and venous blood volumes during increased cerebral blood flow: implications for BOLD fMRI. Magnetic Resonance in Medicine, 45(5):791-800, 2001.

[120] J.J. Sychra, P.A. Bandettini, N. Bhattacharya, and Q. Lin. Synthetic images by subspace transforms. I. Principal components images and related filters. Medical Physics, 21(2):193-201, 1994.

[121] M.J. McKeown, T.P. Jung, S. Makeig, G. Brown, S.S. Kindermann, T.W. Lee, and T.J. Sejnowski. Spatially independent activity patterns in functional MRI data during the stroop color-naming task. Proceedings of the National Academy of Sciences of the United States of America, 95(3):803-810, 1998. 
[122] D. Hu, L. Yan, Y. Liu, Z. Zhou, K.J. Friston, C. Tan, and Daxing Wu. Unified SPM-ICA for fMRI analysis. NeuroImage, 25(3):746-755, 2005.

[123] R. Baumgartner, G. Scarth, C. Teichtmeister, R. Somorjai, and E. Moser. Fuzzy clustering of gradientecho functional MRI in the human visual cortex. Part I: reproducibility. Journal of Magnetic Resonance Imaging, 7(6):1094-1101, 1997.

[124] K.J. Friston, C.D. Frith, P. Fletcher, P.F. Liddle, and R.S. Frackowiak. Functional topography: multidimensional scaling and functional connectivity in the brain. Cerebral cortex, 6(2):156-64, 1996.

[125] E.A. Rancz, S. Canals, J. Moya, N.K. Logothetis, D. Moratal, A.M. Brichta, and T.W. Margrie. A map of vestibular representation in the rodent brain revealed by functional imaging and electrophysiology. In MRC-National Institute for Medical Research/Wellcome Trust, 2010.

[126] C. Goutte, P. Toft, E. Rostrup, F. Nielsen, and L.K. Hansen. On clustering fMRI time series. NeuroImage, 9(3):298-310, 1999.

[127] M.C. McIntyre, A. Wennerberg, Ray L. Somorjai, and Gordon B. Scarth. Activation and deactivation in functional brain images. Second International Conference on Functional Mapping of the Human Brain NeuroImage, 3(3):S82, 1996.

[128] E. Moser, M. Diemling, and R. Baumgartner. Fuzzy clustering of gradient-echo functional MRI in the human visual cortex. Part II: quantification. Journal of Magnetic Resonance Imaging, 7(6):1102-1108, 1997.

[129] S. LaConte, S. Strother, V. Cherkassky, J. Anderson, and X. Hu. Support vector machines for temporal classification of block design fMRI data. NeuroImage, 26(2):317-29, 2005.

[130] C.M. Bishop. Pattern recognition and machine learning. Springer, New York, United States of America, 2006.

[131] R.O. Duda and P.E. Hart. Pattern Classification (2nd edition). Wiley-Interscience, New York, United States of America, 2000.

[132] M. Ester, H. Kriegel, J. Sander, and X. Xu. A Density-Based Algorithm for Discovering Clusters in Large Spatial Databases with Noise. In International Conference on Knowledge Discovery and Data Mining, Portland, 1996.

[133] J. Xiong, L.M. Parsons, J.H. Gao, and P.T. Fox. Interregional connectivity to primary motor cortex revealed using MRI resting state images. Human Brain Mapping, 8(2-3):151-156, 1999.

[134] L. Ma, B. Wang, X. Chen, and J. Xiong. Detecting functional connectivity in the resting brain: a comparison between ICA and CCA. Magnetic Resonance Imaging, 25(1):47-56, 2007.

[135] S. Canals, L. López-Aguado, and O. Herreras. Synaptically recruited apical currents are required to initiate axonal and apical spikes in hippocampal pyramidal cells: modulation by inhibition. Journal of neurophysiology, 93(2):909-18, 2005.

[136] G. Paxinos and C. Watson. The rat brain in stereotaxic coordinates. Academic Press, London, United Kingdom, 1982.

[137] P. Andersen, B. Holmqvist, and P.E. Voorhoeve. Entorhinal Activation of Dentate Granule Cells. Acta Physiologica Scandinavica, 66(4):448-460, 1966. 
[138] A.S. Tolias, F. Sultan, M. Augath, A. Oeltermann, E.J. Tehovnik, P.H. Schiller, and N.K. Logothetis. Mapping cortical activity elicited with electrical microstimulation using FMRI in the macaque. Neuron, 48(6):901-11, 2005.

[139] M. Potegal, L. Abraham, S. Gilman, and P. Copack. Technique for vestibular neurotomy in the rat. Physiology \& Behavior, 14(2):217-221, 1975.

[140] C. Spengere. Paxinos space rat template based on 5 adult female Sprague-Dawley rats. Karolinska Institutet. URL: http://expmr.ki.se/research/ratatlas.jsp. Date Accessed: 07/2012.

[141] S.M. Smith, M. Jenkinson, M.W. Woolrich, C.F. Beckmann, T.E.J. Behrens, H. Johansen-Berg, P.R. Bannister, M. De Luca, I. Drobnjak, and D.E. Flitney. Advances in Functional and Structural MR Image Analysis and Implementation as FSL. NeuroImage, 1(1):208-219, 2004.

[142] J. Talairach and P. Tournoux. Co-planar stereotaxic atlas of the human brain, volume 270. Thieme, Stuttgart, Deutschland, 1988.

[143] A.C. Silva, J.H. Lee, I. Aoki, and A.P. Koretsky. Manganese-enhanced magnetic resonance imaging (MEMRI): methodological and practical considerations. NMR in Biomedicine, 17(8):532-543, 2004.

[144] S. Canals, M. Beyerlein, A.L. Keller, Y. Murayama, and N.K. Logothetis. In vivo brain connectivity: optimization of manganese enhanced MRI for neuronal tract tracing. In Göttingen Meeting of the German Neuroscience Society, 2007.

[145] C. Cai, M. Ding, H. Lei, J. Cao, and A. Liu. A Novel 3D Correspondence-Less Method for MRI and Paxinos-Watson Atlas of Rat Brain Registration. Image Rochester NY, 2006.

[146] P.A. Valdés-Hernández. An in vivo MRI rat template set in the Paxinos and Watson space: Applications in fMRI, morphometry and anatomical connectivity. Manuscript Draft for NeuroImage, 2010.

[147] T. Hjornevik, T.B. Leergaard, D. Darine, O. Moldestad, A.M. Dale, F. Willoch, and J.G. Bjaalie. Threedimensional atlas system for mouse and rat brain imaging data. Molecular Biology, 1(1):1-11, 2007.

[148] M.I. Zakiewicz, Y.C. van Dongen, A.T. Bore, J.O. Kjode, I.A. Moene, T.B. Leergaard, and J.G. Bjaalie. Whole brain connectivity atlas. Center for Molecular Biology and Neuroscience. URL: http://cmbnapprod01.uio.no/zoomgen/connectivity/credits.do. Date Accessed: 07/2012.

[149] P. Schweinhardt. A template for spatial normalisation of MR images of the rat brain. Journal of Neuroscience Methods, 129(2):105-113, 2003.

[150] H. Lu, C.A. Scholl, Y. Zuo, S. Demny, W. Rea, E.A. Stein, and Y. Yang. Registering and analyzing rat fMRI data in the stereotaxic framework by exploiting intrinsic anatomical features. Magnetic Resonance Imaging, 28(1):146-152, 2010.

[151] N. Otsu. A Threshold Selection Method from Gray-Level Histograms. IEEE Transactions On Systems Man And Cybernetics, 9(1):62-66, 1979.

[152] R.W. Cox, J. Ashburner, H. Breman, K. Fissell, C. Haselgrove, C.J. Holmes, J.L. Lancaster, D.E. Rex, S.M. Smith, J.B. Woodward, and S.C. Strother. A (Sort of) New Image Data Format Standard: NIfTI-1. Compute, 1(1):11-21, 2004.

[153] J. Moya, J.M. Pascual, R. Prieto, D. Moratal, and S. Canals. Functional principles of deep brain stimulation (DBS). In XIV Congreso Nacional Sociedad Española de NeuroCiencia, Salamanca, 2011. 
[154] V. Pallarés. Directores: D. Moratal, S. Canals, J. Moya. Estudio de la conectividad cerebral a partir de imágenes de RM potenciadas con manganeso. Desarrollo de un atlas cerebral para un análisis tridimensional. Proyecto Final de Carrera. Escuela Técnica Superior de Ingenieros de Telecomunicación, Universitat Politècnica de València, 2010.

[155] R.D.S. Raizada and A.C. Connolly. What Makes Different Peoples Representations Alike: Neural Similarity Space Solves the Problem of Across-subject fMRI Decoding. Journal of Cognitive Neuroscience, 2012.

[156] C.P. Pawela, B.B. Biswal, A.G. Hudetz, R. Li, S.R. Jones, Y.R. Cho, H.S. Matloub, and J.S. Hyde. Interhemispheric neuroplasticity following limb deafferentation detected by resting-state functional connectivity magnetic resonance imaging (fcMRI) and functional magnetic resonance imaging (fMRI). Neuroimage, 49(3):2467-2478, 2010.

[157] R. Milos, A. Nanopoulos, and N. Ivanovic. Hubs in Space: Popular Nearest Neighbors in High-Dimensional Data. Journal of Machine Learning Research, 11(7):2487-2531, 2010.

[158] L. Leiva and E. Vidal. Assessing Users Interactions for Clustering Web Documents: A Pragmatic Approach. Knowledge Creation Diffusion Utilization, 4(10):1-4, 2010.

[159] A. Meyer-Baese, A. Wismueller, and O. Lange. Comparison of two exploratory data analysis methods for fMRI: unsupervised clustering versus independent component analysis. IEEE Engineering in Medicine and Biology Society, 8(3):387-398, 2004.

[160] K.J. Worsley, J. Chen, J. Lerch, and A.C. Evans. Comparing functional connectivity via thresholding correlations and singular value decomposition. Philosophical Transactions of the Royal Society of London - Series B: Biological Sciences, 360(1457):913-920, 2005.

[161] R. Baumgartner, L. Ryner, W. Richter, R. Summers, M. Jarmasz, and R. Somorjai. Comparison of two exploratory data analysis methods for fMRI: fuzzy clustering vs. principal component analysis. Magnetic Resonance Imaging, 18(1):89-94, 2000.

[162] Y. Zhong, H. Wang, G. Lu, Z. Zhang, Q. Jiao, and Y. Liu. Detecting functional connectivity in fMRI using PCA and regression analysis. Brain Topography, 22(2):134-144, 2009.

[163] J.C. Gower. Some distance properties of latent root and vector methods used in multivariate analysis. Biometrika, 53(3):325-338, 1966.

[164] A.A. O’Connell, I. Borg, and P. Groenen. Modern Multidimensional Scaling: Theory and Applications. Journal of the American Statistical Association, 94(445):338-43, 1999.

[165] D. Carroll and M. Wish. Models and methods for three-way multidimensional scaling. Contemporary Developments in Mathematical Psychology, 2(1):57-88, 1972.

[166] S.M. Smirnakis, A. Brewer, M.C. Schmid, A.S. Tolias, A. Schüz, M. Augath, W. Inhoffen, B. Wandell, and N.K. Logothetis. Lack of long-term cortical reorganization after macaque retinal lesions. Nature, 435(7040):300-7, 2005.

[167] X. Golay, S. Kollias, G. Stoll, D. Meier, A. Valavanis, and P. Boesiger. A new correlation-based fuzzy logic clustering algorithm for fMRI. Magnetic Resonance in Medicine, 40(2):249-260, 1998.

[168] K.G. Derpanis. Mean Shift Clustering. Technical report, 2005.

[169] C. Goutte, L.K. Hansen, M.G. Liptrot, and E. Rostrup. Feature-space clustering for fMRI meta-analysis. Human brain mapping, 13(3):165-83, 2001. 
[170] D. Comaniciu and P. Meer. Mean shift: A robust approach toward feature space analysis. Analysis and Machine Intelligence, , 24(5):1-18, 2002.

[171] D. Comaniciu. An algorithm for data-driven bandwidth selection. IEEE Transactions onPattern Analysis and Machine Intelligence, 25(2):281-288, 2003.

[172] S. Derbyshire. A surface showing a global maximum. Wikipedia Gallery. URL: http://en.wikipedia.org/wiki/User:Sam_Derbyshire/Gallery. Date Accessed: 07/2012.

[173] A. McIntosh and N.J. Lobaugh. Partial least squares analysis of neuroimaging data: applications and advances. NeuroImage, 23(1):250-63, 2004.

[174] M.D. Fox, A.Z. Snyder, J.L. Vincent, M. Corbetta, D.C. Van Essen, and M.E. Raichle. The human brain is intrinsically organized into dynamic, anticorrelated functional networks. Proceedings of the National Academy of Sciences of the United States of America, 102(27):9673-9678, 2005.

[175] F.M. Miezin, L. Maccotta, J.M. Ollinger, S.E. Petersen, and R.L. Buckner. Characterizing the hemodynamic response: effects of presentation rate, sampling procedure, and the possibility of ordering brain activity based on relative timing. NeuroImage, 11(3):735-759, 2000.

[176] C. Quesada, J. Moya, J.M. Pascual, R. Prieto, D. Moratal, and S. Canals. Mechanisms of action of deep brain stimulation. In 8th FENS Forum of Neuroscience, Barcelona, 2012.

[177] A.E. Kelley and K.C. Berridge. The neuroscience of natural rewards: relevance to addictive drugs. The Journal of neuroscience: the official journal of the Society for Neuroscience, 22(9):3306-11, 2002.

[178] H.B.M. Uylings, H.J. Groenewegen, and B. Kolb. Do rats have a prefrontal cortex? Behavioural Brain Research, 146(1-2):3-17, 2003.

[179] G. Di Chiara, G. Tanda, V. Bassareo, F. Pontieri, E. Acquas, S. Fenu, C. Cadoni, and E. Carboni. Drug addiction as a disorder of associative learning. Role of nucleus accumbens shell/extended amygdala dopamine. Annals Of The New York Academy Of Sciences, 877(1):461-485, 1999.

[180] I. Schwienbacher, M. Fendt, R. Richardson, and H. Schnitzler. Temporary inactivation of the nucleus accumbens disrupts acquisition and expression of fear-potentiated startle in rats. Brain Research, 1027(1):8793, 2004.

[181] J.D. Steketee, B.A. Sorg, and P.W. Kalivas. The role of the nucleus accumbens in sensitization to drugs of abuse. Progress in neuropsychopharmacology biological psychiatry, 16(2):237-246, 1992.

[182] Y. Goto and P. O’Donnell. Synchronous activity in the hippocampus and nucleus accumbens in vivo. Journal of Neuroscience, 21(4):131-5, 2001.

[183] T. Raphan, M. Dai, and B. Cohen. Spatial orientation of the vestibular system. Annals Of The New York Academy Of Sciences, 656(5):140-157, 1992.

[184] W.O. Guldin and O.J. Grüsser. Is there a vestibular cortex? Trends in Neurosciences, 21(6):254-259, 1998.

[185] G.T. Gdowski and R.A. McCrea. Integration of vestibular and head movement signals in the vestibular nuclei during whole-body rotation. Journal of Neurophysiology, 82(1):436-449, 1999.

[186] T. Shiroyama, T. Kayahara, Y. Yasui, J. Nomura, and K. Nakano. Projections of the vestibular nuclei to the thalamus in the rat: a Phaseolus vulgaris leucoagglutinin study. The Journal of comparative neurology, 407(3):318-32, 1999. 
[187] A. Zwergal, M. Strupp, T. Brandt, and J. Büttner-Ennever. Parallel ascending vestibular pathways: anatomical localization and functional specialization. Annals of the New York Academy of Sciences, 1164(2):51-9, 2009.

[188] T. Loddenkemper, A. Pan, S. Neme, K.B. Baker, A.R. Rezai, D.S. Dinner, E.B Montgomery, and H.O. Lüders. Deep Brain Stimulation in Epilepsy. Journal of Clinical Neurophysiology, 18(6):514-532, 2001.

[189] A. Benazzouz and M. Hallett. Mechanism of action of deep brain stimulation. Neurology, 12(6):13-6, 2000.

[190] S. Breit, J.B. Schulz, and A-L. Benabid. Deep brain stimulation. Cell and Tissue Research, 10(1):271-272, 1987.

[191] M. Leone. Deep brain stimulation in headache. The Lancet, 5(10):873-877, 2006.

[192] A. May. Hypothalamic deep-brain stimulation: target and potential mechanism for the treatment of cluster headache. Cephalalgia an international journal of headache, 28(7):799-803, 2008.

[193] B. Aouizerate, C. Martin-Guehl, E. Cuny, D. Guehl, H. Amieva, A. Benazzouz, C. Fabrigoule, B. Bioulac, J. Tignol, and P. Burbaud. Deep brain stimulation for OCD and major depression. The American Journal of Psychiatry, 162(11):2192, 2005.

[194] C.H. Halpern, N. Torres, H.I. Hurtig, J.A. Wolf, J. Stephen, M.Y. Oh, Noel N Williams, Marc A Dichter, Jurg L Jaggi, Arthur L Caplan, Kyle M Kampman, Thomas A Wadden, Donald M Whiting, and Gordon H Baltuch. Expanding applications of deep brain stimulation: a potential therapeutic role in obesity and addiction management. Acta neurochirurgica, 153(12):2293-306, 2011.

[195] R.J. Buchanan and Z. Nadasdy. Deep Brain Stimulation. Human Brain Stimulation and Electrophysiology Lab. URL: http://brainstim.psy.utexas.edu/wordpress/. Date Accessed: 07/2012. 